\title{
Intersectoral costs and benefits of health interventions
}

Citation for published version (APA):

Drost, R. M. W. A. (2016). Intersectoral costs and benefits of health interventions: A change of perspective in economic evaluation. [Doctoral Thesis, Maastricht University]. Maastricht University. https://doi.org/10.26481/dis.20161020rd

Document status and date:

Published: 01/01/2016

DOI:

10.26481/dis.20161020rd

Document Version:

Publisher's PDF, also known as Version of record

\section{Please check the document version of this publication:}

- A submitted manuscript is the version of the article upon submission and before peer-review. There can be important differences between the submitted version and the official published version of record.

People interested in the research are advised to contact the author for the final version of the publication, or visit the DOI to the publisher's website.

- The final author version and the galley proof are versions of the publication after peer review.

- The final published version features the final layout of the paper including the volume, issue and page numbers.

Link to publication

\footnotetext{
General rights rights.

- You may freely distribute the URL identifying the publication in the public portal. please follow below link for the End User Agreement:

www.umlib.nl/taverne-license

Take down policy

If you believe that this document breaches copyright please contact us at:

repository@maastrichtuniversity.nl

providing details and we will investigate your claim.
}

Copyright and moral rights for the publications made accessible in the public portal are retained by the authors and/or other copyright owners and it is a condition of accessing publications that users recognise and abide by the legal requirements associated with these

- Users may download and print one copy of any publication from the public portal for the purpose of private study or research.

- You may not further distribute the material or use it for any profit-making activity or commercial gain

If the publication is distributed under the terms of Article $25 \mathrm{fa}$ of the Dutch Copyright Act, indicated by the "Taverne" license above, 


\section{Intersectoral costs and benefits of health interventions}

A change of perspective in economic evaluation 



\section{Intersectoral costs and benefits of}

\section{health interventions}

A change of perspective in economic evaluation 
The research presented in this dissertation was conducted at the School for Public Health and Primary Care (CAPHRI), department of Health Services Research, Maastricht University. CAPHRI is part of the Netherlands School of Primary Care Research (CaRe), which has been acknowledged by the Royal Netherlands Academy of Science (KNAW). This research was funded under a grant from the Netherlands Organisation for Health Research and Development (ZonMw, project number 200400010) and Maastricht University.

\section{ZonMw}

(C) Ruben Drost, Maastricht 2016

No part of this book may be reproduced or transmitted in any form or by any means, without prior permission in writing by the author, or when appropriate, by the publishers of the publications.

Layout: $\quad$ Tiny Wouters

Cover design: Kim Deuning | beeldspinsels.nl

Production: Gildeprint, Enschede

ISBN: 978-94-6233-410-6 


\title{
Intersectoral costs and benefits of health interventions
}

\section{A change of perspective in economic evaluation}

\author{
PROEFSCHRIFT \\ ter verkrijging van de graad van doctor aan de Universiteit Maastricht, \\ op gezag van de Rector Magnificus, Prof. dr. Rianne M. Letschert, \\ volgens het besluit van het College van Decanen, \\ in het openbaar te verdedigen \\ op donderdag 20 oktober 2016 om 16:00 uur
}

door Ruben Marinus Willem Adriaan Drost 


\section{Promotores}

Prof. dr. mr. S.M.A.A. Evers

Prof. dr. D. Ruwaard

\section{Co-promotor}

Dr. A.T.G. Paulus

\section{Beoordelingscommissie}

Prof. dr. C.D. Dirksen (voorzitter)

Dr. G.A.P.G. van Mastrigt

Prof. dr. J.A.M. Maarse

Prof. dr. J.J. Polder (Tilburg University, RIVM)

Prof. dr. H.F.E. Smit (VU Amsterdam, Trimbos) 


\section{Contents}

$\begin{array}{lll}\text { Chapter } 1 \text { General introduction } & 7\end{array}$

Chapter 2 Conceptualizations of the societal perspective within economic evaluations: a systematic review

Submitted for publication

Chapter 3 Intersectoral costs and benefits of mental health prevention:

towards a new classification scheme

Journal of Mental Health Policy and Economics, 2013

Chapter 4 Valuing intersectoral costs and benefits of interventions in the healthcare sector: methods for obtaining unit prices

Expert Review of PharmacoEconomics and Outcomes Research, 2016

Chapter 5 Cost-effectiveness of preventive case management for parents with a mental illness: a randomized controlled trial from three economic perspectives

BMC Health Services Research, 2016

Chapter 6 A web-based computer-tailored alcohol prevention program for adolescents: cost-effectiveness and intersectoral costs and benefits Journal of Medical Internet Research, 2016

Chapter 7 General discussion

Summary

Samenvatting

Valorisation

List of publications

Dankwoord

About the author 



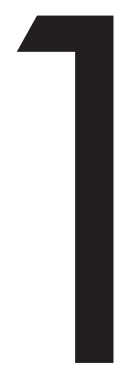

General introduction 
Chapter ] 


\section{General introduction}

The ageing population and new diagnostic and treatment technologies have led to evergrowing health expenditures. Global health expenditure in OECD countries grew on average by $5 \%$ annually from 2000 to 2009 . During that decade, the total health expenditure as percentage of the gross domestic product increased on average from $7.2 \%$ to $9.0 \%$. Even in the aftermath of the 2008 economic crisis, health expenditure has remained high. 'Between 1998 and 2014, overall spending on health and welfare in the Netherlands increased from 40.3 to 95 billion euros. ${ }^{2}$ Accordingly, healthcare policy makers are more challenged than ever to clearly identify the relevant alternatives for current health technologies, and health economics has an important role to fulfill.

Health economics, like general economics, is a science of scarcity. Resources are scarce, and can be spent only once. Consequently, choices need to be made among alternative possibilities. The critical assessment of these alternatives is important not only with regard to differences in effectiveness, but also in regard to their value in terms of costs, additional benefits, and - perhaps most important - how these relate to effectiveness. This goes for curative therapies, for example medicine $A$ versus medicine $B$ in the treatment of high blood pressure, but also preventive (public health) interventions, such as vaccination strategies and health behavior interventions. Such interventions may engender numerous costs and benefits for society. From a societal perspective, capturing all relevant costs and benefits of health(care) interventions can be quite a challenge, as many of these costs and benefits may spill over to sectors outside the healthcare sector. Little specific research has been done on these costs and benefits, which are known as intersectoral costs and benefits (ICBs).

This thesis explores this relatively undeveloped field of research with the aim of providing more insight into ICBs. It aims to contribute to the fields of health economics and health technology assessment (HTA), and thereby support policy makers, health insurers, health providers, and consumers as they are challenged to consider and choose among alternatives. This first chapter first discusses the value of the societal perspective within health economics and healthcare decision making. Further, the importance of ICBs and the inseparable relation between the societal perspective and ICBs are discussed and explained. Next, this chapter provides the reader with some technical information with regards to the basics of health economic analysis, which is needed to interpret the results of the studies presented in this thesis. Explanation is given on the role of ICBs within health economic analyses and how the results of these analyses can be interpreted. Finally, the objectives and outline of this thesis are presented.

\section{The societal perspective}

From a welfarist point of view, i.e. the school of thought which places health not merely as a goal, but also as a contributor to overall welfare, an analysis should take into account not only the intervention costs, but also the (non-)financial consequences of a change in 
health. ${ }^{3}$ Given that health is intertwined with basically all facets of everyday life, e.g. school, work, travelling, and basic everyday activities, such as being physically capable of taking out the trash, many of these consequences are located outside the healthcare sector. However, these non-healthcare sector consequences, even if they are relevant, are not always included in economic evaluations. Analyses and reported results of an economic evaluation depend on the perspective from which it is conducted. ${ }^{4}$ This perspective can be either narrow, in which a selection of costs and consequences are measured and included in the analysis, or broad, comprising all relevant costs and consequences of the interventions under comparison.

Within health economic evaluations, the most commonly used perspectives include 1) the payer perspective, in which only the costs and consequences for a certain party, such as the patient, employer or insurer, are included, 2) the healthcare perspective, which comprises only the costs and consequences within the healthcare sector, and 3) the societal perspective, which considers all costs and consequences that flow from the intervention, regardless of who experiences these. ${ }^{4}$ Given that the choice of perspective determines the results of the evaluation, those who conduct evaluations should be explicit about the perspective they adopt. ${ }^{5}$ Guidelines on good research practices, such as the 'Consolidated Health Economic Evaluation Reporting Standards' (simultaneous publication in Value in Health and nine other renowned journals, 2013), have adopted this statement. ${ }^{6}$ Furthermore, over half of the pharmacoeconomic guidelines which are indexed on the website of the International Society for Pharmacoeconomics and Outcomes Research provide advice with regards to the preferred perspective. ${ }^{7}$

It is argued that the societal perspective is dominant over the others. ${ }^{5,8,9}$ This is because health economics has a foundation in welfare economics, which means that an economic evaluation should include the impact of an intervention on the whole society. ${ }^{5}$ A narrow perspective does not fully reflect this societal impact. Hence, a societal perspective is necessary for making optimal societal decisions. ${ }^{8}$ In theory, the definition of the societal perspective, which states that 'all costs and consequences should be included regardless of who experiences these', ${ }^{4}$ seems appropriate. In practice, however, applying this definition is not so straightforward; the first part of this definition in particular leaves considerable room for discussion as there is notable uncertainty on what could be considered relevant in addition to healthcare costs (HCCs). ${ }^{10}$ ICBs could be important in this regard, and leaving these out of the equation could lead to biased results. This, in turn, might have a negative impact on well-considered healthcare policy making.

\section{Intersectoral costs and benefits}

As mentioned, little is known about ICBs. The limited knowledge about ICBs is related, among other things, to methodological challenges and the fact that most of the existing tools can be used to determine costs and benefits only within the narrow context of the healthcare sector. ${ }^{11-14}$ As a consequence, current health economic evaluations are at risk of not capturing the full societal value of an intervention. Furthermore, methods for the 
economic evaluation of clinical interventions are better established than those for public health, while the latter often generate very broad costs and benefits which accrue in populations and communities rather than in specific individuals. ${ }^{15}$ Without the appropriate tools, identifying and valuing relevant ICBs of particularly these interventions is quite a challenge. However, the essential problem that lies at the foundation of research in this field is the challenge of conceptualizing ICBs. Although the term ICBs is mentioned in some health economics literature, this concept is not well defined and principally introduced as a target area for future research. ${ }^{1,15}$ Yet, operationalizing this concept requires a clear description.

\section{The concept of /CBs}

During the conception and development of this thesis, defining the concept of ICBs was a work in progress. In the context of this thesis, the only initial certainty surrounding the term 'intersectoral' was that it did not reflect the healthcare sector. Before we discuss the objectives of this thesis, it is necessary to disentangle the concept of ICBs and provide a breakdown of the work's title.

First of all, central in ICB is the term "sector". The term "sector" is used widely, and can be interpreted in several ways depending on the context. Within economics, an often-used classification of sectors relates to the type of labor performed (i.e. the primary, secondary, tertiary, quaternary sector). An alternative way of structuring sectors is a classification based on policy domains, as is done in ministries. An example is a classification into the healthcare sector, educational sector, criminal justice sector, et cetera. Given that each of these policy domains has its primary objectives (good population health, high quality education, a safe and crime-free society, respectively), the costs and benefits of health(care) interventions can be regarded intersectoral when they fall in such sectors outside the healthcare sector. Within this thesis, which focuses on the ICBs of health(care) interventions, this approach is adopted with regard to the term sector.

Second, the term ICB deals with costs. Costs can be either monetary or non-monetary. The latter are often referred to as 'intangible costs' (e.g. dissatisfaction, grief, et cetera) and are less easily measured and valued. Intersectoral costs are, therefore, not only the negative financial consequences for other sectors, but also damages which are hard to express in monetary terms. One way of classifying costs is that of Gold et al., who speaks of 'direct costs', which are 'the value of all goods, services, and other resources that are consumed in the provision of an intervention or in dealing with the side effects or other current and future consequences linked to it, both inside and outside the healthcare sector', and 'indirect costs', which refers to 'productivity gains or losses related to illness or death' and future medical costs related to increased life expectancy. ${ }^{4}$ However, the classification into direct and indirect costs is rather vague and conflicts with other disciplines such as accounting, in which the term 'indirect' is used to describe 'overhead or fixed costs of production'. An alternative way of classifying costs is a classification into sectors. A classification by Drummond et al., as opposed to the one described by Gold et al., does mention costs 'other sector costs' as a separate category of costs in addition to costs in the 
healthcare sector, patient and family costs and productivity costs. ${ }^{3}$ The new Dutch guidelines for economic evaluations in healthcare have adopted this classification. ${ }^{16}$ Given that this classification provides clear insight into the location (i.e. policy domain) of the costs, this approach is used in this thesis.

Final, the term ICB includes "benefits". Within health economics literature, the term "benefits" is used interchangeably with the terms "consequences" and "savings". Consequences can be described as the 'overall benefits expected to be received'. Drummond et al. speak of savings, which may follow the intervention as well as health effects and changes in utility. Throughout this thesis, given the main focus on the monetary valuation of ICBs and the focus on including these in the input side of an economic evaluation, benefits are described as reductions in costs (i.e. savings). Furthermore, throughout this thesis, the term "ICB" will be used to describe items, such as "special education", rather than the actual monetary costs and benefits related to these.

\section{Identifying, classifying and valuing ICBs}

Related to the limited knowledge of the concept itself, little is known about identifying, classifying and valuing ICBs. Available methodological tools for the identification and classification of costs and benefits insufficiently support the identification and classification of ICBs. For example, although taxonomies described in the commonplace evaluation texts of Gold et al. and Drummond et al. do focus on productivity at work as an important category outside the healthcare sector, they do not provide readers with a detailed representation of ICBs possibly engendered as a consequence of a (preventive) intervention. ${ }^{3,4}$ The taxonomy of Drummond et al., as opposed to that defined by Gold et al., does mention "other sectors" as a separate category for costs and savings (C2/S2) other than those in the health sector $(\mathrm{Cl} / \mathrm{S} 1)$, patient and family costs and savings (C3/S3) and those related to productivity (C4/S4), but neither taxonomy provides extensive information on which of the sectors outside the healthcare sector can be affected by a change in one's health status, nor do they provide a detailed overview of ICBs within these other sectors. Other taxonomies, such as those described by Luce \& Elixhauser and French et al. do provide some items which have the characteristics of ICBs. ${ }^{17,18}$ However, mention of ICBs is fairly limited in comparison with their more extended focus on items falling under the healthcare sector. Furthermore, like the taxonomies of Gold et al. and Drummond et al., these taxonomies do not provide a sector-specific classification for ICBs.

As for the limited knowledge concerning the identification and classification of ICBs, the same goes for valuing ICBs. While the leading health economic literature explicitly mentions informal care and productivity losses as potentially important, ${ }^{3,4,19-21}$ other ICBs outside the healthcare sector are given much less attention, even if they are important. Yet, the aforementioned definition of the societal perspective does not restrict researchers to merely value informal care and productivity losses in addition to the use of health services. On the contrary, prevention programs and treatment interventions can yield a wide array of ICBs. ${ }^{12,15}$ Given that the lack of insight into ICBs might negatively affect the quality of health economic evaluations and healthcare policy making, internationally usable generic 
methods for identifying, classifying and valuing ICBs are of crucial importance. The availability of such tools could open the door to including ICBs within health economic evaluations, which are becoming increasingly important for healthcare decision-making. The several types of analysis within health economic evaluation, as well as a technical description on the way ICBs can be included in an economic analysis, are described below.

\section{Health economic evaluations}

As noted earlier, the interpretation of the results of the studies which are described in the following chapters requires the reader to have knowledge of economic evaluation, i.e. the types of economic analysis and the way results of these analyses can be interpreted. Within a full (or good) economic evaluation, all relevant alternatives to a health intervention are considered and assessed on both costs (input) and relevant consequences (output). With this information, the relationship between costs and consequences can be investigated to find the most desirable intervention from a health economic point of view (Figure 1.1). ${ }^{3}$

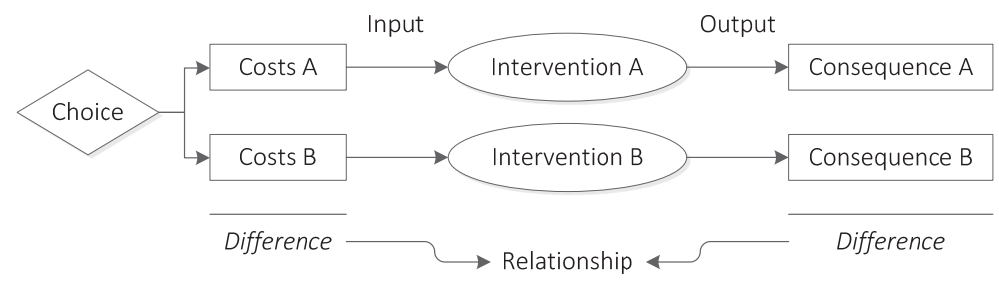

Figure 1.1 Economic evaluation

\section{Types of economic analysis}

An economic evaluation always involves a comparative analysis of alternative courses of action. ${ }^{3}$ All analyses can be conducted from various perspectives, but vary in approach. There are basically five approaches (types) of analysis, which differ predominantly in the way the output is measured and reported. In all of these, ICBs can be included. The types of analysis are cost-minimization analysis (CMA), cost-effectiveness analysis (CEA), costutility analysis (CUA), cost-benefit analysis (CBA) and cost-consequence analysis (CCA). In CMAs consequences are or are assumed to be equal across all alternatives. Within this type of analysis only costs are assessed, which results in the cheapest alternative being dominant over the others. A CMA, therefore, is relatively easy to conduct. However its ease is its downside; a CMA can be conducted only when there is certainty that the consequences of all alternatives under analysis are equal. In practice, this is seldom the case, and a CMA is likely to be useful only when health technologies are nearidentical. $^{3,22}$ 
For the majority of situations, the CEA is a better alternative. Here, the assumption of consequences being equal is rejected. In a CEA, consequences are measured in an appropriate natural unit of effect, such as 'blood pressure' or 'body mass index'. This offers the possibility of quantifying and comparing the incremental costs and incremental effects between an intervention and its alternatives in one disease domain. Furthermore, such analyses are considered to be relevant within disease-specific or health behavior-specific fields of research. However, such specific outcome measures do not permit comparisons with other interventions utilizing other measures; a CEA does not permit, for example, comparing cancer treatments with treatments for mental disorders. From a health economic point of view, therefore, the information CEAs provide is limited with regard to supporting decisions on the allocation of healthcare budgets on a bigger scale.

An analysis with a utility outcome measure, as in a CUA, tackles this problem. The quality adjusted life year (QALY), which combines quantity and quality of life into a single outcome measure, is frequently used within CUAs. Given the generic nature of this outcome measure, a CUA does permit comparisons of totally different health(care) interventions. However, comparisons are also restricted to health(care) interventions; as for diseasespecific outcome measures, reporting merely the QALY without the intervention's monetary worth within and outside the healthcare sector does not permit comparisons with alternative investments in other sectors.

A solution is the CBA, which favors the monetary output of an intervention above a health-related outcome. Within a CBA, a net monetary benefit is calculated, which provides instant insight into whether an intervention is worth the money. Furthermore, given the universal nature of the output (money), a CBA allows for intersectoral comparisons. However, it is relatively hard to conduct a reliable CBA, as many costs and benefits may accrue in the far future, and long-term follow-up studies or models are needed to assess the costs and benefits flowing from the intervention.

The last option is the CCA, in which several types of outcomes are considered and reported alongside each other, but not aggregated into a single outcome measure. The results of a CCA can be interesting, since a wide range of consequences can be considered. However, if there is a positive consequence in one sector while there is a negative consequence in the other, it could be difficult to translate the results into a policy implication.

\section{Interpreting economic evaluation results}

In this thesis, the impact of including ICBs within economic evaluations is assessed by conducting CEAs from two perspectives: the healthcare perspective (including HCCs, excluding $(C B s$ ) and the societal perspective (including HCCs and $(C B s)$, and comparing both outcomes. This is done by including HCCs and ICBs in the input side of the CEA (Figure 1.2). 


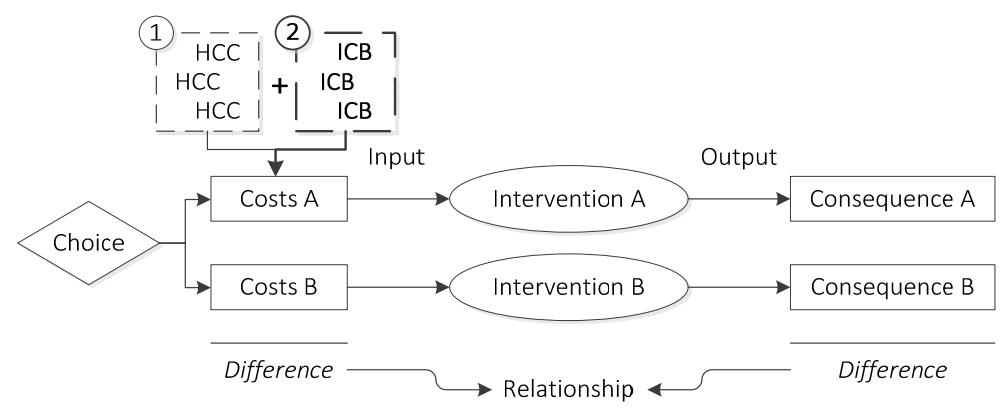

Figure 1.2 Operationalization of the cost-effectiveness analysis within this thesis from the healthcare perspective, in which healthcare costs are measured and valued (1), and the societal perspective, which captures both healthcare costs and intersectoral costs and benefits $(1+2)$

As noted earlier, within a CEA or CUA, the relation between the incremental costs and incremental effects of an intervention can be assessed in comparison with an alternative. This relation is expressed in an incremental cost-effectiveness/utility ratio (ICER/ICUR), ${ }^{3}$ using the following formula:

$$
I C E R=\frac{\left(\text { Costs }_{\text {intervention }}-\text { Costs }_{\text {control }}\right)}{\left(\text { Effects }_{\text {intervention }}-\text { Effects }_{\text {control }}\right)}
$$

Within CEAs and CUAs, ICERs or ICURs are usually presented in cost-effectiveness planes (Figure 1.3). These planes provide a visual representation on the probability of an intervention being cost-effective in comparison with the control condition (the 0.0 coordinate) by showing the distribution of simulated ICERs across four quadrants: 1) the Northeast (NE) quadrant, which means that the intervention is more effective and more costly than care as usual (CAU), 2) the Southeast (SE) quadrant, indicating that the intervention is more effective and less costly, 3) the Southwest (SW) quadrant, indicating that the intervention is less effective and less costly and 4) the Northwest (NW) quadrant, indicating that the intervention is less effective and more costly. A large number of simulated ICERs are presented instead of one, as the plane represents the result of a sensitivity analysis based on non-parametric bootstrap replications. Given the formula provided above, an ICER in the SE and NW quadrant is negative, representing the situation in which the intervention is either clearly dominant over (SE) or inferior to (NW) CAU. An ICER in the SW or NE quadrant is positive, which means, from a costeffectiveness perspective, that the intervention is more favorable than the control condition only when the ICER is lower than the maximum willingness to pay (WTP max/WTP threshold) per unit effect. The WTP max is the maximum expense a society is willing to pay for better outcomes. ${ }^{3}$ 
In the hypothetical scenario of Figure $1.3 a+b$, the majority of simulated ICERs are located in the NE quadrant, indicating that the intervention is most likely to be more effective and more costly than CAU. From the healthcare perspective (Figure 1.3a), the largest proportion of the cloud is located above the threshold, which means that for the given WTP threshold, the intervention will likely not be worth the investment. However, from the societal perspective (Figure 1.3b), the largest proportion of the cloud is located below the threshold, which means that the intervention will likely be cost-effective.
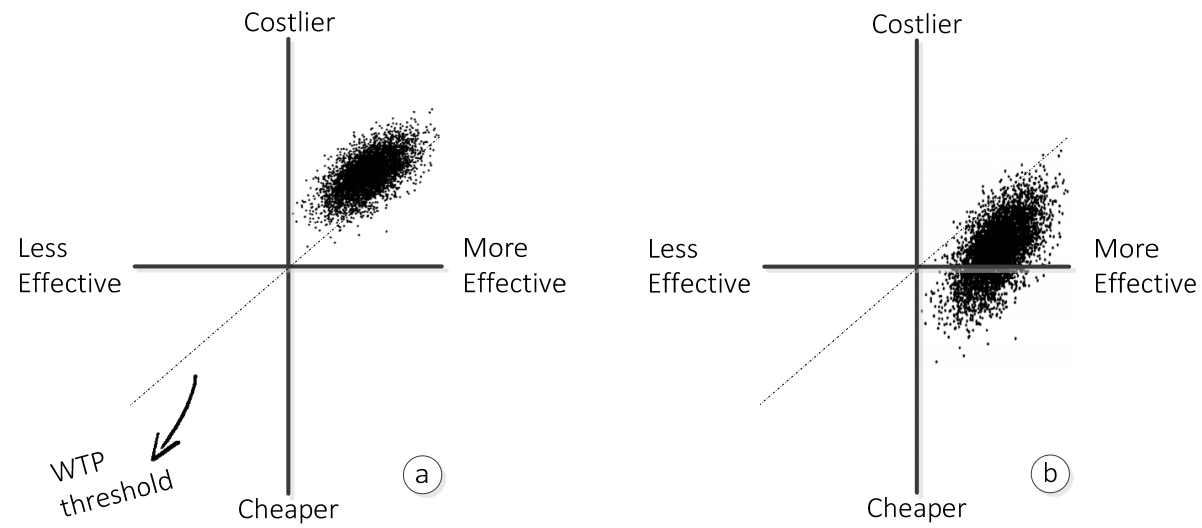

Figure 1.3 Hypothetical cost-effectiveness planes for a cost-effectiveness analysis conducted from a) the healthcare perspective (including healthcare costs, excluding intersectoral costs and benefits) and b) the societal perspective (including both healthcare costs and intersectoral costs and benefits)

The WTP threshold is not always set and may vary, along with other things, depending on the outcome measure and the country in which the analysis is conducted. Contrary to CUAs, for which there is variety in thresholds even between jurisdictions, ${ }^{23}$ these thresholds are usually lacking for CEAs. Cost-effectiveness acceptability curves (CEACs) are of additional importance. CEACs offer insight into the probability of the intervention being cost-effective over CAU for a range of hypothetical WTP thresholds and, hereby, offer decision-supportive information. ${ }^{3}$ The hypothetical CEACs in Figure 1.4 correspond with the planes in Figure 1.3. 

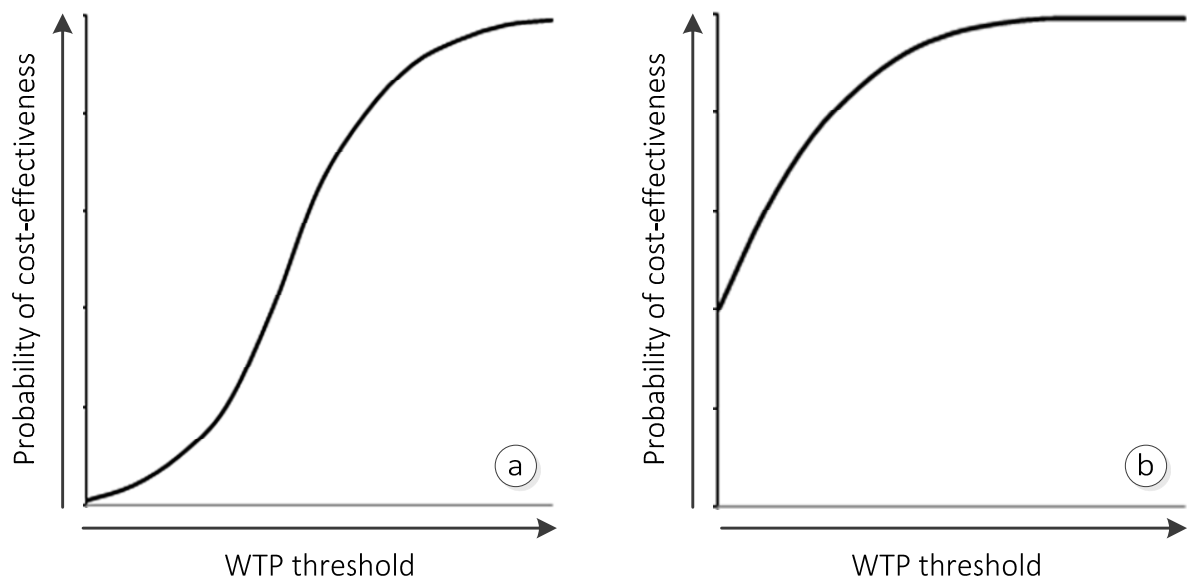

Figure 1.4 Hypothetical cost-effectiveness acceptability curves, corresponding with Figures $1.3 a+b$, for $a$ cost-effectiveness analysis which is conducted from a) the healthcare perspective (including healthcare costs, excluding intersectoral costs and benefits) and b) the societal perspective (including both healthcare costs and intersectoral costs and benefits)

\section{This thesis}

\section{Objectives of the thesis}

The objective of this thesis is threefold: 1) to investigate how the societal perspective is conceptualized and interpreted within health economic evaluations, and to assess how ICBs determine the results of these evaluations, 2) to develop methods for identifying, classifying and valuing $\mathrm{ICBs}$, and 3) to apply these methods within health economic analyses. It is hypothesized that there is a wide variety in ICBs and that these, to a greater or lesser extent, determine health economic evaluation results which are conducted from the societal perspective. By successfully meeting these objectives, this thesis opens up a new field of research and may lay the foundations for further research in a largely unexplored area within health economics.

\section{Outline of the thesis}

Chapter 2 deals with the societal perspective within health economic evaluations. ${ }^{24}$ Based on a systematic literature review, how the societal perspective is conceptualized within these evaluations is investigated, and there is an assessment of how ICBs determine the results of these evaluations. Special interest is focused on the weight of ICBs within the total range of costs, in particular those within the educational sector and criminal justice sector. 
Chapter 3 describes a study aimed at identifying ICBs related to (the prevention of) mental disorders. In this study, based on a literature review and expert interviews, a classification scheme for ICBs is presented. ${ }^{25}$ The scheme provides an extensive and structured overview of ICBs which can be considered when conducting an economic evaluation. It is supportive of both conducting and assessing economic evaluations, and can also be used to serve these purposes outside the mental health domain.

Chapter 4 discusses the process of developing methods for valuing ICBs using unit prices [26]. By means of a review of relevant literature, expert interviews, and a meeting with policy makers and known experts in the fields of HTA, health economics and public health, methods were developed for obtaining unit prices which can be used for valuing ICBs. The study was also aimed at assessing the methods' feasibility through application in the Netherlands. The chapter refers to a Dutch manual on ICBs, which was developed as part of this PhD trajectory. The manual contains extensive descriptions of the applications of methods used to obtain unit prices which can be used for costing research within the Netherlands.

Chapters 5 and 6 describe two applications of the manual within trial-based health economic evaluations. Chapter 5 focuses on the cost-effectiveness of preventive basic care management for improving parenting quality in families with children of parents with a mental illness. ${ }^{27}$ Based on data of the SOOPP study (in Dutch 'Studie naar Ondersteuning voor Ouders met Psychische Problemen'), three comparative CEAs were conducted. One was conducted from a narrow healthcare perspective (including HCCs), one from a social care perspective (including HCCs and childcare costs) and one from a broad societal perspective (all costs, including ICBs). The study explores not only with the question whether the intervention is cost-effective, but also assessed whether cost-effectiveness results differ between perspectives.

Chapter 6 deals with the same data analytic approach, but for a completely different intervention. This chapter focuses on the cost-effectiveness of a web-based computertailored intervention for reducing alcohol use and binge drinking by adolescents [28]. Based on data of the Alcohol Alert study, again three comparative CEAs were conducted. One was conducted from a narrow healthcare perspective (including HCCs, excluding $(C B s$ ), one from a societal perspective (including both HCCs and ICBs) and a second from societal perspective (including HCCs, ICBs and costs of substance use).

Finally, Chapter 7 provides an overview of the main findings, describes the main theoretical and methodological strengths and limitations of the research which is described in this thesis, and discusses policy and research implications. Chapters 8 and 9 provide English and Dutch summaries of this thesis, respectively. Note that Chapters 2 to 6 have either been published (Chapters 3, 4 and 6), been accepted for publication (Chapter 5) or are currently under review (Chapter 2) for publication in international peer-reviewed impact journals and can be read independently. 


\section{References}

1. OECD. Health Expenditure. 2016 [cited 2016 10-6] Available from: http://www.oecd.org/els/healthsystems/health-expenditure.htm.

2. CBS. Zorguitgaven stijgen met 1,8 procent in 2014. 2015 [cited 2016 15-4]; Available from: http://www.cbs.nl/nl-NL/menu/themas/gezondheid-

welzijn/publicaties/artikelen/archief/2015/zorguitgaven-stijgen-met-1-8-procent-in-2014.htm.

3. Drummond M, Sculpher MJ, Claxton K, Stoddart G, Torrance GW. Methods for the Economic Evaluation of Health Care Programmes. New York: Oxford University Press; 2015.

4. Gold MR, Siegel JE, Russel LB, Weinstein MC. Cost-Effectiveness in Health and Medicine. New York: Oxford University Press; 1996.

5. Byford S, Raftery J. Perspectives in economic evaluation. BMJ. 1998;316(7143):1529-30.

6. Husereau D, Drummond M, Petrou S, Carswell C, Moher D, Greenberg D, et al. Consolidated Health Economic Evaluation Reporting Standards (CHEERS) statement. Int J Technol Assess Health Care. 2013;29:117-22.

7. ISPOR. Comparison of PE Guidelines for selected countries on selected key features. 2016 [cited 20167 June]; Available from: http://ispor.org/peguidelines/COMP3.asp.

8. Jonsson B. Ten arguments for a societal perspective in the economic evaluation of medical innovations. Eur J Health Econ. 2009; 10:357-9.

9. Knies S, Severens JL, Ament AJ, Evers SM. The transferability of valuing lost productivity across jurisdictions. differences between national pharmacoeconomic guidelines. Value Health. 2010;13:519-27.

10. Evers SM, Hiligsmann M, Adarkwah CC. Risk of bias in trial-based economic evaluations: identification of sources and bias-reducing strategies. Psychology \& Health. 2015;30:52-71.

11. Lorgelly PK, Lawson KD, Fenwick EA, Briggs AH. Outcome measurement in economic evaluations of public health interventions: a role for the capability approach? Int J Environ Res Public Health. 2010;7:2274-89.

12. O'Connell ME, Boat T, Warner KE. Preventing Mental, Emotional, and Behavioral Disorders Among Young People: Progress and Possibilities. Washington (DC): National Academies Press (US), 2009 9780309126748.

13. Karoly LA, Kilburn MR, Bigelow JH, Caulkins JP, Cannon JS, Chiesa JR. Assessing Costs and Benefits of Early Childhood Intervention Programs: Overview and Application to the Starting Early Starting Smart Program. Santa Monica: RAND, 2001.

14. Aos S, Lieb R, Mayfield J, Miller M, Pennucci A. Benefits and costs of prevention and early intervention programs for youth. Olympia, WA: Washington State Intstitute for Public Policy, 2004.

15. Weatherly H, Drummond M, Claxton K, Cookson R, Ferguson B, Godfrey C, et al. Methods for assessing the cost-effectiveness of public health interventions: key challenges and recommendations. Health Policy. 2009;93):85-92.

16. ZiNL. Richtlijn voor het vitvoeren van economische evaluaties in de gezondheidszorg. 2016.

17. French MT, Rachal JV, Hubbard RL. Conceptual framework for estimating the social cost of drug abuse. J Health Soc Policy. 1991;2:1-22.

18. Luce BR, Elixhauser A. Estimating costs in the economic evaluation of medical technologies. Int J Technol Assess Health Care. 1990;6:57-75.

19. Koopmanschap MA, Rutten FF, van Ineveld BM, van Roijen L. The friction cost method for measuring indirect costs of disease. J Health Econ. 1995; 14:171-89.

20. Koopmanschap MA, van Exel JN, van den Berg B, Brouwer WB. An overview of methods and applications to value informal care in economic evaluations of healthcare. Pharmacoeconomics. 2008;26:269-80.

21. Weisbrod BA. Economics of Public Health: Measuring the Economic Impact of Diseases: University of Pennsylvania Press; 1961.

22. Briggs AH, O'Brien BJ. The death of cost-minimization analysis? Health Econ. 2001;10: 179-84.

23. Vemer $P$, Rutten-van Molken MP. Largely ignored: the impact of the threshold value for a QALY on the importance of a transferability factor. Eur J Health Econ. 201 1; 12:397-404.

24. Drost RMWA, van der Putten IM, Paulus ATG, Ruwaard D, Evers SMAA. Conceptualizations of the societal perspective within economic evaluations: systematic review [under review].

25. Drost RMWA, Paulus ATG, Ruwaard D, Evers SMAA. Intersectoral costs and benefits of mental health prevention: towards a new classification scheme. J Ment Health Policy Econ. 2013;16:179-86. 
26. Drost RMWA, Paulus ATG, Ruwaard D, Evers SMAA. Valuing intersectoral costs and benefits of interventions in the healthcare sector: methods for obtaining unit prices. Expert Rev Pharmacoecon Outcomes Res. 2016 Feb 12:1-8.

27. Drost RMWA, Wansink HJ, Paulus ATG, Ruwaard D, Hosman CMA, Janssens JMAM, et al. Costeffectiveness of preventive case management for parents with a mental illness: a randomized controlled trial from three economic perspectives. BMC Health Serv Res [accepted for publication]. 2016.

28. Drost RMWA, Paulus ATG, Jander AF, Mercken L, de Vries H, Ruwaard D, et al. A Web-Based ComputerTailored Alcohol Prevention Program for Adolescents: Cost-Effectiveness and Intersectoral Costs and Benefits. Journal of Medical Internet Research. 2016;18(4):e93. 


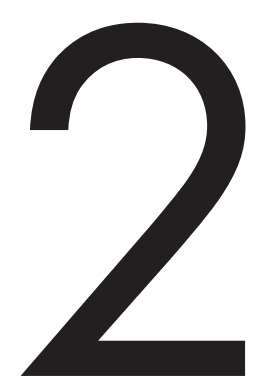

Conceptualizations of the societal perspective within economic evaluations: a systematic review

Drost RMWA, van der Putten IM, Ruwaard D, Evers SMAA, Paulus ATG Submitted 


\section{Abstract}

\section{Objectives}

To investigate how the societal perspective is conceptualized in economic evaluations and to assess the way intersectoral costs and benefits (ICBs), i.e. the costs and benefits pertaining to sectors outside the healthcare sector, determine their results.

\section{Methods}

Using PubMed, Embase, CINAHL and PsychINFO, a systematic literature review was conducted for economic evaluations which were conducted from a societal perspective. Conceptualizations were assessed in NVivo version 11 using conventional and directed content analysis. Additionally, trialbased evaluations in the fields of 'musculoskeletal disorders/dysfunction' (MD) and 'mental and behavioral disorders' (MH) were analyzed, focusing on the way ICBs determine economic evaluation results.

\section{Results}

A total of 107 studies were assessed, of which 74 (69.1\%) provided conceptualizations of the societal perspective. These varied tremendously in types of costs included and in descriptions of cost bearers. Labor productivity costs were included in 72 studies $(67.3 \%)$, while only 38 studies $(35.5 \%)$ included other ICBs, most of which entailed informal care and/or social care costs. ICBs within the educational and criminal justice sectors were each included five times. Most of the MD and MH trialbased evaluations ( $n=21$ of 28 ) reported productivity costs. In nine, these took up more than $50 \%$ of total costs. In several MH studies, criminal justice and informal care costs were also important.

\section{Conclusions}

There is great variety in the way the societal perspective is conceptualized and interpreted within economic evaluations. Use of the term societal perspective is often related to including merely productivity costs, while other ICBs could be relevant as well. 


\section{Introduction}

Increasingly, health economic evaluations are being considered supportive for decision making on healthcare interventions. ${ }^{1-5}$ Since financial resources are scarce and investment options are infinite, it is important that these programmes and interventions are effective not only in terms of health gains and improving quality of life, but that these effects also outweigh the intervention costs and the costs of service use in comparison with the best alternative investment in terms of costs for society as a whole. The analyses and reported results of such economic evaluations depend on the perspective from which the economic evaluation is conducted. ${ }^{6}$ This perspective can be either narrow, in which a selection of costs and effects are measured and included in the analysis, or broad, comprising all costs and effects of the interventions under comparison.

Within health economic evaluations, the most commonly used perspectives include 1) the payer perspective, in which only the costs and effects for a certain party, such as the patient, employer or insurer, are included, 2) the healthcare perspective, which comprises only the costs and effects within the healthcare sector, and 3) the societal perspective, in which the analyst considers all costs and effects that flow from the intervention, regardless of who experiences these. ${ }^{6}$ Since the chosen perspective determines the outcome of the evaluation, economic evaluations should be explicit about the perspective they adopt. ${ }^{7}$ Several guidelines on good research practices, such as reported in 'Principles of Good Practice for Budget Analysis: Report of the ISPOR Task Force on Good Research PracticesBudget Impact Analysis' and 'Consolidated Health Economic Evaluation Reporting Standards (CHEERS) Statement' (simultaneous publication in the International Journal of Technology Assessment in Health Care and nine other renowned journals, 2013), have adopted this statement. $^{8-10}$

The societal perspective is argued to be dominant over the others. $4,7,11$ This is because health economics is founded in welfare economics, which indicates that an economic evaluation should include the impact of an intervention on the whole society. ${ }^{7}$ Hence, a societal perspective is necessary for making optimal societal decisions. ${ }^{4}$ In theory, the definition of the societal perspective, which states that 'all costs and effects should be included regardless of who experiences these', seems appropriate. In practice, however, this definition appears less straightforward; looking at costs, the first part of this definition in particular leaves considerable room for discussion as there is often uncertainty regarding which costs should be included in addition to healthcare costs. ${ }^{12}$ As a result, the way the societal perspective is conceptualized and interpreted can differ between studies, and the choice of conceptualization can seriously affect the outcome of an economic analysis.

While the leading health economic literature explicitly notes that informal care and productivity losses are potentially important, other costs outside the healthcare sector are given considerably less attention. 1,6,13-15 Yet, the aforementioned definition does not limit researchers to merely value informal care and productivity losses along with the use of health services. On the contrary, interventions within the healthcare sector can yield a wide array of costs and benefits in sectors outside the healthcare sector. ${ }^{16,17}$ These are also 
known as 'intersectoral costs and benefits (ICBs)'. ${ }^{17,18}$ Drost et al. (2013) identified more than $70 \mathrm{ICBs}$ of healthcare interventions, which were classified into five categories. These include the sectors 'Education' (e.g. special education), 'Labour and Social Security' (e.g. productivity), 'Household \& Leisure' (e.g. informal care) and 'Criminal Justice System' (e.g. police interventions), and a fifth category for 'Individual \& Family Effects' (e.g. family conflict), which shows that health is connected with the welfare of society through various pathways. $^{18}$

Although it is clear that choices are being made when adopting a societal perspective, it is unclear whether choices to omit specific ICBs are made based on a misinterpretation of the societal perspective or measurement issues and whether an ICBs was deliberately omitted or not. There is a danger of leaving out important costs, which can lead to biased results. ${ }^{4,12,19}$ This, in turn, could lead to poor investment and reimbursement decisions in the healthcare sector. Prior research has already shown that including productivity losses in economic evaluations matters. ${ }^{20}$ Unfortunately, little is known about the impact of other ICBs. Therefore, the aim of this study is to find out how the societal perspective is conceptualized and interpreted in economic evaluations, which ICBs are included within these evaluations and to what extent ICBs determine the results of these evaluations.

\section{Methods}

\section{Literature search}

A systematic literature review was conducted focusing on economic evaluations performed from a societal perspective. In the summer of 2015, relevant studies were sought based on methodologies described in exemplary literature reviews and guidelines for retrieving (economic) evaluations. ${ }^{21-24}$ To increase the likelihood and efficiency of finding studies reporting the required information, the search was limited to studies which were published after publication of the CHEERS statement in 2013. Since the CHEERS publications appeared between March and June of 2013, it was decided to include only studies published between 1 July 2013 and 1 July 2015. Furthermore, the search was limited to full economic evaluation studies with the availability of the complete text, conducted on human subjects, and published in English.

Databases and search terms were initially selected based on recommendations for retrieving relevant economic evaluation studies, which proposes a combined search in PubMed and the National Health Service Electronic Evaluation Database (NHS EED) as an appropriate, cost-effective strategy. ${ }^{22}$ However, since funding to produce NHS EED ceased at the end of March 2015, we replaced NHS EED with its principle renowned sources: Embase, CINAHL and PsychINFO. Searches were conducted using the search term combination 'societal' AND 'economic evaluation' OR 'costs' (PubMed search strategy example in Table 2.1). Adding the search term 'costs' was necessary to increase 
the sensitivity of the search, because 'economic evaluation' and equivalents are not consistently indexed with Medical Subject Heading terms. ${ }^{22}$

Table 2.1 Search strategy in PubMed

\begin{tabular}{l} 
Search terms \\
("cost-benefit analysis"[MeSH Terms] OR ("cost-benefit"[All Fields] AND "analysis"[All Fields]) OR "cost-benefit \\
analysis"[All Fields] OR ("economic"[All Fields] AND "evaluation"[All Fields]) OR "economic evaluation"[All \\
Fields]) OR ("costs and cost analysis"[MeSH Terms] OR ("costs"[All Fields] AND "cost"[All Fields] AND \\
"analysis"[All Fields]) OR "costs and cost analysis"[All Fields] OR "costs"[All Fields]) AND societal[All Fields] \\
\hline Limits \\
((Clinical Trial[ptyp] OR Evaluation Studies[ptyp]) AND hasabstract[text] AND ("2013/07/01"[PDAT] : \\
"2015/07/O1"[PDAT]) AND "humans"[MeSH Terms] AND English[lang]) \\
\hline
\end{tabular}

\section{Post-search article selection}

Of the studies found, all duplicates, reviews, design articles, and animal studies which passed the search filter were excluded. Two reviewers independently assessed all titles and abstracts (RD and IP). Titles were selected based on a recommendation in the first item of the CHEERS statement, which states that the study's title "identifies the study as an economic evaluation or uses more specific terms such as cost-effectiveness analysis". Subsequently, the abstracts were also checked for describing a health economic evaluation. Furthermore, abstracts were checked for use of the word 'societal' in combination with either 'perspective' or 'costs' (or equivalents). Abstracts lacking this combination were excluded. Finally, full texts (which were all retrieved) were examined for describing full health economic evaluations conducted from a societal perspective. Only these were included in our study.

\section{Data extraction and analysis}

In the second half of 2015, two reviewers (RD and IP) independently assessed all included studies, after which they compared the assessments. Differences in the results were discussed in author meetings with all authors until uniformity was reached. The data extracted and assessed included conceptualizations of the societal perspective, general study characteristics, and economic evaluation-specific characteristics.

\section{Conceptualizations of the societal perspective}

Conceptualizations of the societal perspective (if provided) were labelled as one or more of the following, which were not mutually exclusive: 1) provision of a general conceptualization, i.e. mention of broad categories such as 'direct costs' and 'indirect costs', 2) provision of a specific conceptualization, i.e. mention of cost types such as 'absenteeism costs' and 'general practitioner costs' or 3) citation of a health economic guideline, journal article or handbook. Furthermore, we also assessed whether studies further specified their conceptualizations to a specific country context, for example the Dutch or Danish societal perspective. From here, all conceptualizations of the societal 
perspective were assessed using content analysis in NVivo version $11 .^{25,26}$ This entails an analysis of quotes of the societal perspective (e.g. "this study was conducted from a societal perspective, which means... ' and was done separately for general and specific conceptualizations. General conceptualizations were analyzed using conventional content analysis, which means that for each new conceptualization a code was added to the overview. ${ }^{26}$ Specific conceptualizations were analyzed using directed content analysis. Costs were classified based on the $C_{1}-C_{4}$ classification of Drummond et al. (2015), which categorizes costs as healthcare costs $\left(C_{1}\right)$, costs in other sectors $\left(C_{2}\right)$, patient and family costs, such as out of pocket and travel expenses $\left(C_{3}\right)$, and productivity costs $\left(C_{4}\right)(1)$. ICBs (category $\mathrm{C}_{2}$ ) were further subdivided based on a classification scheme by Drost et al. (2013), which provides a sub-classification into the 'educational sector', 'the criminal justice system', and 'household and leisure'. ${ }^{18}$ The latter covers ICBs related to informal care, social care, household help, leisure time and voluntary work.

\section{General study characteristics}

The general study characteristics extracted from the full text included year of publication, country of study and the disease area targeted by the intervention, based on the International Statistical Classification of Diseases and Related Health Problems 10th Revision. ${ }^{27}$ Interventions which did not target a specific disease, but overall health such as certain health behavior interventions, were clustered in a separate group. Furthermore, we assessed the type of economic analysis (cost-minimization; cost-effectiveness; cost-utility; cost-benefit; combination), study design (trial; modeling), time horizon ( $\leq 1$ year; $\leq 2$ years; $\leq 5$ years; $\leq 10$ years; lifetime) and cost categories included in the evaluation. Types of costs were categorized using the classification schemes of Drummond et al. (2015) and Drost et al. (2013) mentioned earlier. ${ }^{1,18}$ Costs which were reported as direct or indirect costs were reclassified based on the abovementioned classification schemes.

\section{Economic evaluation specific characteristics}

Economic evaluation specific characteristics were drawn from a subset of studies. Based on the general study characteristics (Table 2.3), it was decided to restrict this extensive analysis to trial-based economic evaluations of interventions within the disease areas of 'musculoskeletal disorders/dysfunction' (MD, 13 studies) and 'mental and behavioral disorders' (MH, 15 studies). For all other disease areas, no more than three trial-based evaluations were identified per area. Furthermore, trial-based evaluations offered revealed (measured) costs, while costs in model-based economic evaluations are (largely) hypothetical. Therefore, and given the limited level of required information provided in these studies, model-based evaluations were not further assessed.

Specific characteristics of economic evaluations extracted from the full text included: the outcome measure (monetary; quality adjusted life years; other), outcome in the analysis conducted from the societal perspective, such as the net-monetary benefit, incremental cost-effectiveness ratio (ICER) and incremental cost-utility ratio (ICUR), whether the 
intervention was cost effective and/or had a positive net benefit from the societal perspective, specific types of $C_{2}$ and $C_{4}$ costs, whether a second economic analysis was conducted from a different perspective, whether the outcome of this second analysis was different from the one conducted from the societal perspective, and whether the author mentions cost types which were not included in the evaluation conducted from the societal perspective and if this was considered to be a limitation of the study.

For each study and based on available information, we calculated the proportion of ICB-related costs relative to total costs for the intervention condition(s) and control condition. From here, as is done for productivity costs in earlier research, ${ }^{20}$ we recalculated incremental costs (i.e. costs in intervention condition minus costs in control condition) by leaving out costs in the educational sector and criminal justice sector. We chose to assess costs in these two sectors, because little is known about the extent to which these ICBs determine the results of economic evaluations. Main economic evaluation specific findings are presented and discussed in this paper. More detailed informationon the trial-based MD and MH studies can be found in Supplementary File S2.1.

\section{Results}

Based on the searches in PubMed, CINAHL, Psychlnfo and Embase, 725 unique studies were identified. Of these, 590 were excluded based on an assessment of the titles and abstracts. These were excluded on the basis of being design articles, reviews, not describing the study as being an economic evaluation or not mentioning the societal perspective. Of the $135 \mathrm{left}$, another 28 were excluded, of which 17 were excluded because they appeared to have been published before 1 July 2013. This resulted in 107 included studies (Figure 2.1).

\section{Conceptualizations of the societal perspective}

Of the 107 studies, 21 studies both did not conceptualize the societal perspective and did not provide a reference. Of the 86 studies which did at least one of both, 25 refer to a health economic guideline, journal article or handbook, of which ten studies merely cite a source without providing a conceptualization. Cited references include, among others, Gold et al. (1996), ${ }^{6}$ Byford (1998), ${ }^{7}$ and Drummond et al. (2005). ${ }^{28}$ Five studies explicitly (of which two merely) mentioned that a country-specific societal perspective was used. A number of 25 studies (23.4\%) provided a general conceptualization of the societal perspective and 29 studies (27.1\%) provided a specific conceptualization. An additional twenty studies (18.7\%) provided both, which makes a total of 74 conceptualizations that were analysed in NVivo. 


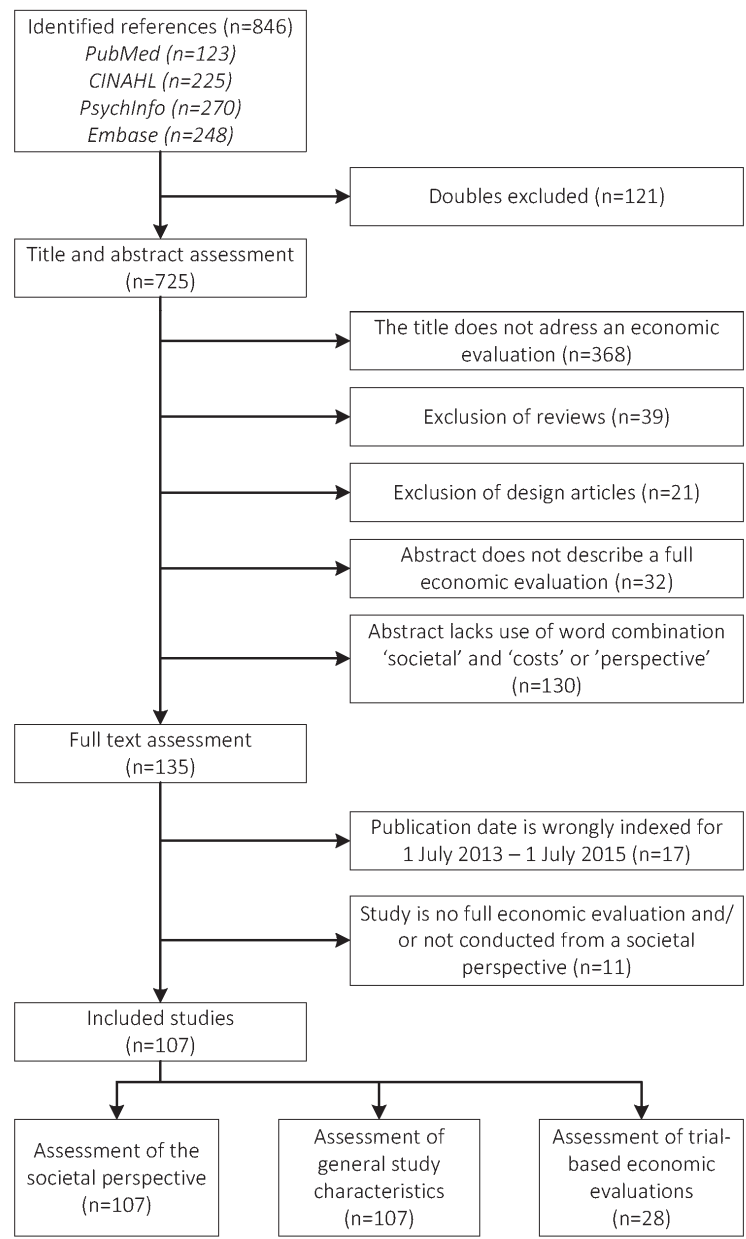

Figure 2.1 Flow chart describing the selection of studies

Thirteen clusters of general conceptualizations could be identified; these were placed in three subcategories (Table 2.2). In the first subcategory, authors of studies described the societal perspective by providing the party which bears the costs (such as society). The most commonly used was "all costs irrespective of the payer". The second category consists of conceptualizations which describe a proposed cost categorization. The most commonly used was "all direct and indirect costs". Four of the conceptualizations were different and were placed in a third category named 'other'. 
Table 2.2 General and specific conceptualizations of the societal perspective

\begin{tabular}{|c|c|c|c|}
\hline \multicolumn{3}{|c|}{ General } & $\mathrm{N}$ \\
\hline \multicolumn{4}{|c|}{ Costs (and benefits) for specified groups } \\
\hline \multicolumn{3}{|c|}{ All costs and benefits irrespective to who } & 2 \\
\hline \multicolumn{3}{|c|}{ All costs irrespective of the payer } & 6 \\
\hline \multicolumn{3}{|c|}{ All costs to all individuals in society } & 2 \\
\hline \multicolumn{3}{|c|}{ All relevant costs for and effects on society } & 2 \\
\hline \multicolumn{3}{|c|}{ Costs shouldered by both provider and household } & 1 \\
\hline \multicolumn{3}{|c|}{ Any costs incurred by the patients } & 2 \\
\hline \multicolumn{4}{|c|}{ Origin of costs described } \\
\hline \multicolumn{3}{|l|}{ Direct and indirect costs } & 20 \\
\hline \multicolumn{3}{|c|}{ Payer, participant, and opportunity costs } & 1 \\
\hline \multicolumn{3}{|c|}{ Health care and non-health care resources } & 1 \\
\hline \multicolumn{4}{|l|}{ Other } \\
\hline \multicolumn{3}{|c|}{ The overall societal benefits of the program whether intended or not } & 1 \\
\hline \multicolumn{3}{|c|}{ All relevant costs associated with the burden of the disease } & 1 \\
\hline \multicolumn{3}{|c|}{ Costs associated with utilization of health care } & 2 \\
\hline \multicolumn{3}{|c|}{ All costs from whatever source } & 4 \\
\hline \multicolumn{4}{|l|}{ Specific } \\
\hline Type & $\mathrm{N}$ & Type & $\mathrm{N}$ \\
\hline \multirow{2}{*}{$\begin{array}{l}\text { Intervention costs } \\
\text { Treatment costs }\end{array}$} & 9 & Costs in other sectors & 0 \\
\hline & 1 & Educational sector & \\
\hline Health care costs & 9 & School absenteeism & 1 \\
\hline Community health & 2 & Criminal justice system & \\
\hline Day activity & 1 & Automobile accident & 1 \\
\hline Drug & 2 & Criminal activity & 2 \\
\hline Health care utilization & 1 & Criminal justice & 2 \\
\hline Health system & 5 & Victim & 2 \\
\hline Home care services & 1 & Household \& leisure & \\
\hline Hospital & 9 & Informal care & 6 \\
\hline Laboratory tests & 1 & Household cost & 1 \\
\hline Medical & 8 & Caregiver & 3 \\
\hline Medicare reimbursement & 3 & Housekeeping & 2 \\
\hline Nursing home care & 1 & Absenteeism normal activities & 1 \\
\hline Primary care & 2 & Unpaid work & 1 \\
\hline Provider & 2 & Patient and family costs & 6 \\
\hline Social care & 3 & Mortality & 2 \\
\hline Productivity costs & 25 & Out-of-pocket & 5 \\
\hline Absenteeism work & 8 & Patient time & 2 \\
\hline Disability payment & 1 & Respondent cost & 3 \\
\hline Lost income & 2 & Travel expenses & 6 \\
\hline Lost labour force & 1 & Other costs & 0 \\
\hline Work time lost & 6 & Direct costs & 7 \\
\hline Outcomes & 3 & Indirect costs & 10 \\
\hline & & Intangible costs & 1 \\
\hline & & Non-medical costs & 3 \\
\hline & & Non-health(care) costs & 3 \\
\hline
\end{tabular}

${ }^{a} \mathrm{~A}$ list of references and detailed information can be found in Supplementary File S2.2

Looking at the 49 specific conceptualizations (Table 2.2), types of healthcare costs or productivity costs were named most (both in 33 studies). Patient and family costs were 
named in nineteen of the conceptualizations, and fifteen conceptualizations mentioned costs in other sectors. Costs in the educational sector were mentioned in one conceptualization, costs in the criminal justice sector in five and household and/or leisure costs in ten. Intervention costs were mentioned in only ten of the specific conceptualizations. Some specific costs could not be classified based on specific classification schemes and were included in the category "other". Three studies mentioned the outcomes in their conceptualization of societal perspective. Detailed information on the conceptualizations can be found in Supplementary File S2.2.

It is important to mention that the costs named in these conceptualizations don't always represent the variety of costs taken into account, for many costs are mentioned elsewhere in the methods and results sections of the articles. For example, most studies included intervention costs in their analysis, while hardly any included these costs in the conceptualization of the societal perspective. This becomes evident when comparing the results in Table 2.2 and Table 2.4, of which the latter is discussed later on.

\section{General study characteristics}

Half of the included studies $(n=56)$ covered trial-based economic evaluations and half $(n=51)$ covered modelling studies (Table 2.3). Approximately one-third of the 107 included studies were US-based $(n=36)$ and more than one-fifth were based in the Netherlands $(n=24)$. Sweden $(n=8)$ and Canada $(n=7)$ took third and fourth place in numbers of included studies. In contrast, a fairly limited number of studies from the UK $(n=5)$ were included. Despite the societal perspective being considered dominant in international literature, ${ }^{7}$ it is recommended and commonplace in the UK to conduct health economic evaluations from the perspective of the $\mathrm{NHS}^{29}$ The main focus in the US studies was on modelling $(n=30,83.3 \%)$, whereas most of the evaluations in the Netherlands were trial-based $(n=23,95.8 \%)$. The majority of studies $(n=60)$ covered interventions targeting $M D, M H$, cardiovascular diseases or infectious diseases. Most economic evaluations within the field of $\mathrm{MH}$ were trial-based (15 out of 17 studies), while in the fields of cardiovascular and infectious diseases model-based economic evaluations were more common ( 18 out of 21 studies).

In total, 79 studies were CUA-based, either as a standalone analysis or in combination with a CEA. Most CEAs were trial-based, while the majority of less common CBAs were model-based. The majority of the trial-based evaluations (78.6\%) had a follow-up of no longer than one year. Apart from one study, which assessed costs over a one year timeframe fifteen years post intervention, no trial-based evaluations were identified with a follow-up longer than five years. Most modelling studies (58.8\%) projected the lifetime costs and consequences of the intervention. 
Table 2.3 Study characteristics of the included economic evaluations ( $\mathrm{n}, \%$ )

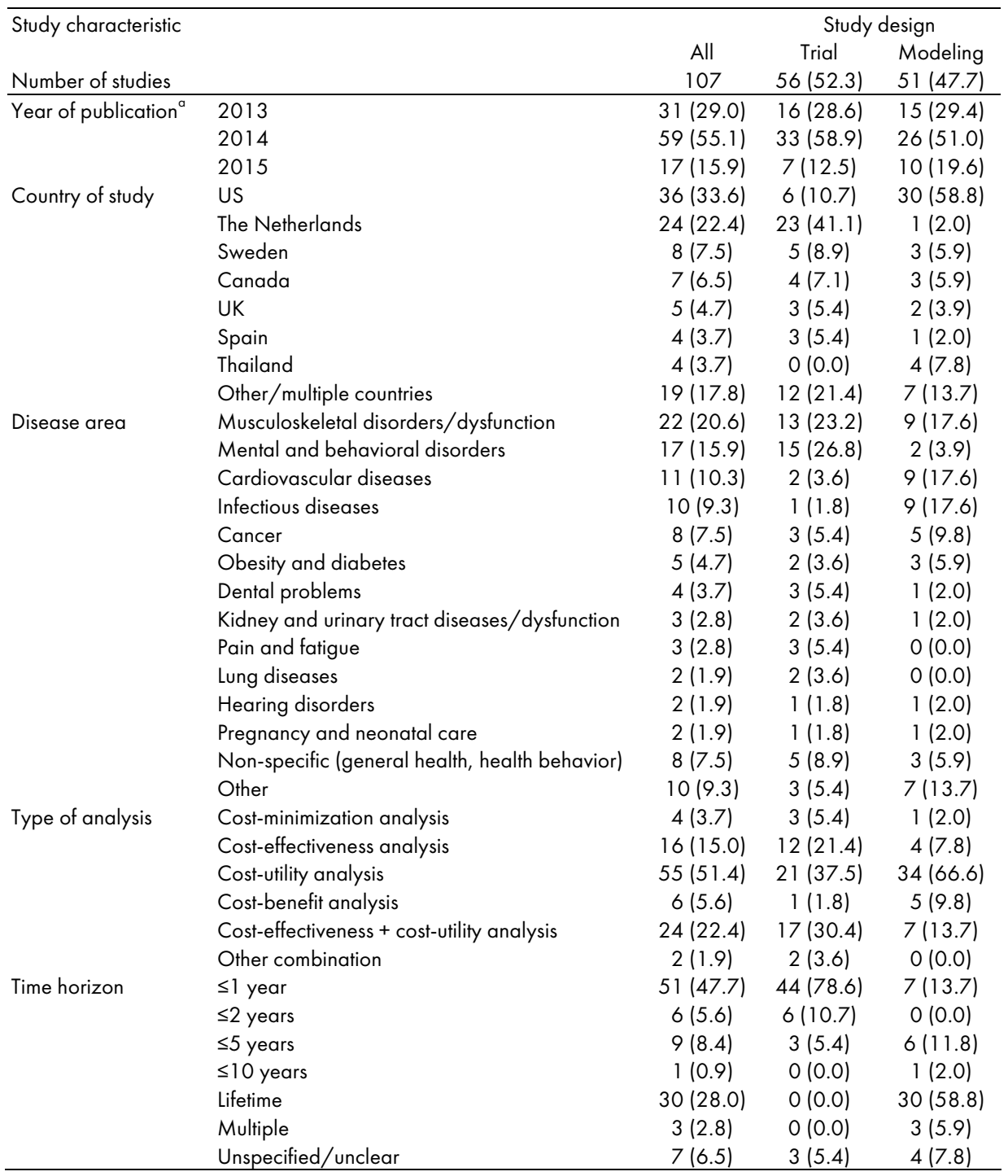

${ }^{a} 2013$ and 2015 each cover a half year and 2014 covers a full year

\section{Types of costs included}

Nearly all studies clearly report having included intervention costs and healthcare costs (Table 2.4), of which some might have used these terms interchangeably for the same types of costs. Nearly half of the 107 included studies $(n=49)$ included patient and family costs such as out of pocket expenses, travel costs and/or living costs. The majority of the studies $(n=72,67.3 \%)$ included costs related to labor productivity, such as costs related to 
absenteeism, presenteeism and unemployment. However, productivity costs were more frequently included in studies on interventions targeting $M D(86.4 \%)$ and $\mathrm{MH}(94.1 \%)$ than in studies on interventions targeting cardiovascular diseases $(36.4 \%)$ and infectious diseases $(60.0 \%)$. Related to this finding, productivity costs were more often included in trial-based economic evaluations $(n=43,76.8 \%)$ than in model-based economic evaluations ( $n=29,56.9 \%$ ). Only 38 studies (35.5\%) included other ICBs, of which most included only costs related to informal care, household help and/or social care. Again, these were more frequently included in trial-based evaluations. Studies which included ICBs within the educational sector and criminal justice sector were scarce. Both types were included five times, of which two of the studies which included criminal justice costs were in the field of $\mathrm{MH}$.

\section{Analysis of MD and MH trial-based economic evaluations}

Of the thirteen trial-based economic evaluations in the disease area of MD, nine explicitly reported the follow-up costs for ICBs. All of these reported costs related to labor productivity, such as absenteeism and presenteeism costs. In six of these, (combined) productivity-related costs took up more than $50 \%$ of the total costs in both the intervention as well as the control arms. Two studies reported costs related to informal care. In one of these, informal care costs took up $18.4 \%$ of the costs in the control condition and $28.7 \%$ of the costs in the intervention condition. In the other study, the weight of these costs relative to the total costs was close to $0 \%$. Costs related to other ICBs were not explicitly reported. Seven studies conducted additional analyses from other perspectives: six were from the healthcare/health system perspective and one from the employer's perspective. Differences in results between the societal perspective and other perspectives underlined the important role of ICBs. Six studies explicitly mentioned cost types which were not included in the study, but could have been of importance. The types and number of cost items mentioned in the discussion sections varied per study.

Of the fifteen trial-based economic evaluations in the disease area of $\mathrm{MH}$, thirteen explicitly reported the follow-up costs for ICBs. Twelve of these reported costs related to labor productivity, such as absenteeism and presenteeism costs. In three of these, productivity-related costs took up more than $50 \%$ of the total costs in both the intervention as well as the control arms and in all three, presenteeism costs outweighed absenteeism costs. Five studies reported costs related to informal care or domestic productivity. In one of these, informal care costs took up $66.3 \%$ of the costs in the control condition and $66.6 \%$ of the costs in the intervention condition. In the other five studies, the weight of these costs relative to the total costs was below $20 \%$. 


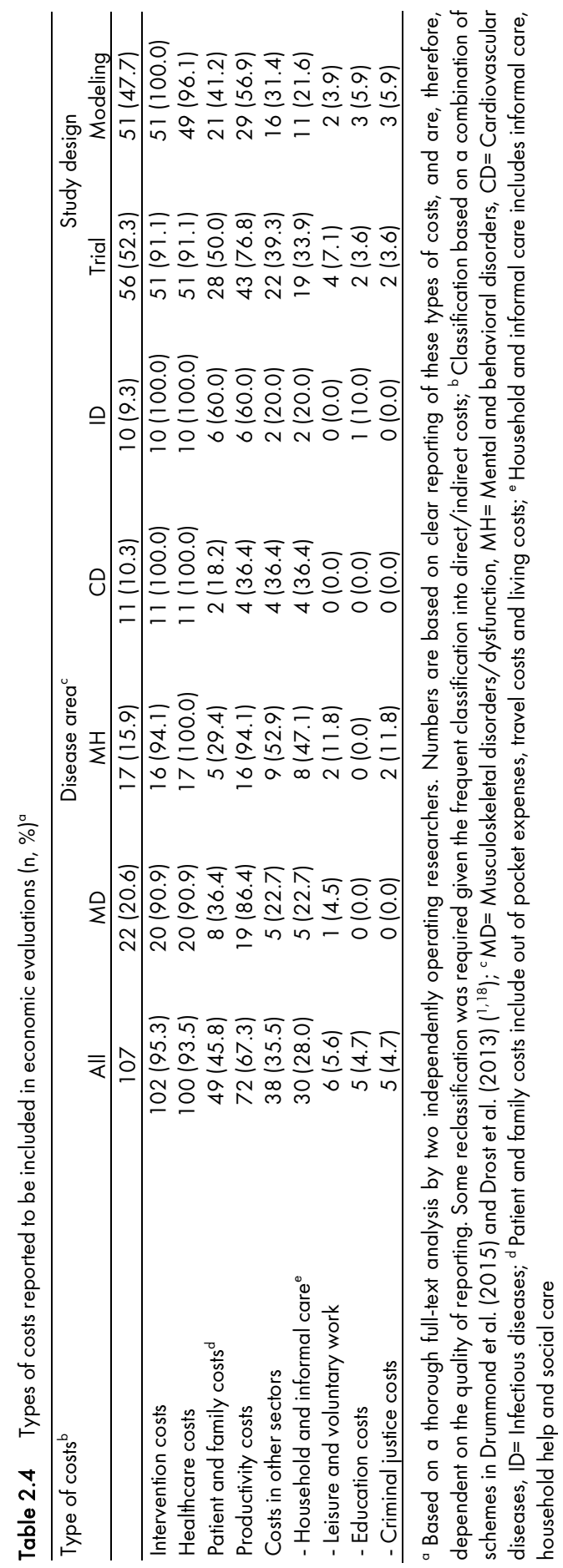


Two studies in the field of $\mathrm{MH}$ reported costs within the criminal justice sector. In one, crime costs and criminal justice costs took up $25.0 \%$ of the total costs in the intervention condition and $17.8 \%$ of the total costs in the control condition. ${ }^{30}$ The recalculation without these costs shifted incremental costs from $£-350$ to $£-1,896$. In the other study, costs related to arrests, court, probation and jail/prison time took up $23.5 \%$ of the total costs in the intervention condition and $62.5 \%$ of the total costs in the control condition. ${ }^{31}$ Here, the recalculation resulted in a shift from $\$-1,630$ to $\$-423$. Costs related to other ICBs were not explicitly reported. Eight studies conducted additional analyses from other perspectives: five were from the healthcare/health system perspective, two from the employer's perspective and one from the criminal justice services perspective. Differences in results between the societal perspective and other perspectives underlined the important role of ICBs. Three studies explicitly mentioned costs which were not included in the study, but could have been of importance.

As mentioned earlier, more detailed information on the trial-based MD and MH studies can be found in Supplementary File S2.1.

\section{Discussion}

\section{Conclusion}

Based on the results, it can be concluded that there is great variety in the way the societal perspective is conceptualized and executed within health economic evaluations. Consequently, there is great variety in the types of costs included in the analyses of the assessed studies.

The authors of included studies who did pay attention to the conceptualization of the societal perspective $(n=74)$ used a general conceptualization, of which most used the terms 'direct' and 'indirect' for categories, and/or used a specific conceptualization, by mentioning specific costs to describe their interpretation of the societal perspective. Both types were commonly used; roughly one-third used a general conceptualization, one-third used a specific conceptualization and one-third used both. Most of the authors who operationalized the societal perspective in a specific conceptualization explicitly mentioned productivity costs or related terms, which could have been their justification for using the term societal perspective. The conceptualization of the societal perspective was not often mentioned and discussed in the discussion sections of studies. However, some studies did discuss this issue. Some studies regarded their interpretation of the societal perspective to be a weakness of the study. ${ }^{32,33}$ Others perceived their interpretation of the societal perspective as a strength. ${ }^{34-38}$

In trial-based evaluations within the field of MD, productivity costs more often took up a large proportion of the total costs than in evaluations in the field of $\mathrm{MH}$. However, these costs showed to be important in the field of $\mathrm{MH}$ as well. The two of the studies in the field of $\mathrm{MH}$ which explicitly reported costs related to ICBs within the criminal justice sector showed 
that restricting economic evaluations to healthcare costs and productivity costs alone could sometimes be insufficient. Despite the differences between disease areas and even between studies within these disease areas, this literature review shows that costs related to ICBs often take up a considerable proportion of the total costs of an intervention. Although this evidence for ICBs other than those related to productivity is scarce, it is clear that, depending on the type of intervention, the disease area, and the target group, omitting ICBs from analyses conducted from the societal perspective could lead to biased results. In turn, when this leads to a biased ICER, ICUR or other important health economic outcome, omitting ICBs may lead to poor decision making when choosing between care as usual and an alternative.

\section{Research and policy implications}

How the societal perspective is operationalized remains largely in the eye of the beholder. ${ }^{39}$ Referring to the classification scheme of Drost et al. (2013), it is clear that, even if the societal perspective is chosen, not all 70 ICBs can be or should be included. ${ }^{18}$ Adopting the societal perspective raises measurement challenges. ${ }^{12}$ Furthermore, not all ICBs may be considered important enough to be included in the economic evaluations of certain interventions. For example, it is clear that costs within the criminal justice sector are not important for the economic evaluation of blood pressure medication, while the results of this literature review show that they might be important for the field of $\mathrm{MH}$. Although the decision regarding which $I C B$ s to include will remain based on expectations on what are considered to be 'big tickets', the results of this literature review underline the importance of making well-informed and argued decisions on which costs to include and exclude from analysis. As mentioned earlier, wrong decisions lead to biased results. ${ }^{12}$

The way the societal perspective is conceptualized and executed within health economic evaluations is partly dependent on country-specific health economic guidelines. Looking at productivity costs, a review of Knies et al. (2010) showed that the majority of examined guidelines (22 of 30 ) recommend using the societal perspective, but vary in the way productivity costs should be valued. " However, the use of the term 'societal perspective' should not be justifiable merely based on the choice of including productivity costs. Acclamation for this can be found in the updated version of the Dutch guidelines for costing research, which was published and presented in February 2016. These state that ICBs within the educational sector and criminal justice sector could play a vital role in health economic evaluations as well. ${ }^{40}$ This goes for all types of analysis, including CEA, CUA and CBA.

\section{Limitations}

The findings of this study need to be placed in the context of two limitations. First, the findings of the review were dependent on the quality of the reporting in included studies. The amount and quality of information which could be drawn from these studies varied. Some studies were less detailed and structured than others, which made it harder or 
impossible to retrieve the required information. Furthermore, some elements were harder to retrieve than others. For example, although a classification of costs into sectors is considered to provide more structure, ${ }^{1}$ the majority of studies ( $n=60,56.1 \%$ ) used the alternative of classifying costs into direct and indirect costs. Therefore, costs had to be reclassified. However, the chance of errors in retrieving and reclassifying information has been minimized through a double and independent analysis by two of the authors. Furthermore, the choice to include only papers which were published after publication of the CHEERS might have helped. Notwithstanding, what is not reported in papers might be more interesting than what is, and our study was limited due to this (un)deliberate reporting bias. This limitation shows the value of and need for reporting guidelines such as the CHEERS and the Consolidated Standards of Reporting Trials."

Second, several methodological choices needed to be made for feasibility and practical reasons, of which some could be important for future studies. The included studies were not assessed for methodological quality. Furthermore, costs were classified based on the classification schemes of Drummond et al. (2015) and Drost et al. (2013), 1, ${ }^{18}$ while other ways of classifying costs could have influenced results. Last, the in-depth analysis on ICBs was restricted to trial-based economic evaluations within the disease areas of MD and $\mathrm{MH}$. The number of studies in other disease areas was limited. Model-based evaluations were not assessed, given the fact that the majority of the model-based studies did not offer a detailed overview of costs. Furthermore, trial-based evaluations offered revealed (measured) costs, while costs in model-based economic evaluations are (largely) hypothetical. 


\section{References}

1. Drummond M, Sculpher MJ, Claxton K, Stoddart G, Torrance GW. Methods for the Economic Evaluation of Health Care Programmes. New York: Oxford University Press; 2015.

2. Hutubessy R, Chisholm D, Edejer TT. Generalized cost-effectiveness analysis for national-level prioritysetting in the health sector. Cost effectiveness and resource allocation : C/E, 2003; 1(1):8.

3. Johannesson M. Economic evaluation of health care and policymaking. Health Policy. 1995;33:179-90.

4. Jonsson B. Ten arguments for a societal perspective in the economic evaluation of medical innovations. Eur J Health Eecon 2009; 10:357-9.

5. Power EJ, Eisenberg JM. Are we ready to use cost-effectiveness analysis in health care decision-making? A health services research challenge for clinicians, patients, health care systems, and public policy. Med Care. 1998;36(5 Suppl):MS10-147.

6. Gold MR, Siegel JE, Russel LB, Weinstein MC. Cost-Effectiveness in Health and Medicine. New York: Oxford University Press; 1996.

7. Byford S, Raftery J. Perspectives in economic evaluation. BMJ, 1998;316(7143):1529-30.

8. ISPOR (2013). Health Economic Evaluation Publication Guidelines (CHEERS): Good Reporting Practices. http://www.ispor.org/Health-Economic-Evaluation-Publication-CHEERS-Guidelines.asp laccessed August 28, 2015).

9. Husereau D, Drummond M, Petrou S, et al. Consolidated Health Economic Evaluation Reporting Standards (CHEERS) statement. Int J Technol Assess Health Care, 2013;29(2):117-22.

10. Mauskopf JA, Sullivan SD, Annemans L, et al. Principles of good practice for budget impact analysis: report of the ISPOR Task Force on good research practices--budget impact analysis. Value Health, 2007; 10(5):336-47.

11. Knies S, Severens JL, Ament AJ, Evers SM. The transferability of valuing lost productivity across jurisdictions. differences between national pharmacoeconomic guidelines. Value Health, 2010;13(5):519-27.

12. Evers SM, Hiligsmann M, Adarkwah CC. Risk of bias in trial-based economic evaluations: identification of sources and bias-reducing strategies. Psychol Health, 2015;30(1):52-71.

13. Koopmanschap MA, Rutten FF, van Ineveld BM, van Roijen L. The friction cost method for measuring indirect costs of disease. Journal of health economics, 1995; 14(2):171-89.

14. Koopmanschap MA, van Exel JN, van den Berg B, Brouwer WB. An overview of methods and applications to value informal care in economic evaluations of healthcare. PharmacoEconomics, 2008;26(4):269-80.

15. Weisbrod BA. Economics of Public Health: Measuring the Economic Impact of Diseases. Philadelphia: University of Pennsylvania Press; 1961.

16. O'Connell ME, Boat T, Warner KE. Preventing Mental, Emotional, and Behavioral Disorders Among Young People: Progress and Possibilities. Washington (DC): National Academies Press (US); 2009.

17. Weatherly $\mathrm{H}$, Drummond $\mathrm{M}$, Claxton K, et al. Methods for assessing the cost-effectiveness of public health interventions: key challenges and recommendations. Health policy, 2009;93(2-3):85-92.

18. Drost RMWA, Paulus ATG, Ruwaard D, Evers SMAA. Intersectoral costs and benefits of mental health prevention: towards a new classification scheme. J Ment Health Policy Econ, 2013; 16(4):179-86.

19. Drummond $M$, Sculpher M. Common methodological flaws in economic evaluations. Med Care, 2005;43(7 Suppl):5-14.

20. Krol M, Papenburg J, Koopmanschap M, Brouwer W. Do Productivity Costs Matter?: the impact of including productivity costs on the incremental costs of interventions targeted at depressive disorders. PharmacoEconomics, $2011 ; 29(7): 601-19$.

21. Alayli-Goebbels AF, Evers SM, Alexeeva D, et al. A review of economic evaluations of behavior change interventions: setting an agenda for research methods and practice. J Public Health (Oxf), 2014;36(2):336-44.

22. Alton V, Eckerlund I, Norlund A. Health economic evaluations: how to find them. Int J Technol Assess Health Care, 2006;22(4):512-7.

23. Aveyard H. Doing a literature review in health and social care: a practical guide (3rd edition). Berkshire: Open University Press: McGraw - Hill Education; 2014.

24. Pitt C, Goodman C, Hanson K. Economic Evaluation in Global Perspective: A Bibliometric Analysis of the Recent Literature. Health economics, 2016;25 Suppl 1:9-28.

25. QSR. 2016. http://www.qsrinternational.com/what-is-nvivo (accessed January 18, 2016 ). 
26. Hsieh HF, Shannon SE. Three approaches to qualitative content analysis. Qual Health Res, 2005; 15(9): 1277-88.

27. WHO. International Statistical Classification of Diseases and Related Health Problems 10th Revision. http://www.who.int/classifications/icd/en/ (accessed November 9, 2015).

28. Drummond M, O'Brien BJ, Stoddart G, Torrance GW. Methods for the Economic Evaluation of Health Care Programmes. New York: Oxford University Press; 2005.

29. NICE (2014). Developing NICE guidelines: the manual. https://www.nice.org.uk/article/pmg20/chapter/1\%20introduction\%20and\%20overview (accessed January 21, 2016).

30. Barrett B, Waheed W, Farrelly S, et al. Randomised controlled trial of joint crisis plans to reduce compulsory treatment for people with psychosis: economic outcomes. PLoS One, 2013;8(11):e74210.

31. Herman PM, Mahrer NE, Wolchik SA, et al. Cost-benefit analysis of a preventive intervention for divorced families: reduction in mental health and justice system service use costs 15 years later. Prev Sci, $2015 ; 16(4): 586-96$.

32. Christensen A, Hoy K, Bunger C, et al. Transforaminal lumbar interbody fusion vs. posterolateral instrumented fusion: cost-utility evaluation along side an RCT with a 2-year follow-up. Eur Spine J, $2014 ; 23(5): 1137-43$.

33. Lewis DJ, Attiah MA, Malhotra NR, Burnett MG, Stein SC. Anterior surgical management of single-level cervical disc disease: a cost-effectiveness analysis. Spine (Phila Pa 1976), 2014;39(25):2084-92.

34. Golsteijn RH, Peels DA, Evers SM, et al. Cost-effectiveness and cost-utility of a Web-based or printdelivered tailored intervention to promote physical activity among adults aged over fifty: an economic evaluation of the Active Plus intervention. Int J Behav Nutr Phys Act, 2014;1 1:122.

35. Imaz I, Rubio B, Cornejo AM, Gonzalez-Enriquez J. Budget impact and cost-utility analysis of universal infant rotavirus vaccination in Spain. Preventive medicine, 2014;61:116-21.

36. Marsh J, Hoch JS, Bryant D, et al. Economic evaluation of web-based compared with in-person follow-up after total joint arthroplasty. J Bone Joint Surg Am, 2014;96(22):1910-6.

37. van Apeldoorn FJ, Stant AD, van Hout WJ, Mersch PP, den Boer JA. Cost-effectiveness of CBT, SSRI, and CBT+SSRI in the treatment for panic disorder. Acta psychiatrica Scandinavica, 2014; 129(4):286-95.

38. Wilson EC, Shulgina L, Cahn AP, et al. Treating idiopathic pulmonary fibrosis with the addition of cotrimoxazole: an economic evaluation alongside a randomised controlled trial. PharmacoEconomics, 2014;32(1):87-99.

39. Sculpher M. How Should a Societal Perspective in Economic Evaluation be Implemented? ISPOR. Amsterdam; 2014.

40. ZiNL. De nieuwe richtlijn Economische Evaluaties in Nederland: Verschillen en verbeteringen ten opzichte van de vorige richtlijn. Nieuwe richtlijn economische evaluaties: "Verduidelijking en verdieping". Amsterdam; 2016.

41. Moher D, Schulz KF, Altman DG. The CONSORT statement: revised recommendations for improving the quality of reports of parallel-group randomised trials. Lancet, 2001;357(9263):1191-4. 


\section{Supplemental file 2.1}

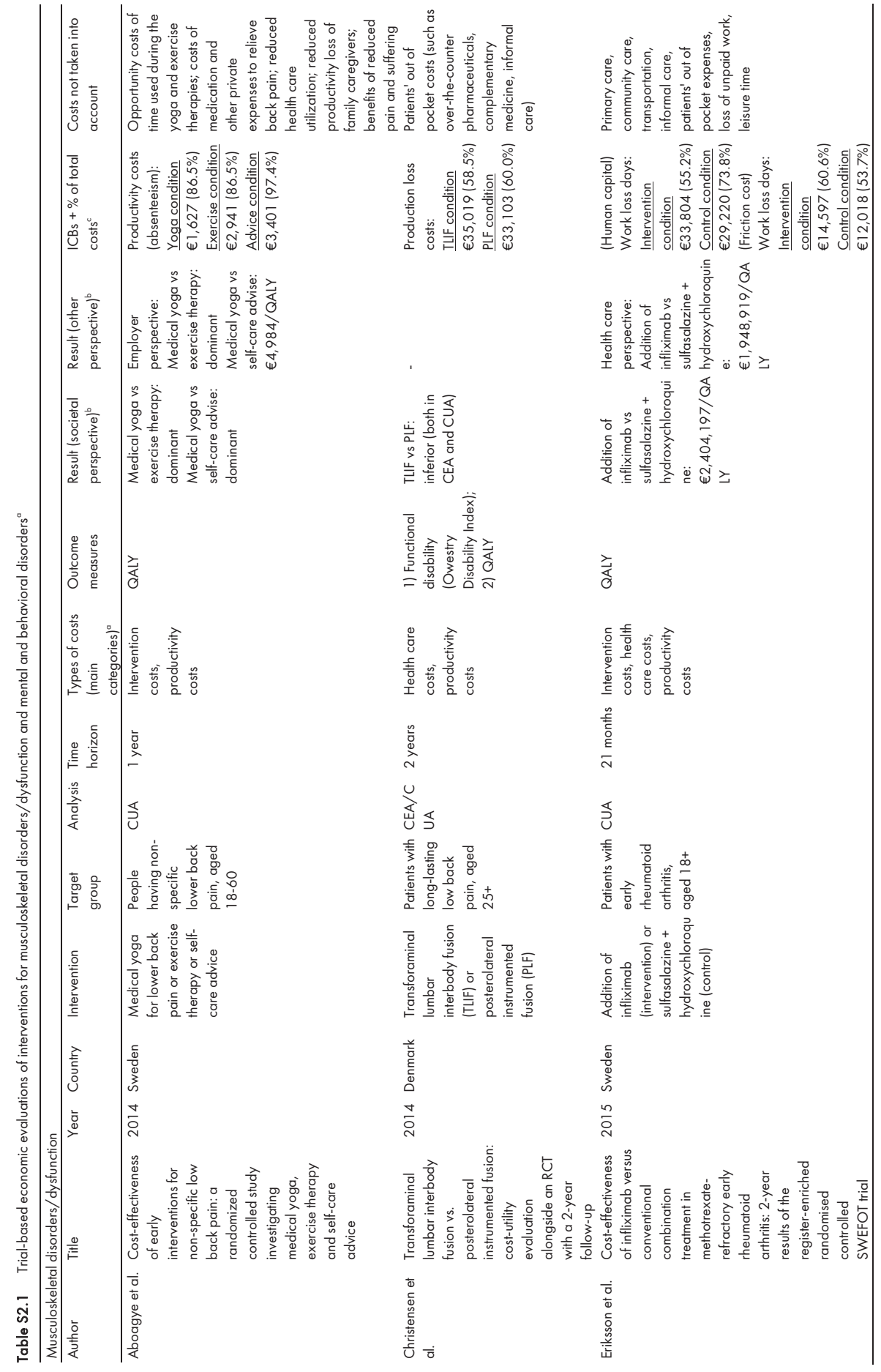




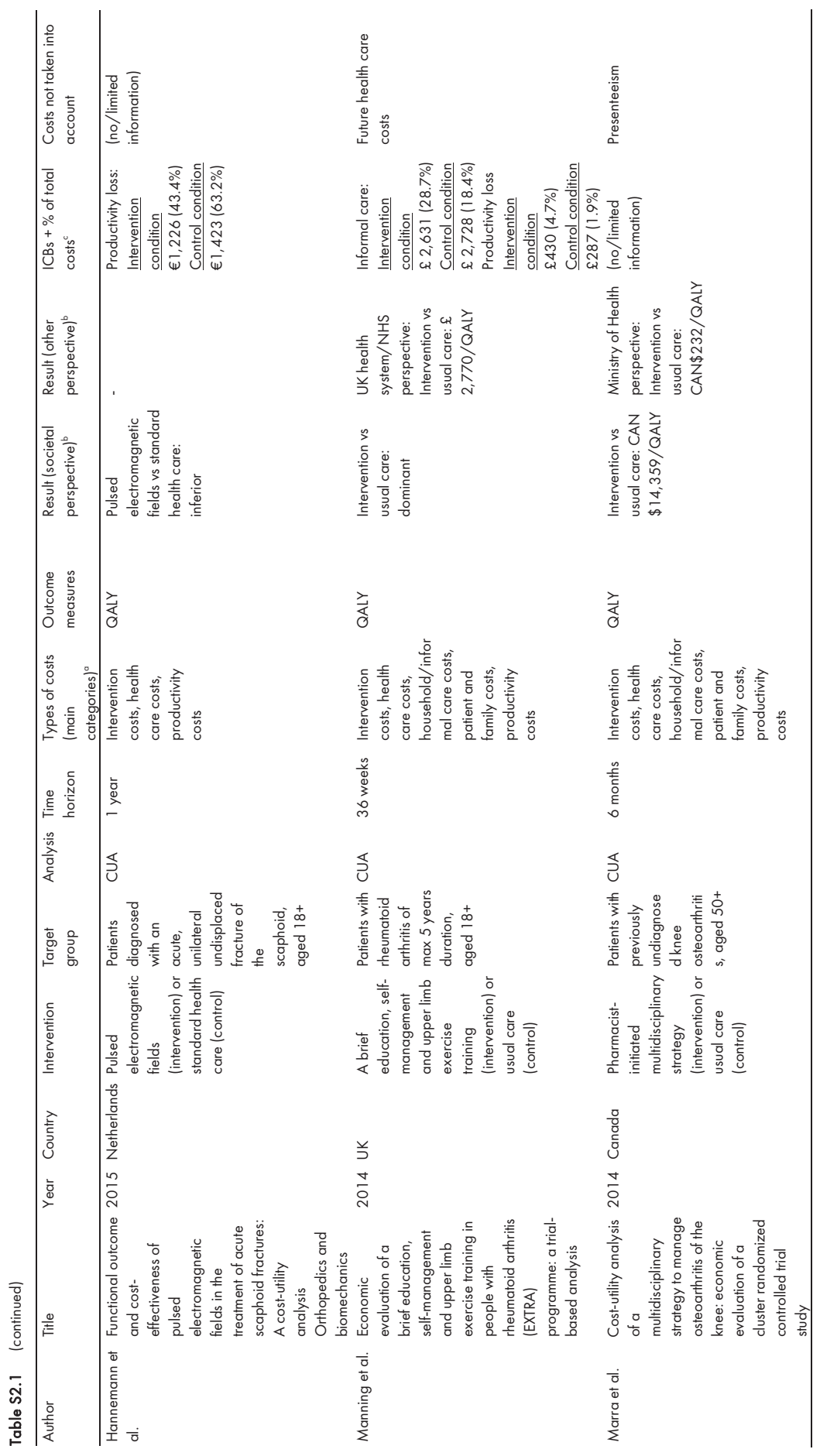




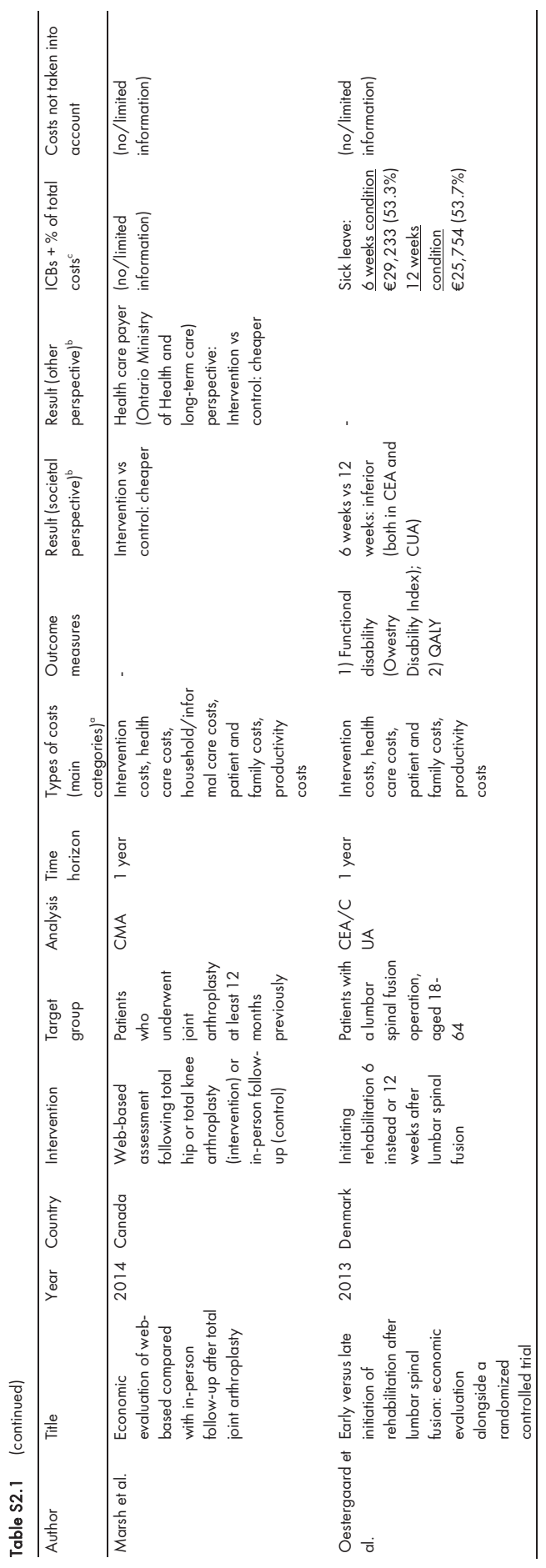




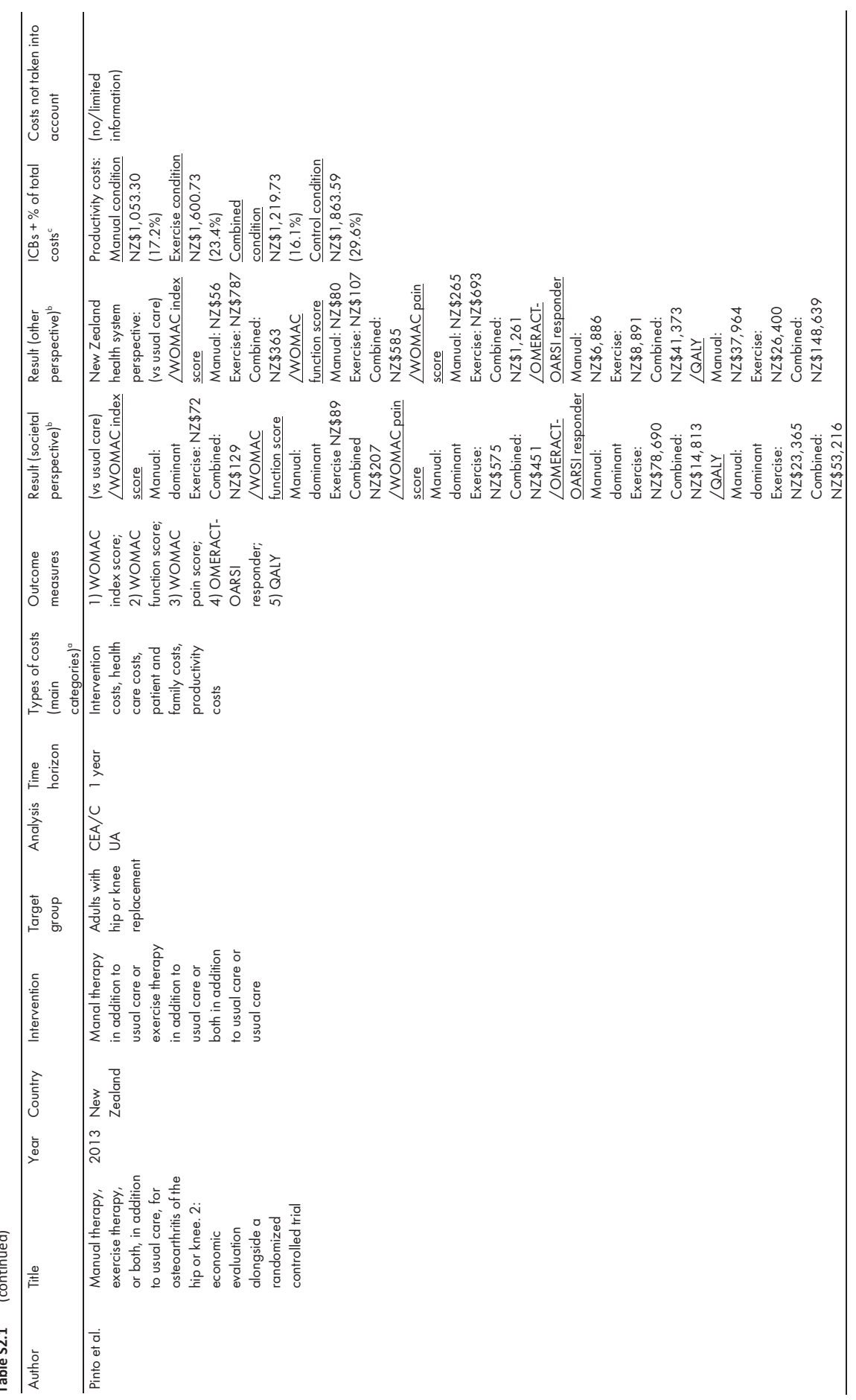




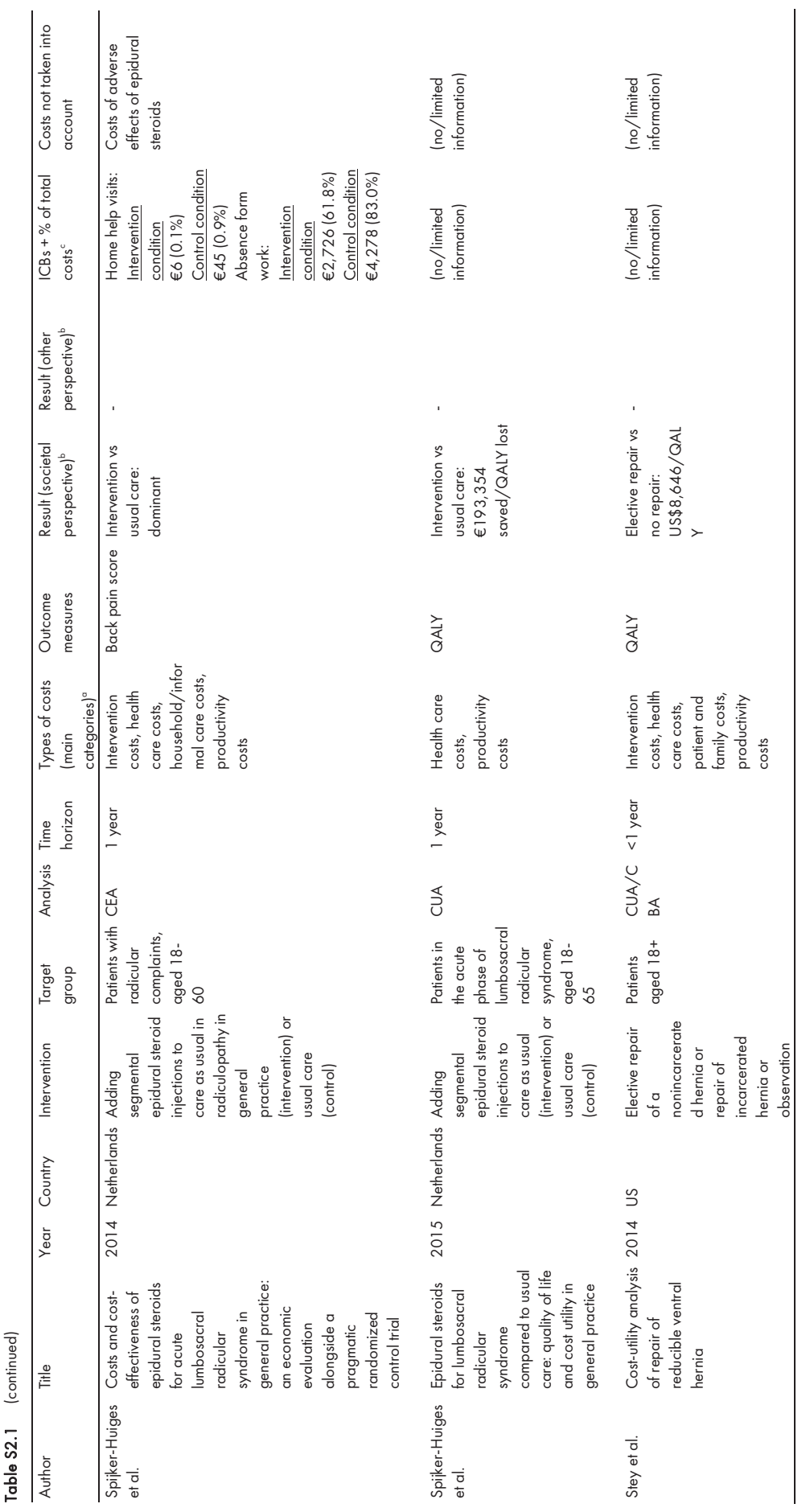




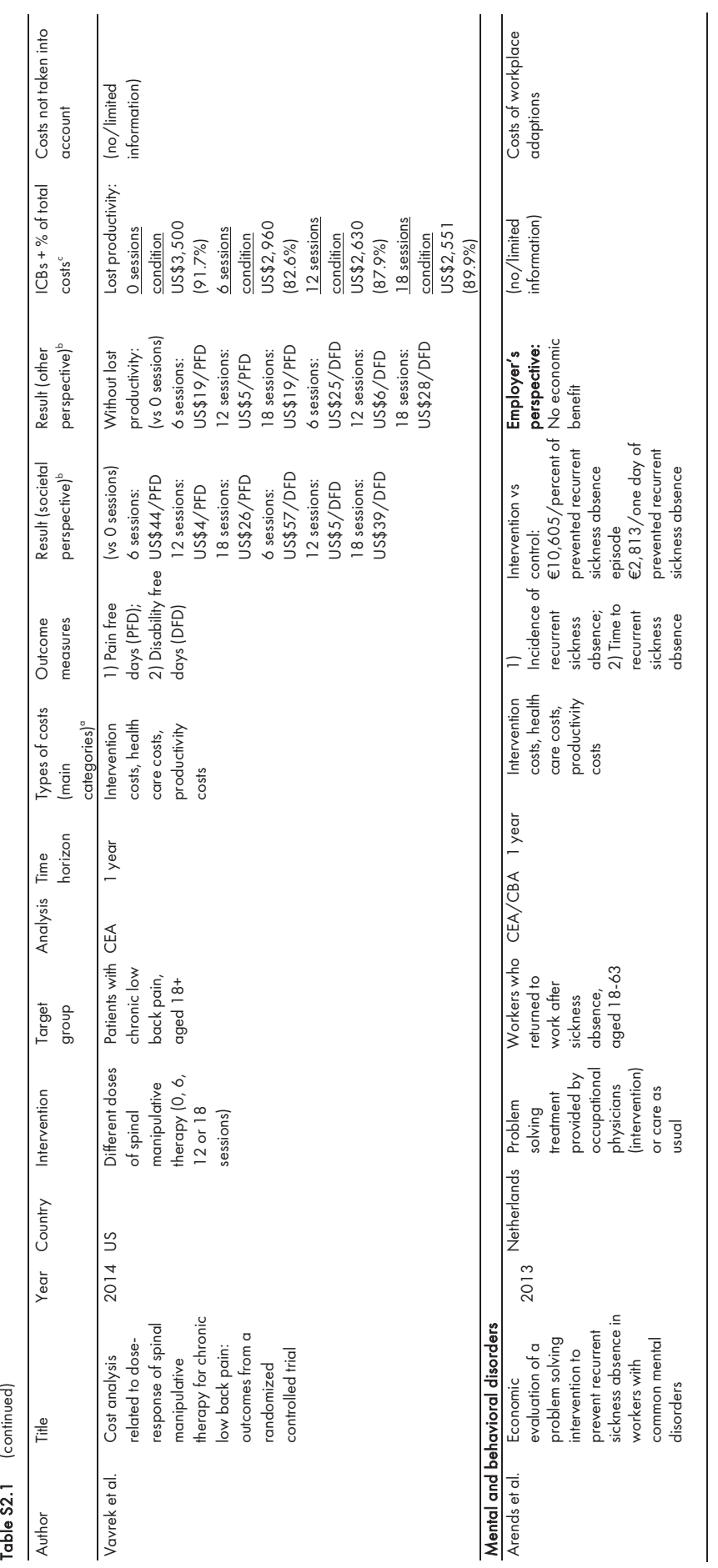




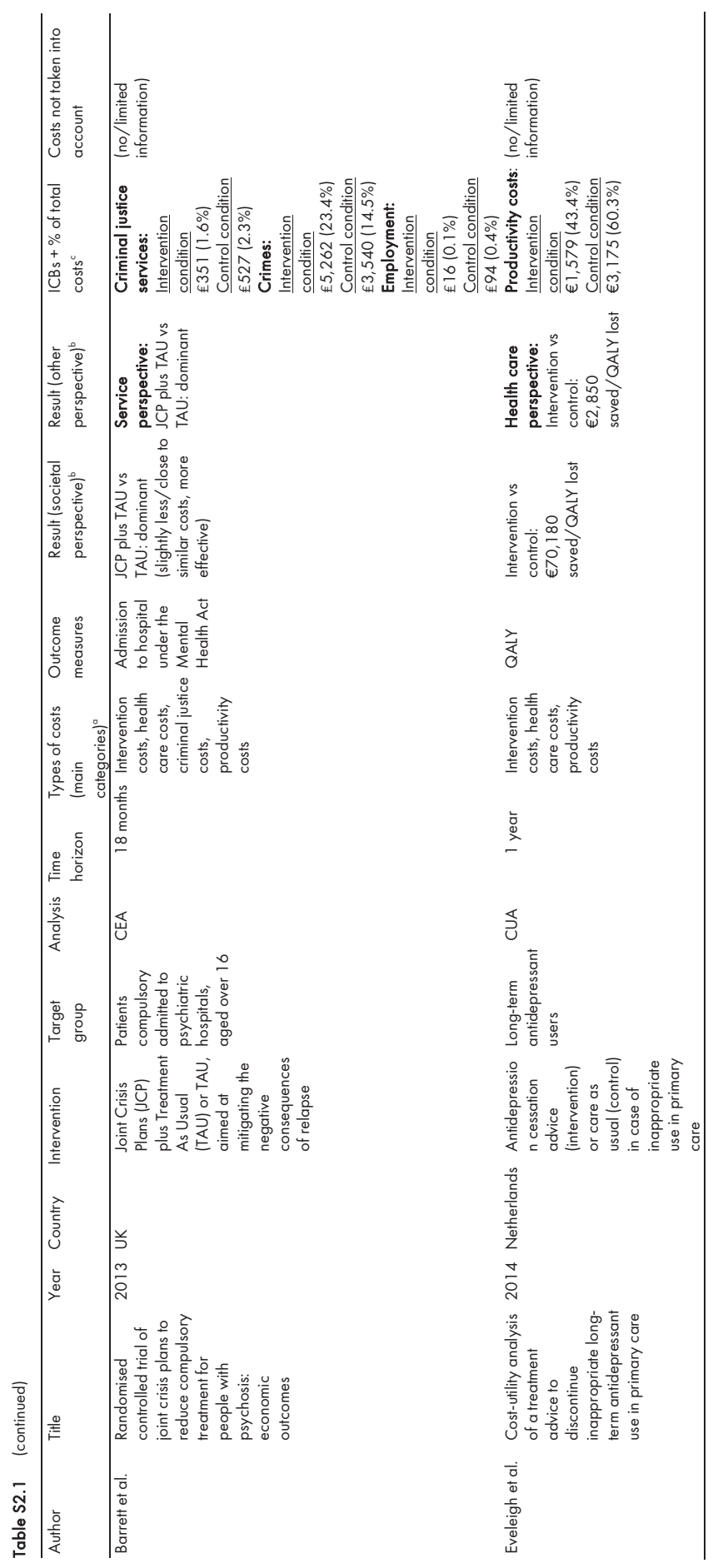




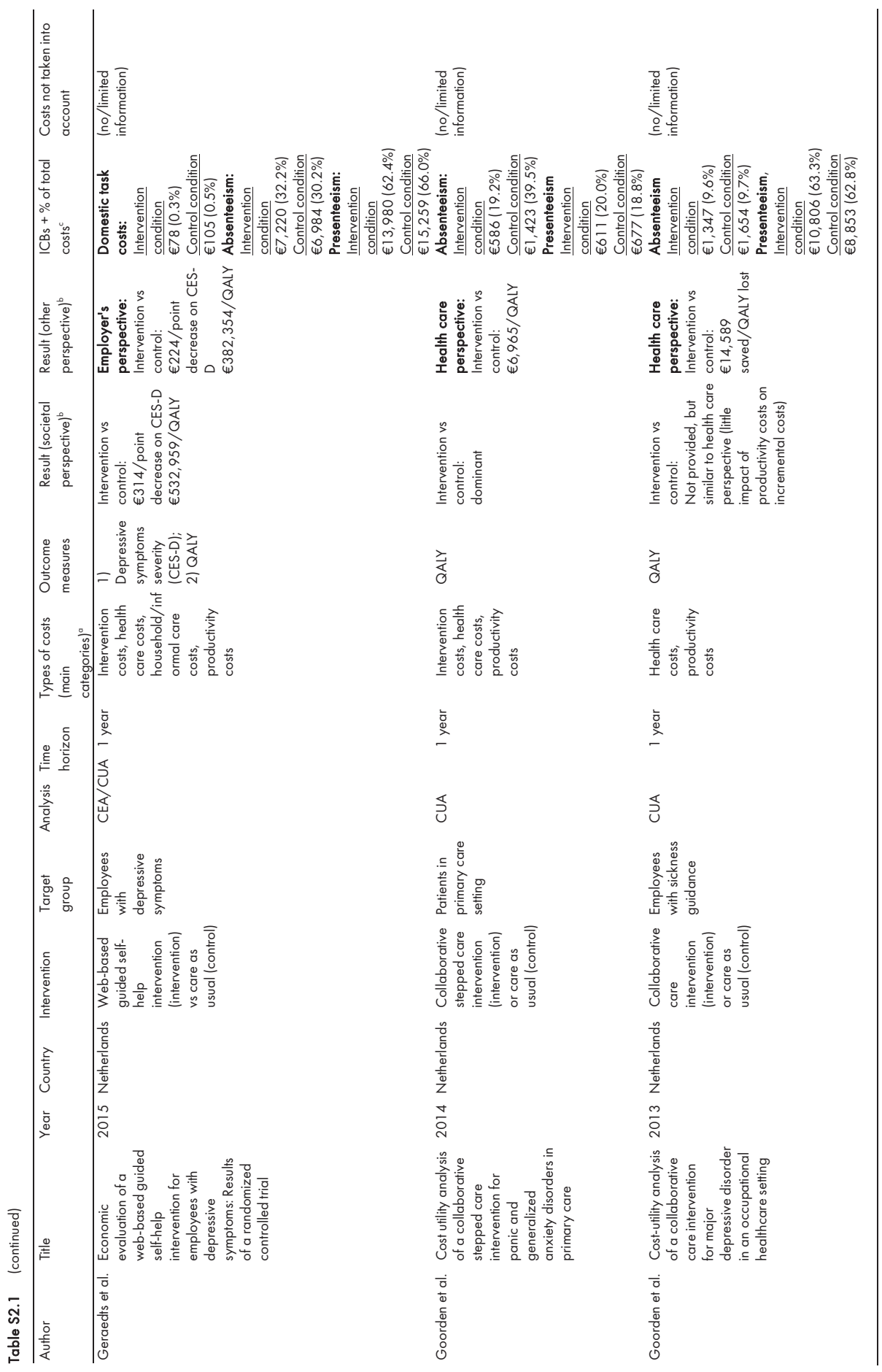




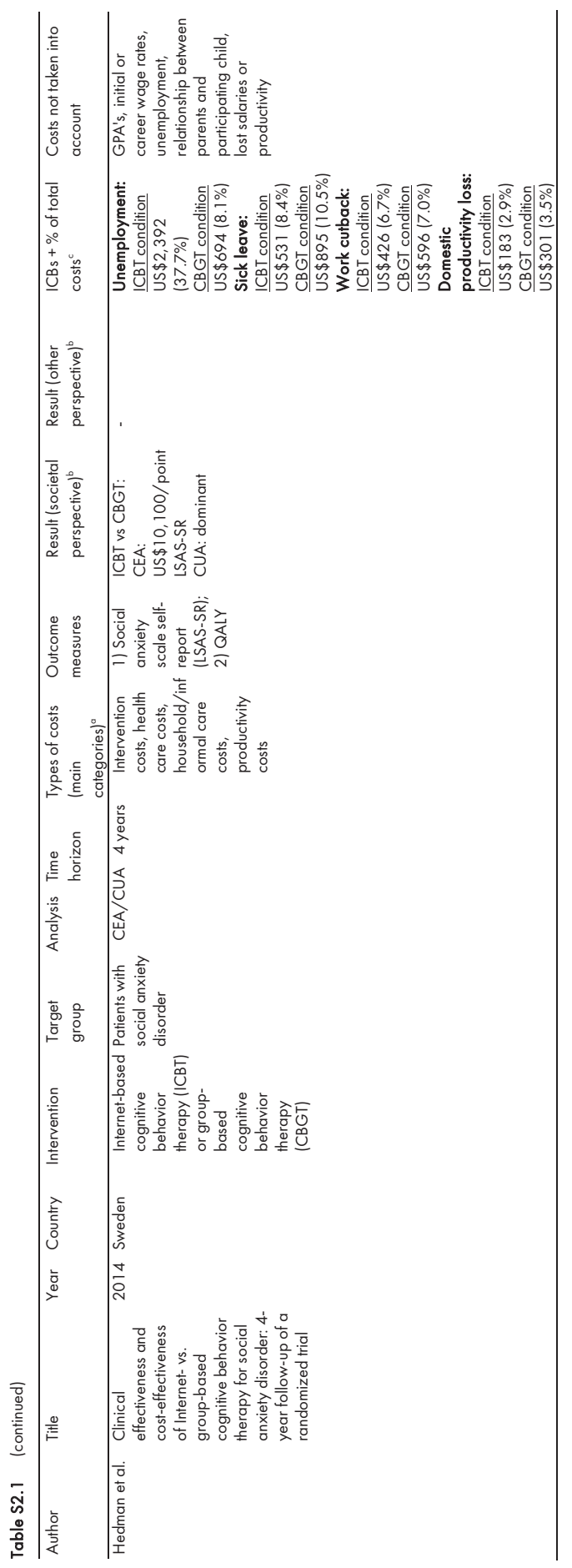




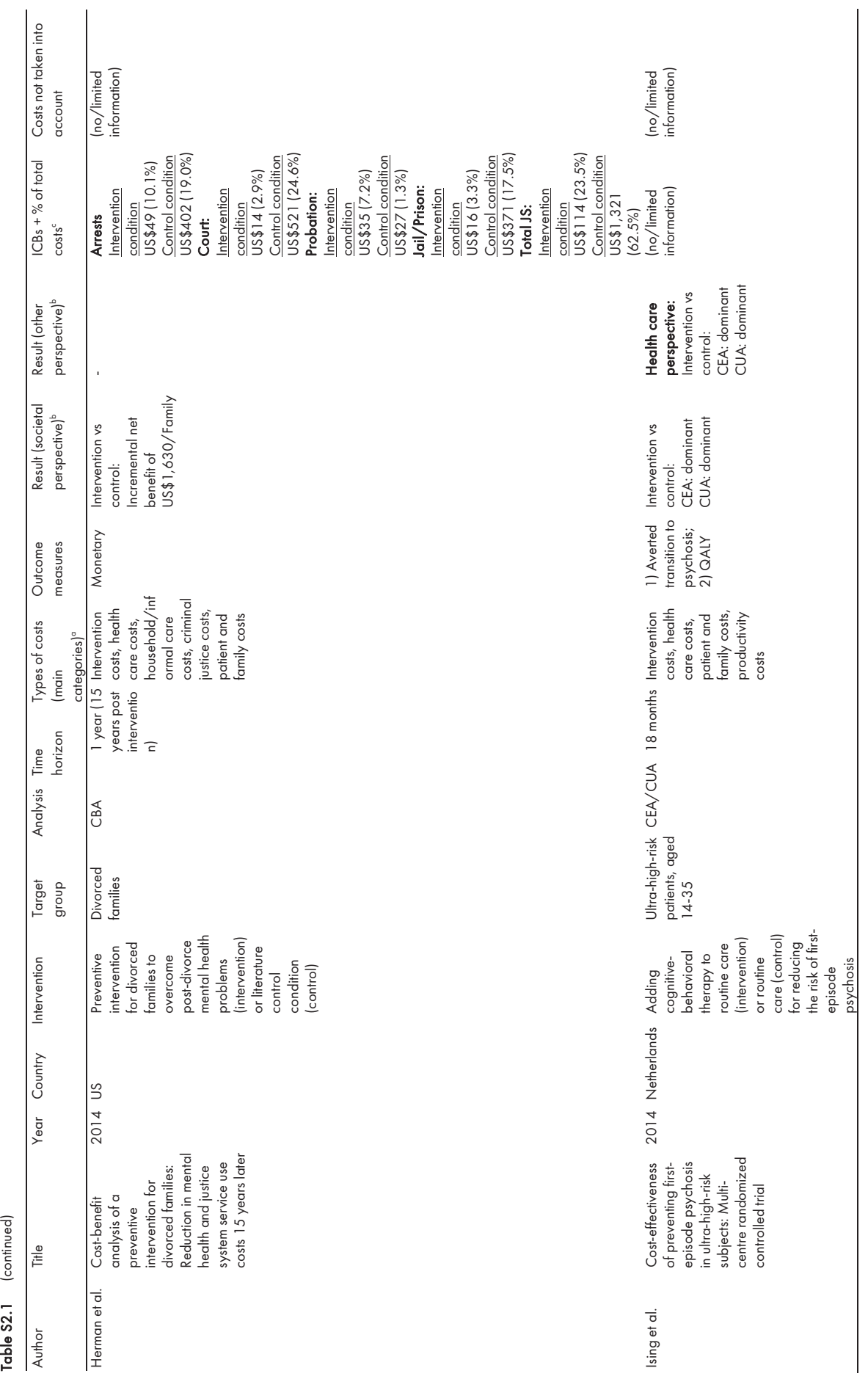



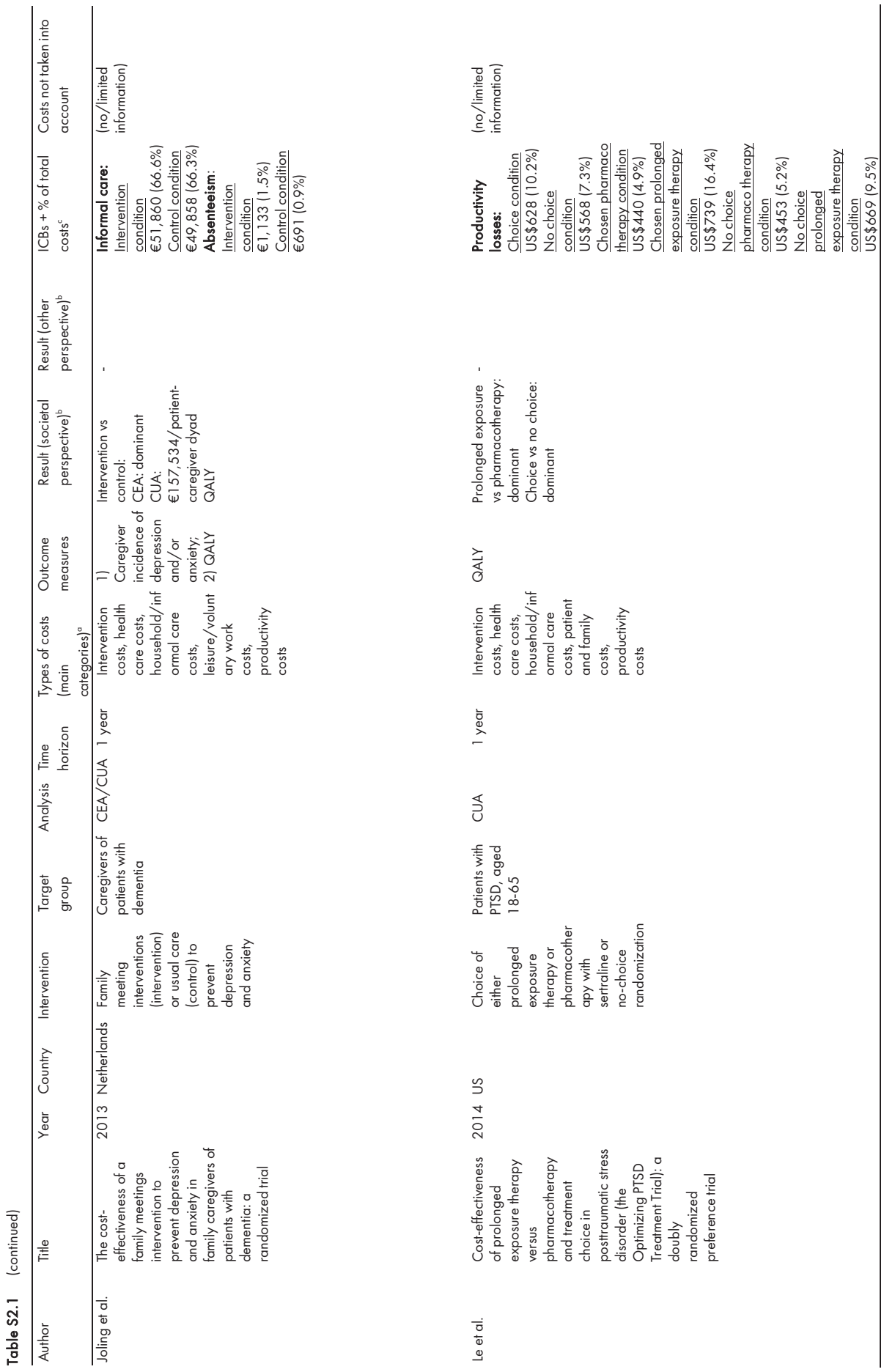

خे

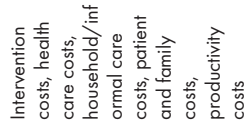

$\stackrel{\substack{\underline{d}\\}}{-}$

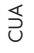

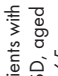

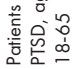

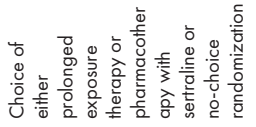

$\stackrel{4}{a}$
$\stackrel{2}{3}$

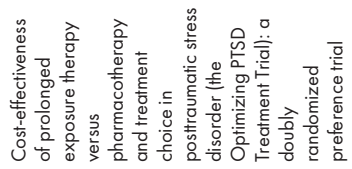

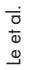




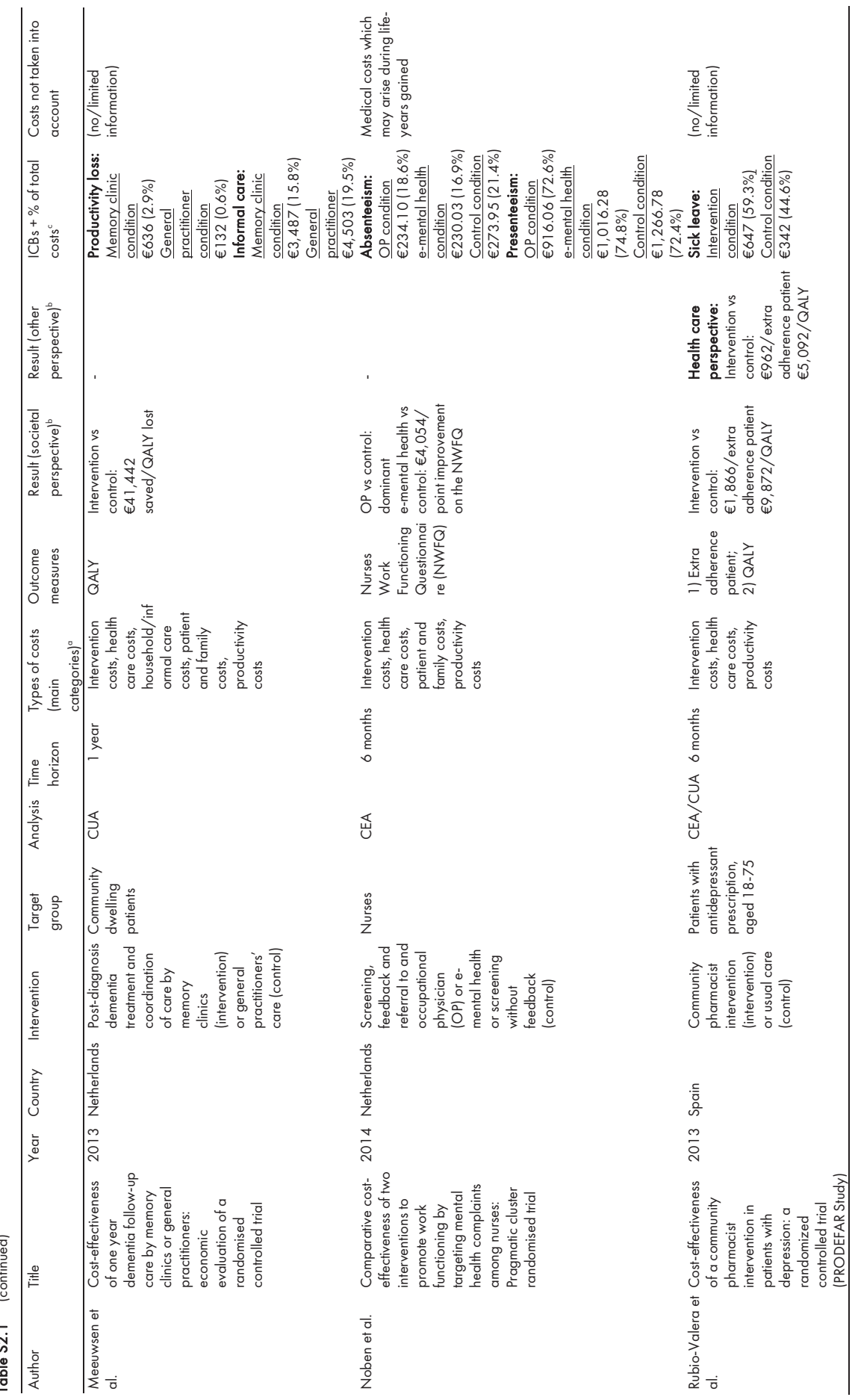




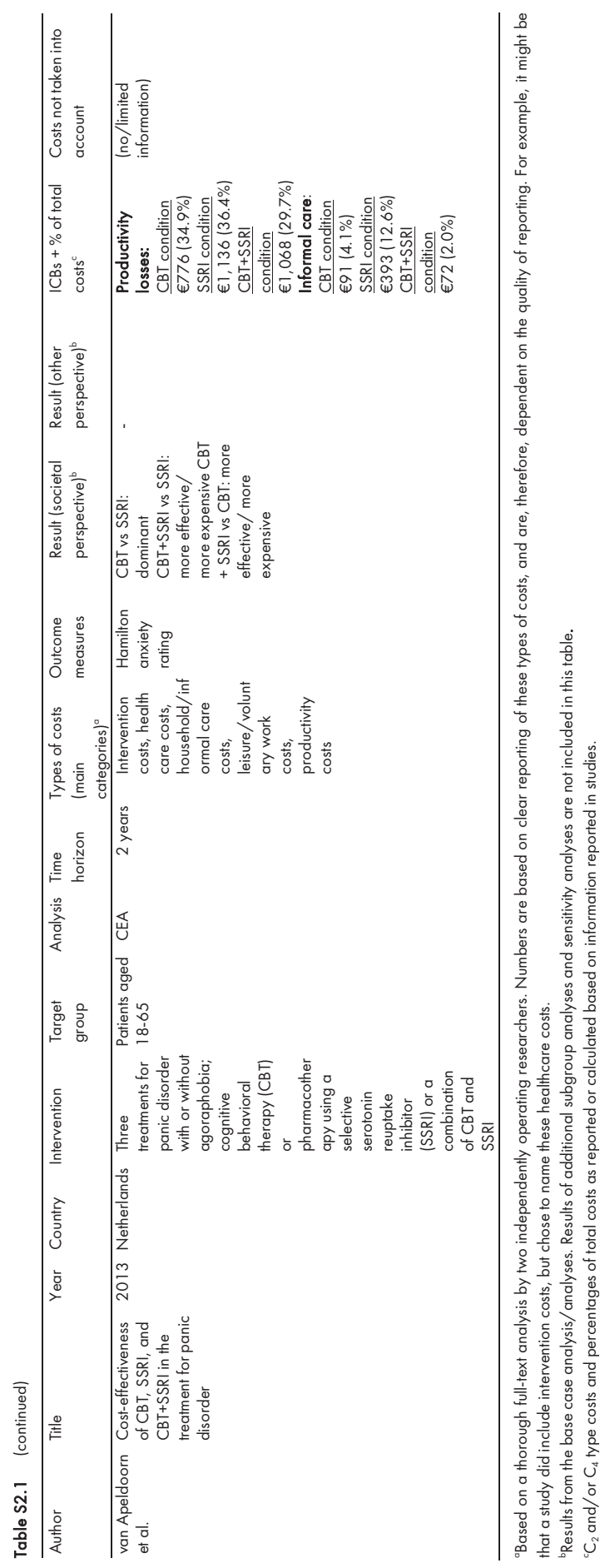




\section{Supplemental file 2.2}

Table S2.2.1 General conceptualizations and perceptions of the societal perspective

\begin{tabular}{|c|c|c|}
\hline Definition & $\mathrm{N}$ & Articles $^{a}$ \\
\hline \multicolumn{3}{|l|}{ Costs (and benefits) for specified groups } \\
\hline All costs and benefits irrespective to who & 2 & $52 ; 74$ \\
\hline All costs irrespective of the payer & 6 & $6 ; 11 ; 24 ; 32 ; 79 ; 85$ \\
\hline All costs to all individual in society & 2 & $32 ; 102$ \\
\hline All relevant costs and effect to society & 2 & $26 ; 28$ \\
\hline Costs shouldered by both provider and household & 1 & 100 \\
\hline \multicolumn{3}{|l|}{ Any costs incurred by the patients } \\
\hline & 2 & $56 ; 72$ \\
\hline \multicolumn{3}{|l|}{ Origin of costs described } \\
\hline Direct and indirect costs & 20 & $\begin{array}{l}21 ; 30 ; 34 ; 37 ; 38 ; 39 ; 42 ; 51 ; 54 ; 59 ; 61 ; 69 ; 80 ; 83 \\
; 84 ; 87 ; 89 ; 92 ; 93 ; 107\end{array}$ \\
\hline Payer, participant, and opportunity costs & 1 & 17 \\
\hline Health care and non-health care resources & 1 & 45 \\
\hline \multicolumn{3}{|l|}{ Other } \\
\hline The overall societal benefits of the program whether & 1 & 67 \\
\hline intended or not & 1 & 27 \\
\hline All relevant costs associated with the burden of the & 2 & $5 ; 94$ \\
\hline disease & 4 & $3 ; 19 ; 20 ; 99$ \\
\hline \multicolumn{3}{|l|}{ Costs associated with health care utilization } \\
\hline All costs from whatever source & & \\
\hline
\end{tabular}

${ }^{a}$ References can be found in Supplementary Table S2.2.3

Table S2.2.2 Specific conceptualizations and perceptions of the societal perspective

\begin{tabular}{lll}
\hline Type of costs & $\mathrm{N}$ & Articles $^{\mathrm{a}}$ \\
\hline CO Intervention costs & 9 & $1 ; 26 ; 48 ; 82 ; 88 ; 93 ; 98 ; 102 ; 103$ \\
\hline - Treatment costs & 1 & 47 \\
\hline C1 Health care costs & 9 & $26 ; 34 ; 50 ; 55 ; 77 ; 82 ; 83 ; 88 ; 93$ \\
\hline - Community health & 2 & $9 ; 93$ \\
- Day activity & 1 & 93 \\
- Drug & 2 & $42 ; 101$ \\
- Health care utilization & 1 & 8 \\
- Health system & 5 & $2 ; 6 ; 58 ; 59 ; 101$ \\
- Home care services & 1 & 31 \\
- Hospital & 9 & $9 ; 12 ; 14 ; 42 ; 47 ; 50 ; 93 ; 103 ; 107$ \\
- Laboratory tests & 1 & 107 \\
- Medical & 8 & $19 ; 27 ; 34 ; 61 ; 75 ; 80 ; 102 ; 106$ \\
- Medicare reimbursement & 3 & $50 ; 63 ; 102$ \\
- Nursing home care & 1 & 31 \\
- Primary care & 2 & $12 ; 58$ \\
- Provider & 2 & $57 ; 107$ \\
- Social care & 3 & $9 ; 57 ; 101$ \\
\hline C2 Costs in other sectors & 0 & \\
\hline Education & & \\
\hline - School absenteeism & 1 & 75 \\
Criminal justice system & & 8 \\
- Automobile accident & 1 & $8 ; 9$ \\
- Criminal activity & 2 &
\end{tabular}




\begin{tabular}{|c|c|c|}
\hline - Criminal justice & 2 & $9 ; 77$ \\
\hline - Victim & 2 & $22 ; 77$ \\
\hline \multicolumn{3}{|l|}{ Household \& Leisure } \\
\hline - Informal care & 6 & $31 ; 38 ; 41 ; 44 ; 58 ; 93$ \\
\hline - Household cost & 1 & 48 \\
\hline - Care giver & 3 & $38 ; 89 ; 106$ \\
\hline - Housekeeping & 2 & $41 ; 58$ \\
\hline - Absenteeism normal activities & 1 & 60 \\
\hline - Unpaid work & 1 & 58 \\
\hline C3 Patient and family costs & 6 & $6 ; 26 ; 38 ; 55 ; 59 ; 98$ \\
\hline - Mortality & 2 & $47 ; 106$ \\
\hline - Out-of-pocket & 5 & $34 ; 58 ; 89 ; 99 ; 101 ;$ \\
\hline - Patient time & 2 & $93 ; 99 ; 102 ; 106$ \\
\hline - Respondent cost & 3 & $82 ; 88 ; 102$ \\
\hline - Travel expenses & 6 & $34 ; 75 ; 89 ; 99 ; 106 ; 107$ \\
\hline C4 Productivity costs & 25 & $\begin{array}{l}1 ; 2 ; 12 ; 19 ; 26 ; 27 ; 31 ; 38 ; 41 ; 42 ; 44 ; 47 ; 54 ; 55 ; 58 ; 69 ; 77 ; 87 ; 88 ; 9 \\
1 ; \\
93 ; 98 ; 106\end{array}$ \\
\hline - Absenteeism work & 8 & $1 ; 4 ; 47 ; 54 ; 60 ; 61 ; 75 ; 93$ \\
\hline - Disability payment & 1 & 61 \\
\hline - Lost income & 2 & $8 ; 61$ \\
\hline - Lost labour force & 1 & 12 \\
\hline - Work time lost & 6 & $9 ; 30 ; 34 ; 58 ; 89 ; 107$ \\
\hline Other costs & 0 & \\
\hline - Direct costs & 7 & $30 ; 34 ; 42 ; 54 ; 59 ; 61 ; 69$ \\
\hline - Indirect costs & 10 & $30 ; 34 ; 42 ; 47 ; 54 ; 59 ; 61 ; 69 ; 80 ; 101$ \\
\hline - Intangible costs & 1 & 42 \\
\hline - Non medical costs & 3 & $80 ; 87 ; 93$ \\
\hline - Non health (care) costs & 3 & $34 ; 83 ; 89$ \\
\hline Outcomes & 3 & $14 ; 42 ; 82$ \\
\hline
\end{tabular}

${ }^{a}$ References can be found in Supplementary Table S2.2.3 


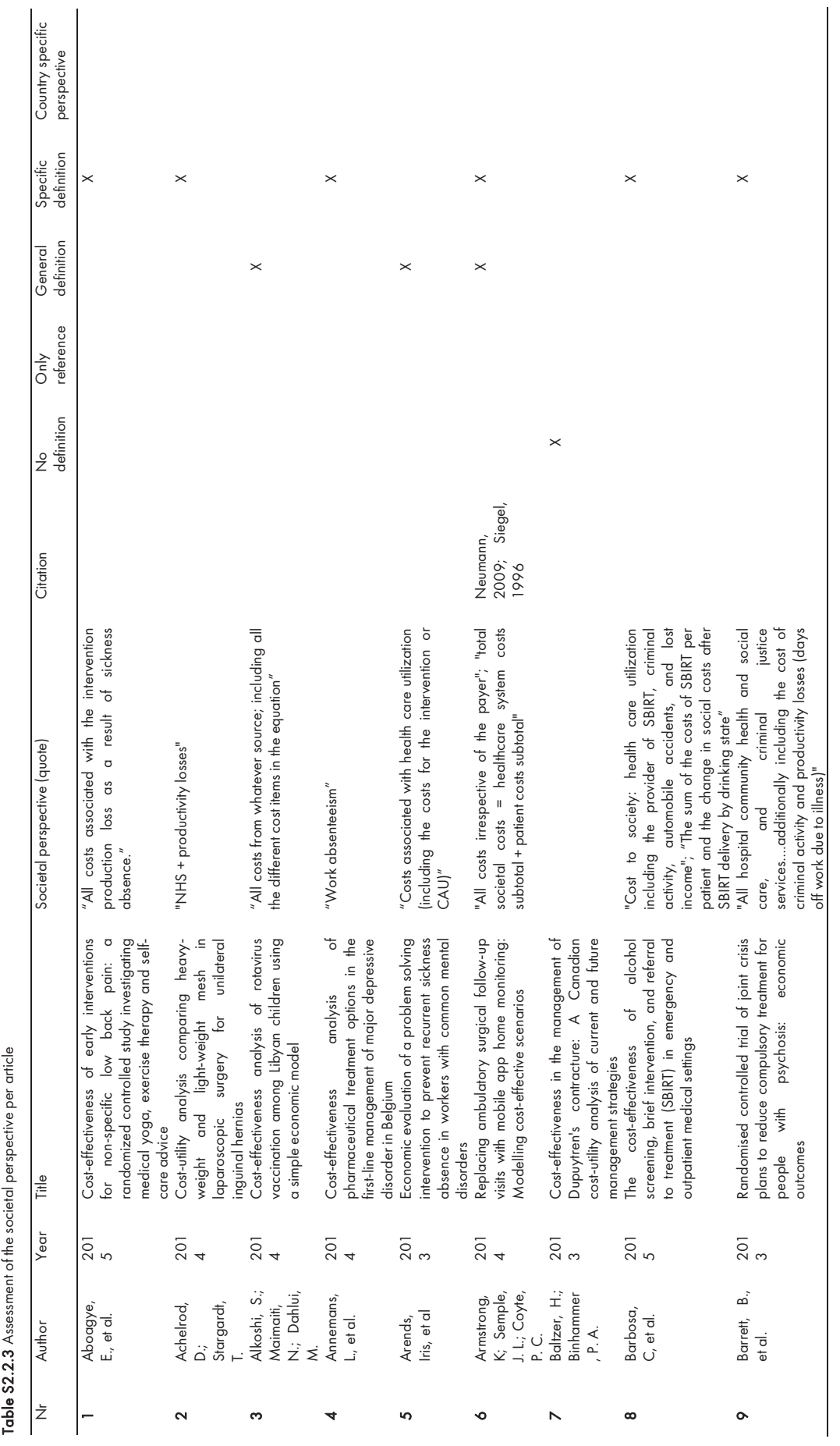




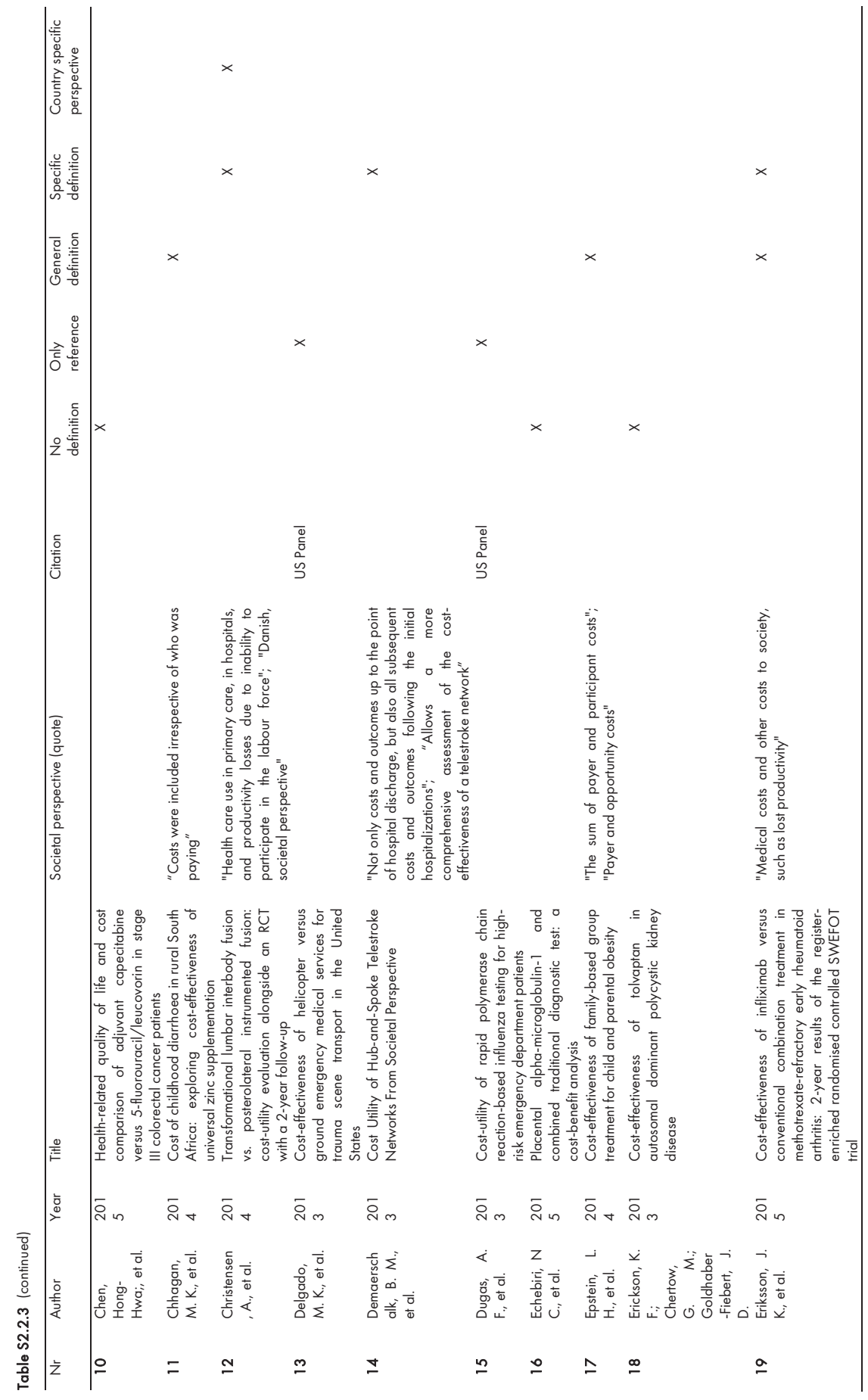




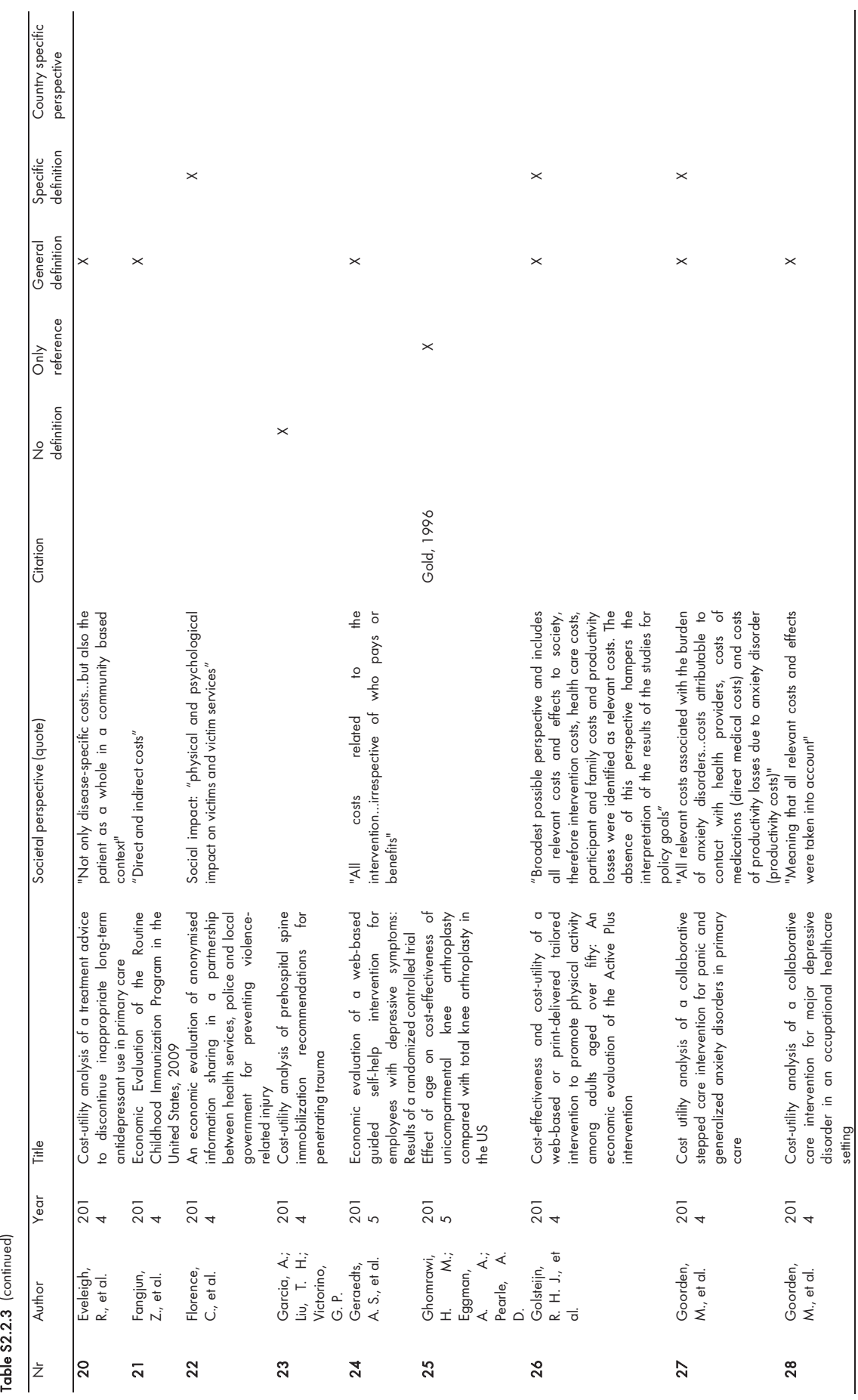




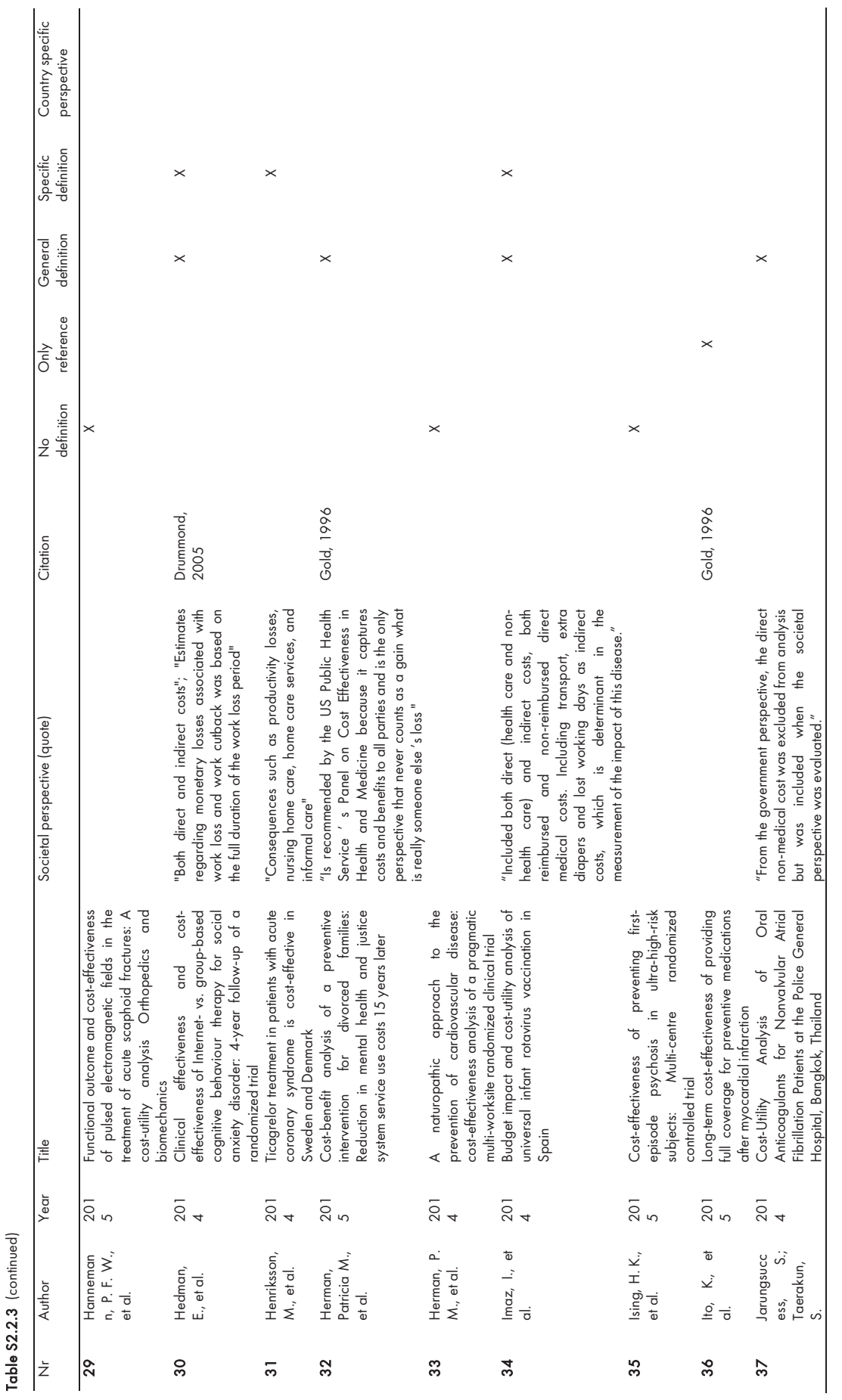




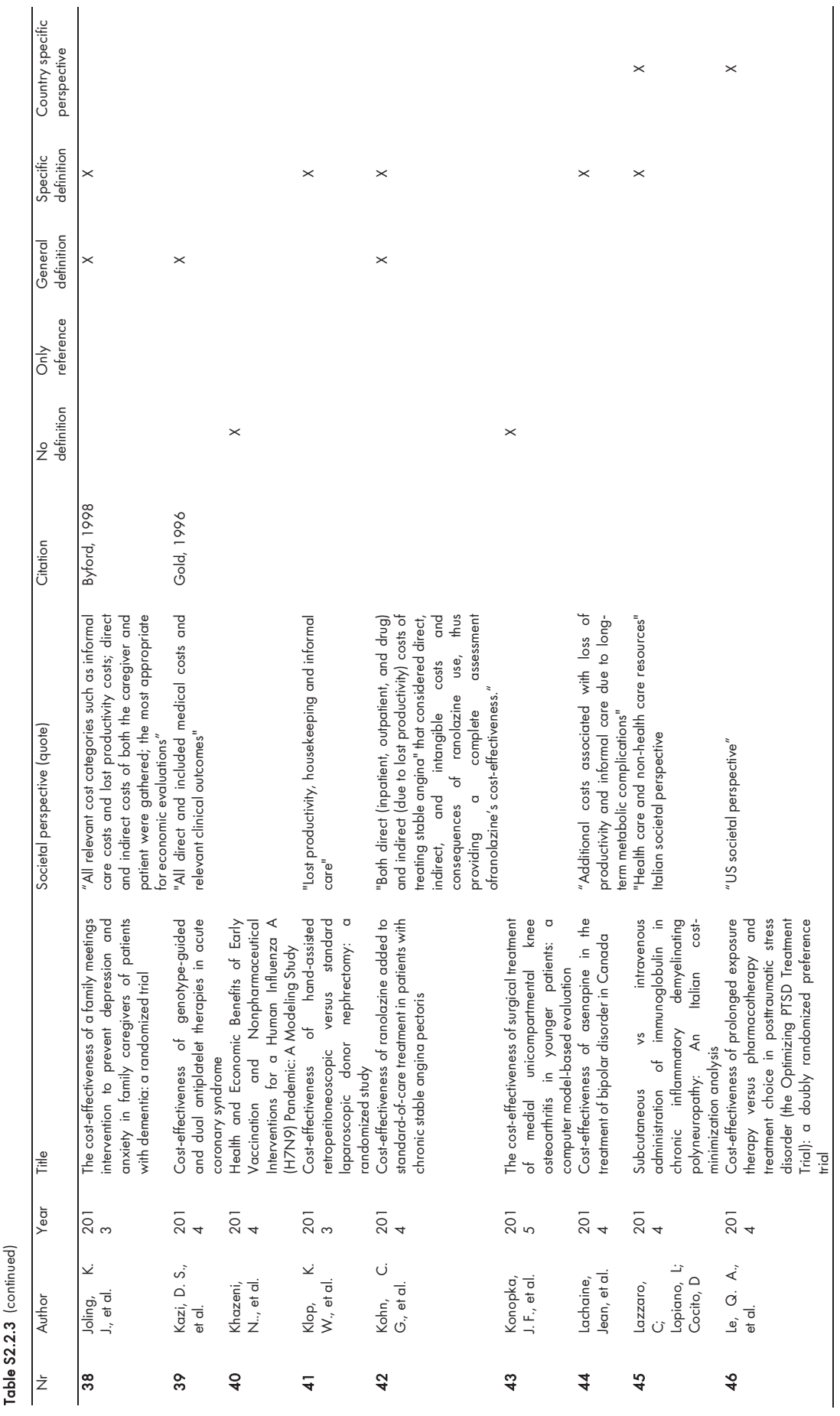




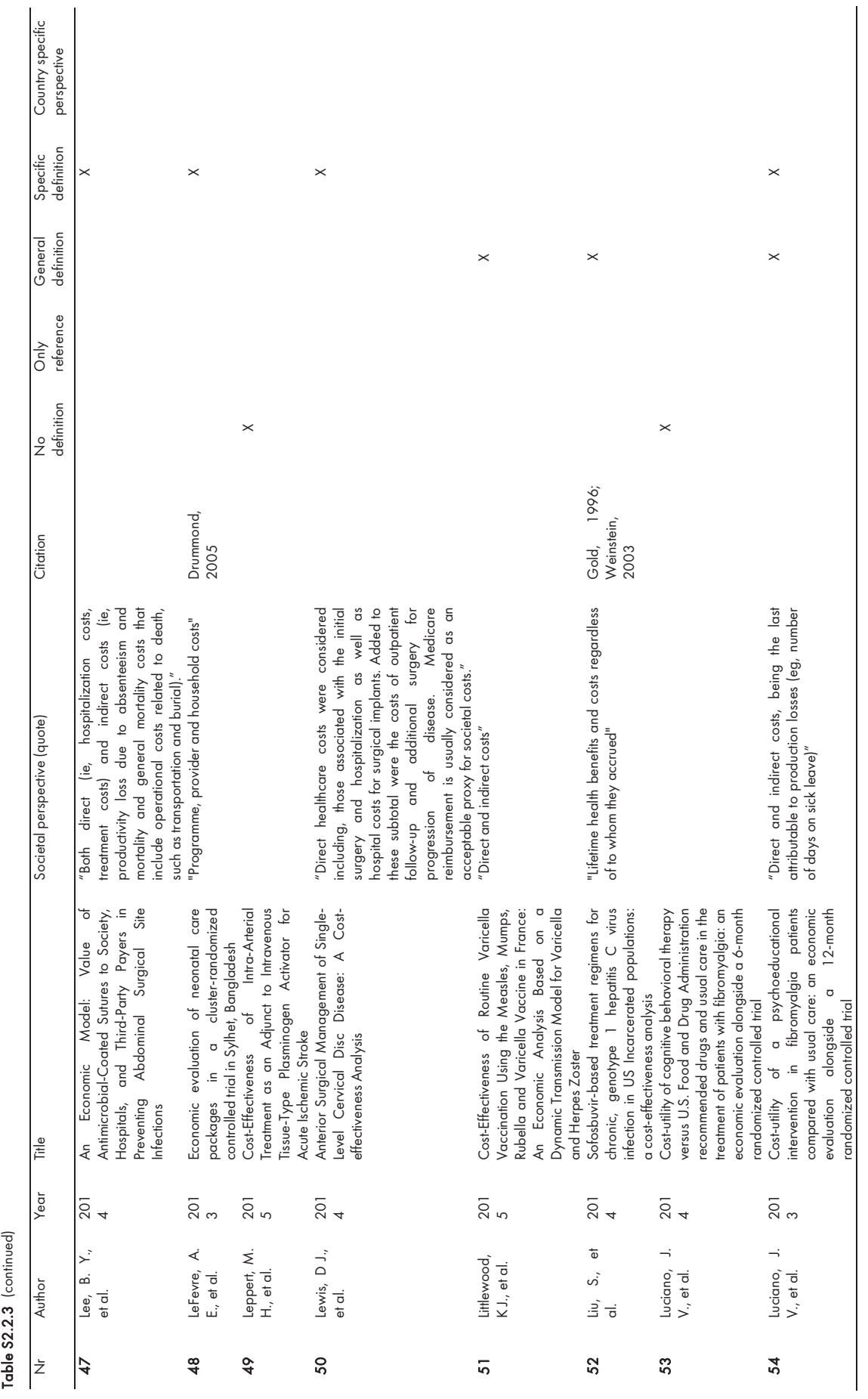




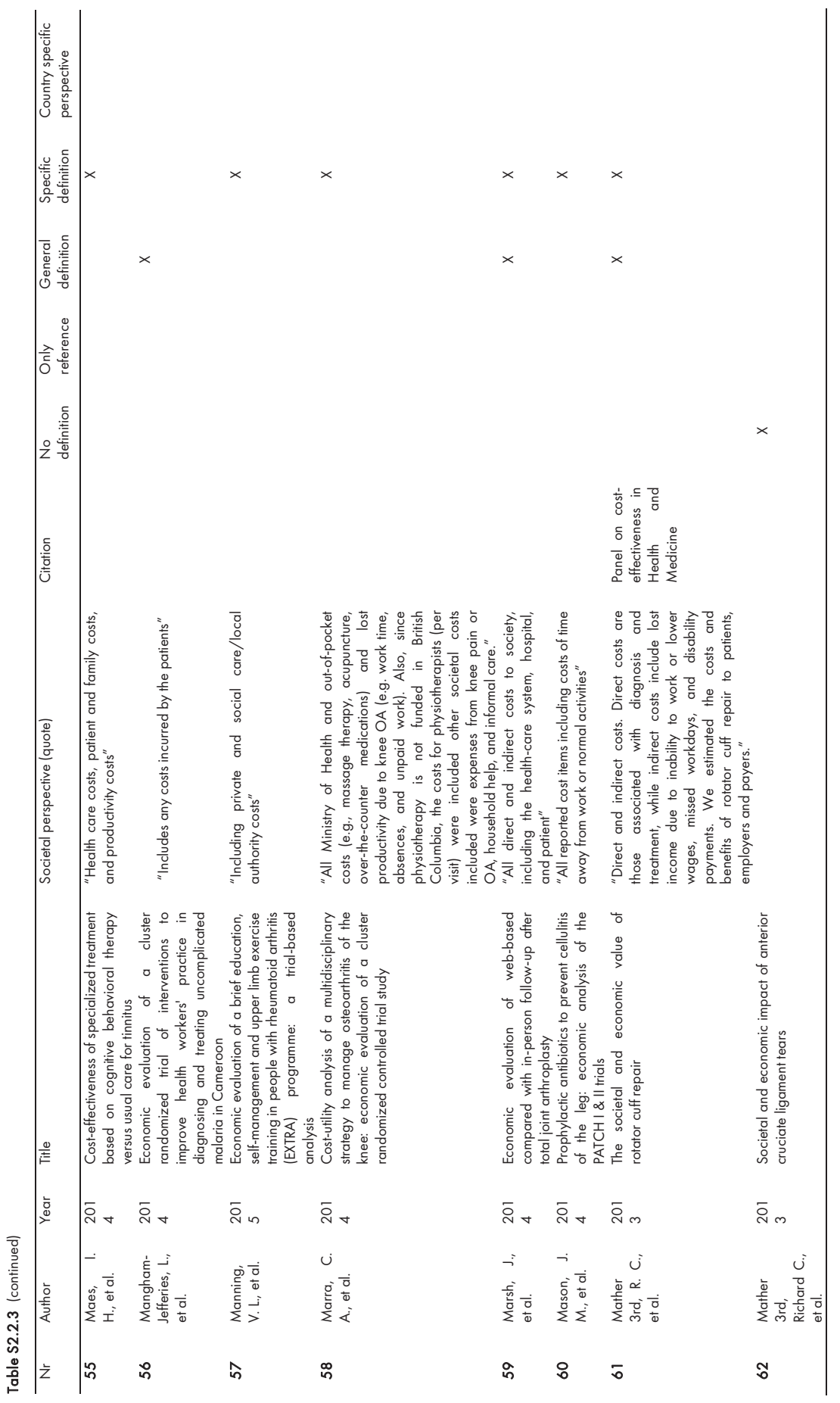




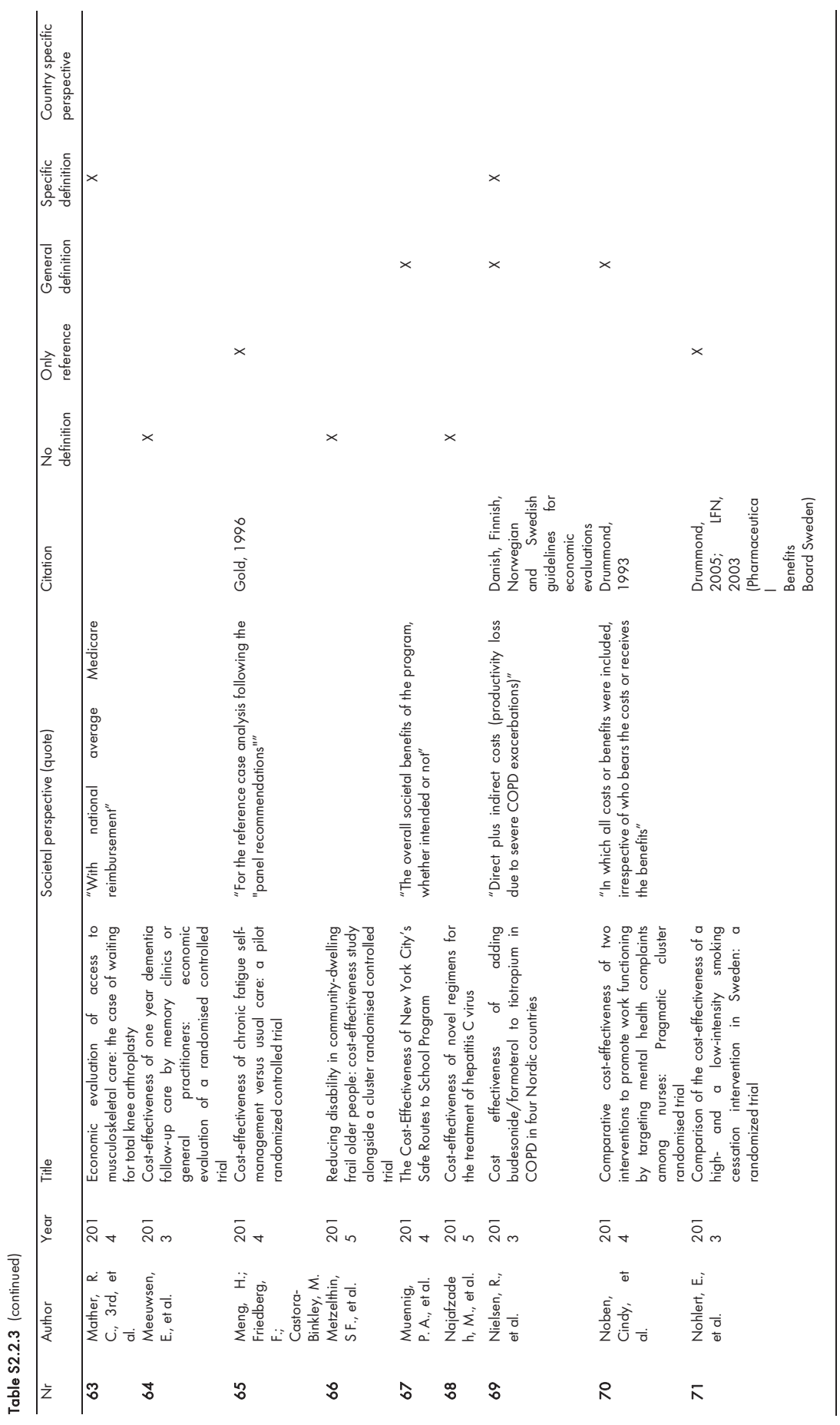




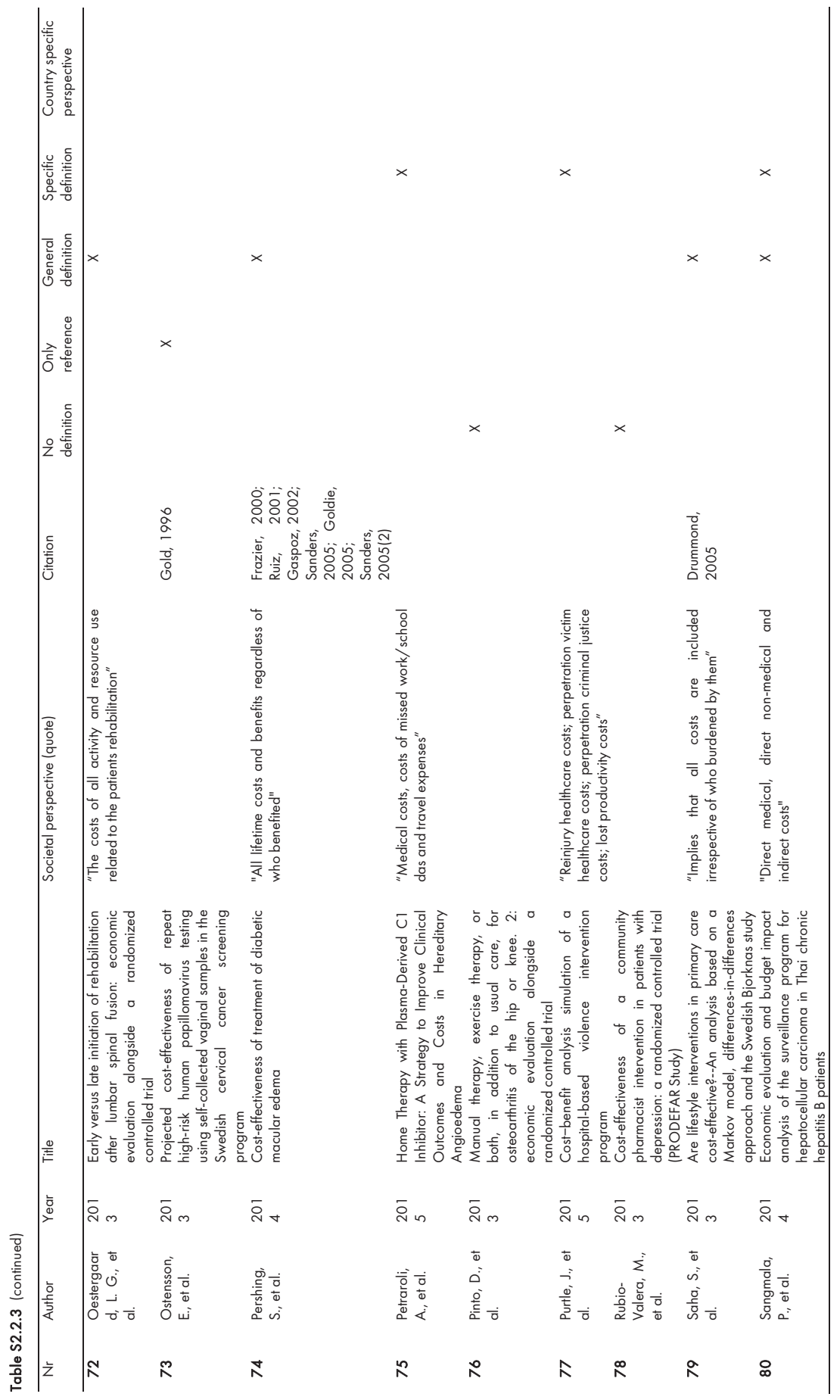




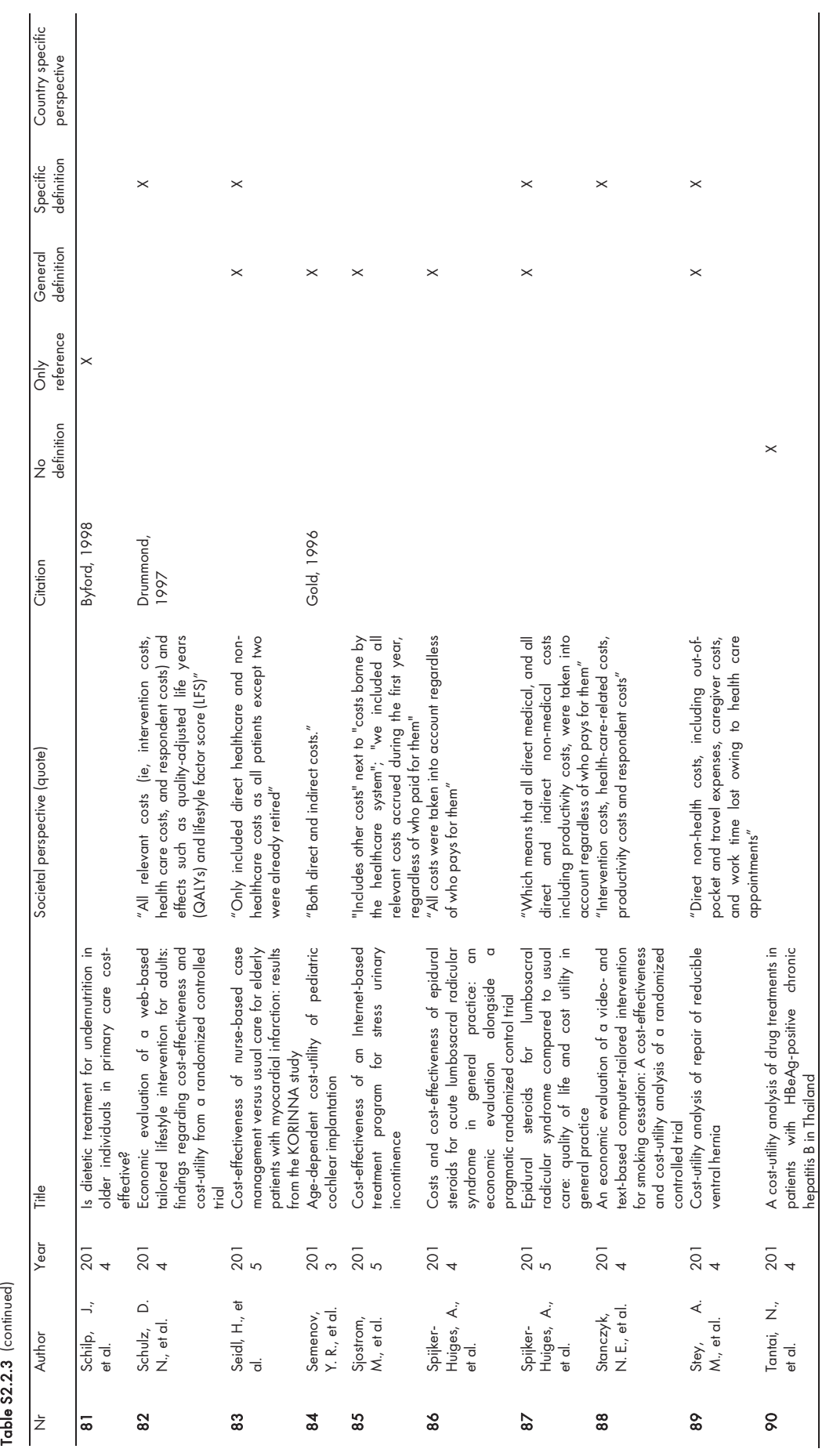




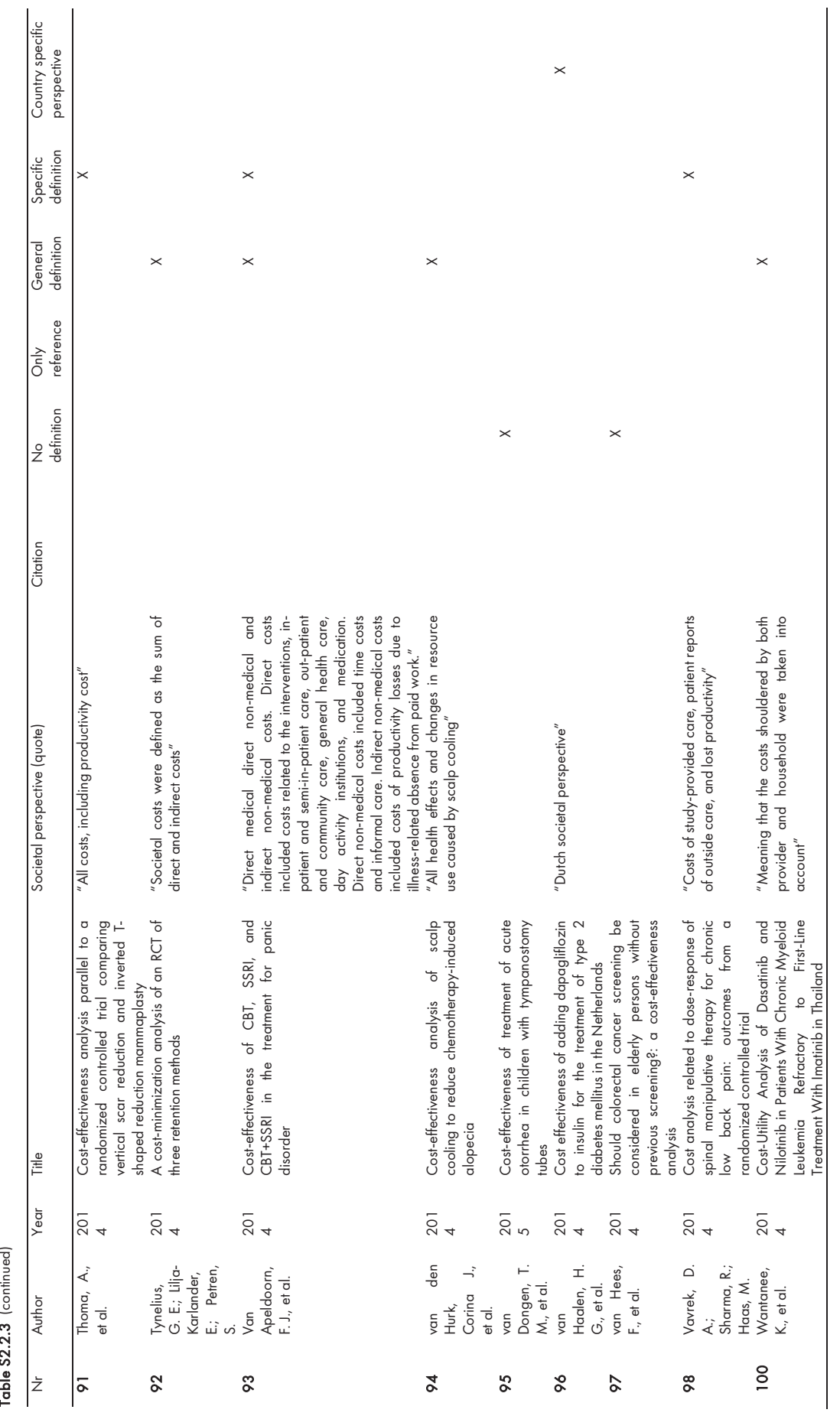




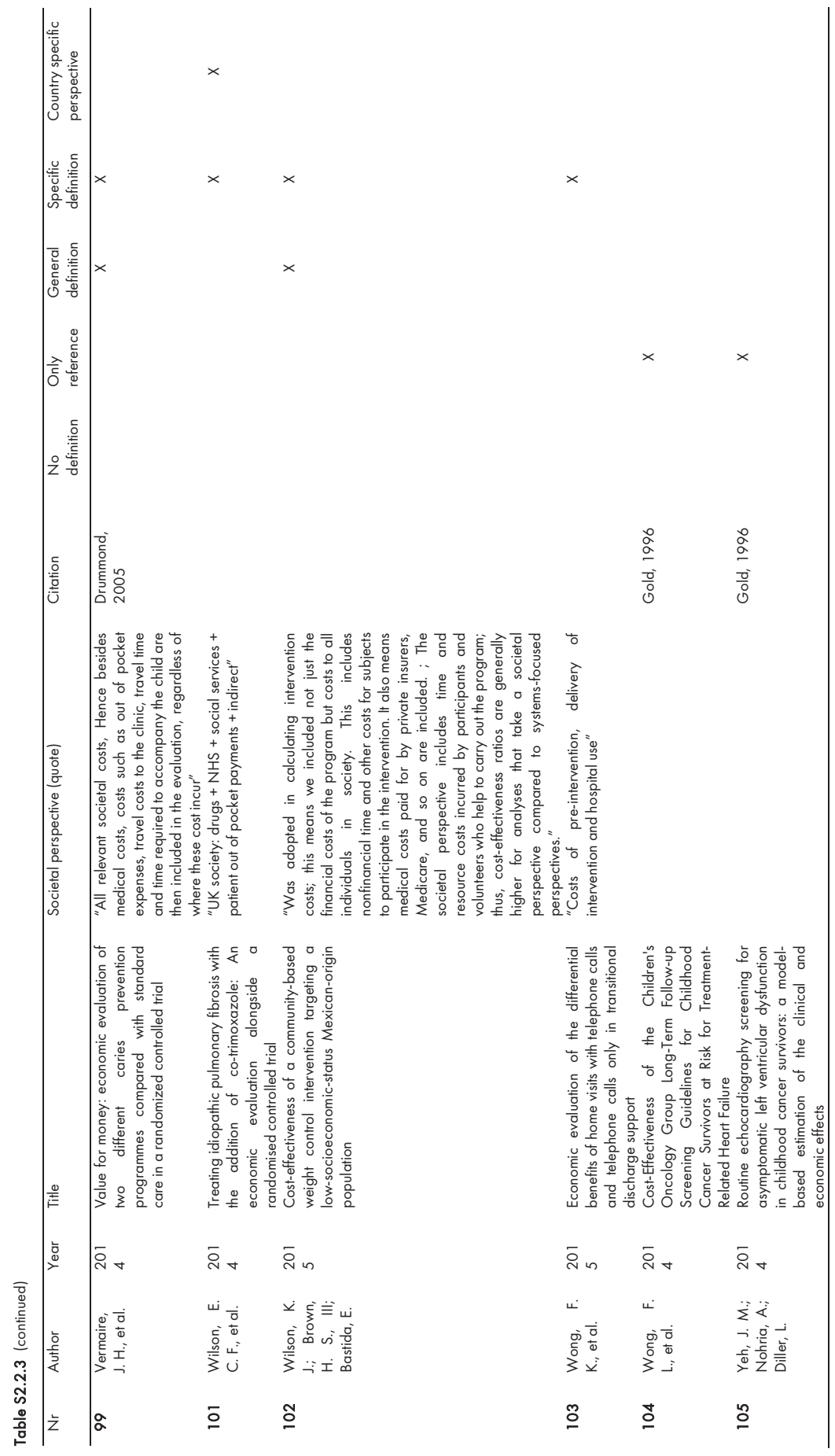




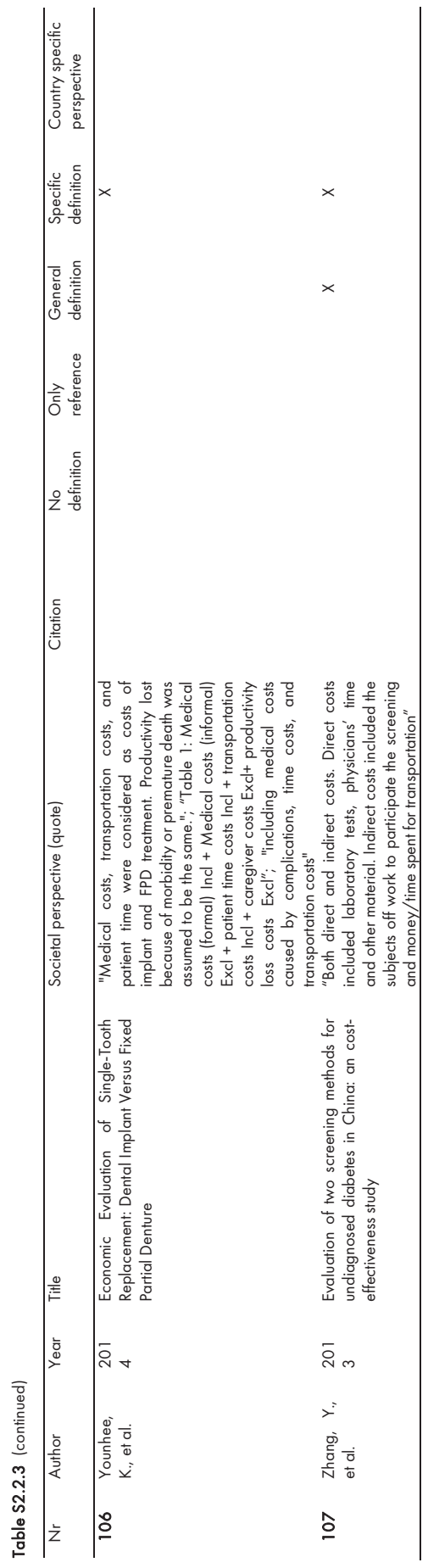




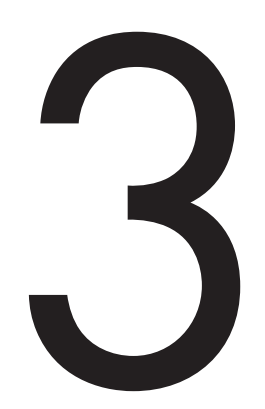

\section{Intersectoral costs and benefits of mental health prevention: towards a new classification scheme}

This chapter was published as:

Drost RMWA, Paulus ATG, Ruwaard D, Evers SMAA Intersectoral costs and benefits of mental health prevention: towards a new classification scheme Journal of Mental Health Policy and Economics 2013;16:179-186. 


\title{
Abstract
}

\section{Background}

Many preventive interventions for mental disorders have costs and benefits that spill over to sectors outside the healthcare sector. Little is known about these "intersectoral costs and benefits" (ICBs) of prevention. However, to achieve an efficient allocation of scarce resources, insights on ICBs are indispensable.

\begin{abstract}
Aim of the study
The main aim was to identify the ICBs related to the prevention of mental disorders and provide a sector-specific classification scheme for these ICBs.

\section{Methods}

Using PubMed, a literature search was conducted for ICBs of mental disorders and related (psycho)social effects. A policy perspective was used to build the scheme's structure, which was adapted to the outcomes of the literature search. In order to validate the scheme's international applicability inside and outside the mental health domain, semi-structured interviews were conducted with (inter)national experts in the broad fields of health promotion and disease prevention.
\end{abstract}

\section{Results}

The searched-for items appeared in a total of 52 studies. The ICBs found were classified in one of four sectors: "Education", "Labor \& Social Security", "Household \& Leisure" or "Criminal Justice System". Psycho(social) effects were placed in a separate section under "Individual \& Family". Based on interviews, the scheme remained unadjusted, apart from adding a population-based dimension.

\section{Discussion}

This is the first study which offers a sector-specific classification of ICBs. Given the explorative nature of the study, no guidelines on sector-specific classification of ICBs were available. Nevertheless, the classification scheme was acknowledged by an international audience and could therefore provide added value to researchers and policymakers in the field of mental health economics and prevention.

\section{Implications for health policies}

The identification and classification of ICBs offers decision makers supporting information on how to optimally allocate scarce resources with respect to preventive interventions for mental disorders.

\section{Implications for further research}

By exploring a new area of research, which has remained largely unexplored until now, the current study has an added value as it may form the basis for the development of a tool which can be used to calculate the ICBs of specific mental health related preventive interventions. 


\section{Introduction}

Many mental disorders are known for their wide impact on the capabilities and social behavior of those diagnosed, as well as on that of significant others, such as family members.' Interventions to prevent these mental disorders are expected to generate costs and benefits that spill over to sectors outside the healthcare sector. ${ }^{2}$ These so-called 'intersectoral costs and benefits' (ICBs) of prevention can be defined as "The indirect spillover costs and benefits for all non-healthcare sectors of society, attributable to the implementation of a health-related prevention program". Examples of such non-healthcare sectors include the educational sector and the criminal justice system.

Currently, little is known about the ICBs of mental health prevention. This is related, among other things, to methodological challenges and the fact that most of the existing tools can be used to determine costs and benefits only within the narrow context of the healthcare sector. ${ }^{2-5}$ Consequently, many health economic evaluations tend to be incomplete and are at risk of leading to invalid estimations of the true societal impact of mental health prevention. Therefore, even studies that adopt a societal perspective (i.e. those which include costs and benefits outside the healthcare sector) in fact often have a focus limited to the labor sector. Although costs and benefits related to productivity losses can be considerable, ${ }^{6}$ studies show that other sectors may account for a considerable part of total societal mental health-related costs and benefits as well. ${ }^{7-9}$

Accordingly, it is worth investigating which ICBs of mental health prevention can be identified in sectors other than the labor sector. This requires an intersectoral approach, ${ }^{10}$ using a sector-specific classification of ICBs. Unfortunately, current overviews lack such a specific classification. For example, although taxonomies described in the commonplace evaluation texts of Gold et al. (1996) and Drummond et al. (2005) do focus on productivity at work as an important category outside the healthcare sector, they don't provide readers with a detailed representation of ICBs possibly engendered as a consequence of a (preventive) intervention. ${ }^{11,12}$ Although the taxonomy of Drummond et al. (2005), as opposed to the one described by Gold et al. (1996), does mention "other sectors" as a separate category for costs and savings $\left(C_{2} / S_{2}\right)$ next to the health sector $\left(C_{1} / S_{1}\right)$, patient and family $\left(C_{3} / S_{3}\right)$ and productivity $\left(C_{4} / S_{4}\right)$, neither taxonomy provides information on which of the "other sectors" can be affected by a change in one's health status, nor do they provide a detailed overview of ICBs within these other sectors. Other taxonomies, such as those described by Luce \& Elixhauser (1990) and French et al. (1991) do provide some items which have the characteristics of ICBs of prevention. ${ }^{13,14}$ However, mention of these items is fairly limited in comparison with their more extended focus on items falling under the health care sector. Furthermore, like the taxonomies of Gold et al. (1996) and Drummond et al. (2005), these taxonomies don't provide a sectorspecific classification for ICBs. Since many mental disorders can broadly impact costs outside the healthcare sector, these taxonomies are therefore particularly less suited for use in the context of mental disorders. 
Against this background, the main objective of this study is to identify the ICBs of prevention within the mental health context and provide a sector-specific classification scheme for these ICBs. An additional objective is to assess this scheme's applicability outside the mental health domain.

\section{Methods}

\section{Data collection}

Data were collected in the summer of 2012. To identify ICBs of mental health prevention, an exploratory literature search was conducted using PubMed. As a preliminary search with the search term "intersectoral" yielded very few results, more commonly acknowledged terms with close to similar meaning were selected and embedded in key word combinations. The following terms were used in separate combinations: "prevention" and "intersectoral" or "indirect" or "spillover" or "external" or "societal" and "costs" or "benefits" or "effects" or "consequences" or "burden". In order to assess if the use of the selected synonyms would yield enough relevant studies - and given the explorative nature of this research - the search with these synonyms was initially not restricted to mental health-related studies. Selection criteria included restriction to publications in the English language and only those journal articles published between January 2000 and June 2012. Studies were not restricted to a specific study design; articles describing various types of research could be included.

Since studies were not scored for methodological properties and screened only for use of the searched items, the literature search could be performed by one researcher, i.e. RD. To compensate for the consequential heightened risk of excluding valuable studies on the basis of abstracts, double hits were removed after reading abstracts, rather than before. As it was assumed that studies flagged by multiple key word combinations were more likely to contain relevant information, a double reading of their abstracts has likely lowered the risk of excluding relevant studies.

\section{Article inclusion and exclusion}

The search with synonyms of "intersectoral" yielded a large batch of unique studies (379). It was therefore decided not to extend the search further with additional databases or to use extra keywords, but to prioritize extraction of mental health-related studies from the batch.

The extraction of mental health-related studies was performed through implementing a Boolean search filter in PubMed, by selecting MeSH terms frequently used to index studies concerning mental disorders and related behavioral problems. The following terms were included in the filter: "mental health", "depressive disorder", "conduct disorder", "alcohol abuse", "substance abuse" and "child abuse". Furthermore, an additional hand search 
was performed within the batch for relevant studies which were not labeled and indexed as such.

\section{Data analytic procedures}

The inextricable connection between the societal impact of disease and that of its prevention allowed for a search not only for ICBs of the prevention of mental disorders, but also for ICBs of mental disorders themselves. This was expected to be a fruifful method for efficiently identifying the ICBs of prevention. The use of this so-called 'social cost method' has been proven to identify many non-health care costs and benefits, in particular for studies performed from a societal perspective. ${ }^{13,15}$

Many of the ICBs found in the literature were expected to have an indirect rather than direct relationship with mental disorders, as these are direct consequences of disorderrelated change in behavior and social interaction. Therefore, subsequent to including or excluding studies based on the analysis of titles and abstracts, full articles were scanned for three types of items: 1) psychosocial effects of prevention and disease, 2) changes in social interaction and behavior and 3) ICBs of mental disorder-related morbidity and diseaserelated pre-mature mortality, such as suicide. All of these items could belong to either the primary individual, i.e. the target of a preventive intervention, or to affected significant others. For inclusion, costs and benefits had to meet the criteria stipulated by the definition of ICBs. All items had to be directly or indirectly attributable to a mental disorder. Studies mentioning at least one of the searched items were included.

Before classification, items found in the literature were listed and those with a similar meaning clustered under one denominator.

\section{Classification of data}

Providing a sector-specific classification scheme required a two-stage process. First, preliminary to the literature search, a classification scheme was created which is supportive of decision making on whether or not specific preventive interventions should be introduced. The starting point for classification was an aggregate of different sector classifications used by several Dutch public institutions; these included Statistics Netherlands (CBS), the Netherlands Bureau for Economic Policy Analysis (CPB), the Netherlands Institute for Social Research (SCP) and the Dutch National Government. Second, subsequent to the literature search, items were classified in the scheme. Sectors used by these institutions for which no ICBs were found, such as the environment and media, were excluded from the scheme. Furthermore, when results of the identification stage did not allow for a more detailed classification into separate sectors, closely related ICBs needed to be placed under one generic denominator. ICB-related (psycho)social items were placed in a separate section of the scheme.

In addition to the sector-specific classification, items were further classified under subcategories; these were based on the context in which ICBs are expressed. In addition, wherever possible, a division was made between items belonging to primary individuals 
and those belonging to affected significant others, such as family members or colleagues at work.

\section{Expert interviews}

In order to validate the classification scheme for use inside and outside the mental health domain, semi-structured expert-interviews were conducted in the fall of 2012. Those eligible for an interview fulfilled the criterion of being experts in the broad fields of disease prevention and/or health promotion. Following this criterion, six experts were selected to be interviewed. During the first interviews, it was already noted that there was a high level of saturation. Interviewees expressed comparable comments and feedback and suggested comparable minor if any changes to the classification scheme. Each expert was also asked whether he/she knew additional experts in their fields (snowballing). Based on the level of saturation that had already been achieved and the suggestions made by the experts, only one additional interview was held. The names of the experts are noted in the acknowledgements section of this article.

Guided by pre-determined, open-ended questions, experts were asked to give feedback on the results of the identification and classification of ICBs. Apart from validation purposes for the mental health domain, interviews also contained separate questions concerning the applicability of the scheme for non-mental health-related prevention. The interviews, which were conducted either in person or via telephone, were recorded.

The analysis of the qualitative responses was conducted in several steps. First, recordings of the interviews were used to extract important remarks, suggestions and comments made by the interviewees. The interview questions were used to structure these responses. Expert answers to the questions were then listed in bullet points, which were compared and discussed during author meetings. For feedback to be adopted and processed into the classification scheme, it had to add specificity to the scheme without diminishing its generic applicability across domains of prevention. Finally, all four authors needed to agree on whether and how to use the feedback to change the scheme's structure or contents.

\section{Conferences and workshops}

In addition to interviews, to assure the validity of the results obtained through our literature study, the classification scheme was also presented and discussed at different workshops and conferences, including a meeting organized by the Netherlands Organisation for Health Research and Development (ZonMw) in Utrecht (the Netherlands) with external researchers in the field of prevention, the 'Eleventh Workshop on Costs and Assessment in Psychiatry' in Venice (Italy), organized by the International Center of Mental Health Policy And Economics (ICMPE), and a meeting in Nunspeet (The Netherlands), organized by the Lowlands Health Economics Study Group 'LolaHESG'. 


\section{Results}

\section{Identification of ICBs}

As Figure 3.1 shows, the literature search yielded a total of 2558 titles, of which 1991 were excluded based on reading the titles and abstracts. Of the 567 studies left, 188 were removed based on double reading. This led to a batch of 379 unique studies, of which 69 passed the mental health search filter and another three passed during the additional hand search within the batch. Based on reading the 69 abstracts which passed the filter, eight studies were excluded because they did not focus on mental disorders or related changes in social behavior. Of the 64 studies left, all were fully reviewed, and 52 were included based on clear use of at least one of the searched-for items. ${ }^{15-66}$

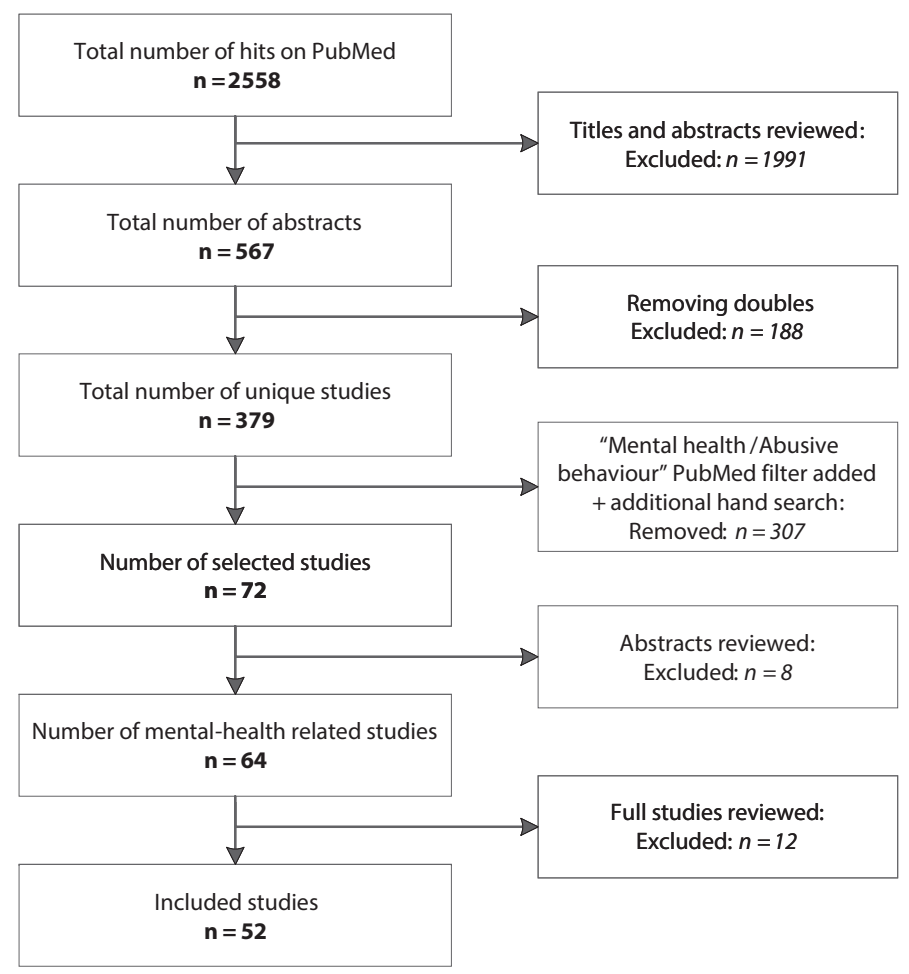

Figure 3.1 Flow chart describing the selection of studies on the ICBs of mental health prevention

The studies included provided a wide variety of items, varying from one to over twenty per study. These included over 70 different items which could be indexed as an ICB of mental health prevention. Items were often found to be scattered throughout the article, 
varying in the level of detail and mentioned either in context of the aim of the study or in a different context, such as a single mention in the discussion section of the article. Many of the items were extracted from non-prevention-related studies, such as cost of illness studies. An example of an ICB found to be related to mental health prevention is 'grade retention', referring to the relation between a child's mental health state and his/her chances of proceeding to the next grade. A second example is 'police interventions', which may be more or less needed when an intervention aimed at preventing one's mental disorder leads to a change in violent or other unwanted behavior. For a complete overview of all ICBs, see Figure 3.2.

\section{Classification scheme characteristics}

As Figure 3.2 shows, four sectors were distinguished in which ICBs were classified, namely "Education" (E), "Labor \& Social Security" (L\&S), "Household \& Leisure" (H\&L) and "Criminal Justice System" (CJS). In the 52 studies included in our research, "productivity (losses)" was mentioned most often. Furthermore, 43 of the 52 studies mentioned items eligible to be placed under L\&S, 15,16,18-23,25,27-32,34-37,39-41,44, 45,47-51,53-66 21 studies mentioned items to be placed under $E_{1}^{20-24,27,28,31-34,40,43,46,50,53,57,59-62} 11$ studies mentioned items to be placed under $\mathrm{H} \& \mathrm{~L}^{19,22,23,28,34,35,37,38,47,48,54}$ and 31 studies mentioned items to be placed under CJS. ${ }^{15,17,19,21,23,25-27,29,30,32,33,35,39,41,43,45,47,49}$ $58,61,63,66$ In order to classify further for the context of expression of ICBs, subheadings were added under each sector, such as "Pre-school" (E-p), "School" (E-s), "Un/underemployed" (L\&S-u) and "Employed" (L\&S-e).

In order to show the relationship between ICBs and (psycho)social effects of change in health, "Individual \& Family" (I\&F) was added to the scheme as a denominator for ICBrelated (psycho)social effects of disease or prevention. In total, 33 of the 52 studies mentioned items eligible to be placed under I\&F. ${ }^{15,19-27,31-33,36-38,40,42-47,55-61,63,65,66}$ As these effects could not be classified as intersectoral according to the classification scheme, this category was therefore placed in a separate section. Additionally, as in particular the items mentioned under I\&F, such as "anger" or "pain", might already be captured in one of the many psychiatric-specific outcome measures used in studies or even in many of the generic health-related quality of life instruments used to derive quality-adjusted life years (QALYs), separating (psycho)social effects from ICBs functions as a visual reminder to readers that health-related impacts should be taken into account. Arrows were added to the scheme to underline the relation between health-related (psycho)social effects and ICBs. Psychosocial effects (I\&F-p) were separated from social interaction effects between the individual and either a member of the family, classified under "Family (I\&F-f)", or a person outside the family, classified under "Social (I\&F-s)". 


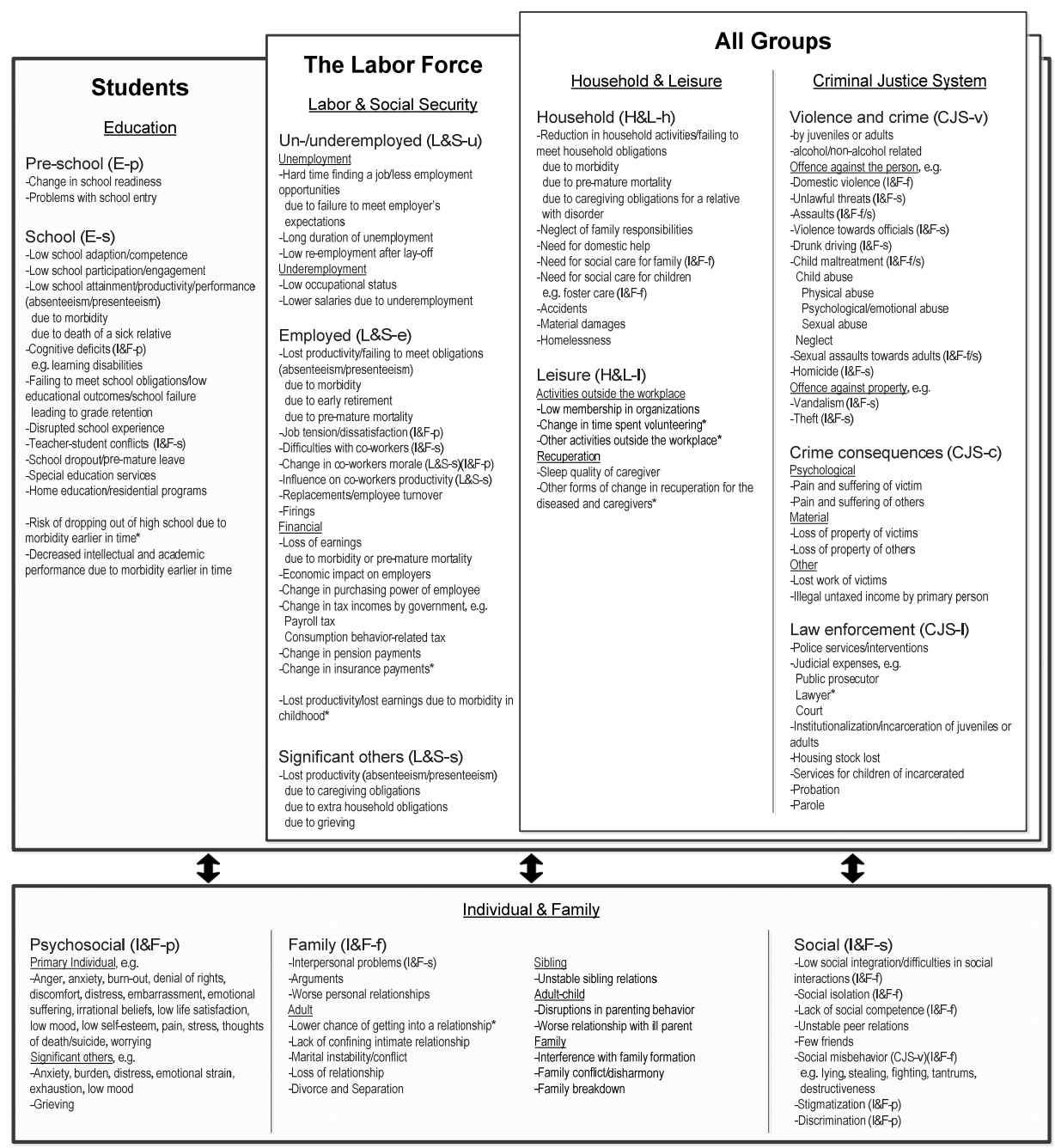

Notes

1. *Added after expert interviews.

Figure 3.2 The intersectoral classification scheme of ICBs of mental health prevention

\section{Expert interviews, conferences and workshops}

Expert interviews yielded a few additional items which were added to the classification scheme (Figure 3.2). Furthermore, multiple experts suggested adding a specification based on subgroups of the population which might encounter specific ICBs. Sectors were therefore classified under three headings, namely "Students", referring to anyone obliged to follow some form of schooling or who has chosen to follow higher education; "the Labor 
Force", referring to all those currently working or in search of a job, and "All Groups", referring to anyone in the general population. Also based on the expert interviews, additional cross-links were placed behind items which were classified under a subheading, but which could also be classified somewhere else in the scheme. An example is "child maltreatment", which was classified under "Violence and crime (CJS-v)", since many forms of child maltreatment are punishable by law. However, this item could also be classified under "Family (I\&F-f)" or "Social (I\&F-s)", for it is a type of social interaction between a child and either a family member or someone from outside the family.

Concerning the number of sectors used for sector-specific classification, multiple experts commented on the use of the term "Labor \& Social Security" as a general denominator for the whole labor sector. They mentioned that specific interventions may lead to specific ICBs in particular branches of the labor sector and that the scheme was not informative on these particular branches. An example mentioned was the interventions aimed at the prevention of spreading bird flu, which, rather than preventing mental disorders, would be more likely to affect the tourism and transportation sector. However, experts acknowledged that the outcomes of the literature search did not allow for more detailed classification into smaller sectors. Furthermore, mentioning detailed diseasespecific ICBs rather than generic ICBs would have hindered the scheme's applicability within and across multiple domains of diseases and disorders. The broad demarcations of sectors led to a generic classification of $\mathrm{ICBs}$; this was clear to both national and international experts operating inside and outside the mental health domain.

Based on the comments received during the congresses and workshops, no further adjustments needed to be made to the classification scheme.

\section{Conclusion}

As stated in the introduction, little is known about the ICBs of prevention. The main objective of this study was therefore to identify the ICBs of prevention within the mental health context and add value for future use in economic evaluation by creating a sectorspecific classification scheme for these ICBs. This resulted in the first detailed sector-specific classification of mental health-related costs and benefits outside the healthcare sector.

Three distinct features provide the usability of the new scheme with an advantage over the old taxonomies. First, as a policy perspective was used to classify ICBs, the classification scheme presented in this study provides stakeholders involved in decision making processes on the implementation of interventions not only with a wide overview of $\mathrm{ICBs}$, but also with insight into which ICBs belong to which sectors. Second, apart from a classification on a macro-economic scale, the scheme provides insight into which ICBs belong to primary individuals and which belong to affected significant others. Third, the inclusion of population subgroups provides the reader with guidance on which ICBs should be taken into consideration. The scheme may therefore function as a source of inspiration to those seeking relevant ICBs to include in an evaluation and as a generic frame of 
reference for those who after careful consideration decided to exclude specific ICBs from their evaluation.

Compared to the taxonomies presented in Luce \& Elixhauser (1990) and French et al. (1991), the new classification scheme has a greater level of detail. ${ }^{13,14}$ On the assumption that most if not all important items missed by the literature search would have come up during the expert interviews, congresses or other meetings, it can be concluded that the scheme is saturated enough to function as a reliable foundation for a checklist which stakeholders can use to assess whether all relevant ICBs of a specific (preventive) intervention are included in its evaluation. Because of the generic use and representation of $I C B s$, this goes even beyond the mental health domain.

The scheme's applicability in costing research requires, among other factors, more information on the nature of the intervention ${ }^{11}$ and the level of economic entity, such as "individual", "household" or "government". ${ }^{67}$ Nevertheless, this categorization is informative for both researchers and decision-makers, as it shows that preventive interventions for mental disorders can prevent disorder-related ICBs in a wider societal context. The identification and classification of ICBs hereby offers decision supporting information on how to optimally allocate scarce resources with respect to interventions for mental disorders.

Even though the focus of this study was on the ICBs related to preventive interventions, the classification scheme presented in Figure 3.2 could also be useful for an assessment of the ICBs of treatment interventions. As the ICBs of prevention are derived from ICBs of mental disorders, the items listed and classified in the scheme represent possible intersectoral impacts of a change in one's health status, not so much of the kind of treatment that is responsible for the change.

The classification scheme which is depicted in Figure 3.2 could, in our opinion, be a good starting point when looking at the identification of relevant costs and benefits which are expressed in monetary terms in economic evaluations. Since identification of the main cost-driving elements is considered an important basis from which a cost-benefit analysis can be conducted, ${ }^{68}$ providing those in search of ICBs with an overview of important items to be taken into consideration can be of great help in conducting a proper economic evaluation. However, as mentioned before by other authors, such as Johannesson (1997), researchers should be aware of double counting when performing an economic evaluation. $^{69}$ This means that a relevant impact is reflected in either only the cost side or only the outcome side of an economic evaluation. Some of the impacts listed in Figure 3.2, especially those listed under I\&F, can be expressed both in costs and in outcomes, for instance in mental health instruments or in quality of life measures. Researchers should be aware of this bias.

Although the framework of the classification scheme was based initially on sector classifications used by Dutch public institutions, the scheme presented in this study is general enough to be used in other countries. The broad classes used in the classification scheme, which were recognized by both national and international experts, allow for its international use for all types of mental health (preventive) interventions and for 
(preventive) interventions outside the mental health domain. As smaller policy domains can be country-specific, such as those for particular branches of the labor sector, further research into a more detailed classification of ICBs would have been more informative on a national level, but would have lowered its international applicability.

By exploring a new research area, which so far has remained largely unexplored, the current study has an added value as it may form the basis for the development of a tool which can be used to calculate the intersectoral costs and benefits of specific mental health-related (preventive) interventions. In order for such a tool to be widely accepted and used, it should first be acknowledged that ICBs are important and could make up a large part of the total costs and benefits related to (preventive) interventions for mental disorders.

ICBs are, among other factors, disease-specific. For example, arachnophobia will affect sectors outside the healthcare sector differently than borderline personality disorder. The set of ICBs affected by one disorder will therefore - to a greater or lesser extent - differ from that of another. Future research in order to distinguish the relative importance of disease-specific ICBs could therefore be of added value to costing research.

A discussion on whether to adopt a sector-specific classification of ICBs as best practice could lead to a shift in the information provided by researchers who perform economic evaluations from a societal perspective. Since this type of classification might be more informative for stakeholders involved in decision-making processes on the implementation of (preventive) interventions for mental disorders, the authors recommend that research councils and taskforces involved in establishing good practices in health outcomes research should consider adopting the proposed sector-specific classification of costs and benefits as a part of good research practices.

\section{Acknowledgements}

This research was supported by Grant 200400010 from the Dutch Organisation for Health Research and Development (ZonMw), The Hague. The authors would like to thank Daniel Chisholm (World Health Organization, Geneva, Switzerland), Raymond Hutubessy (World Health Organization, Geneva, Switzerland), Johan Polder (National Institute for Public Health and the Environment, Bilthoven, the Netherlands), Alan Shiell (the Centre of Excellence in Intervention and Prevention Science, Carlton, Australia), Filip Smit (Trimbos Institute, Utrecht, The Netherlands), Richard Smith (London School of Hygiene \& Tropical Medicine, London, UK) and Nanne de Vries (Maastricht University, Maastricht, The Netherlands) for their valuable feedback concerning the results of the identification and classification of ICBs. The authors would also like to thank the discussant and others present at the 'Eleventh Workshop on Costs and Assessment in Psychiatry' in Venice, March 2013, for the pleasant discussion after the presentation of the findings of this study. 


\section{References}

1. WHO. Mental health and work: Impact, issues and good practices. Geneva: World Health Organization, 2000.

2. O'Connell ME, Boat T, Warner KE. Preventing Mental, Emotional, and Behavioral Disorders Among Young People: Progress and Possibilities. Washington (DC): National Academies Press (US), 2009.

3. Aos S, Lieb R, Mayfield J, Miller M, Pennucci A. Benefits and costs of prevention and early intervention programs for youth. Olympia, WA: Washington State Intstitute for Public Policy, 2004.

4. Karoly LA, Kilburn MR, Bigelow JH, Caulkins JP, Cannon JS, Chiesa JR. Assessing Costs and Benefits of Early Childhood Intervention Programs: Overview and Application to the Starting Early Starting Smart Program. Santa Monica: RAND, 2001.

5. Lorgelly PK, Lawson KD, Fenwick EA, Briggs AH. Outcome measurement in economic evaluations of public health interventions: a role for the capability approach? Int J Environ Res Public Health 2010;7:2274-89.

6. Krol M, Papenburg J, Koopmanschap M, Brouwer W. Do Productivity Costs Matter?: the impact of including productivity costs on the incremental costs of interventions targeted at depressive disorders. Pharmacoeconomics 2011;29:601-19.

7. Barrett $B$, Byford S, Chitsabesan P, Kenning C. Mental health provision for young offenders: service use and cost. Br J Psychiatry 2006; 188:541-6.

8. Costello EJ, Copeland W, Cowell A, Keeler G. Service costs of caring for adolescents with mental illness in a rural community, 1993-2000. Am J Psychiatry 2007; 164:36-42.

9. Zechmeister I, Kilian R, McDaid D. Is it worth investing in mental health promotion and prevention of mental illness? A systematic review of the evidence from economic evaluations. BMC public health 2008;8:20.

10. Weatherly H, Drummond M, Claxton K, Cookson R, Ferguson B, Godfrey C, Rice N, Sculpher M, Sowden A. Methods for assessing the cost-effectiveness of public health interventions: key challenges and recommendations. Health policy 2009;93:85-92.

11. Drummond M, O'Brien BJ, Stoddart G, Torrance GW, Methods for the Economic Evaluation of Health Care Programmes. 2005, New York: Oxford University Press.

12. Gold MR, Siegel JE, Russel LB, Weinstein MC, Cost-Effectiveness in Health and Medicine. 1996, New York: Oxford University Press.

13. French MT, Rachal JV, Hubbard RL. Conceptual framework for estimating the social cost of drug abuse. J Health Soc Policy 1991;2:1-22.

14. Luce BR and Elixhauser A. Estimating costs in the economic evaluation of medical technologies. Int J Technol Assess Health Care 1990;6:57-75.

15. Cartwright WS. Cost-benefit analysis of drug treatment services: review of the literature*. J Ment Health Policy Econ 2000;3:1 1-26.

16. Berto P, D'llario D, Ruffo P, Di Virgilio R, Rizzo F. Depression: cost-of-illness studies in the international literature, a review. J Ment Health Policy Econ 2000;3:3-10.

17. MacMillan HL. Preventive health care, 2000 update: prevention of child maltreatment. CMAJ 2000; 163:1451-8.

18. Vinokur AD, Schul Y, Vuori J, Price RH. Two years after a job loss: long-term impact of the JOBS program on reemployment and mental health. J Occup Health Psychol 2000;5:32-47.

19. Begley CE, Annegers JF, Swann AC, Lewis C, Coan S, Schnapp WB, Bryant-Comstock L. The lifetime cost of bipolar disorder in the US: an estimate for new cases in 1998. Pharmacoeconomics 2001; 19:483-95.

20. Parikh SV and Lam RW. Clinical guidelines for the treatment of depressive disorders, I. Definitions, prevalence, and health burden. Can J Psychiatry 2001;46 Suppl 1:13S-20S.

21. Scott S, Knapp M, Henderson J, Maughan B. Financial cost of social exclusion: follow up study of antisocial children into adulthood. BMJ 2001;323:191.

22. Bruce ML, Wells KB, Miranda J, Lewis L, Gonzalez JL. Barriers to reducing burden of affective disorders. Ment Health Serv Res 2002;4:187-97.

23. Cook PJ and Moore MJ. The economics of alcohol abuse and alcohol-control policies. Health Aff 2002;21:120-33.

24. Freres DR, Gillham JE, Reivich K, Shatte AJ. Preventing depressive symptoms in middle school students: the Penn Resiliency Program. Int J Emerg Ment Health 2002;4:31-40. 
25. Garcia-Altes A, Olle JM, Antonanzas F, Colom J. The social cost of illegal drug consumption in Spain. Addiction 2002;97:1145-53.

26. O'Farrell TJ and Fals-Stewart W. Behavioral couples and family therapy for substance abusers. Curr Psychiatry Rep 2002;4:371-6.

27. Browne G, Gafni A, Roberts J, Byrne C, Majumdar B. Effective/efficient mental health programs for schoolage children: a synthesis of reviews. Soc Sci Med 2004;58:1367-84.

28. CDC. Economic costs associated with mental retardation, cerebral palsy, hearing loss, and vision impairment--United States, 2003. MMWR Morb Mortal Wkly Rep 2004;53:57-9.

29. Miller T, Blewden M, Zhang JF. Cost savings from a sustained compulsory breath testing and media campaign in New Zealand. Accid Anal Prev 2004;36:783-94.

30. Sheerin I, Green T, Sellman D, Adamson S, Deering D. Reduction in crime by drug users on a methadone maintenance therapy programme in New Zealand. N Z Med J 2004; 1 17:U795.

31. Lynch FL, Hornbrook M, Clarke GN, Perrin N, Polen MR, O'Connor E, Dickerson J. Cost-effectiveness of an intervention to prevent depression in at-risk teens. Arch Gen Psychiatry 2005;62:1241-8.

32. Conrad C. Measuring costs of child abuse and neglect: a mathematic model of specific cost estimations. J Health Hum Serv Adm 2006;29:103-23.

33. Mortimer D and Segal L. Economic evaluation of interventions for problem drinking and alcohol dependence: do within-family external effects make a difference? Alcohol Alcohol 2006;41:92-8.

34. Ruggiero KJ, Resnick HS, Acierno R, Coffey SF, Carpenter MJ, Ruscio AM, Stephens RS, Kilpatrick DG, Stasiewicz PR, Roffman RA, Bucuvalas M, Galea S. Internet-based intervention for mental health and substance use problems in disaster-affected populations: a pilot feasibility study. Behav Ther 2006; 37:190-205.

35. Smit F, Cuijpers P, Oostenbrink J, Batelaan N, de Graaf R, Beekman A. Costs of nine common mental disorders: implications for curative and preventive psychiatry. J Ment Health Policy Econ 2006;9:193-200.

36. Sobocki P, Jonsson B, Angst J, Rehnberg C. Cost of depression in Europe. J Ment Health Policy Econ 2006;9:87-98.

37. Wang PS, Patrick A, Avorn J, Azocar F, Ludman E, McCulloch J, Simon G, Kessler R. The costs and benefits of enhanced depression care to employers. Arch Gen Psychiatry 2006;63:1345-53.

38. Willette-Murphy K, Todero C, Yeaworth R. Mental health and sleep of older wife caregivers for spouses with Alzheimer's disease and related disorders. Issues Ment Health Nurs 2006;27:837-52.

39. Mansdotter AM, Rydberg MK, Wallin E, Lindholm LA, Andreasson S. A cost-effectiveness analysis of alcohol prevention targeting licensed premises. Eur J Public Health 2007; 17: 61 8-23.

40. Stack S. Societal economic costs and benefits from death: another look. Death Stud 2007;3 1:363-72.

41. Doran CM. Economic evaluation of interventions to treat opiate dependence : a review of the evidence. Pharmacoeconomics 2008;26:71-93.

42. Joling KJ, van Hout HP, Scheltens P, Vernooij-Dassen M, van den Berg B, Bosmans J, Gillissen F, Mittelman $M$, van Marwijk HW. (Cost)-effectiveness of family meetings on indicated prevention of anxiety and depressive symptoms and disorders of primary family caregivers of patients with dementia: design of a randomized controlled trial. BMC Geriatr 2008;8:2.

43. Lunkenheimer ES, Dishion TJ, Shaw DS, Connell AM, Gardner F, Wilson MN, Skuban EM. Collateral benefits of the Family Check-Up on early childhood school readiness: indirect effects of parents' positive behavior support. Dev Psychol 2008;44:1737-52.

44. Sherbourne CD, Edelen MO, Zhou A, Bird C, Duan N, Wells KB. How a therapy-based quality improvement intervention for depression affected life events and psychological well-being over time: a 9year longitudinal analysis. Med Care 2008;46:78-84.

45. Lu C, Frank RG, Liu Y, Shen J. The impact of mental health on labour market outcomes in China. J Ment Health Policy Econ 2009; 12:157-66.

46. Sarkar M, Burnett M, Carriere S, Cox LV, Dell CA, Gammon H, Geller B, Koren G, Lee L, Midmer D, Mousmanis P, Schuurmans N, Senikas V, Soucy D, Wood R. Screening and recording of alcohol use among women of child-bearing age and pregnant women. Can J Clin Pharmacol 2009; 16:e242-63.

47. Serretti A, Mandelli L, Bajo E, Cevenini N, Papili P, Mori E, Bigelli M, Berardi D. The socio-economical burden of schizophrenia: a simulation of cost-offset of early intervention program in Italy. Eur Psychiatry 2009;24:11-6. 
48. Smit F, Willemse G, Meulenbeek P, Koopmanschap M, van Balkom A, Spinhoven P, Cuijpers P. Preventing panic disorder: cost-effectiveness analysis alongside a pragmatic randomised trial. Cost Eff Resour Alloc 2009;7:8.

49. Strassels SA. Economic burden of prescription opioid misuse and abuse. J Manag Care Pharm 2009; 15:556-62.

50. Thanh NX and Jonsson E. Costs of fetal alcohol spectrum disorder in Alberta, Canada. Can J Clin Pharmacol 2009; 16:e80-90.

51. Andresen MA and Boyd N. A cost-benefit and cost-effectiveness analysis of Vancouver's supervised injection facility. Int J Drug Policy 2010;21:70-6.

52. Corso PS, Fang X, Begle AM, Dumas J. Predictors of engagement in a parenting intervention designed to prevent child maltreatment. West J Emerg Med 2010;11:235-41.

53. Gifford AE, Farkas KJ, Jackson LW, Molteno CD, Jacobson JL, Jacobson SW, Bearer CF. Assessment of benefits of a universal screen for maternal alcohol use during pregnancy. Birth Defects Res A Clin Mol Teratol 2010;88:838-46.

54. Mohapatra S, Patra J, Popova S, Duhig A, Rehm J. Social cost of heavy drinking and alcohol dependence in high-income countries. Int J Public Health 2010;55:149-57.

55. Quanbeck A, Lang K, Enami K, Brown RL. A cost-benefit analysis of Wisconsin's screening, brief intervention, and referral to treatment program: adding the employer's perspective. WMJ 2010;109:9-14.

56. van Gils PF, Hamberg-van Reenen HH, van den Berg M, Tariq L, de Wit GA. The scope of costs in alcohol studies: Cost-of-illness studies differ from economic evaluations. Cost Eff Resour Alloc 2010;8:15.

57. Woolderink M, Smit F, van der Zanden R, Beecham J, Knapp M, Paulus A, Evers S. Design of an internetbased health economic evaluation of a preventive group-intervention for children of parents with mental illness or substance use disorders. BMC public health 2010;10:470.

58. Zohrabian A and Philipson TJ. External costs of risky health behaviors associated with leading actual causes of death in the U.S.: a review of the evidence and implications for future research. Int J Environ Res Public Health 2010;7:2460-72.

59. Bayer JK, Rapee RM, Hiscock H, Ukoumunne OC, Mihalopoulos C, Clifford S, Wake M. The Cool Little Kids randomised controlled trial: population-level early prevention for anxiety disorders. BMC public health $2011 ; 11: 11$.

60. Bayer JK, Rapee RM, Hiscock H, Ukoumunne OC, Mihalopoulos C, Wake M. Translational research to prevent internalizing problems early in childhood. Depress Anxiety 201 1;28:50-7.

61. Bonin EM, Stevens M, Beecham J, Byford S, Parsonage M. Costs and longer-term savings of parenting programmes for the prevention of persistent conduct disorder: a modelling study. BMC public health $2011 ; 11: 803$.

62. Crede S, Sinanovic E, Adnams C, London L. The utilization of health care services by children with Foetal Alcohol Syndrome in the Western Cape, South Africa. Drug Alcohol Depend $2011 ; 1$ 15:175-82.

63. McDaid D and Park AL. Investing in mental health and well-being: findings from the DataPrev project. Health Promot Int 201 1;26 Suppl 1:i108-39.

64. van den Berg M, Smit F, Vos T, van Baal PH. Cost-effectiveness of opportunistic screening and minimal contact psychotherapy to prevent depression in primary care patients. PLoS One 201 1;6:e22884.

65. Dietrich S, Deckert S, Ceynowa M, Hegerl U, Stengler K. Depression in the workplace: a systematic review of evidence-based prevention strategies. Int Arch Occup Environ Health 2012;85:1-11.

66. Fernandez-Hermida JR, Calafat A, Becona E, Tsertsvadze A, Foxcroft DR. Assessment of generalizability, applicability and predictability (GAP) for evaluating external validity in studies of universal family-based prevention of alcohol misuse in young people: systematic methodological review of randomized controlled trials. Addiction 2012;107:1570-9.

67. Chisholm D, Stanciole AE, Tan Torres Edejer T, Evans DB. Economic impact of disease and injury: counting what matters. BMJ 2010;340:c924.

68. Thorn JC, Coast J, Cohen D, Hollingworth W, Knapp M, Noble SM, Ridyard C, Wordsworth S, Hughes D. Resource-use measurement based on patient recall: issues and challenges for economic evaluation. Appl Health Econ Health Policy 2013;1 1:155-61

69. Johannesson M. Avoiding double-counting in pharmacoeconomic studies. Pharmacoeconomics 1997; 11:385-8. 


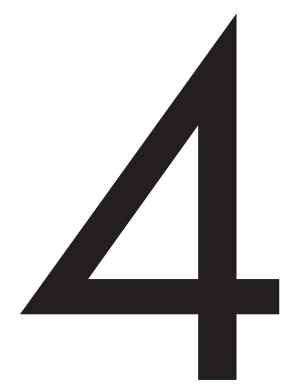

Valuing intersectoral costs and benefits of interventions in the healthcare sector: methods for obtaining unit prices

This chapter was published as: Drost RMWA, Paulus ATG, Ruwaard D, Evers SMAA Valuing intersectoral costs and benefits of interventions in the healthcare sector: methods for obtaining unit prices Expert Rev Pharmacoecon Outcomes Res 2016:1-8 epub ahead of print 


\section{Abstract}

\section{Introduction}

There is a lack of knowledge about methods for valuing health intervention-related costs and monetary benefits in the education and criminal justice sectors, also known as 'intersectoral costs and benefits' (ICBs). The objective of this study was to develop methods for obtaining unit prices for the valuation of ICBs.

\section{Methods}

By conducting an exploratory literature study and expert interviews, several generic methods were developed. The methods' feasibility was assessed through application in the Netherlands. Results were validated in an expert meeting, which was attended by policy makers, public health experts, health economists and HTA-experts, and discussed at several international conferences and symposia.

\section{Results}

The study resulted in four methods, including the opportunity cost method (A) and valuation using available unit prices (B), self-constructed unit prices (C) or hourly labor costs (D).

\section{Discussion}

The methods developed can be used internationally and are valuable for the broad international field of HTA. 


\section{Introduction}

Many interventions within the healthcare sector have costs and monetary benefits which spread to other sectors. These are known as 'intersectoral costs and benefits' (ICBs). ${ }^{1-3}$ Drost et al. (2013) identified more than 70 ICBs of healthcare interventions, which were classified into five categories. These include the sectors 'Education' (e.g. special education), 'Labor and Social Security' (e.g. productivity), 'Household \& Leisure' (e.g. informal care) and 'Criminal Justice System' (e.g. police interventions), and a fifth category for 'individual and family effects' (e.g. family conflict).

ICBs could contribute a considerable amount to the total monetary costs and monetary benefits (throughout this paper defined as reduction of monetary costs) of interventions in the healthcare sector, with consequent serious effects on the outcomes of their economic evaluations. Earlier research has shown that including ICBs within economic evaluation studies is important and that methods are needed to value them. ${ }^{4-6}$ However, this research on revealed preference methods for valuing ICBs was restricted mainly to productivity costs (human capital method, friction cost method) ${ }^{7,8}$ and informal care costs (opportunity cost method, proxy good method), ${ }^{4,6}$ while over half of the identified ICBs in our classification scheme belong to the educational sector and criminal justice sector. ${ }^{1}$ The lack of attention to the educational and criminal justice sector is due, among other things, to the lack of methodological knowledge which is required for valuing these ICBs. ${ }^{1-3,9}$

The importance of a monetary valuation of the aforementioned ICBs is receiving increasing recognition. ${ }^{1,3,9}$ This is partly due to the growing interest in (social) cost-benefit analyses (CBAs) and the increased attention for 'Health in All Policies' (HiAP). ${ }^{10-12}$ This is true internationally and for the Netherlands in particular. Illustrative is the mention of the ICBs 'special education' and 'legal costs' in the updated version of the Dutch manual for costing in economic evaluations. ${ }^{13,14}$ In addition, guidelines have recently been developed for structuring social CBAs. ${ }^{11,15}$ For such analyses, reliable information on costs and benefits, such as educational and criminal justice ICBs, is essential. The monetary valuation of these ICBs is, therefore, more and more important.

In short, although recognition of the importance of including educational and criminal justice ICBs in economic evaluations is growing, as yet little is known within health economics literature about the methods for obtaining unit prices which can be used for valuing these ICBs. Therefore, the main aim of this study was to develop generic (internationally usable) methods to obtain unit prices which support their valuation. A second aim was to assess the feasibility of these methods by applying them in practice. Within this study, we chose the Netherlands. 


\section{Methods}

\section{Selecting relevant ICBs}

Educational and criminal justice ICBs were taken from a classification scheme, ' after which a selection was made of those which could likely be expressed in monetary terms using revealed costs and reported unit prices. To distinguish between likely and not likely, those concerning changes in damages and use of services were separated from those concerning changes in behavior or functioning (which are often causally linked to these changes in damages and use of services). The second group of ICBs, which are commonly valued using stated preference methods, was excluded from further analysis. For example, as a change in 'special educational services' stands for a change in use of services, this ICB was considered eligible. Conversely, the ICB 'teacher-student conflicts' falls under change in behavior and was, therefore, excluded.

\section{Developing and applying methods for the valuation of ICBs}

The total costs and monetary benefits per ICB can be calculated by multiplying a unit price with a measured volume change. The search was, accordingly, for methods which could produce reliable unit prices.

Providing and assessing methods for the valuation of ICBs required a four-stage process. First, since the level of usability affects whether a particular method will be adopted, assessing usability was an essential part of the development process. Therefore, a study needed to be performed on the structures of the educational and a criminal justice system. Information on the Dutch educational system and criminal justice system was drawn from acknowledged, publicly available governmental reports. ${ }^{16,17}$ Outcomes were used to break down the selected ICBs from the classification scheme into the country-specific ICBs to which methods could be applied.

Second, to develop methods for the valuation of these ICBs, a scoping review was conducted. The search was for acknowledged reports, such as the above mentioned governmental reports, and relevant databases which provide reliable unit prices or information on the basis of which unit prices can be constructed. Therefore, the search was also for information sources containing underlying methodologies and figures containing total costs related to ICBs. Based on the information gathered, lists with unit prices were constructed.

Third, as part of this explorative process, several interviews were conducted with experts on the educational sector and criminal justice sector. Among these experts were the authors of the consulted cost figures. Guided by pre-determined, open-ended questions, they were asked to provide feedback on the results of the literature study. Questions were asked concerning the selection of ICBs and methods for obtaining unit prices. Apart from those interviewed, if the methodology for cost calculations was not clear, several other authors were contacted and asked to provide clarification via e-mail. Expert answers were used to make adaptations to the lists. For uniformity purposes, unit prices found and/or 
calculated were indexed for the year 2012 using consumer price index numbers found on Statline. $^{18}$

Fourth, to assess and improve the usability of the unit prices for the valuation of ICBs, units of prices had to reflect the standard measurement units, i.e. hours, contacts etc. Measurement units were sought using the Database of Instruments for Resource Use Measurement (DIRUM) ${ }^{19}$ and the website of the Institute for Medical Technology Assessment (iMTA), ${ }^{20}$ which were consulted for prominent questionnaires containing items concerning educational and criminal justice services. Measurement units were drawn from the questionnaires, ${ }^{21-27}$ after which prices were compared with these units and, if found to be necessary and possible, converted.

\section{Expert meeting and conferences}

To validate the valuation methods and resulting unit prices, an expert meeting was held in the fall of 2013. Experts were recruited based on expertise. The meeting was attended by lead authors of Dutch manuals on costing in health economic evaluations and other researchers who fulfilled the criterion of being a leading expert in the field of public health, health economics and/or health technology assessment. Furthermore, to discuss the policy implications of this study, the meeting was attended by policy makers within the field of public health. All authors of this study were present as well.

Methods and results of the study were sent to the experts before the meeting, so that they could prepare for it. Through an e-mail, all experts were asked to assess the methods. Furthermore, three subgroups were made based on the individual expertise and experience of the experts, with each being specifically asked to assess the methods' application to the educational sector, the criminal justice sector or policy implications. However, all experts had access to the full contents of the paper so that they could provide feedback on other parts as well.

During the semi-structured meeting, the findings were presented by the lead author (RD) and discussed by all participants. The meeting was structured into four themes, i.e. 1) methods for valuing ICBs, 2) application to the educational sector, 3) application to the criminal justice sector, and 4) policy implications, which were consecutively addressed. Apart from policy implications, experts were asked to provide feedback and discuss the selection of ICBs, (inter)national usability of the valuation methods and unit prices. In each phase, first the expert subgroup was asked to provide feedback, after which all could join the discussion. The expert meeting was recorded. For the names and affiliations of the experts, see the acknowledgements section of this article.

The analysis of the qualitative responses was conducted in several steps. Recordings were used to extract important suggestions, remarks and comments made by participants in the expert meeting. Subsequently, these expert answers were clustered according to topic. Before adjustments were made to the methods and unit prices, strategies were discussed by the project team (RD, AP, DR, SE) until consensus was reached. Finally, a letter of reply, in which the clustered comments of the experts and strategies of how to deal with these were 
specified, was sent to the expert meeting participants in the beginning of 2014. Experts were given the opportunity to send final comments via e-mail, and these were used to make final adjustments.

In addition to the expert meeting, to strengthen the validity of the results, the methods for the valuation of ICBs were also presented and discussed at various workshops and conferences, including a meeting with health economists and HTA-experts in Nunspeet (the Netherlands), organized by the Lowlands Health Economics Study Group 'LolaHESG', at the 'Dutch Conference on Public Health' in The Hague (the Netherlands), and during an organized session at the 'iHEA $10^{\text {th }}$ World Congress on Health Economics' in Dublin (Ireland).

\section{Results}

\section{Relevant ICBs}

The selection process resulted in two shortlists, i.e. one for the educational sector and one for the criminal justice sector (Table 4.1). As depicted in Table 4.1, less than half of the $\mathrm{ICBs}$ within the educational sector were comprised of damages or use of services and were, accordingly, considered eligible for further analysis. The relative and absolute number within the criminal justice sector is higher. This implies that, in comparison with educational ICBs, there are more criminal justice ICBs concerning damages and use of services use.

Table 4.1 Selected ICBs ${ }^{a}$

\begin{tabular}{|c|c|c|}
\hline & Educational sector & Criminal justice sector \\
\hline Selected & $\begin{array}{l}\text { - Problems with school entry } \\
\text { - } \quad \text { Grade retention } \\
\text { - } \quad \text { School dropout/pre-mature leave } \\
\text { - } \quad \text { Special education services (schools) } \\
\text { - } \quad \text { Special education services (personal budget) } \\
\text { - } \quad \text { Special education services (transport) } \\
\text { - }\end{array}$ & $\begin{array}{l}\text { - (Im)material damages (victims) } \\
\text { - Lost work of victims } \\
\text { - Illegal untaxed income } \\
\text { - Police services, prosecutor } \\
\text { - Judicial expenses (lawyer) } \\
\text { - Judicial expenses (court) } \\
\text { - Forensic services } \\
\text { - Forensic psychiatrist } \\
\text { - Imprisonment } \\
\text { - Fines and transactions } \\
\text { - Other penalties } \\
\text { - Lost work and belongings (offender) } \\
\text { - Probation } \\
\text { - Child protective services }\end{array}$ \\
\hline Non-selected & $\begin{array}{l}\text { - School readiness, adaption, competence, } \\
\text { participation, engagement, attainment, } \\
\text { productivity, meeting obligations, experience } \\
\text { - Cognitive deficits (e.g. learning disabilities) } \\
\text { - Change in educational outcomes, intellectual } \\
\text { and academic performance } \\
\text { - School teacher-student relationship } \\
\text { - Home education, residential programs }\end{array}$ & $\begin{array}{l}\text { - Violence and crime (domestic violence, } \\
\text { unlawful threats, assaults, violence towards } \\
\text { officials, drunk driving, sexual assaults } \\
\text { towards adults, homicide, vandalism, theft, } \\
\text { and child maltreatment including physical, } \\
\text { psychological, emotional, sexual abuse and } \\
\text { neglect) } \\
\text { - Parole }\end{array}$ \\
\hline
\end{tabular}


Based on information drawn from yearly reports of the Ministry of Education, Culture and Science, and the Ministry of Security and Justice, ${ }^{16,17}$ the generic ICBs (Table 4.1) were broken down into eight Dutch ICBs for the educational sector and fourteen Dutch ICBs for the criminal justice sector (Tables 4.2 and 4.3). For example, the classification scheme provides the ICB 'special education services'. Within the Netherlands, for some disabilities, these services can be provided in special schools and, through a personal budget, in regular schools. Therefore, a distinction was made between 'special education (schools)' and 'special education (personal budget)'.

\section{Valuing ICBs}

The study resulted in four methods (referred to as methods $A$ to D), which can be systematically and consecutively applied to produce unit prices for the valuation of ICBs (Figure 4.1).

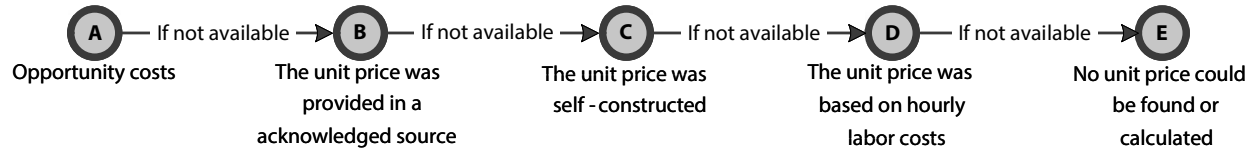

Figure 4.1 Methods for the valuation of $\mathrm{ICBs}^{\mathrm{a}}$

${ }^{a}$ The order in which methods are placed suggests that there is a hierarchy. However, the choice of method is also dependent on the quality of the data sources

During the expert meeting, the idea was proposed and discussed to use the opportunity cost method for valuing ICBs (method $A$ ). Opportunity costs are the benefits omitted as a result of the time spent providing alternative services. ${ }^{4,28,29}$ For example, to value informal care, opportunity costs equal the informal caregiver's benefits foregone as a result of spending time on providing informal care. ${ }^{4}$ To apply this method, information is required on both the time spent providing these services and an individual's market wage rate or reservation wage rate for those in nonlabor market participation. ${ }^{6}$ As for informal care, this method can also be applied for valuing ICBs in the educational and criminal justice sectors. An advantage of this method is the accuracy with which costs and benefits can be valued in monetary terms, especially when micro-costing is applied to assess the economic costs. However, although micro-costing produces the most precise estimate of true costs, ${ }^{28}$ it has a disadvantage in that it is time-consuming to gather all of the required information. This is especially true when individuals' market wages differ and when these differences are hard to retrieve, hereby rendering it a high quality but also a less feasible method to value ICBs.

When specific information on an individual's market wages is not available or is considered too time-consuming to approximate, valuation can be based on proxy unit prices, which should be sought in acknowledged reports (method B). Key here is that these reports should be reliable, freely accessible and transparent, and that these should be 
cited when used. These include, among others, governmental annual reports and annual reports of related institutions responsible for providing services related to ICBs. Unit prices can be retrieved from reports of the ministries covering policies within those ICB sectors for which unit prices are required for which unit prices are required. For example, unit prices for special education may be retrievable from the annual report of the ministry responsible for policies within the educational sector. Policies on ICBs such as these, however, can also be governed by regulatory public or private organizations outside the central government which have been granted authority and responsibility for providing services related to ICBs. An example of such an ICB is re-integration after imprisonment, which can be supervised by an independent organization. In this case, the unit price should be sought in the annual report of this organization.

If unit prices are not provided, valuation can be based on self-constructed unit prices (method C). The same reports should be searched for total costs provided in income statements and production output figures. Unit prices can then be calculated by dividing total annual costs by total annual output. When organizations provide multiple types of services, unit prices should be calculated based on the specific costs and output figures of these specific services. Given the example provided earlier, if the unit price for reintegration cannot be found using method $B$, the annual reports of the organization responsible for re-integration can be searched for the total costs for this specific service and the number of subjects who were provided this service.

When reports do not provide the required information, valuation can be based on hourly labor costs (method D). Acknowledged data sources should be searched for labor costs for services related to ICBs. Reliable data on labor costs is often stored and made available publicly by the government or organizations which have been given responsibility by and can be held accountable by the government. Looking at the ICB reintegration after imprisonment the hourly labor costs of those providing re-integration services may be retrievable from an acknowledged data source. In this case, to convert hourly labor costs to the costs of re-integration, additional information is needed on the number of hours of service required to complete a re-integration trajectory.

The order in which methods are placed suggests that there is a hierarchy, with one method being dominant over or inferior to another. This was discussed during the expert meeting. Although the high level of detail to which micro-costing produces reliable cost estimates places the opportunity cost method on the top of this hierarchy - which was agreed upon during the expert meeting - the order in which the other methods were placed had to do with feasibility. Nevertheless, what should be clear is that the reliability of the data sources is important for choosing between method $B, C$ or $D$. This means, for example, that the data source which is used for method $D$ can sometimes be more reliable than the one used for methods B and $C$. In these cases, method D should be applied. We tested the usability and feasibility of methods $B, C$ and $D$, of which the results are provided below. For the results of the feasibility, when no unit price could be obtained or calculated based on the analysis of consulted sources, the ICB is marked with an ' $E$ '. 


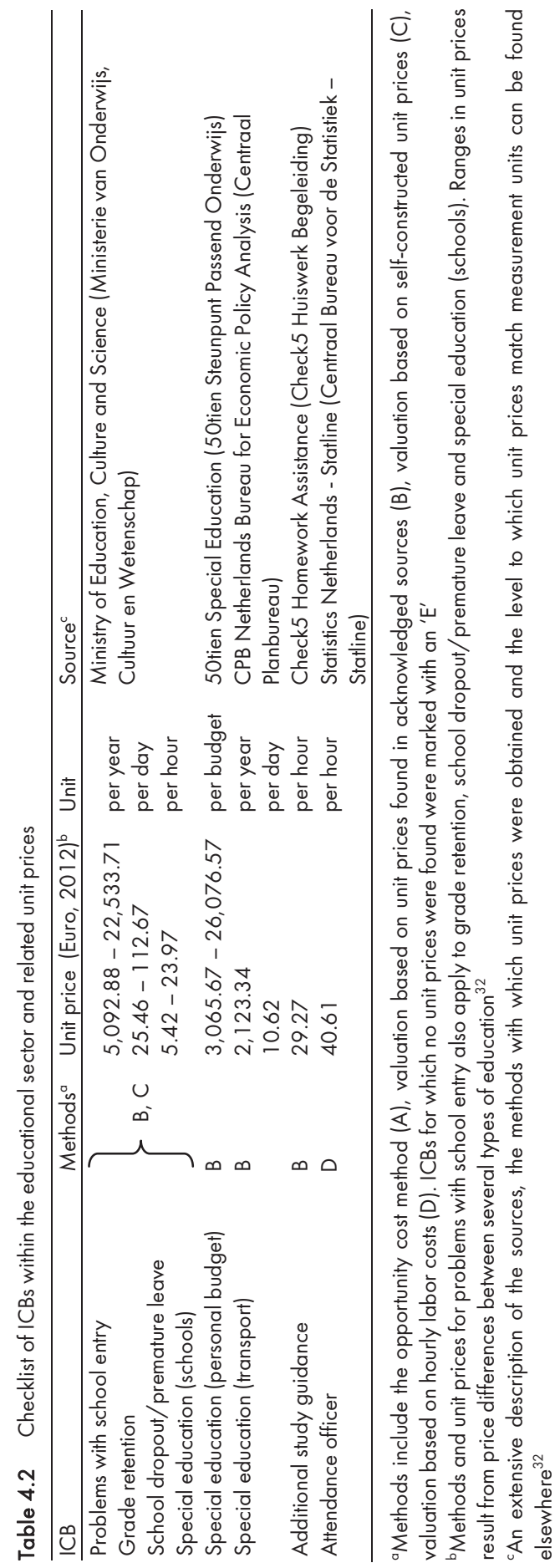




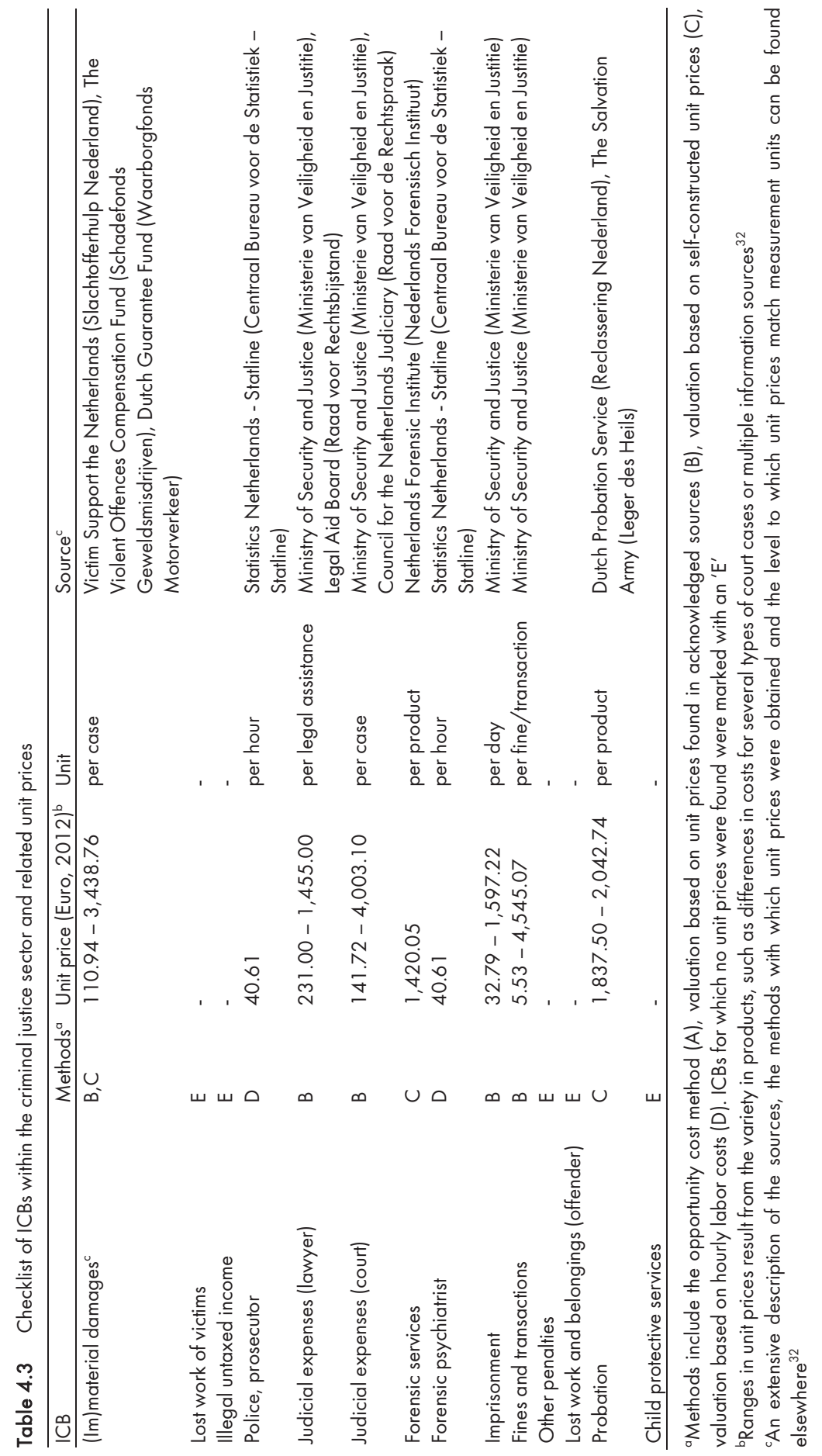




\section{Usability and feasibility}

To assess the usability and feasibility of methods $B, C$ and $D$, we applied them to obtain unit prices for the valuation of ICBs in the Netherlands. Application of methods $B$ and $C$ required acknowledged reports, such as the annual governmental reports which were consulted for background information on the Dutch educational and criminal justice system. ${ }^{16,17}$ For method D, hourly labor costs were derived from Statline, the public website service of Statistics Netherlands. ${ }^{18}$ A comparative analysis of regularly used questionnaires and units attached to unit prices showed that units of unit prices acquired using method $D$ (per hour) differed from frequently found measurement units (per contact). These unit prices were not converted. Examples include the ICBs 'police' and 'attendance officer'. Since the duration of contacts will differ within and between studies, these can, in combination with additional information on the duration of contacts, be used to calculate specific unit prices.

As shown in Table 4.2, most of the unit prices for the valuation of ICBs within the Dutch educational sector were produced using method B. Unit prices related to problems with school entry are the same as those needed to value grade retention, school dropout/premature leave and special education (schools). Ranges in unit prices result from the variety in products. An example is the price differences between several types of education (€5,092.88 - 22,533.71 per year). Unit prices for these ICBs per day and per hour were calculated, respectively, by dividing the costs per year by the annual amount of schooldays and hours. The unit price needed for valuation of the activities of attendance officers could not be derived from information drawn from reports.

As shown in Table 4.3, for five out of fourteen ICBs within the Dutch criminal justice sector, no unit price could be obtained or calculated. Consulted sources lacked unit prices or the information required to produce unit prices. For six out of the resulting nine other $I C B s$, unit prices were identified using method $B$. Due to the variety in types and severity of (im)material damages, both methods $B$ and $C$ were used. To adapt for the variety in measurement units used to express services provided by the police and prosecutors, both methods $B$ and $D$ were used. Ranges in unit prices result from the variety in products. An example is the price differences among several fines and transactions (€5.53-4,545.07 per fine/transaction).

\section{Discussion}

\section{Main findings}

The main objective of this study was to develop methods which support the valuation of educational and criminal justice ICBs of interventions in the healthcare sector. A second objective was to apply these methods to assess their feasibility. Multiple methods were proposed, which can be applied internationally to value ICBs in monetary terms. These 
include the opportunity cost method $(\operatorname{method} A)$, valuation based on a unit price provided by an acknowledged source (method B), valuation based on a self-constructed unit price (method C) and valuation using hourly labor costs (method D). Within this particular study, method $A$ was considered not feasible for deriving unit prices. However, overall, the combined application of methods $B, C$ and $D$ turned out to be feasible. The application resulted in two lists with unit prices, one for the educational sector and one for criminal justice sector, which can be used for costing research in the Netherlands.

\section{Limitations}

The findings of the study need to be placed in the context of the study's limitations. First, this study was conducted based on the conclusion that little is known about the methods for valuing ICBs. Since we adopted a health care perspective and used health as a starting point for this study, this conclusion was reached from studying health care evaluation literature only. A study of the evaluation literature in the educational and criminal justice domains could have provided us with more information regarding the impact of health outside the health care sector.

Second, as noted earlier, the study resulted in a certain 'hierarchy' between valuation methods, which can be systematically and consecutively applied to produce unit prices for the valuation of ICBs. However, the variety in methods still raises the question of whether there is a 'best' method. Further research on the feasibility, reliability and validity of the unit prices may provide an answer to this issue. In this regard it might be helpful to develop measurement tools which are specifically designed to cover ICBs. This might improve the extent to which the unit prices can be applied. In response to the applicability, however, this is partly met by adapting the units of prices to measurement units.

\section{Implications for research and policy}

Although the aim was to develop generic methods, a characteristic of the products - i.e. unit prices - is that these are country-specific. Part of this specificity can be explained by inter-country differences between the structures of educational and criminal justice systems. For example, differences in the way special education is organized will affect the number and actual size of related unit prices. Researchers operating outside the Netherlands could retrieve or calculate unit prices fit for use within their own country by applying the valuation methods provided in this study. Although the success of applying these methods is dependent on the availability of local or national data and might differ between countries, it is expected, within this information age, that this availability will often be sufficient. The methods provided in this study will, therefore, be valuable for the broad international field of HTA.

Including ICBs within costing research may improve the reliability of economic analyses. The types of analyses for which this might be the case are, among others, costeffectiveness analysis (CEA), cost-utility analysis (CUA) and CBA. As for informal care, ${ }^{6}$ it is expected that the monetary costs and benefits (i.e. reduction in costs) related to the ICBs 
which have been selected in this study can be included in the cost side of CEA and CUA. Double counting with effect or utility outcomes measures such as the QALY, which should be avoided in health economic evaluations, ${ }^{30}$ is not expected to be a serious problem. Nevertheless, in these analyses, the decision to invest time in measuring ICBs could be dependent on their expected weight relative to the total costs and benefits of an intervention. Further research could provide insight regarding the circumstances (such as types of interventions) in which ICBs should be included.

When adopting a societal perspective, which is considered to lead to the broadest representation of costs and benefits, it is important to value all affected ICBs, regardless of who pays for the costs or receives the benefits. ${ }^{31}$ An intervention can be perceived to be not worthwhile from a narrow perspective, whereas from a societal perspective benefits can exceed costs. ${ }^{9}$ A complete and reliable coverage of ICBs in the educational and criminal justice sector can, therefore, be of added value for making decisions on interventions in the healthcare sector. This can be accomplished by adopting ICBs within social cost-benefit analyses, which - as noted earlier - are becoming more important in decision making processes.

In addition to policy making within the healthcare sector, an overview of the financial impact of health interventions may draw the interest of policymakers operating outside the healthcare sector for health-related issues. This, in turn, may stimulate policymakers operating outside the healthcare sector into putting health-related issues on their agenda. Adopting health-related policy in policy domains outside the healthcare sector is considered a step towards including health in all policies (HiAP). ${ }^{12}$ Adopting a societal perspective in research, as was performed in this study, may accelerate the process of realizing HiAP.

\section{Dissemination}

We have laid out the classification scheme, valuation methods and lists with unit prices, along with detailed descriptions of the specific processes for producing unit prices and the implications for researchers and policymakers, in a manual for conducting and assessing research on ICBs in the Netherlands. ${ }^{32}$ The manual provides support during the classification, identification and valuation of ICBs. Simultaneously, a plan was written for its dissemination. The contents of the manual were presented at several conferences (see methods section) and a website has been created, in which user experiences can be shared with the authors. ${ }^{33}$ Furthermore, the manual on ICBs will be referred to in the upcoming updated version of the official Dutch manual for costing in economic evaluations of The Dutch National Health Care Institute.

Although the unit prices depicted in this manual are limited to use only in the Netherlands, the generic methods provided in this study can be used for conducting research on ICBs in other countries as well. The application of the manual will provide further insight into their feasibility and value for specific costing research studies. 


\section{Key issues}

- Many interventions within the healthcare sector have costs and monetary benefits which spread to other sectors. These are known as 'intersectoral costs and benefits' (ICBs).

- Current methods to value ICBs are restricted mainly to productivity costs and informal care costs. The lack of attention on the educational and criminal justice sector in health economic evaluations is due, among other things, to the lack of methodological knowledge which is required for valuing these ICBs.

- The study resulted in four methods which support the valuation of ICBs. These include the opportunity cost method (A), valuation using unit prices provided by acknowledged written sources (B), valuation on the basis of self-constructed unit prices using information retrieved from these sources $(C)$, and valuation using hourly labor costs (D). Application showed that especially methods B and C turned out to be feasible.

- Depending on the type of health care intervention being evaluated, including ICBs within costing research may improve the reliability of economic analyses. The types of analyses for which this might be the case are, among others, cost-effectiveness analysis, cost-utility analysis and cost-benefit analysis.

- As a complete and reliable coverage of ICBs in the educational and criminal justice sector improves the quality of decision supportive information, it will be of added value for making decisions on interventions in the healthcare sector. Decision makers within the health care sector should carefully consider which ICBs should be included when setting out research projects.

- Interventions in the healthcare sector may serve as effective tools to reach non-health objectives (e.g. improving educational outcomes and lowering crime rates). Therefore, reporting ICBs of health interventions may draw the interest of policymakers operating outside the healthcare sector for health-related issues. Adopting health-related policy in policy domains outside the healthcare sector is considered a step towards health in all policies (HiAP).

- The valuation methods and lists with unit prices, along with detailed descriptions of the specific processes for producing unit prices and the implications for researchers and policymakers, were used to construct guidelines for conducting and assessing research on ICBs in the Netherlands.

- The generic methods provided in this study can be used to develop guidelines on ICBs in other countries as well. 


\section{Acknowledgements}

The authors would like to thank Eddy Adang (Radboud University Medical Center, Nijmegen), Lea den Broeder (National Institute for Public Health and the Environment, Bilthoven), Wim Groot (The Council for Public Health and Health Care, The Hague), Leona Hakkaart-van Roijen (Institute for Medical Technology Assessment, Rotterdam), Jack Hutten (Ministry of Education, Culture and Science, The Hague), Debora Moolenaar (Ministry of Security and Justice, The Hague), Johan Polder (National Institute for Public Health and the Environment, Bilthoven), Gerbert Romijn (Netherlands Bureau for Economic Policy Analysis, The Hague), Filip Smit (Trimbos Institute, Utrecht), Rolf van der Velden (Maastricht University, Maastricht) and Ardine de Wit (National Institute for Public Health and the Environment, Bilthoven) for their valuable feedback on the methods and results of this study. The authors would also like to thank the discussants and participants of the following conferences: 'Dutch Conference on Public Health' in The Hague, April 2014, 'Lowlands Health Economists' Studygroup' in Oostvoorne, May 2014, 'iHEA 10th World Congress on Health Economics' in Dublin, July 2014 and 'Symposium on Social CostBenefit Analysis and Inter-Sectoral Costs and Benefits' at the Ministry of Health, Welfare and Sport in The Hague, October 2014. Furthermore, the authors would like to thank Barbara Greenberg for her English editing services. 


\section{References}

1 Drost RMWA, Paulus ATG, Ruwaard D, Evers SMAA. Intersectoral costs and benefits of mental health prevention: towards a new classification scheme. J Ment Health Policy Econ 2013;16:179-86.

2. Lorgelly PK, Lawson KD, Fenwick EA, Briggs AH. Outcome measurement in economic evaluations of public health interventions: a role for the capability approach? Int J Environ Res Public Health 2010;7:2274-89.

3. Weatherly $\mathrm{H}$, Drummond $\mathrm{M}$, Claxton $\mathrm{K}$ et al. Methods for assessing the cost-effectiveness of public health interventions: key challenges and recommendations. Health Policy 2009;93: 85-92.

4. Koopmanschap MA, van Exel JN, van den Berg B, Brouwer WB. An overview of methods and applications to value informal care in economic evaluations of healthcare. Pharmacoeconomics 2008;26:269-80.

5. Krol M, Papenburg J, Koopmanschap M, Brouwer W. Do productivity costs matter?: the impact of including productivity costs on the incremental costs of interventions targeted at depressive disorders. Pharmacoeconomics 2011;29:601-19.

6. van den Berg B, Brouwer WB, Koopmanschap MA. Economic valuation of informal care. An overview of methods and applications. Eur J Health Econ 2004;5:36-45.

7. Koopmanschap MA, Rutten FF, van Ineveld BM, van Roijen L. The friction cost method for measuring indirect costs of disease. J Health Econ 1995; 14:171-89.

8. Weisbrod BA. Economics of Public Health: Measuring the Economic Impact of Diseases. Philadelphia: University of Pennsylvania Press, 1961.

9. O'Connell ME, Boat T, Warner KE. Preventing Mental, Emotional, and Behavioral Disorders Among Young People: Progress and Possibilities. Washington (DC): National Academies Press (US), 2009.

10. Evers SMAA. Value of integrated care: revival of the monetary valuation of health care benefits. Int J Integr Care 2010; 10:e045.

11. Pomp M, Schoemaker CG, Polder JJ. Themarapport Volksgezondheid Toekomst Verkenning (VTV). Op weg naar maatschappelijke kosten-baten analyses voor preventie en zorg. Bilthoven: Rijksinstituut voor Volksgezondheid en Milieu, Bilthoven, 2014

12. McQueen DV, Wismar M, Lin V et al. Intersectoral Governance for Health in All Policies. Copenhagen: World Health Organization, 2012.

13. Hakkaart-van Roijen L, Tan SS, Bouwmans CA. Handleiding voor kostenonderzoek. Methoden en referentieprijzen voor economische evaluaties in de gezondheidszorg. Geactualiseerde versie 2010. Diemen: College voor Zorgverzekeringen, 2011.

14. Tan SS, Bouwmans CA, Rutten FF, Hakkaart-van Roijen L. Update of the Dutch Manual for Costing in Economic Evaluations. Int J Technol Assess Health Care 2012;28:152-8.

15. Romijn G, Renes G. Algemene leidraad voor maatschappelijke kosten-batenanalyse. Den Haag: Centraal Planbureau/Planbureau voor de Leefomgeving, 2013.

16. OCW. OCW Kernciifers 2008-2012, 2013. Available at: http://www.rijksoverheid.nl/bestanden/documenten-en-publicaties/jaarverslagen/2013/05/08/ocwkerncijfers-2008-2012/onderwijs-cultuur-en-wetenschap-kernciifers-2008-2012.pdf [Last accessed 6 May 2015].

17. VenJ. Criminaliteit en rechtshandhaving 2012, 2013. Available at: http://www.cbs.nl/NR/rdonlyres/83165864-9367-4034-B588C398C623E462/0/2013criminaliteitrechtshandhaving2012pub.pdf [Last accessed 6 May 2015 ].

18. Statline, 2014. Available at: http://statline.cbs.nl/statweb/ [Last accessed 6 May 2015].

19. DIRUM, 2014. Available at: http://www.dirum.org/ [Last accessed 18 November 2014].

20. iMTA, 2014. Available at: http://www.bmg.eur.nl/english/imta/publications/questionnaires_manuals/ [Last accessed 20 November 2014].

21. Beecham J. Client Service Receipt Inventory - Children's version, 1999. Available at: http://www.dirum.org/assets/downloads/634462397526425351-CSRI\%20\%20Childrens\%20Version.pdf [Last accessed 18 November 2014].

22. Beecham J, Knapp M. Client Service Receipt Inventory (CSRI), 1992. Available at: http://www.dirum.org/assets/downloads/634462388066137028-CSRI.pdf [Last accessed 18 November 2014]. 
23. Beecham J, Knapp M. Client Sociodemographic and Service Receipt Inventory (CSSRI-EU), 1997. Available at: http://www.dirum.org/assets/downloads/634462380166178864-CSSRI\%20\%20EU.pdf [Last accessed 18 November 2014].

24. Bouwmans C, De Jong K, Timman R et al. Feasibility, reliability and validity of a questionnaire on healthcare consumption and productivity loss in patients with a psychiatric disorder (TiC-P). BMC Health Serv Res 2013;13:217.

25. Bouwmans CA. Trimbos/iMTA questionnaire for Costs associated with Psychiatric Illness (TiC-P children), 2012. Available at:

http://www.bmg.eur.nl/fileadmin/ASSETS/bmg/english/iMTA/Publications/Manuals__uestionnair es/Vragenlijsten_2013/Vragenlijst_TiC_P_kinderen_excl_optionele_vragen.pdf [Last accessed 20 November 2014].

26. Bouwmans CA, Hakkaart-van Roijen L. Trimbos/iMTA questionnaire for Costs associated with Psychiatric Illness (TiC-P adults). Update 2012, 2012. Available at:

http://www.bmg.eur.nl/fileadmin/ASSETS/bmg/english/iMTA/Publications/Manuals__Questionnair es/Vragenliisten_2013/Questionnaire_TiC-P_initial_version_in_English.pdf [Last accessed 20 November $2014]$.

27. Bouwmans CAM, Schawo SJ, Jansen DEMC, Vermeulen KM, Reijneveld SA, Hakkaart-van Roijen L. iMTA Questionnaire Intensive Youth Care, 2012. Available at:

http://www.bmg.eur.nl/fileadmin/ASSETS/bmg/english/iMTA/Publications/Manuals_Questionnair es/Vragenlijsten_2013/Vragenlijst_TiC_P_kinderen_excl_optionele_vragen.pdf [Last accessed 20 November 2014].

28. Drummond M, O'Brien BJ, Stoddart G, Torrance GW. Methods for the Economic Evaluation of Health Care Programmes. New York: Oxford University Press, 2005.

29. Posnett J, Jan S. Indirect cost in economic evaluation: the opportunity cost of unpaid inputs. Health Econ 1996;5:13-23.

30. Johannesson M. Avoiding double-counting in pharmacoeconomic studies. Pharmacoeconomics. 1997; 11:385-8.

31. Johansson $P$, Tillgren P. Financing intersectoral health promotion programmes: some reasons why collaborators are collaborating as indicated by cost-effectiveness analyses. Scand J Public Health $2011 ; 39(6$ Suppl):26-32.

32. Drost RMWA, Paulus ATG, Ruwaard D, Evers SMAA. Handleiding intersectorale kosten en baten van (preventieve) interventies: Classificatie, identificatie en kostprijzen. Maastricht: Maastricht University, Department of Health Services Research, 2014.

33. Maastricht University, 2014. Available at:

http://www.maastrichtuniversity.nl/web/Main/Sitewide/Content/ClassificatieldentificatieEnWaardering VanIntersectoraleKostenEnBatenVanPreventievelnterventies.htm [Last accessed 18 June 2014]. 


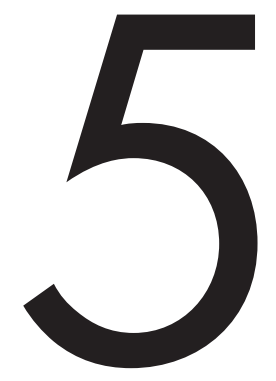

\section{Cost-effectiveness of preventive case management for parents with a mental illness: a randomized controlled trial from three economic perspectives}

This chapter was published as: Drost RMWA * ,Wansink HJ*, Paulus ATG, Ruwaard D, Hosman CMH, Janssens JMAM, Evers SMAA Cost-effectiveness of preventive case management for parents with a mental illness: a randomized controlled trial from three economic perspectives

BMC Health Services Research 2016; 16:228 * shared first author 


\section{Abstract}

\section{Background}

The children of parents with a mental illness (COPMI) are at increased risk for developing costly psychiatric disorders because of multiple risk factors which threaten parenting quality and thereby child development. Preventive basic care management (PBCM) is an intervention aimed at reducing risk factors and addressing the needs of COPMI-families in different domains. The intervention may lead to financial consequences in the healthcare sector and in other sectors, also known as intersectoral costs and benefits (ICBs). The objective of this study was to assess the cost-effectiveness of PBCM from three perspectives: a narrow healthcare perspective, a social care perspective (including childcare costs) and a broad societal perspective (including all ICBs).

\section{Methods}

Effects on parenting quality (as measured by the HOME) and costs during an 18-month period were studied in in a randomized controlled trial. Families received PBCM $(n=49)$ or care as usual (CAU) $(n=50)$. For all three perspectives, incremental cost-effectiveness ratios (ICERs) were calculated. Stochastic uncertainty in the data was dealt with using non-parametric bootstraps. Sensitivity analyses included calculating ICERs excluding cost outliers, and making an adjustment for baseline cost differences.

\section{Results}

Parenting quality improved in the PBCM group and declined in the CAU group, and PBCM was shown to be more costly than CAU. ICERs differ from $€ 461$ (healthcare perspective) to $€ 215$ (social care perspective) to $€ 175$ (societal perspective) per one point improvement on the HOME T-score. The results of the sensitivity analyses, based on complete cases and excluding cost outliers, support the finding that the ICER is lower when adopting a broader perspective. The subgroup analysis and the analysis with baseline adjustments resulted in higher ICERs.

\section{Conclusions}

This study is the first economic evaluation of family-focused preventive basic care management for COPMI in psychiatric and family services. The effects of the chosen perspective on determining the cost-effectiveness of PBCM underscore the importance of economic studies of interdepartmental policies. Future studies focusing on the cost-effectiveness of programs like PBCM in other sites and studies with more power are encouraged as this may improve the quality of information used in supporting decision making. 


\section{Background}

Children of parents with a mental illness (COPMI) have an increased risk of developing mental health disorders such as depression, anxiety disorders, personality disorders and alcohol dependence. ${ }^{1-3}$ Across different studies, relative risks of 1.5 to 8.0 have been found $^{2,4-6}$ for COPMI in comparison with children of parents without a mental illness. Apart from the burden this may pose on children and caregivers, COPMI put a substantial burden on youth mental health services and child health expenditures. ${ }^{7}$ Case registers of the Dutch Youth Mental Health Services show that COPMI consume five times the amount of mental healthcare than do other children, and that they are overrepresented in clinical care. ${ }^{8}$ Furthermore, COPMI use more costly specialized youth care and youth protection services $^{9,10}$ than do other children. The emotional, social, and economic burden of mental illness has also led to growing awareness, among professionals worldwide, of the impact that mental illness has on patients' families and children in particular. ${ }^{11}$ It is estimated that more than half of the male and two-thirds of female patients have minor children. ${ }^{12}$ Epidemiological studies in the Netherlands and Norway already show one out of six to one out of three children having a parent with a mental illness. 13,14

Parental mental illness is often accompanied by many adversities, such as a history of being abused or neglected in childhood, poverty, divorce, isolation, and children having special needs or behavioral problems. In fact, it is the accumulation of such adversities that forms the greatest threat to parenting quality and healthy child development. ${ }^{3,4}$ Parenting quality is defined as the quality and quantity of stimulation and support available to a child in his/her home environment. This accumulation of adversities calls for preventive and proactive family support. Since families of COPMI have a variety of needs in different domains, interventions aimed at improving parenting quality should include a variety of services; accordingly, this requires a comprehensive coordinated approach. One such approach is preventive basic care management (PBCM).

$\mathrm{PBCM}$ is a preventive program targeting threats to parenting quality. ${ }^{15}$ By assessing multiple risk factors for poor parenting and the needs of families in different domains, facilitating access to preventive services, tailoring services to assessed needs and coordinating psychiatric and preventive services, $\mathrm{PBCM}$ aims to support effective parenting by maintaining a good balance between the adversities, vulnerabilities, and strengths of parents. Ultimately PBCM aims thereby to promote the socio-emotional development of COPMI and to reduce the risk of developing behavioral problems. The effects of PBCM on parenting outcomes (parenting quality, parenting skills and parenting stress) were studied in an RCT. ${ }^{16}$ Evidence was found that PBCM had a statistically significant positive effect on parenting skills $\left({ }^{2}=.055, p<0.05\right)$. Significant effects on the quality of parenting, and the frequency and intensity of parenting stress were not found, although findings did suggest trends toward improved parenting quality $\left({ }^{2}=.026, p<0.10\right)$ and reduced frequency and intensity of parenting stress $\left({ }^{2}=.029, p<0.10\right.$ and $\left.{ }^{2}=.011, p<0.10\right)$.

Serving the needs of families of COPMI within the available financial resources is a major issue in health systems worldwide. ${ }^{17-18}$ Furthermore, within governmental health 
policies there is a growing emphasis on coherent, efficient and cost-effective health systems. ${ }^{19}$ In addition to the effectiveness of preventive interventions, the outcomes of costeffectiveness analyses (CEAs) are becoming more and more important within healthcare decision making. ${ }^{20,21}$ However, to our knowledge, no CEAs on COPMI interventions have yet been performed. ${ }^{22,23}$ Since one of the aims of PBCM is to improve parenting quality and prevent child behavioral problems, it might diminish the need for costly services in the long run. Other studies on preventive parenting programs for vulnerable families (not specifically designed for families of COPMI) have shown long-term economic benefits. For example, Karoly and colleagues (1998) reported governmental savings of up to $\$ 18,000$ for the home visitation program Nurse-Family Partnership, related to better maternal and children's health and effects on the life course such as maternal income, youth criminality and substance abuse. ${ }^{24}$ However, short-term benefits, e.g. fewer emergency room visits and better child development, could potentially already outweigh costs. By creating customized, efficient and optimized basic care packages for families, PBCM may lead to a reduction in costs by reducing overlap among services, which means PBCM is potentially already cost-effective in the short run.

The services which COPMI may encounter are widespread and include both services within the healthcare sector and services in other sectors, such as social (child) care, the educational sector and the criminal justice system. For example, the higher risk of academic underachievement, when borne out, may result in the need for special educational services, and alcohol misuse may result in police contact and arrests. ${ }^{4,25}$ Accordingly, although interventions may present financial expenses in the healthcare sector, considerable costs or benefits (i.e. cost savings) can be expected in other sectors. These are known collectively as intersectoral costs and benefits (ICBs). Drost et al. (2013) identified over seventy different ICBs which can be included in health-related economic evaluations, depending on the type of intervention and the population of the program under study. ${ }^{26}$ Including ICBs within a CEA might affect the outcome of an evaluation, which, in turn, can affect decision making on interventions.

The aim of this study was two-fold. First, the study examined the costs and costeffectiveness of PBCM in comparison with care as usual (CAU) - i.e. basic information about available COPMI-interventions, such as consultation and COPMI groups along with psychiatric treatment. A second aim of this study was to answer the question whether a shift from a narrow (healthcare) perspective to broader perspectives, in which either childcare costs (social care perspective) or childcare costs and other ICBs (societal perspective) were included, results in a change in the cost-effectiveness of PBCM.

\section{Methods}

\section{Trial design}

In a randomized controlled trial (RCT), participants were randomized to either the PBCM condition or the control condition. ${ }^{16}$ Participants in the PBCM condition received preventive 
service coordination, while participants in the control condition received information about COPMI-interventions and had the opportunity to make use of COPMI consultations and COPMI support groups in addition to psychiatric treatment (CAU). The time horizon of the study was eighteen months. Data on the quality of parenting and costs were recorded at baseline (TO) and after nine (T1) and eighteen months (T2). The CEAs in this study were conducted from three perspectives: a) the healthcare perspective, which included costs for health and child/family support services, b) the social care perspective, which also included costs for childcare and c) the societal perspective, which was the most comprehensive and included all measured use of services, including ICBs within the educational sector, the criminal justice system and services for debt restructuring. All analyses included intervention costs.

\section{Participants}

Participants were outpatients of a community mental health institute located in the urban, western part of the Netherlands. Patients with longstanding psychiatric problems and an accumulation of risk factors for poor parenting were selected. Inclusion criteria were: being treated for a psychiatric disorder, being a caregiver for a child aged between three and ten years of age, the parents being interested in PBCM, and the family being exposed to three or more of a list of sixteen risk factors for poor parenting. This list (see Box 5.1) was based on a literature review on the impact of parental mental illness on parenting quality, and on risk and protective factors for poor parenting, child abuse and neglect. ${ }^{15}$ The age was restricted to the phase of life of the primary school age so that the group was more homogeneous. In order to study preventive effects in children, children with a mental health diagnosis (e.g. ADHD, or conduct disorder) were excluded. Other exclusion criteria included an expected duration of less than three months for further therapy, living outside the catchment area and previous help utilizing PBCM. Recruitment took place between September 2010 and April 2012; the last follow-up was between March 2012 and November 2013.

\section{Interventions}

Using a family-focused strength-oriented rehabilitation model, the focus was on strengthening positive parenting and providing community and network support. ${ }^{15,27}$ The PBCM intervention consisted of five steps: 1) the enrolment procedures, in which families were referred by the parent's therapist, 2) a systematic assessment of the strengths and vulnerabilities regarding parenting and children's development based on information from parents, children, school, therapists, and other services involved, 3) the design of an integrated preventive plan for tailored preventive care, which was discussed in a meeting with the parents and the services involved, 4) linking families to and coordinating services for childcare for young children, clubs for older children, community health services, services for debt restructuring and financial resources, and, finally 5) PBCM monitored the 
implementation of the plan and evaluated effects in regular meetings with parents and services. Every family had an own tailored plan, and a personal PBCM coordinator, who monitored whether indicated services were provided. Fidelity was systematically supervised in meetings with colleague-coordinators. The PBCM program ended when parenting and the children's development were sufficient according to the PBCM coordinator and the continuity of the necessary services over a longer period was secured. Further information on the PBCM intervention can be found elsewhere. ${ }^{15}$

In the control condition, all parents received a brochure about the impact of parental problems on children and information about available services, such as free consultations by a COPMI-expert or COPMI groups for parents and children in which they can exchange experiences and learn about coping with the challenges of living with the parental illness. Participation was optional. Parents could refer themselves or their children by calling the COPMI team.

Box 5.1 Risk factors for poor parenting

\begin{tabular}{|ll|}
\hline 1. & single parenthood \\
2. & little support from spouse \\
3. & little network support \\
4. & relational problems \\
5. & partner with mental health problems \\
6. & children with poor health/handicaps/difficult temperament \\
7. & changes in family structure/housing \\
8. & two or more life events in the past two years \\
9. & housing problems \\
10. & poverty or debts \\
11. & parents having been abused as a child \\
12. & severe psychiatric symptoms \\
13. low compliance with psychiatric treatment \\
14. impulse control problems \\
15. alcohol or drug problems \\
16. low intelligence
\end{tabular}

\section{Outcome measure}

The primary outcome measure was quality of parenting. This was measured using the Home Observation for Measurement of the Environment (HOME) Inventory. ${ }^{28,29}$ The HOME is an instrument used widely and internationally to measure the quality and quantity of stimulation and support available to a child in the home environment. This instrument measures the availability and impact of objects, events and interactions with parents and covers four dimensions, namely responsiveness, learning materials, stimulation, and harsh parenting. The HOME has been used worldwide in studies in different cultures, sometimes adapted to local child rearing beliefs and practices. These studies showed consistent relations between most items and children's adaptive functioning. ${ }^{30}$ We used the 'InfantToddler', 'Early Childhood', 'Middle Childhood' and 'Early Adolescent' versions of Vedder, Eldering and Bradley (1995), ${ }^{31}$ which was used in studies with ethnic minorities in 
the Netherlands. Items and content differ for different age groups. Items were scored as binary (yes/no) by a trained interviewer. The score was based on observations and a semi-structured interview with the parent and focal child during a home visit of one hour (in Dutch, Turkish or Moroccan). Following the recommendation in the $\mathrm{HOME} \mathrm{manual}_{,}{ }^{28}$ three interviewers were trained in vivo by the first author. We reached an inter-observer agreement of $96 \%$ (i.e. the percentage of items that both observers scored the same in a joint observation).

Furthermore, several sample characteristics were assessed at TO. These included primary patient (mother and/or father), family structure (single-, two-parent family), diagnosis and disease progression of parent(s) (depressive and anxiety disorders, other Axis I disorders, personality disorders, comorbidity, severity of illness, chronic course of illness), ethnicity (Dutch, Moroccan, Turkish, Surinamese, Netherlands Antilles, other), children (number of children, age and gender of index child), number of risk factors and receiving social benefits (yes/no).

\section{Resource usage and costing}

Costs were related to running PBCM or CAU (intervention costs) and to utilization of services. Costs were measured irrespective of who bears them and were indexed (in $€$ ) for the reference year 2012 using price indices from Statistics Netherlands. ${ }^{32}$ Cost prices used for calculation can be obtained via supplementary material which is published online (Additional file 5.1).

\section{Intervention costs}

Intervention costs were calculated based on the average time spent by human resources needed to execute PBCM or CAU. The measurement of PBCM intervention costs was based on the time investment of the $\mathrm{PBCM}$ coordinator, plus the time investment by other professionals in the meetings. Information on the time invested in PBCM was retrieved from the medical records, counting all telephone calls, reported e-mail exchanges, home visits, face-to-face contact of the PBCM coordinator with parents or the family, and coordination meetings. Time spent by the coordinator on telephone calls and e-mails was valued at $€ 23.90$ per contact. Series of several telephone calls or mails (three or more) were valued at $€ 95.61$, face-to-face contacts were valued at $€ 119.51$, home visits by PBCM including traveling time at $€ 191.22$ and coordination meetings were valued at $€ 191.22$. The price rate of PBCM is the tariff as billed by the organization for integral costs, which includes gross salary costs plus overhead. We used one standard tariff for professionals for participating in the coordination meetings, namely €95.61.

The costs of the control intervention included optional participation in consultation and COPMI groups. Cost units for COPMI were the number of consultations as reported in the medical records (€95.61) and participation in the COPMI groups by parents or children $(€ 350)$. Costs for psychiatric treatment are included in the healthcare service costs (see below). 


\section{Costs related to utilization of services}

Costs related to the family's utilization of services (healthcare costs, childcare costs, and other intersectoral costs) were measured by interviewing the parents, using a study-specific family support questionnaire (Dutch Services and Support Questionnaire, Vragenlijst Hulp en Ondersteuning, $\mathrm{VHO}$ ). The $\mathrm{VHO}$ was based on the Trimbos/iMTA questionnaire for Costs associated with Psychiatric Illness (TiC-P), ${ }^{33,34}$ with an appended list of services from the PBCM manual. ${ }^{27}$ The questionnaire was tested on five families and adapted to make it feasible in practice. Within the questions, we used a three-month time frame for highly frequent, inexpensive services, such as childcare services, and a six-month time frame for less frequent, highly expensive services, such as hospital admissions. The total service costs for each family were estimated by multiplying the quantity of each type of resource with its relevant cost price. ${ }^{35}$

\section{Health service costs}

Health service costs included costs related to the use of mental healthcare, other primary and secondary care, youth care, such as youth care agencies and preventive family support. Most costs were calculated by multiplying the units (contacts, sessions, hours) with the standard cost prices as noted in the Dutch guidelines for health economic research and the manual of the iMTA questionnaire on intensive youth care. ${ }^{36,37}$ When these sources did not report prices for specific services, cost prices were drawn from reports of the Dutch Healthcare Authority and the National Health Tariffs Act or the Netherlands Youth Institute. ${ }^{38,39}$ When these reports did not provide cost prices for measured services, costs were estimated based on equivalent services for which cost prices were available.

\section{Childcare costs}

Childcare included day care (professional childcare) and babysitter (informal childcare). Cost prices for professional and informal childcare were drawn from the Dutch guidelines for health economic research. ${ }^{37}$

\section{Intersectoral costs}

In addition to childcare services, other ICBs were measured. These included services in the educational sector, such as costs for special education, services in the criminal justice sector, such as costs for court proceedings, police services, and costs for debt restructuring services. These were calculated by multiplying the units (contacts, sessions, hours) with the prices provided by a Dutch manual for ICBs. ${ }^{40}$. When the manual did not provide the required cost prices, these cost prices were estimated based on valuation techniques described in the manual or, if available, drawn from the manual of the iMTA questionnaire on intensive youth care. ${ }^{36}$ 


\section{Randomization}

After having given written informed consent, ninety-nine families were randomized on a 50-50 ratio, by drawing an envelope from a container; the envelopes contained either information about the PBCM condition or information about the control condition. After randomization, 49 families were assigned to the PBCM condition and 50 were assigned to the control condition by the researcher.

\section{Data preparation for analysis}

Missing values and invalid scores of the items of the $\mathrm{HOME}$ and $\mathrm{VHO}$ were checked with the interviewer. Of the entered data, 10\% were double scored and checked for differences. Outliers and missing values in the total scores on the HOME were analyzed using the Missing Values Analysis in SPSS. Less than 5\% of the items of the HOME were missing. No outliers were found. Missing items of the HOME were imputed with the mean of the scores at TO, T1 and T2. Missing assessments of the HOME at T1 and T2 were imputed using the expectation maximization technique (EM) in SPSS. Because of differences in content and number of items in each age version of the $H O M E$, we calculated standardized T-scores, range $0-100$ and $S D=10$, as suggested by Bradley (2009, February 12, personal communication) and De Beurs (2010). ${ }^{41}$ A higher T-score means better parenting quality.

If costing data were missing for $\mathrm{T} 1$ or $\mathrm{T} 2$, the mean costs of the other two measures (TO and $\mathrm{T} 1$ or T2) for that family were imputed. If a family dropped out after baseline, the mean costs of the total group at T1 and T2 were imputed. Subsequently, measured costs were extrapolated. ${ }^{42}$ To cover the period of nine months, costs were extrapolated by multiplying the costs related to highly frequent inexpensive services times three and the costs related to less frequent, highly expensive services times 1.5. Extrapolated costs for services measured at $\mathrm{T} 1$ and $\mathrm{T} 2$ were aggregated to cover the whole follow-up period of eighteen months, which were then used for the analyses.

\section{Analyses}

Descriptive statistics were used to describe the characteristics of the sample at baseline. Differences between the groups were assessed using t-tests for continuous variables and chi-square tests for discrete variables in spss. From all three perspectives, for both conditions the costs were significantly tailed to the right $(p<0.01)$; skewness scores for the control and intervention condition were respectively 2.46 and 1.69 (healthcare perspective), 1.93 and 1.20 (social care perspective), and 1.67 and 1.05 (societal perspective). Skewed data is common among costing studies. ${ }^{43}$ To determine the costeffectiveness of PBCM, incremental cost-effectiveness ratios (ICERs) were calculated from all three perspectives (healthcare, social care and societal). Results are presented in costeffectiveness planes and cost-effectiveness acceptability curves (CEACs). ${ }^{35,44}$ 
Box 5.2 The incremental cost-effectiveness ratio, the cost-effectiveness plane and the cost-effectiveness acceptability curve

The ICER is a ratio comparing the additional costs and effects in the experimental intervention with the control intervention. ICERs were calculated using the formula:

$$
\text { ICER }=\frac{\left(C_{i}-C_{c}\right)}{\left(E_{i}-E_{c}\right)}
$$

In this study, $C$ represents the average total costs per family during the whole follow-up period of eighteen months, and $E$ represents the mean difference between the HOME score at T2 and the HOME score at TO in the PBCM condition (subscript i) and control condition (subscript c).

Stochastic uncertainty in the data was dealt with using non-parametric bootstraps. By using the bootstrapping technique in Excel, the original sample was re-sampled, which resulted in 5000 simulated ICERs per scenario. These were plotted in cost-effectiveness planes (Figure 5.2a,b,c). These planes provide a visual representation on the probability of PBCM being cost-effective in comparison with the control condition (the 0,0 coordinate) by showing the distribution of simulated ICERs across four quadrants: 1) the Northeast (NE) quadrant, which means that the intervention is more effective and more costly than CAU, 2) the Southeast (SE) quadrant, indicating that the intervention is more effective and less costly, 3) the Southwest (SW) quadrant, indicating that the intervention is less effective and less costly and 4) the Northwest (NW) quadrant, indicating that the intervention is less effective and more costly.

An ICER in the SE and NW quadrant is negative, which represents the situation in which the intervention is either clearly dominant over (SE) or inferior to (NW) CAU. An ICER in the SW or NE quadrant is positive, which means, from a cost-effectiveness perspective, that the intervention is more favorable than the control condition only when the ICER is lower than the maximum willingness to pay (WTP max) per unit effect. The WTP max is the maximum expense a society is willing to pay for better outcomes (parenting quality, in this study). Since no acknowledged threshold, i.e. WTP max, is available for the HOME outcome measure, a CEAC was created for each perspective (Figure 5.2d,e,f). The CEAC shows the likelihood of PBCM being favorable over the control intervention for several different hypothetical maximum WTPs.

\section{Sensitivity analysis}

For each perspective, several additional sensitivity analyses were performed to test the robustness of the ICERs calculated in the base case scenario. First, to examine the impact of cost outliers (i.e. high cost families) on the calculated cost-effectiveness, ICERs were calculated based on data in which the top $5 \%$ cost outliers were excluded (alternative scenario A). Second, to assess the impact of imputation, the same analyses were conducted on complete cases (alternative scenario B). Third, to examine the effects of implementing the intervention, a subgroup analysis (alternative scenario $\mathrm{C}$ ) was carried out on the sample that actually received PBCM $(\mathrm{N}=38)$ (see flow chart, Figure 5.1). Finally, apart from the routine unadjusted base case scenario, CEAs should include an alternative scenario in which baseline cost differences are adjusted. ${ }^{43}$ To adjust for baseline cost differences between the two conditions in this study, ICERs were calculated based on mean difference adjustments (alternative scenario D). By using this method, the mean difference in costs between conditions at baseline is first extrapolated to equal the length of the follow-up period (i.e. 18 months), and subsequently subtracted from the total postrandomization costs (intervention costs and costs for services after randomization) of the condition with the highest baseline costs. ${ }^{43}$ The base case scenario and alternative scenarios resulted in a total of fifteen ICERs. Finally, we compared reported contacts with 
registered community mental health service contacts to estimate the reliability of selfreporting.

\section{Results}

\section{Participant flow}

As can be seen in the flow chart (Figure 5.1), families were recruited in two steps. In the first step, researchers screened each therapist's caseload for eligible families, using the exclusion criteria. This resulted in 497 patients, who were approached by letter, in which the therapists asked the patients for permission to be contacted by the researchers. In the second step, the researchers contacted 256 eligible and interested families, checked whether the parent(s) were interested in PBCM, and checked all inclusion- and exclusion criteria. Ninety-nine families were included and randomly allocated to either PBCM ( $n=49)$ or to the control condition $(n=50)$. Of the 49 families allocated to PBCM, $38(77 \%)$ actually did receive the intervention. The reasons for not receiving PBCM were: PBCM was not indicated according to the PBCM coordinator, treatment was terminated, the parents withdrew consent at the start, or the PBCM coordinator was not able to contact parents. Of the 50 families in the control group, 22 (44\%) made use of the COPMI team for consultation or of COPMI groups, and two were also referred to the PBCM intervention. Dropout was low in both arms (Figure 5.1), namely four of the 49 families in the PBCM group and three of the 50 in the control group $\left({ }^{2}=.18, d f=1, p=0.68\right)$, and these were not related to characteristics or outcome measures. At baseline, 99 files were available, 86 files were available at the second assessment, and 88 files at the third assessment. A total of 82 families (83\%) had complete datasets for the HOME.

\section{Baseline data}

As shown in Table 5.1, in most families the mother was the primary patient, and most parents were diagnosed with depressive or anxiety disorders. Half of the families included were single parents, and two-thirds were of ethnic minorities. The mean number of children was 2.1, and most children were of primary school age. The mean T-score on HOME was 50 (an average score compared with the population norm in the manual ${ }^{28}$ ), and the mean number of risk factors was five on a scale of sixteen. The PBCM group contained significantly more single parent families, more families from ethnic minorities, and the mean age of the index child was significantly higher than in the control group. The groups did not differ on other aspects. 


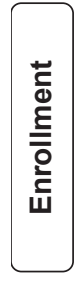

step 1: Assessed by therapist for eligibility and informed by letter $(n=497)$

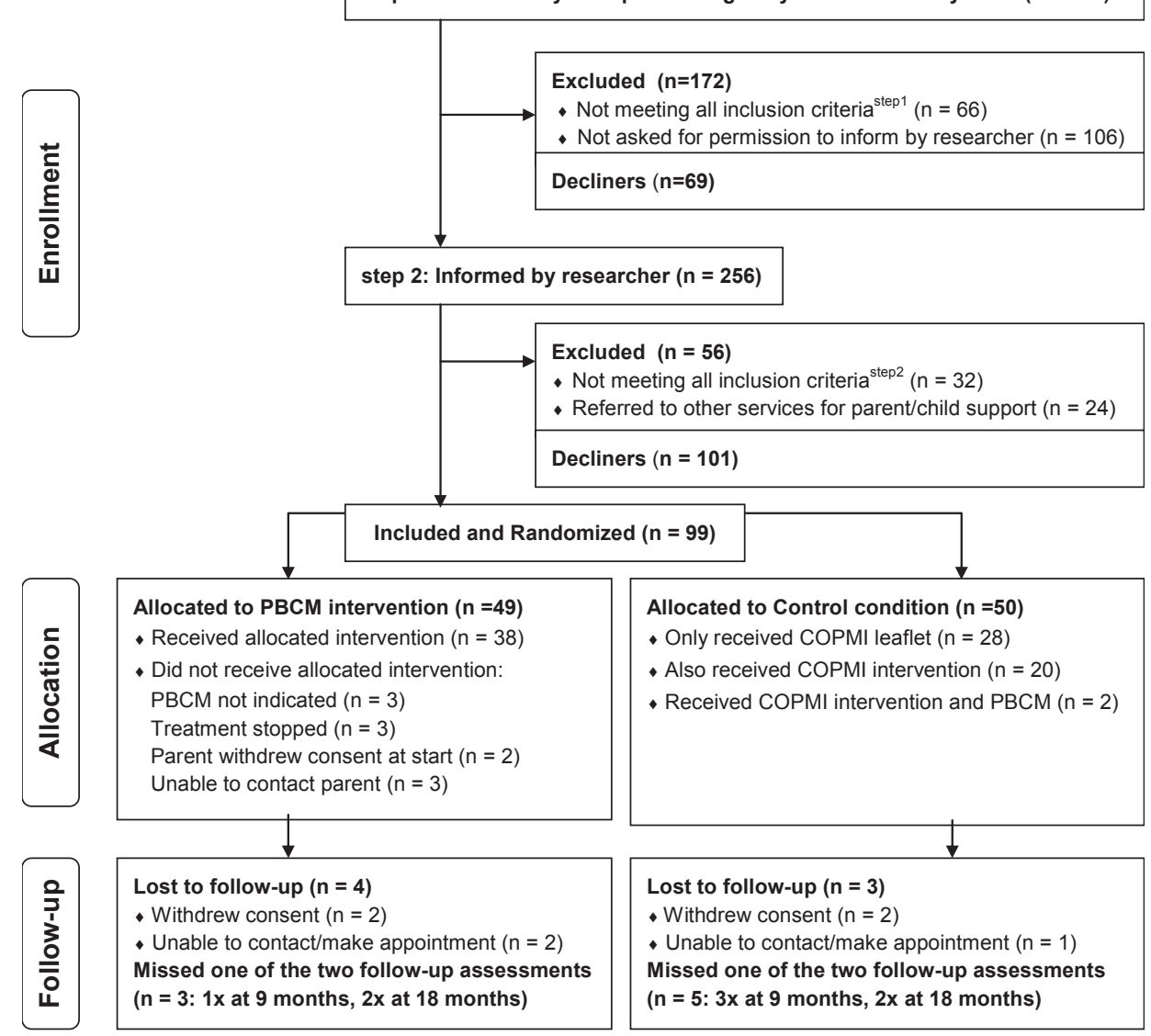

Figure 5.1 Flow chart of the participating families through recruitment and the study

Information about excluded patients and decliners: In step 1, 106 families were not contacted by the researcher due to lack of continuity or ending of contact between therapist and patient, or not being able to contact them in person by phone. In step 2, 32 families were found to be ineligible because the children were not in the required age category or because the child had been diagnosed with mental health problems; 24 families were referred by the researchers to relevant parental support services or child services; and 101 families declined to participate, mostly because they were not interested in support or in participating in a research project

\section{Costs}

The mean intervention costs for PBCM $(n=49)$ were $€ 1,685$, and mean costs for the control condition ( $n=50$ ) were $€ 229$ (Table 5.2). Intervention costs for the subgroup of allocated families who did receive the intervention were $€ 2,053$ in the PBCM group $(n=38)$ and $€ 285$ for the control group ( $n=22)$ (data not shown). Therefore, depending on the approach, the intervention costs of PBCM are $1,456(n=49)$ or $€ 1,768(n=38)$ more costly in comparison with CAU. 


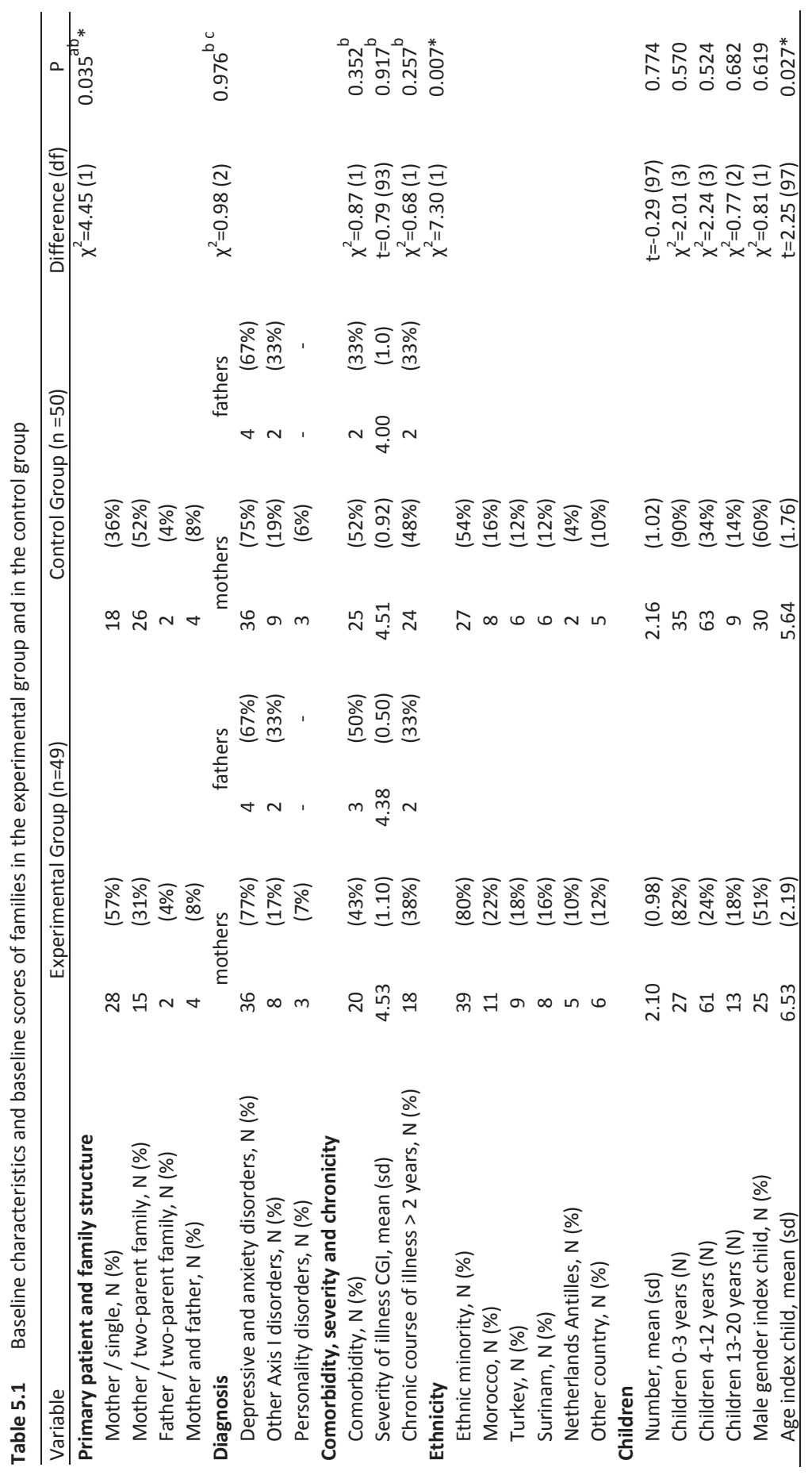




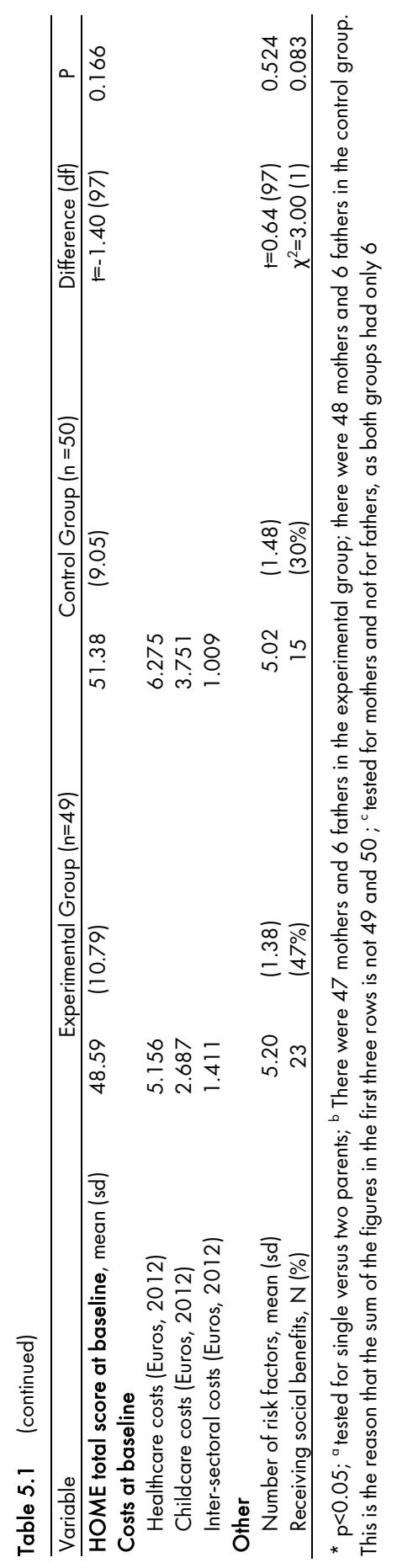




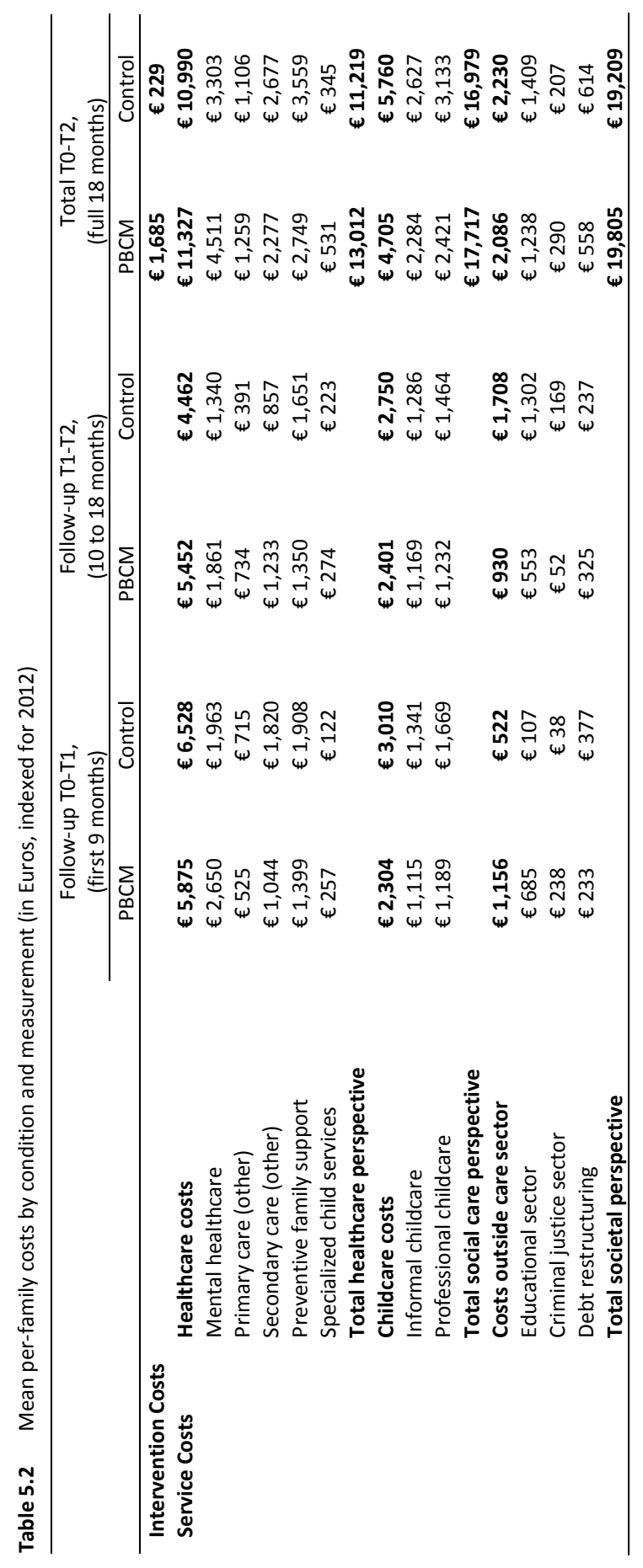


During the whole follow-up period of eighteen months, the mean healthcare costs per family in the PBCM condition were $€ 11,327$, which was higher than in the control condition $(€ 10,990)$. Childcare costs were lower in the PBCM condition, namely $€ 4,705$ versus $€ 5,760$ in the control condition. The same goes for costs in other sectors, where mean costs in the PBCM condition were $€ 2,086$ and mean costs in the control condition were $€ 2,230$. Table 5.2 also provides the mean per-family costs from each perspective (intervention costs plus costs for use of services), which were used for calculating the ICERs. Differences in costs between $\mathrm{T} 1$ and $\mathrm{T} 2$, such as differences in costs in the educational sector, can be explained by irregular use of services.

\section{Incremental costs}

Table 5.3 (upper panel) shows costs per condition for the base case scenario. The difference in average per-family costs between the PBCM and control condition varies for each of the three perspectives, namely $€ 1,793$ from the healthcare perspective, $€ 738$ from the social care perspective and $€ 596$ from the societal perspective. For each perspective, costs were higher in the PBCM condition.

\section{Incremental effects}

Table 5.3 (upper panel) shows the effects per condition for the base case scenario. PBCM had a positive effect on parenting quality, with an increase of the HOME T-score of 1.93 from 48.59 (SD 10.79) at baseline to 50.52 (SD 11.92) after eighteen months. In the control condition the HOME T-score decreased by 1.89 points, from 51.38 (SD 9.05) to 49.49 (SD 6.48). The mean incremental effect per family between the PBCM and control condition was, therefore, 3.82 , and did not change with perspective, since the change of perspective within the base case scenario stipulated only a change in costs.

\section{Incremental cost-effectiveness}

From all three perspectives, costs per unit of the outcome measure (HOME T-score) were higher for the PBCM condition in comparison with the control condition. Since PBCM was more effective than CAU, this resulted in positive ICERs (Table 5.3, upper panel). However, ICERs differ for each perspective, varying from $€ 461$ (healthcare perspective) to $€ 215$ (social care perspective) to $€ 175$ (societal perspective) per one point improvement on the HOME T-score. Differences can be explained by healthcare costs being higher and childcare costs and costs in other sectors being lower for the PBCM condition in comparison with the control condition (Table 5.2).

The cost-effectiveness planes (Figures 5.2a,b,c) show differences in distributions of the 5,000 simulated ICERs across the four quadrants between the CEAs carried out from the three perspectives. Corresponding with median ICERs presented in Table 5.3, the majority of simulated ICERs are located in the NE quadrant. However, the distribution of the simulated ICERs among the two eastern quadrants differs among the perspectives. Notable 
is the shift of the cloud of ICERs towards the SE quadrant in the analysis carried out from the societal perspective $(39 \%)$ and the social care perspective $(37 \%)$ in comparison with the analysis carried out from the healthcare perspective (20\%).

Table 5.3 Summary statistics of the base case analyses and sensitivity analyses from three perspectives

\begin{tabular}{|c|c|c|c|c|c|c|c|c|}
\hline Perspective $^{a}$ & Condition & Costs, $€^{b}$ & Effect $^{c}$ & ICER $^{d}$ & Northeast & $\begin{array}{l}\text { Northwest } \\
\text { (inferior) }\end{array}$ & Southwest & $\begin{array}{l}\text { Southeast } \\
\text { (dominant) }\end{array}$ \\
\hline \multicolumn{9}{|c|}{$\begin{array}{l}\text { Base case scenario } \\
\text { (imputed data, including cost outliers') }\end{array}$} \\
\hline \multirow[t]{2}{*}{ Healthcare } & Control $(n=50)$ & 11,219 & -1.89 & & & & & \\
\hline & $\mathrm{PBCM}(n=49)$ & 13,012 & 1.93 & 461 & $78 \%$ & $2 \%$ & $1 \%$ & $20 \%$ \\
\hline \multirow[t]{2}{*}{ Social care } & Control $(n=50)$ & 16,979 & -1.89 & & & & & \\
\hline & $\operatorname{PBCM}(n=49)$ & 17,717 & 1.93 & 215 & $60 \%$ & $1 \%$ & $1 \%$ & $37 \%$ \\
\hline \multirow[t]{2}{*}{ Societal } & Control $(n=50)$ & 19,209 & -1.89 & & & & & \\
\hline & $\mathrm{PBCM}(n=49)$ & 19,805 & 1.93 & 175 & $59 \%$ & $1 \%$ & $1 \%$ & $39 \%$ \\
\hline \multicolumn{9}{|c|}{ Alternative scenario A } \\
\hline \multicolumn{9}{|c|}{ (imputed data, excluding cost outliers) } \\
\hline \multirow[t]{2}{*}{ Healthcare } & Control $(n=4 \lambda)$ & 8,969 & -1.28 & & & & & \\
\hline & $\operatorname{PBCM}(n=4 \lambda)$ & 11,564 & 1.70 & 776 & $90 \%$ & $6 \%$ & $0 \%$ & $4 \%$ \\
\hline \multirow[t]{2}{*}{ Social care } & Control $(n=4 \lambda)$ & 14,422 & -1.40 & & & & & \\
\hline & $\operatorname{PBCM}(n=4 \lambda)$ & 16,138 & 1.70 & 517 & $81 \%$ & $4 \%$ & $1 \%$ & $15 \%$ \\
\hline \multirow[t]{2}{*}{ Societal } & Control $(n=4 \lambda)$ & 16,634 & -1.82 & & & & & \\
\hline & $\mathrm{PBCM}(n=4 \lambda)$ & 18,194 & 1.70 & 410 & $76 \%$ & $3 \%$ & $1 \%$ & $21 \%$ \\
\hline \multicolumn{9}{|c|}{ Alternative scenario B } \\
\hline \multirow[t]{2}{*}{ Healthcare } & Control $(n=47)$ & 11,475 & -2.06 & & & & & \\
\hline & $\operatorname{PBCM}(n=47)$ & 13,480 & 2.34 & 446 & $79 \%$ & $1 \%$ & $0 \%$ & $20 \%$ \\
\hline \multirow[t]{2}{*}{ Social care } & Control $(n=47)$ & 17,765 & -2.06 & & & & & \\
\hline & $\operatorname{PBCM}(n=47)$ & 18,375 & 2.34 & 133 & $58 \%$ & $1 \%$ & $1 \%$ & $40 \%$ \\
\hline \multirow[t]{2}{*}{ Societal } & Control $(n=47)$ & 20,242 & -2.06 & & & & & \\
\hline & $\operatorname{PBCM}(n=47)$ & 19,621 & 2.34 & dominant ${ }^{f}$ & $41 \%$ & $0 \%$ & $1 \%$ & $58 \%$ \\
\hline \multicolumn{9}{|c|}{ Alternative scenario $\mathrm{C}$} \\
\hline \multicolumn{9}{|c|}{ (imputed data, including cost outliers, PBCM-families who received the intervention) } \\
\hline \multirow[t]{2}{*}{ Healthcare } & Control $(n=48)$ & 10,933 & -1.65 & & & & & \\
\hline & $\operatorname{PBCM}(n=38)$ & 14,579 & 2.24 & 897 & $93 \%$ & $2 \%$ & $0 \%$ & $5 \%$ \\
\hline \multirow[t]{2}{*}{ Social care } & Control $(n=48)$ & 16,140 & -1.65 & & & & & \\
\hline & $\operatorname{PBCM}(n=38)$ & 19,522 & 2.24 & 843 & $90 \%$ & $2 \%$ & $0 \%$ & $8 \%$ \\
\hline \multirow[t]{2}{*}{ Societal } & Control $(n=48)$ & 18,458 & -1.65 & & & & & \\
\hline & $\operatorname{PBCM}(n=38)$ & 20,736 & 2.24 & 558 & $79 \%$ & $2 \%$ & $0 \%$ & $20 \%$ \\
\hline \multicolumn{9}{|c|}{ Alternative scenario D } \\
\hline \multicolumn{9}{|c|}{ (imputed data, including cost outliers, mean difference adjustment) } \\
\hline \multirow[t]{2}{*}{ Healthcare } & Control $(n=50)$ & 8,981 & -1.89 & & & & & \\
\hline & $\mathrm{PBCM}(n=49)$ & 13,012 & 1.93 & 1,031 & $95 \%$ & $2 \%$ & $0 \%$ & $3 \%$ \\
\hline \multirow[t]{2}{*}{ Social care } & Control $(n=50)$ & 12,613 & -1.89 & & & & & \\
\hline & $\operatorname{PBCM}(n=49)$ & 17,717 & 1.93 & 1,313 & $96 \%$ & $2 \%$ & $0 \%$ & $2 \%$ \\
\hline \multirow[t]{2}{*}{ Societal } & Control $(n=50)$ & 15,647 & -1.89 & & & & & \\
\hline & $\mathrm{PBCM}(n=49)$ & 19,804 & 1.93 & 1,059 & $92 \%$ & $2 \%$ & $0 \%$ & $6 \%$ \\
\hline
\end{tabular}

a In the analyses either 1) intervention and healthcare and costs (healthcare perspective), 2) intervention, healthcare and child care costs (social care perspective) or 3) all measured costs (societal perspective) were included; ${ }^{b}$ Costs per family at 2012 prices; ${ }^{c}$ Average effectiveness (T-score) compared with the baseline assessment; ${ }^{d}$ The presented median ICER is the 50 th percentile of 5000 bootstrap replications of the ICER; ${ }^{e}$ Differences in effects between the three perspectives are caused by the exclusion of cost outliers, which differed among the three perspectives; ${ }^{f}$ Lower incremental costs and a positive incremental effect of PBCM in comparison with the control condition leads to a negative ICER, which means that PBCM is superior to the control condition on cost-effectiveness 
The percentages mentioned above equal the probabilities of PBCM being costeffective at a WTP max of $€ 0$ - i.e. the situation in which one is not willing to pay for this intervention - in the CEACs (Figures 5.2d,e,f), and explain why for low WTP thresholds the probability of $\mathrm{PBCM}$ being cost-effective over the control intervention is lower from a healthcare perspective than it is from broader perspectives. However, since for all three perspectives the vast majority of simulated incremental effects are in the NE, all CEACs rise when the WTP max increases and all asymptote close to $100 \%$ around $€ 2,500$. The probabilities of PBCM being cost-effective do not differ among perspectives for WTP thresholds higher than $€ 2,500$ (Figures 5.2d,e,f).

\section{Sensitivity analysis}

The results of the sensitivity analyses are presented in the second to fifth panel of Table 5.3. In scenario A (second panel), ICERs were higher than in the base case scenario. This can be explained by the fact that in all three perspectives, the majority of cost outliers - three or four out of the five excluded - were families in the control condition. In scenario B (third panel), in which incomplete cases were removed before data was analyzed, ICERs were lower than in the base case scenario. The analysis conducted from a societal perspective resulted in an ICER of -143 , with $58 \%$ of the cloud situated in the SE quadrant, and was therefore marked as 'dominant' in Table 5.3. Scenario C - i.e. the subgroup analyses (fourth panel) - resulted in ICERs higher than in the base case scenario. In all these scenarios, ICERs were highest from the healthcare perspective and lowest from the societal perspective. In scenario D (fifth panel), in which the analyses were performed based on mean baseline difference adjustments, the ICERs were highest in all scenarios, varying from $€ 1,031$ (healthcare perspective) to $€ 1,313$ (social care perspective) to $€ 1,059$ (societal perspective). This can be explained by the higher baseline costs in the control condition for all three perspectives. Cost-effectiveness planes and CEACs of the sensitivity analyses can be obtained via supplementary material which is published online (Additional File 5.2). To estimate the reliability of self-reporting, we compared reported contacts with registered community mental health service contacts. These showed a significant underreporting of $€ 1,543$ in the follow-up period $(t=4.06, d f=87, p=0.000)$. No differences in underreporting were found between the intervention and control condition $(t=1.09, d f=86$, $p=0.278$ ). No correction for underreporting was made in the analyses of costs and ICERs. 


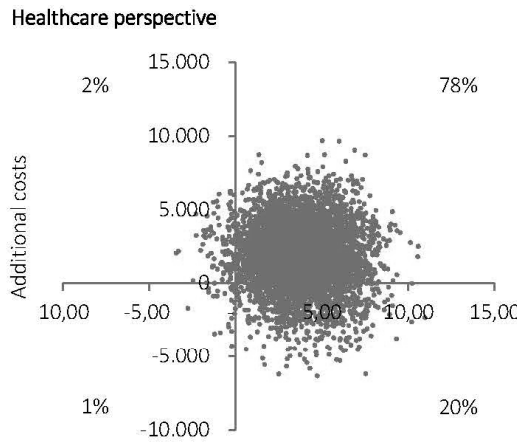

a

Additional effects

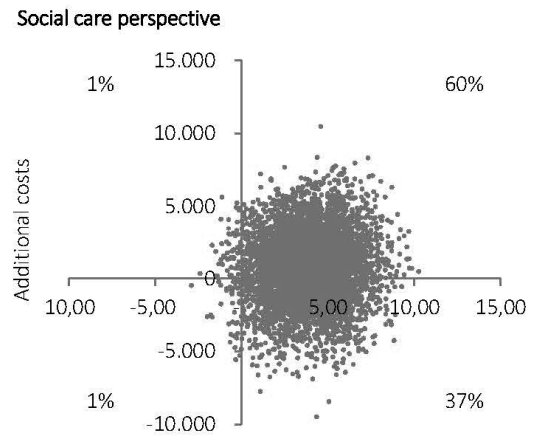

b

Additional effects

\section{Societal perspective}

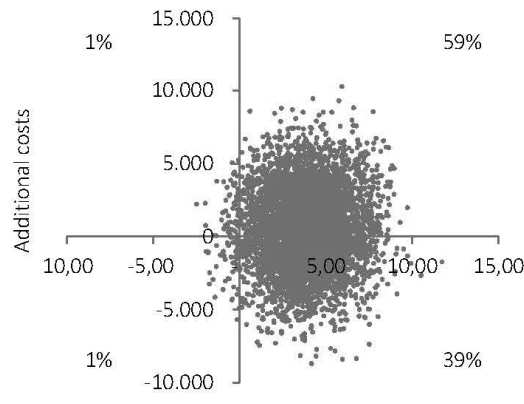

c

Additional effects

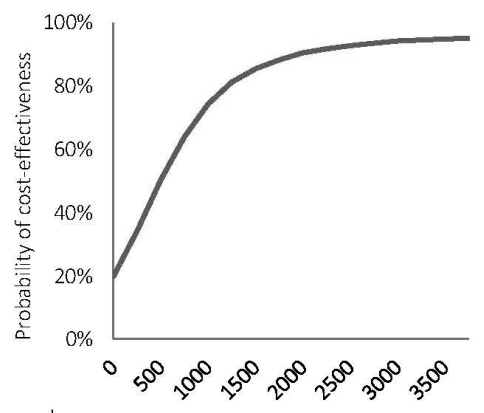

d Willingness to pay; $€ /$ point on T-score

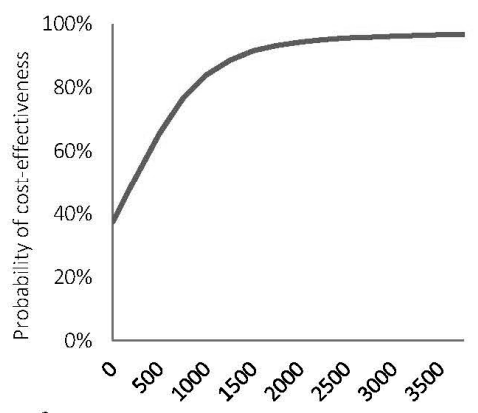

e Willingness to pay; $€$ / point on T-score

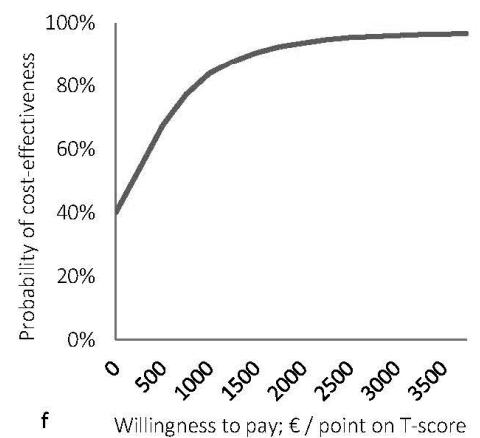

Figure 5.2 Cost-effectiveness planes and CEACs from the three perspectives

Scatterplots of simulated incremental cost-effectiveness ratios $(n=5000)$ on cost-effectiveness planes $(a, b, c)$ and CEACs $(d, e, f)$ for the PBCM versus the control condition from the healthcare perspective $(a, d)$, social care perspective $(b, e)$ and societal perspective $(c, f)$ 


\section{Discussion}

\section{Main findings}

The aim of this study was to (a) examine the costs and cost-effectiveness of PBCM and (b) answer the question whether shifting from a narrow (healthcare) perspective to broader perspectives, in which either childcare costs (social care perspective) or childcare costs and other ICBs (societal perspective) were included, results in a change in the costeffectiveness of PBCM.

Comparing the total costs (intervention costs plus costs of service utilization) in the PBCM group and the control group, the conclusion is that PBCM is more costly. The extra costs of $P B M C$ ranged from $€ 1,793$ from a healthcare perspective to $€ 738$ from a social care perspective to $€ 596$ from a societal perspective. The savings in the last two perspectives can be attributed to lower costs for childcare, debt reconstruction and in the educational sector of the PBCM group in comparison with the control group.

PBCM had better effects on parenting quality than CAU, but also had higher costs. Therefore, ICERs were positive. The cost differences among perspectives are reflected in the ICERs; the ICER is highest in the analysis conducted from the narrowest perspective (healthcare, $€ 461$ ), lower in the analysis conducted from a broader perspective (social, $€ 215$ ), and lowest in the analysis conducted from the broadest perspective (societal, $€ 175)$. Sensitivity analyses based on excluding cost outliers, excluding incomplete cases and the subgroup analysis, confirmed that a broader perspective leads to a lower ICER. It can be concluded that, for this study, the choice of perspective has had an impact on the outcome of the analysis. However, the difference between ICERs is larger between the healthcare perspective and the social care perspective $(€ 246)$ than it is between the social care perspective and the societal perspective (€40). This shows that the impact of including ICBs other than childcare on the outcomes of this CEA was fairly limited. Nevertheless, they did show an impact on the results.

Whether PBCM is considered cost-effective over CAU depends on the WTP max per point gain on the HOME T-score (Figure 5.2d,e,f). The probabilities of PBCM being costeffective start at 20\% (healthcare perspective), 37\% (social care perspective) and 39\% (societal perspective) at a WTP max of $€ 0$ and increase with an increasing WTP max. For thresholds lower than $€ 2,500$, the chances of PBCM being favorable over the control intervention are higher when a broader perspective is adopted. For thresholds higher than $€ 2,500$, there is a near $100 \%$ probability of PBCM being cost-effective regardless of the perspective chosen.

\section{Strengths and limitations}

This study was the first to assess the costs of a preventive family intervention for COPMI families and relate it to parenting outcomes. The strengths of this study are the randomized controlled design and the broad range of sensitivity analyses conducted to test the robustness of the analysis in the base case scenario. The sensitivity analyses were limited to 
costs and not to effects; the analyses showed no outliers on effects and showed no significant baseline differences in the HOME T-scores. Furthermore, the real world setting strengthens the generalizability of the results. The PBCM method and the population in this study represent the state of the art.

The study has several limitations, which should be addressed for the interpretation of the findings. First, no adequate instruments were available to assess the quality adjusted life years (QALYs) of young COPMI. However, the HOME instrument is a valid instrument, used widely and internationally to measure parenting quality, and it can be interpreted as a proxy for quality of life; the HOME measures many aspects of parenting and the home environment which are suggested as being essential within the concept of quality of life for COPMI's physical, emotional, social and material well-being. ${ }^{22}$ Nevertheless, it should be noted that the HOME has ceiling effects, ${ }^{31}$ which may have reduced sensitivity for effects and for PBCM's cost-effectiveness.

Second, although the HOME T-score was a clinically relevant outcome measure for parenting quality, its use within a CEA is new. The lack of clinical cut-off scores impedes interpretation of improvement in parenting quality, in terms of the economic value, for policy making. Also, no thresholds for WTP on costs per unit effect are available for the HOME T-score, as are widely used outcome measures capturing utility such as the QALY. ${ }^{45,46}$ Since the intervention is both more costly and more effective than CAU, the lack of WTP thresholds makes it hard to interpret the economic value of the improvement of parenting quality. However, the CEACs provide decision supportive information because these provide cost-effectiveness probabilities for a wide range of hypothetical thresholds for all analyses. Furthermore, looking at effects, prospective studies on the long-term outcomes of parenting quality (measured by the HOME) showed positive health or societal outcomes. These studies showed low to moderate correlations with (later) child development such as intelligence, academic achievement, school performance, language development, social competence, classroom behavior, peer acceptance, and emotional health. ${ }^{47}$ Furthermore, HOME scores were shown to be related to such health issues as malnutrition, failure-to-thrive, and child abuse. ${ }^{48}$

Third, given limitations regarding the feasibility of assessing the costs for vulnerable parents within an RCT, we chose to focus on services which are important partners for PBCM, such as youth care, childcare, education, and the justice and social systems. Productivity costs in parents were not measured. Including this ICB within the analysis conducted from a societal perspective might have had an influence on the costeffectiveness. Also, self-reported service utilization may have distorted the calculation of costs. As no differences in underreporting were found between the intervention and control condition, the effect of self-reporting on the cost-effectiveness is not obvious. Furthermore, we did not closely monitor the occurrence of waiting lists for the families during the study, though none was reported in the PBCM files. But waiting lists might have obscured the results of this study.

Fourth, differences in the baseline costs of both groups substantially affected ICERs. After adjusting for differences in baseline costs, ICERs climbed to more than $€ 1,000$. The 
differences in costs are probably related to differences in family composition, such as being a one-parent family, and the age of the children. The needs and barriers for different kind of services might vary depending on the family composition. For instance, savings in childcare might also be related to differences in family composition, since the control group contained more young preschool children (35 versus 27). However, it is hard to predict how this affects the total costs. We found no relation between baseline total costs and one/two-parent families, the number of children under the age of four or ethnicity (data not shown). Still, incorporating family characteristics (such as composition, ages of family members) in CEAs remains a challenge, especially in multi-ethnic samples.

Fifth, the study was conducted on a relatively small and rather heterogeneous sample (e.g. parental diagnosis, family composition, ethnicity, and source of income). The effect of scores of single families on variances in effects and costs, such as outliers, might have affected the cost-effectiveness found in this study. This is reflected in the differences between the ICERs in the base case scenario and alternative scenario $A$, where ICERs were calculated excluding cost outliers.

Finally, the chosen time frame of eighteen months might not have been long enough to study all meaningful effects and costs, such as long-term ICBs related to the school career, work or criminality of youngsters. Moreover, the young age of the children and absence of evident behavioral problems may have reduced the chance of finding these ICBs. The need for a long time frame for cost-effectiveness studies on preventive family support has been shown in the Nurse-Family Partnership study. ${ }^{49}$ Long-term prospective studies are needed to explore the effects in children and co-occurring costs in the long run. As a consequence of the limitations described above, it is difficult to determine whether PBCM provides "value for money". Nevertheless, in this study PBCM showed better effects on parenting quality than CAU and this study gives an overall estimate of the additional costs.

\section{Conclusion}

This study is the first economic evaluation of a family-focused preventive COPMI approach in psychiatric and family services. The results of this study show, from both a healthcare and a societal perspective, that the intervention is both more costly and more effective than CAU. Since no WTP study was conducted, no conclusive 'yes' or 'no' can be provided to the question whether the intervention is cost-effective. However, as mentioned earlier, the CEACs provide decision supportive information. Furthermore, the found size of the effect and savings in several sectors support focusing on prevention and on the health of vulnerable children and families in all policies.

The results of our study may be of interest for community policy makers and stakeholders in health policy and youth care when optimizing service systems for COPMI families within a framework of restricted financial resources. It underscores the importance of evaluating costs and benefits in other sectors when planning and evaluating innovative integrative services for children or families at risk. However, before implementing PBCM on a wider scale, replication studies, preferably along with cost-utility analyses measuring 
costs, benefits and QALYs of young COPMI, and multi-center studies of case management programs for COPMI families are needed. These studies could also help to gain insight over the various effects and the economic costs and benefits in subgroups, to better indicate which families are best served. Studies in systems with lower provision of and/or accessibility to services in different countries are needed, since the current Dutch service system is one of the richest and egalitarian ones in the world, with good accessibility for poor families. This study punctuates the importance of choosing a broad societal perspective in economic evaluations. ICBs should be and already are increasingly considered in underpinning (the financing of) health policies. 


\section{References}

1. Beardslee WR, Versage EM, Gladstone TR: Children of affectively ill parents: a review of the past 10 years. Journal of the American Academy of Child and Adolescent Psychiatry 1998;37(1 1):1 134-41.

2. Bijl RV, Cuijpers P, Smit F: Psychiatric disorders in adult children of parents with a history of psychopathology. Soc Psychiatry Psychiatr Epidemio/2002;37(1):7-12.

3. Rutter M, Quinton D: Parental psychiatric disorder: effects on children. Psychol Med 1984, 14(4):853-880.

4. Sameroff AJ: Ecological perspectives on developmental risk. In: WAIMH handbook of infant mental health: Infant mental health in groups at high risk. Volume 4, edn. New York, NY: Wiley; 2000.

5. Weissman MM, Wickramaratne P, Nomura Y, Warner V, Pilowsky D, Verdeli H: Offspring of depressed parents: 20 years later. Am J Psychiatry 2006; 163(6):1001-8.

6. McLaughlin KA, Gadermann AM, Hwang I, Sampson NA, Al-Hamzawi A, Andrade LH, Angermeyer MC, Benjet C, Bromet EJ, Bruffaerts R et al: Parent psychopathology and offspring mental disorders: results from the WHO World Mental Health Surveys. BrJ Psychiatry $2012 ; 200(4): 290-9$.

7. Olfson M, Marcus SC, Druss B, Pincus HA, Weissman MM: Parental depression, child mental health problems, and health care utilization. Med Care 2003;41(6):716-21.

8. Sytema S, Gunther N, Reelick F, Drukker M, Pijl B, Van ' $t$ Land H: Verkenningen in de kinder- en jeugdpsychiatrie. Een bijdrage uit de psychiatrische casusregisters Rijnmond, Zuid-Limburg en NoordNederland. [Explorations in child and adolescent psychiatry, contributions from the psychiatric case registers Rijnmond, Zuid-Limburg and Noord-Nederland.] Utrecht: Trimbos Institute; 2006.

9. Oyserman D, Mowbray CT, Meares PA, Firminger KB: Parenting among mothers with a serious mental illness. The American journal of orthopsychiatry 2000;70(3):296-315.

10. Cobussen M, Hammink A, De Graaf I, Wits E, De Mheen D: Toeleiding naar zorg bij kindermishandeling. [Child abuse and reference to care.] Rotterdam: IVO; 2014.

11. WHO: Mental Health Action Plan 2013-2020. Geneva: World Health Organization; 2013.

12. Nicholson J, Biebel K, Williams VF, Katz-Leavy J: Prevalence of parenthood in adults with mental illness: Implications for state and federal policy, programs, and providers., Rockville, Maryland: Psychiatry Publications and Presentations, Vol. 153; 2002.

13. Lauritzen $C$ : The importance of intervening in adult mental health services when patients are parents. Journal of Hospital Administration 2014;3(6):1-10.

14. De Graaf R, Ten Have M, Van Dorsselaer S: De psychische gezondheid van de Nederlandse bevolking. NEMESIS-2: Opzet en eerste resultaten. [The mental health of the Dutch population. NEMESIS 2: Design and first results.] Utrecht: Trimbos Netherlands Institute for Mental Health and Addiction; 2010.

15. Wansink HJ, Hosman CM, Janssens JM, Hoencamp E, Willems WJ: Preventive family service coordination for parents with a mental illness in the Netherlands. Psychiatric rehabilitation journa/2014;37(3):216-21.

16. Wansink HJ, Janssens JMAM, Hoencamp E, Middelkoop BJC, Hosman CMH: Effects of preventive family service coordination for parents with mental illnesses and their children, a RCT. Families, Systems, \& Health 2015;33(2): $110-9$.

17. Nicholson J, Henry AD: Achieving the goal of evidence-based psychiatric rehabilitation practices for mothers with mental illnesses. Psychiatric rehabilitation journa/2003;27(2): 122-30.

18. Falkov A: The family model handbook, an integrated approach to supporting mentally ill parents and their children. Hove, Sussex: Pavilion Publishing; 2012.

19. OECD: Health care systems: Getting more value for money. Paris: Organisation for Economic Co-operation and Development, Economics Department; 2010.

20. Power EJ, Eisenberg JM: Are we ready to use cost-effectiveness analysis in health care decision-making? A health services research challenge for clinicians, patients, health care systems, and public policy. Med Care 1998;36(5 Suppl):MS10-47.

21. Russell LB, Gold MR, Siegel JE, Daniels N, Weinstein MC: The role of cost-effectiveness analysis in health and medicine. Panel on cost-effectiveness in health and medicine. JAMA 1996;276(14):1172-7.

22. Bee P, Bower P, Byford S, Churchill R, Calam R, Stallard P, Pryjmachuk S, Berzins K, Cary M, Wan M et at. The clinical effectiveness, cost-effectiveness and acceptability of community-based interventions aimed at improving or maintaining quality of life in children of parents with serious mental illness: a systematic review. Health Technol Assess 2014;18(8):1-250. 
23. Woolderink M, Smit F, Van der Zanden R, Beecham J, Knapp M, Paulus A, Evers S: Design of an internetbased health economic evaluation of a preventive group-intervention for children of parents with mental illness or substance use disorders. BMC Public Health 2010;10:470.

24. Karoly LA, Greenwood PW, Everingham SS, Hoube J, Kilburn MR, Rydell CP et at: Investing in our children: What we know and don't know about the costs and benefits of early childhood interventions. Santa Monica, CA: RAND Corporation; 1998.

25. Solis JM, Shadur JM, Burns AR, Hussong AM: Understanding the diverse needs of children whose parents abuse substances. Current drug abuse reviews 2012;5(2):135-47.

26. Drost RMWA, Paulus ATG, Ruwaard D, Evers SMAA: Intersectoral costs and benefits of mental health prevention: towards a new classification scheme. J Ment Health Policy Econ 2013; 16(4):179-86.

27. Wansink HJ, Hosman $\mathrm{CMH}$, Verdoold CJ: Basiszorg, een handleiding: Preventieve zorgcoördinatie voor ouders met psychiatrische problemen. [Basic care, a manual: Preventive basic care manamgement for parent with psychiatric problems.] The Hague: Parnassia Bavo Group, Prevention Department; 2010.

28. Caldwell BM, Bradley RH: Home observation for measurement of the environment: Administration manual. Tempe: Family \& Human Dynamics Research Institute, Arizona State University; 2003.

29. HOME inventory [http://fhdri.clas.asu.edu/home/inventory.html].

30. Bradley RH, Corwyn RF: Caring for children around the world: A view from HOME. Int J Behav Dev 2005; 29(6):468-78.

31. Vedder P, Eldering L, Bradley RH: The home environments of at risk children in the Netherlands. In: Advances in family research. edn. Amsterdam: Thesis Publishers; 1995: 69-76.

32. CBS Statline [http://statline.cbs.nl/statweb/]

33. Bouwmans C, De Jong K, Timman R, Zijlstra-Vlasveld M, Van der Feltz-Cornelis C, Tan Swan S, Hakkaartvan Roijen L: Feasibility, reliability and validity of a questionnaire on healthcare consumption and productivity loss in patients with a psychiatric disorder (TiC-P). BMC Health Serv Res 2013;13:217.

34. Trimbos/iMTA questionnaire for costs associated with psychiatric illness (TiC-P adults). Update 2012 [http://www.bmg.eur.nl/fileadmin/ASSETS/bmg/english/iMTA/Publications/Manuals__uestionnair es/Vragenlijsten_2013/Questionnaire_TiC-P_initial_version_in_English.pdf]

35. Drummond M, Sculpher MJ, Claxton K, Stoddart G, Torrance GW: Methods for the economic evaluation of health care programmes. New York: Oxford University Press; 2015.

36. iMTA Questionnaire Intensive Youth Care [https://www.bmg.eur.nl/fileadmin/ASSETS/bmg/Onderzoek/Onderzoeksrapporten__Working_Pap ers/2012.06_-_Handleiding_Vragenlijst_Intensieve_Jeugdzorg.pdf]

37. Hakkaart-van Roijen L, Tan SS, Bouwmans CA: Handleiding voor kostenonderzoek. Methoden en referentieprijzen voor economische evaluaties in de gezondheidszorg. Geactualiseerde versie 2010. [Manual for studying costs. Methods and reference prices for economic evaluations in health care. Update 2010]. Diemen: College voor Zorgverzekeringen; 2011.

38. Normprijzenonderzoek jeugd \& opvoedhulp Noord-Brabant. [Standard pricing research for youth care and parenting support Noord-Brabant.]

[http://www.nji.nl/nl/Normprijzen_jeugd_opvoedhulp_Brabant.pdf]

39. NZA: Prestatiebeschrijvingen en tarieven extramurale zorg 2012. [Standards and rates for outpatient care in 2012.] In: Policy letter CA-300-487. 2012.

40. Drost RMWA, Paulus ATG, Ruwaard D, Evers SMAA: Handleiding intersectorale kosten en baten van (preventieve) interventies: Classificatie, identificatie en kostprijzen. [Manual on intersectoral costs and benefits of (preventive) interventions: Classification, identification and cost prices.] Maastricht: Maastrich University, Department of Health Services Research; 2014.

41. De Beurs E: De genormaliseerde Tscore: Een euro voor testuitslagen. [The normalized T-score, an 'euro' for test results.] Maandblad Geestelijke volksgezondheid 2010;65(9):684-95.

42. Hendriks MR, AI MJ, Bleijlevens MH, Van Haastregt JC, Crebolder HF, Van Eijk JT, Evers SM: Continuous versus intermittent data collection of health care utilization. Med Decis Making 2013;33(8):998-1008.

43. Van Asselt AD, Van Mastrigt GA, Dirksen CD, Arntz A, Severens JL, Kessels AG: How to deal with cost differences at baseline. Pharmacoeconomics 2009;27(6):519-28.

44. Manca A, Rice N, Sculpher MJ, Briggs AH: Assessing generalisability by location in trial-based costeffectiveness analysis: the use of multilevel models. Health Econ 2005; 14(5): 471-85. 
45. Donaldson C, Baker R, Mason H, Jones-Lee M, Lancsar E, Wildman J, Bateman I, Loomes G, Robinson A, Sugden $\mathrm{R}$ et at: The social value of a QALY: raising the bar or barring the raise? BMC Health Serv Res $2011 ; 11(1): 8$.

46. Neumann PJ, Cohen JT, Weinstein MC: Updating cost-effectiveness - the curious resilience of the $\$ 50,000$ per-QALY threshold. NEng/J Med 2014;371(9):796-7.

47. Wen-Jui $H$, Leventhal T, Linver MR: The Home observation for measurement of the environment (HOME) in middle childhood: A study of three large-scale data sets. Parenting: Science and Practice 2004;4(2): 189-210.

48. Bradley RH: The Home Inventory: Review and reflections. Advances in child development and behavior 1994;25:241-88.

49. Olds DL: The nurse-family partnership: An evidence-based preventive intervention. Infant Mental Health Journa/2006;27(1):5-25.

50. Husereau D, Drummond M, Petrou S, Carswell C, Moher D, Greenberg D, Augustovski F, Briggs AH, Mauskopf J, Loder E et at: Consolidated health economic evaluation reporting standards (CHEERS) statement. BMC medicine 2013;1 1 (1):80. 


\section{Additional file 5.1}

\section{Services and sources for prices}

This categorization of services in Health Care, Youth Care, Child Care and services in other sectors follows the current system in the Netherlands. Health Care and Youth Care are services financed by health insurances and the government for prevention and treatment of somatic, mental, and developmental problems. Child Care is financed by parents themselves for babysitting or kindergarten. Other sectors include the school en criminal system. For each service sources are given for pricing.

\begin{tabular}{|c|c|c|c|}
\hline Category & Included services & Source & Reference, or Alternative Method for pricing (AM) \\
\hline \multicolumn{4}{|c|}{ Health Care } \\
\hline $\begin{array}{l}\text { Mental } \\
\text { health care }\end{array}$ & $\begin{array}{l}\text { primary mental health care, } \\
\text { community mental health services, } \\
\text { psychiatric clinics }\end{array}$ & (1) & $\begin{array}{l}\text { (1) Hakkaart-van Roijen L, Tan SS, Bouwmans CA. } \\
\text { Manual for cost studies. Methods and reference prices } \\
\text { for economic evaluations in health care. Updated } \\
\text { version. [Handleiding voor kostenonderzoek. } \\
\text { Methoden en referentieprijzen voor economische } \\
\text { evaluaties in de gezondheidszorg.] Geactualiseerde } \\
\text { versie } 2010 \text { ]. Diemen: College voor } \\
\text { Zorgverzekeringen, } 2011 \text {. }\end{array}$ \\
\hline \multirow[t]{3}{*}{$\begin{array}{l}\text { Other } \\
\text { Primary } \\
\text { health care }\end{array}$} & $\begin{array}{l}\text { GP, paramedical services, } \\
\text { logopedics, dietician, health and } \\
\text { safety service, social welfare work }\end{array}$ & (1) & \\
\hline & alternative medicine & (2) & $\begin{array}{l}\text { (2) Bouwmans CAM, Schawo SJ, Jansen DEMC, } \\
\text { Vermeulen KM, Reijneveld SA, Hakkaart-van Roijen L. } \\
\text { iMTA Questionnaire Intensive Youth Care } \\
\text { [Handleiding } \\
\text { Vragenlijst Intensieve Jeugdzorg Zorggebruik en } \\
\text { productieverlies]. } 2012 \text {; Available from: } \\
\text { https://www.bmg.eur.nl/fileadmin/ASSETS/bmg/ }\end{array}$ \\
\hline & & & $\begin{array}{l}\text { Onderzoek/Onderzoeksrapporten__Working_Pape } \\
\text { rs/2012.06_- } \\
\text { _Handleiding_Vragenlijst_Intensieve_Jeugdzorg.pdf. }\end{array}$ \\
\hline \multirow[t]{2}{*}{$\begin{array}{l}\text { Other } \\
\text { Secondary } \\
\text { health care }\end{array}$} & $\begin{array}{l}\text { somatic (general/academic) } \\
\text { hospitals, emergency room, } \\
\text { revalidations centers }\end{array}$ & (1) & \\
\hline & $\begin{array}{l}\text { specialized clinics for obesity } \\
\text { specialized burns department }\end{array}$ & AM & $\begin{array}{l}\text { Costs were estimated to be equivalent to costs of } \\
\text { general hospital admissions, of which prices were } \\
\text { given in (1). }\end{array}$ \\
\hline
\end{tabular}




\begin{tabular}{|c|c|c|c|}
\hline Category & Included services & Source & Reference, or Alternative Method for pricing (AM) \\
\hline Youth Care & Youth and Family Centers & $A M$ & Costs were estimated to be equivalent to costs of \\
\hline Preventive & & & personal nursing of which prices were given in (1). \\
\hline Family & domestic services & (1) & \\
\hline Support & preventive home-based family & (3) & (3) Nederlands Jeugd instituut. Prices standard \\
\hline \multirow[t]{22}{*}{ Services } & care & & research Youth and parenting support Noord- \\
\hline & & & Brabant. [Normprijzenonderzoek Jeugd \& \\
\hline & & & Opvoedhulp Noord-Brabant.] Utrecht: NJi, 2010. \\
\hline & & & http://www.nji.nl/nl/Normprijzen_jeugd \\
\hline & & & _opvoedhulp_Brabant.pdf \\
\hline & preventive orthopedagogical & $A M$ & Costs were estimated based on equivalent services for \\
\hline & services (Salvation Army, & & social work, of which cost prices were available in (1) \\
\hline & Preventive Youth Care) & & \\
\hline & parenting classes and parenting & $A M(4)$ & Costs were estimated based on equivalent to domestic \\
\hline & education & & services, of which prices were given in (4) Drost \\
\hline & & & RMWA, Paulus ATG, Ruwaard D, Evers SMAA. \\
\hline & & & Manual intersectoral costs and benefits of (preventive) \\
\hline & & & interventions: Classification, identification and prices. \\
\hline & & & [Handleiding intersectorale kosten en baten van \\
\hline & & & $\begin{array}{l}\text { (preventieve) interventies: Classificatie, identificatie en } \\
\text { kostprijzen.] Maastricht: Maastricht University, }\end{array}$ \\
\hline & & & Department of Health Services Research, 2014. \\
\hline & preventive mental health & $A M$ & Price as billed by the institute www.context.nl \\
\hline & education for children and & & \\
\hline & parents & & \\
\hline & family coaches of Youth and & $A M$ & Costs were estimated based on equivalent services for \\
\hline & Family Centers & & social work, of which cost prices were given in (1). \\
\hline & $\begin{array}{l}\text { home-based family support by } \\
\text { non-professionals }\end{array}$ & $\mathrm{AM}$ & $\begin{array}{l}\text { Costs were estimated based on equivalent services for } \\
\text { domestic services, of which cost prices were given in } \\
\text { (4). }\end{array}$ \\
\hline \multirow{12}{*}{$\begin{array}{l}\text { Youth Care } \\
\text { Specialized } \\
\text { Youth Care } \\
\text { Services }\end{array}$} & youth care services (semi- & (3) & \\
\hline & residential care, residential care), & & \\
\hline & foster care and secure care & (5) & (5) https://www.pleegzorg.nl/media/uploads/ \\
\hline & & & nieuws/indexering_ \\
\hline & & & $\begin{array}{l}\text { pleegvergoeding_2012_staatscourant_stcrt-2011- } \\
23215 . p d f\end{array}$ \\
\hline & $\begin{array}{l}\text { child protection and probation } \\
\text { services }\end{array}$ & $A M$ & $\begin{array}{l}\text { Costs were estimated to be equivalent to costs of } \\
\text { social work, of which prices were given in (1). }\end{array}$ \\
\hline & $\begin{array}{l}\text { Youth Care Agencies (indication } \\
\text { assessment) }\end{array}$ & (1) & \\
\hline & intensive ambulatory home based & (3) & \\
\hline & $\begin{array}{l}\text { specialized support for multi- } \\
\text { problem families }\end{array}$ & & \\
\hline & care for youth with mental & (6) & (6) NZA (2012). BELEIDSREGEL CA-300-487, \\
\hline & and/or cognitive disabilities & & Prestatiebeschrijvingen en tarieven extramurale zorg \\
\hline & & & $\begin{array}{l}\text { 2012, Kenmerk CA- 300-487, Bijlage } 14 \text { bij } \\
\text { circulaire AWBZ/Care/11/9c. }\end{array}$ \\
\hline
\end{tabular}




\begin{tabular}{|c|c|c|c|}
\hline Category & Included services & Source & Reference, or Alternative Method for pricing (AM) \\
\hline \multicolumn{4}{|l|}{ Child Care } \\
\hline Informal Child & child care given by & $(2)$ & \\
\hline Care & $\begin{array}{l}\text { nonprofessionals (babysitter, } \\
\text { granny) }\end{array}$ & & \\
\hline Professional & child care services, such as & (2) & \\
\hline Child Care & kindergarten & & \\
\hline \multicolumn{4}{|l|}{ Other Sectors } \\
\hline Educational & school attendance officer, interne & (4) & \\
\hline sector & $\begin{array}{l}\text { special education teacher, special } \\
\text { education, specialized }\end{array}$ & & \\
\hline & educational services & & \\
\hline $\begin{array}{l}\text { Criminal/justi } \\
\text { ce sector }\end{array}$ & lawyers, police, court & (4) & \\
\hline $\begin{array}{l}\text { Debts } \\
\text { restructuring } \\
\text { services }\end{array}$ & debts restructuring services & $\mathrm{AM}$ & $\begin{array}{l}\text { Costs were estimated to be equivalent to the costs of } \\
\text { social work, of which prices were given in (1). }\end{array}$ \\
\hline
\end{tabular}




\section{Additional file 5.2}

This figure shows the scatterplots of simulated incremental cost-effectiveness ratios $(n=5000)$ on cost-effectiveness planes and CEACs for the PBCM versus the control condition in four alternative scenarios: 1) excluding outliers (alternative scenario A), 2) based on complete cases (alternative scenario B), 3) the sample that actually received the intervention (alternative scenario C) and 4) corrected for baseline cost differences (alternative scenario D). 
Alternative scenario $\mathrm{A}$

Healthcare perspective

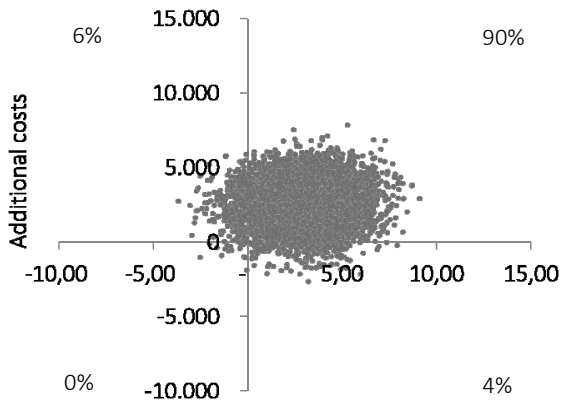

Additional effects

Social care perspective

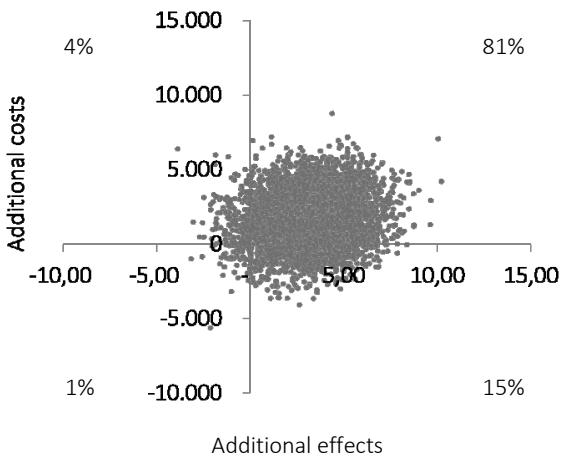

Societal perspective

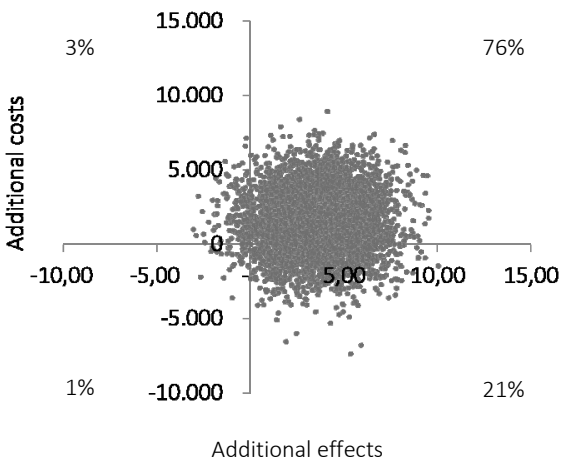

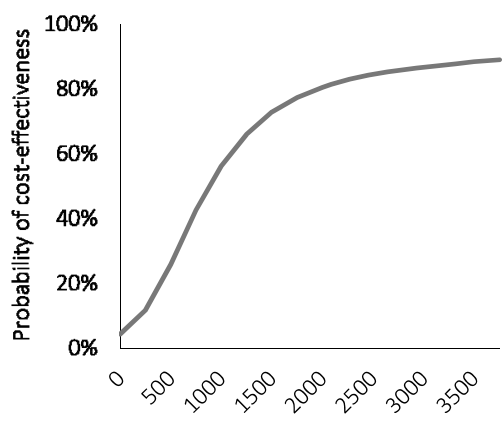

Willingness to pay; $€ /$ point on T-score
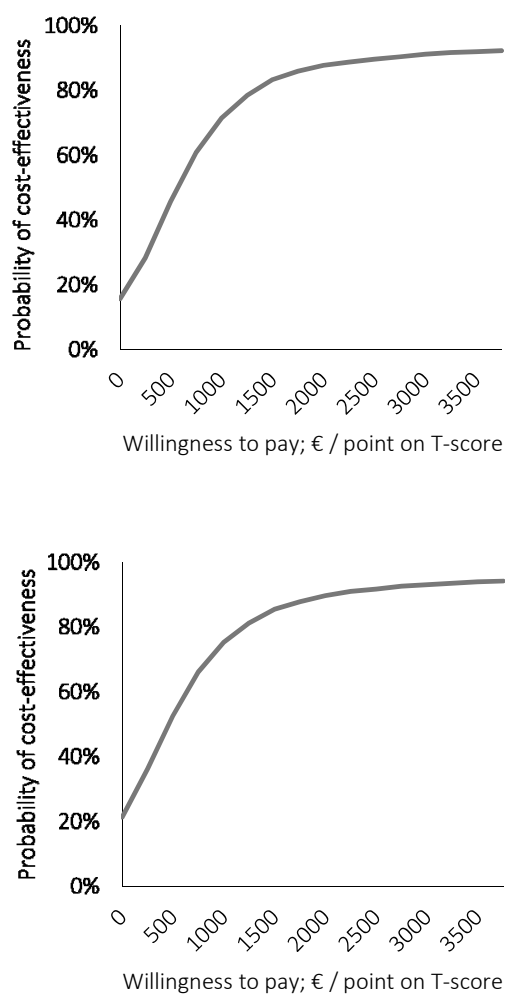
Alternative scenario B

Healthcare perspective

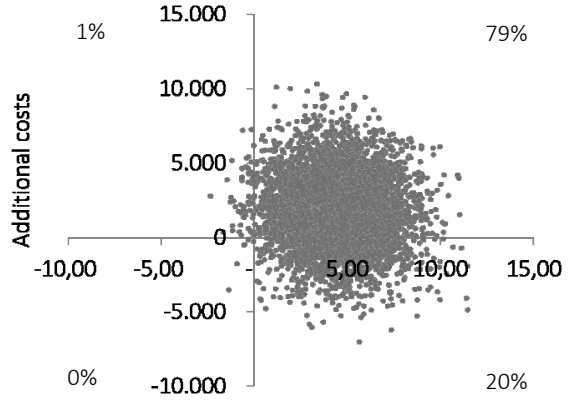

Additional effects

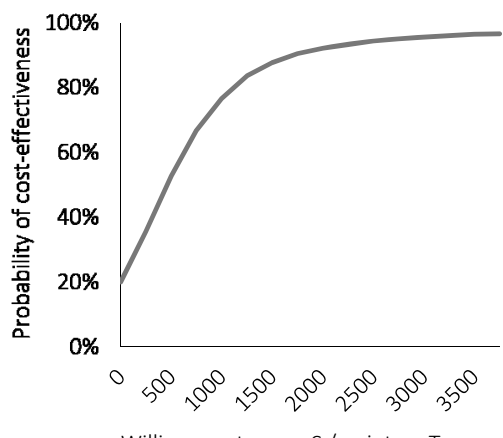

Willingness to pay; $€$ / point on T-score
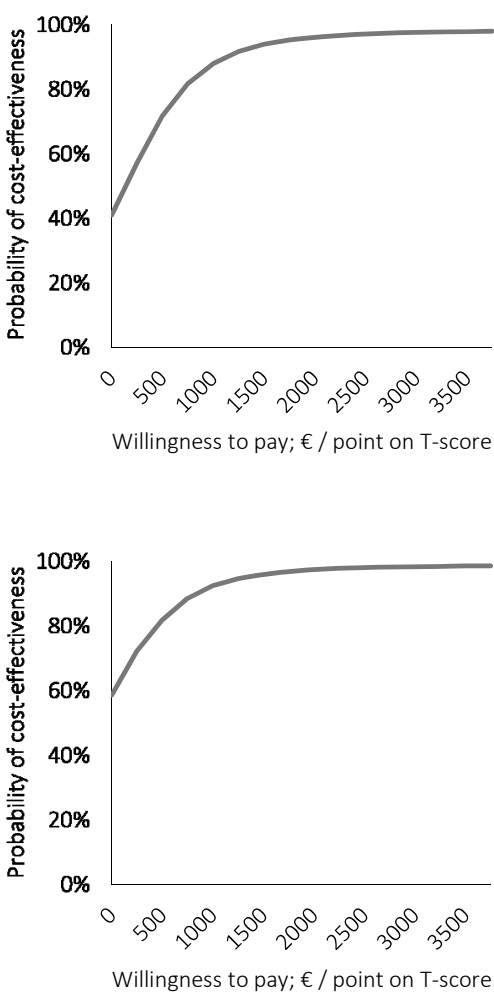

Willingness to pay; $€$ / point on T-score
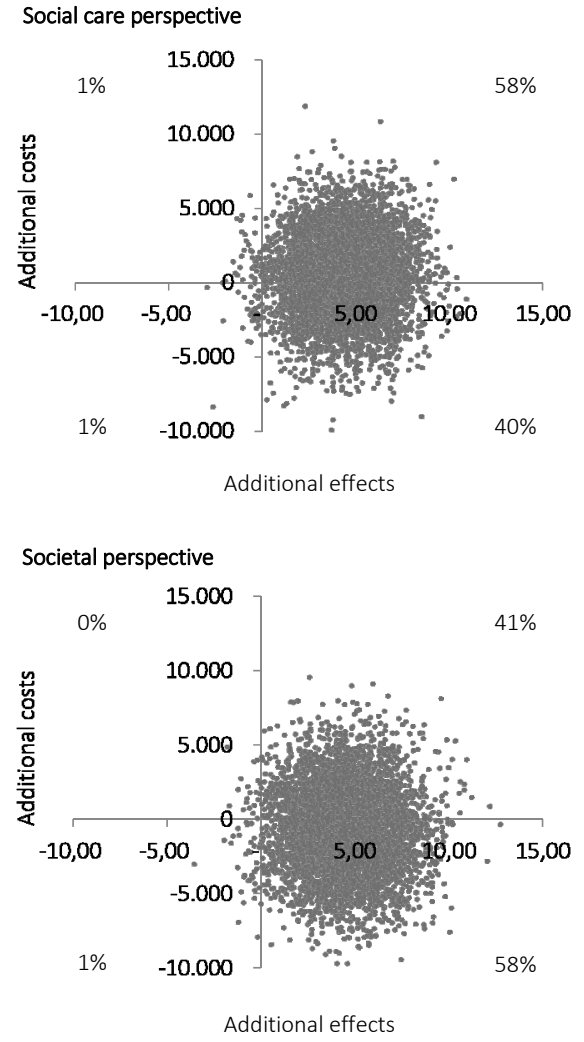
Alternative scenario C

Healthcare perspective

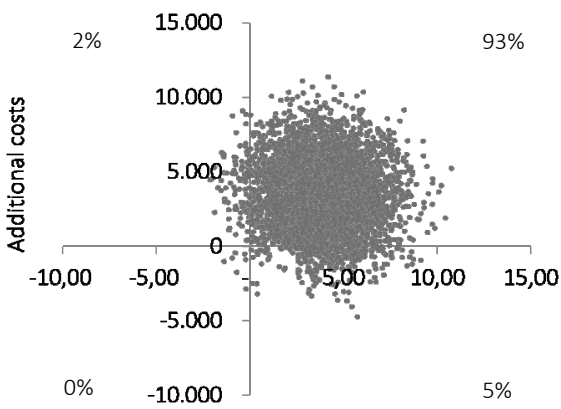

Additional effects

Social care perspective

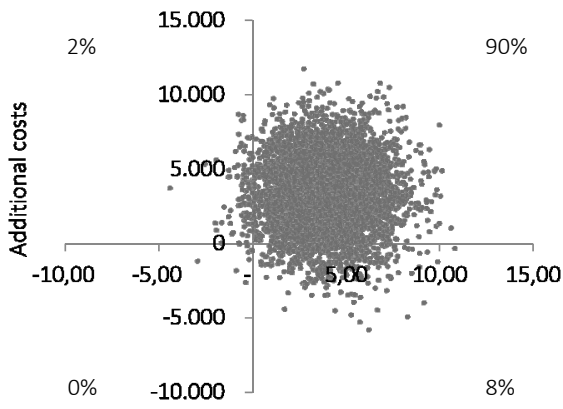

Additional effects

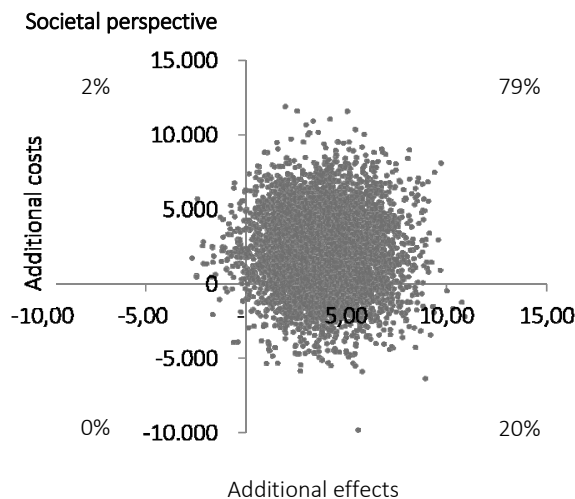

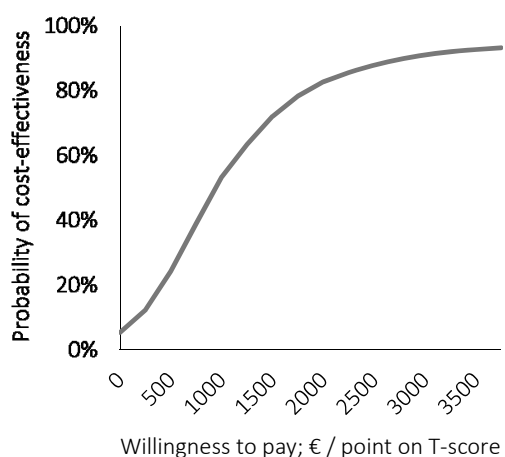
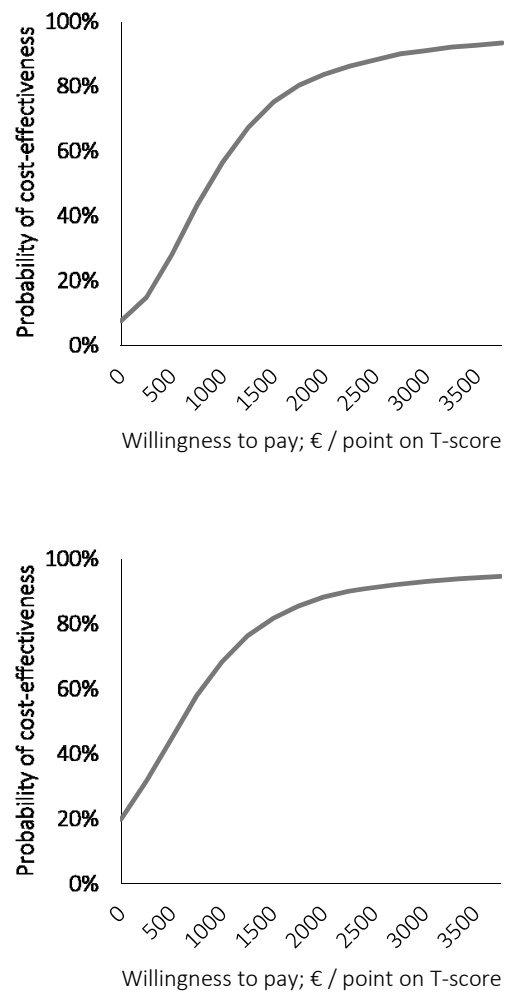


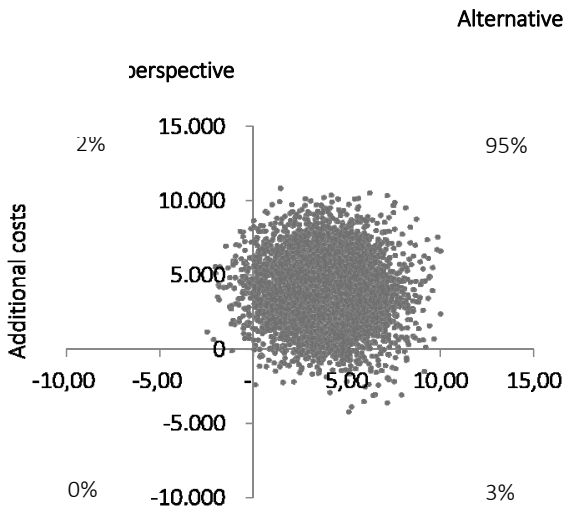

Additional effects

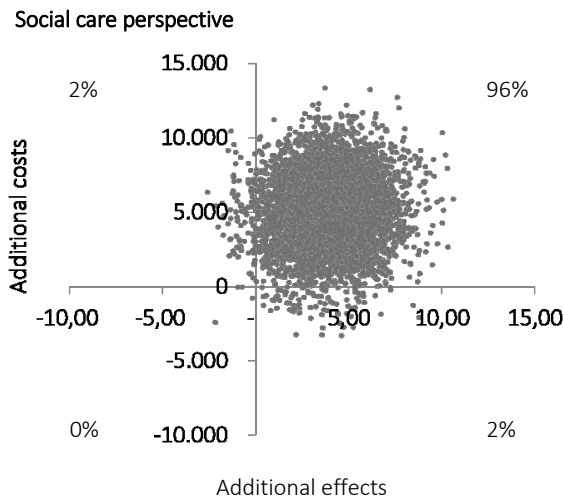

Societal perspective

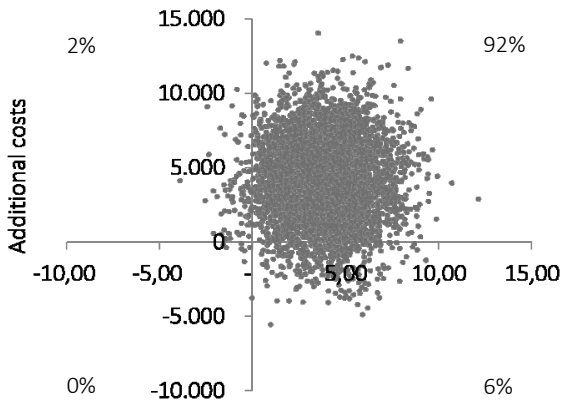

Additional effects
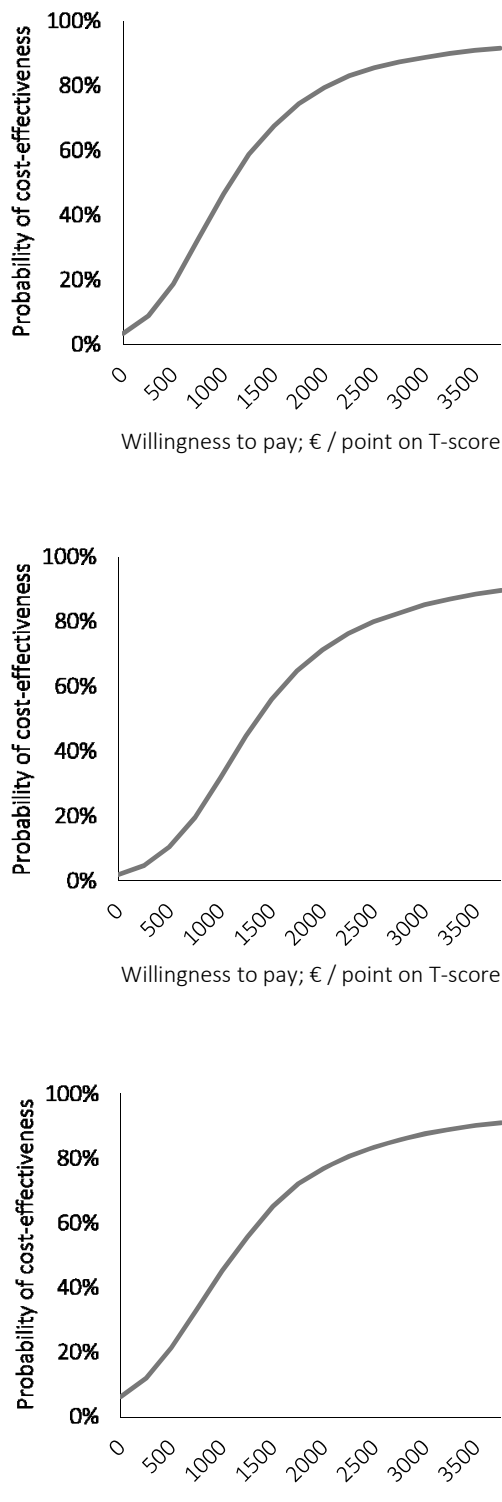

Willingness to pay; $€$ / point on T-score 


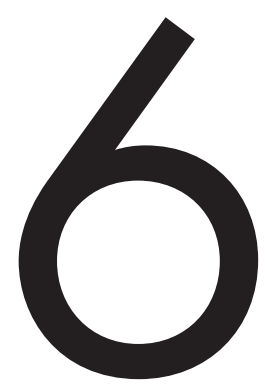

A web-based computer-tailored alcohol prevention program for adolescents: costeffectiveness and intersectoral costs and benefits

This chapter was published as:

Drost RMWA, Paulus ATG, Jander AF, Mercken L, de Vries H, Ruwaard D,

Evers SMAA

A web-based computer-tailored alcohol prevention program for adolescents: costeffectiveness and intersectoral costs and benefits Journal of Medical Internet Research 2016;18(4):e93 


\section{Abstract}

\section{Background}

Preventing excessive alcohol use among adolescents is important not only to foster individual and public health, but also to reduce alcohol-related costs inside and outside the health care sector. Computer tailoring can be both effective and cost-effective for working with many lifestyle behaviors, yet the available information on the cost-effectiveness of computer tailoring for reducing alcohol use by adolescents is limited as is information on the costs and benefits pertaining to sectors outside the health care sector, also known as intersectoral costs and benefits (ICBs).

\section{Objective}

The aim was to assess the cost-effectiveness of a Web-based computer-tailored intervention for reducing alcohol use and binge drinking by adolescents from a health care perspective (excluding ICBs) and from a societal perspective (including ICBs).

\section{Methods}

Data were used from the Alcoholic Alert study, a cluster randomized controlled trial with randomization at the level of schools into two conditions. Participants either played a game with tailored feedback on alcohol awareness after the baseline assessment (intervention condition) or received care as usual (CAU), meaning that they had the opportunity to play the game subsequent to the final measurement (waiting list control condition). Data were recorded at baseline ( $\mathrm{TO}=$ =anuary/February 2014) and after 4 months ( $\mathrm{T} 1=$ May/June 2014) and were used to calculate incremental cost-effectiveness ratios (ICERs), both from a health care perspective and a societal perspective. Stochastic uncertainty in the data was dealt with by using nonparametric bootstraps (5000 simulated replications). Additional sensitivity analyses were conducted based on excluding cost outliers. Subgroup cost-effectiveness analyses were conducted based on several background variables, including gender, age, educational level, religion, and ethnicity.

\section{Results}

From both the health care perspective and the societal perspective, for both outcome measures, the intervention was more costly and more effective in comparison with CAU. ICERs differ for both perspectives, namely $€ 40$ and $€ 79$ from the health care perspective to $€ 62$ and $€ 144$ for the societal perspective per incremental reduction of one glass of alcohol per week and one binge drinking occasion per 30 days, respectively. Subgroup analyses showed, from both perspectives, and for both outcome measures, that the intervention was cost-effective for older adolescents (aged 17-19 years) and those at a lower educational level, and, from a health care perspective, the male and nonreligious adolescent subgroups.

\section{Conclusions}

Computer-tailored feedback could be a cost-effective way to target alcohol use and binge drinking among adolescents. Including ICBs in the economic evaluation had an impact on the costeffectiveness results of the analysis. It could be worthwhile to aim the intervention specifically at specific subgroups. 


\section{Introduction}

Excessive alcohol use and alcohol use disorders are major causes of death and disability worldwide. $^{1-4}$ In 2012, approximately 3.3 million deaths, or $5.9 \%$ of all global deaths, were attributable to alcohol use. ${ }^{4}$ In addition, alcohol use led to an estimated total of 139 million disability-adjusted life years, representing $5.1 \%$ of the global burden of disease and injury in that year. ${ }^{4}$ For all age groups, outliers on the proportion of alcohol-related deaths can be seen in the World Health Organization European Region, varying from $10 \%$ for the population aged 80 years and older to $25 \%$ for the 20 to 39 age group. It is particularly striking that in this region 10\% of adolescent deaths (those aged 15 to 19 years) were attributable to alcohol.

Apart from the impact of alcohol use on morbidity and mortality, the harmful use of alcohol may also lead to significant societal costs. ${ }^{3-7}$ For example, in the European Union alone, alcohol-attributable costs were estimated at $€ 125$ billion in 2003. ${ }^{4}$ These encompass health care services, such as hospitalizations, home health care, and ambulatory care, but also costs outside the health care sector, such as costs resulting from productivity losses and costs in the criminal justice system. Examples of the latter include vehicle crashes, increased crime, and arrests. Studies have shown that youthful drinkers are at greater risk of being victimized and perpetrating youth violence, low educational attainment, and low college expectations, ${ }^{8,9}$ putting a financial burden on the criminal justice system and educational sector.

Preventing excessive alcohol use in the whole population and in the young population in particular is thus important, not only to improve the health of individuals and of the whole population, but also to reduce alcohol-related costs inside and outside the health care sector. Computer tailoring could be a means to achieve these goals. Computer tailoring is a behavioral intervention that can be effective in changing health behaviors in general, including the use of alcohol, ${ }^{10-15}$ Within a computer-tailored intervention, the content is adapted to individual characteristics of respondents. ${ }^{16}$ Often a questionnaire is used as a screening instrument, assessing behavior, relevant sociodemographics, and motivational factors. ${ }^{17,18}$ Respondent answers are collected into a data file and automatically matched with tailored feedback messages. ${ }^{16,19}$ An advantage of tailored information is that it is perceived as more relevant than nontailored information. ${ }^{20,21}$ Moreover, through the Internet, these programs are accessible by a growing percentage of the world population-42.3\% had access to Internet in 2014 in comparison to $5.9 \%$ in $2000^{22}$-and can be accessed wherever and whenever it suits the respondents. For Europe and its younger population (aged 16-24 years), the current Internet penetration is even higher: $70.5 \%{ }^{22}$ and $91.0 \%,{ }^{23}$ respectively. Taking advantage of this high accessibility by providing Internet-based behavior interventions might significantly limit the need for and burden on health professionals and could, in turn, lead to less administrative costs. ${ }^{19}$ Subsequently, the resulting savings of time and resources contributes to a more efficient health care system. 
Although the effectiveness of multiple Internet-based and computer-tailored interventions have been studied, ${ }^{24,25}$ limited information exists on their cost-effectiveness. ${ }^{26}$ To date, studies which have included cost-effectiveness analyses (CEAs) focused on adults aged 18 to 65 years $^{21,27}$ and 18 to 69 years, ${ }^{3}$ whereas the cost-effectiveness of such interventions for adolescents younger than 18 years has not yet been studied. Available economic analyses of interventions aimed at reducing alcohol use among adolescents are those of interventions which are not Internet-based and not computer-tailored. ${ }^{28,29}$ Furthermore, as acknowledged by Smit et al., ${ }^{3}$ these studies show a limitation in terms of disregarding many of the costs and benefits in sectors outside the health care sector, also known as intersectoral costs and benefits $(I C B s) .{ }^{30}$ Excluding $I C B s$, such as costs and benefits in the educational and criminal justice sector, may significantly affect the results of the CEAs of interventions. ${ }^{30}$ Moreover, including and reporting ICBs within economic evaluations could support decision making regarding the large-scale implementation of such programs. Therefore, the aim of this study is to answer the question of whether a Web-based computer-tailored intervention for adolescents for reducing the use of alcohol is cost-effective from both a health care and societal perspective, and to assess the impact of including ICBs on the outcomes of the analysis.

\section{Methods}

\section{Design}

Data used was from the Alcoholic Alert study, which was designed as a cluster randomized controlled trial (RCT) with randomization at the level of schools into two conditions. $^{31}$ Participants either played a game on alcohol awareness after the baseline assessment (intervention condition) or received care as usual (CAU), meaning they had the opportunity to play the game subsequent to the final measurement (waiting list control condition). Providing this opportunity was due to ethical considerations. Data were recorded at baseline ( $\mathrm{TO}=$ January/February 2014) and after 4 months ( $\mathrm{T} 1=$ May/June 2014). These were used to conduct two sets of comparative CEAs; one was performed from a health care perspective (including health care costs, excluding ICBs) and one from a societal perspective (including both health care costs and ICBs). Because of a rapid change in Dutch government policy on the minimum legal drinking age (i.e. 18 years vs. 17 years as of January 1, 2014), the abovementioned time frame and start date differed from the original design. ${ }^{31}$ The Alcoholic Alert study was approved by the Medical Ethics Committee of Atrium Orbis Zuyd (METC number: 12-N-104) and was registered in the Dutch Trial Register (NTR 4048). 


\section{Randomization}

Randomization was performed at school level to prevent contamination between participants. Randomization was conducted by drawing lots. After randomization, 21 schools were assigned to the intervention condition and 23 schools were assigned to the control condition.

\section{Sample}

The study population consisted of Dutch adolescents (aged 15-19 years) attending school. ${ }^{31}$ Participants included students at schools of higher secondary education, lower secondary education, and lower vocational training. To have enough power for the evaluation, a participant target was made based on the following criteria: $10 \%$ reduction in binge drinking occasions (i.e. for girls, at least four glasses or, for boys, five glasses of alcohol-containing drinks in one occasion) ${ }^{32}$ during the preceding 30 days between the intervention and control group, with an intraclass correlation of .02, a power of $80 \%$, and a significance level of .05. Furthermore, taking into account the drop in power due to an expected dropout of $50 \%$ at follow-up, it was estimated that at least 34 schools should be included at TO. ${ }^{31}$

To reach the required number of 34 , schools were recruited via several media; schools first received flyers with information about the Alcoholic Alert study, after which they were contacted via telephone and email. If schools enrolled in the study, students of the schools were eligible to participate. However, they could do so only if they provided informed consent by clicking a checkbox, which preceded the Web-based questionnaire at $\mathrm{TO}^{31}$

\section{Intervention}

Adolescents in the intervention condition participated in a Web-based computer-tailored alcohol reduction program called Alcoholic Alert. ${ }^{31}$ After completing a Web-based questionnaire on the Alcoholic Alert website at TO, the participants entered a game called "Watskeburt" (Dutch slang for "What Happened?!"). In the game, the participant played a character whose goal it was to find out what happened after a night of heavy drinking. Participants received in-game questions concerning alcohol-related sociocognitive factors, including attitude, social influences, self-efficacy expectations, and action plans toward alcohol drinking. These questions were based on the I-Change model, which is an integrated model explaining motivational and behavioral change. ${ }^{33}$ Based on their answers, they received computer-tailored feedback on these determinants. They played in three game scenarios within three sessions. A week after playing the third game scenario, the participants were asked to revisit the intervention website to answer several questions. In this fourth session, they were asked about their drinking behavior during the preceding week and then they received computer-tailored feedback on their alcohol use compared to Dutch drinking guidelines. Subsequently, the participants were asked whether they had an event (eg, party, wedding) in the upcoming 30 days then they were challenged to drink 
less than usual and were asked for the maximum amount they wanted to drink. An email, with a reminder of accepting the challenge, was sent to them a day before the event. Two days after the event, during a fifth session, they were asked to visit the intervention website and fill in their alcohol use. If the participant failed the challenge, they received computertailored feedback with tailored advice and had the opportunity to take on a new challenge. If the participant met the challenge, he or she received congratulations and the intervention was over (Figure 6.1).

Participants receiving CAU also filled in the Web-based questionnaire at TO and T1, but they did not have access to the game and did not receive computer-tailored feedback until after the final measurement. Further information on the intervention can be found elsewhere. $^{31}$

\section{Measurements and outcomes}

The measurements at $\mathrm{TO}$ and $\mathrm{T} 1$ were performed at school after participants received instructions from their teachers. ${ }^{31}$ The Web-based questionnaires used for the measurements included items related to alcohol drinking behavior, use of services within the health care sector, and ICBs. In addition, several background variables were measured at TO, including gender, age, educational level (higher secondary level, lower secondary level, and lower vocational), religion (Catholic, Protestant, Muslim, other religion, no religion), and ethnicity (Dutch, Antillean, Belgian, German, Surinamese, Moroccan, Turkish, other). ${ }^{31}$

In this study, the outcome measures were weekly alcohol use and the number of binge drinking occasions in the preceding 30 days. Weekly alcohol use was assessed by asking participants on which days in the past week they had been drinking and, if they did, how many glasses of alcohol they had on these days. Based on this information, the total amount of glasses of alcohol was calculated. ${ }^{17}$ From this, as for binge drinking occasions, the weekly alcohol use at T1 was subtracted from the alcohol use at TO. This led to positive scores in case of a reduction in weekly alcohol use or number of binge drinking occasions, and negative scores in case weekly alcohol use or the number of binge drinking occasions increased.

\section{Resource use and costing}

The following costs related to the Alcoholic Alert intervention were identified as important and measured: (1) intervention costs, (2) health care costs (i.e. costs for services inside the health care sector), (3) intersectoral costs (ie, costs for services outside the health care sector), and (4) costs of substance use (eg, use of hard drugs). Because alcohol use was the outcome measure in this study, the costs of alcohol use were not included in the CEA. Doing so would have led to double counting. ${ }^{34}$ 


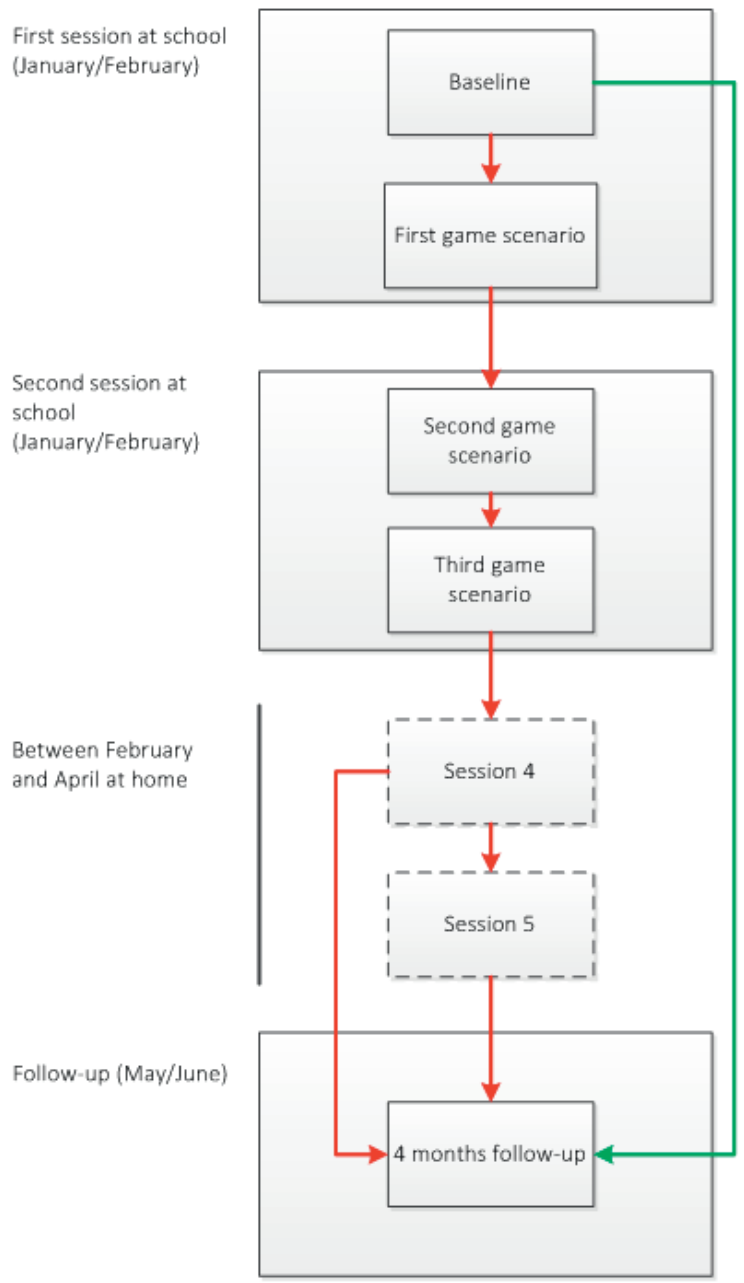

Figure 6.1 Flowchart of the intervention. Based on Jander et al. (2014) $)^{31}$. Red line: routing intervention condition, green line: routing control line, dashed boxes: intervention parts that had to be done at home

Costs (in $€$ ) were measured irrespective of who bore them and were indexed for the reference year 2014 using price indexes from Statistics Netherlands. ${ }^{35}$ Calculations for specific costs of service utilization and substance use can be obtained from the first author (RD).

\section{Intervention costs}

Intervention costs were divided into costs made during the development of the intervention and costs for running the intervention. Costs incurred during the development included 
game development costs $(€ 20,328)$ and automatic tailoring software license and development costs (€8367.15). These costs and costs for other personnel involved in the development and application of the intervention for this study, such as costs incurred contacting schools, recruiting participants, and analyzing data are sunk costs. ${ }^{36}$ Therefore, these are not included in the CEA. This is further justified by the fact that the intervention itself is Web-based and universal for adolescents, meaning the intervention has a wide reach and the development costs per participant drop to a minimum when it is used widely and structurally.

Costs for running the intervention include hosting costs for the website, tailored feedback software, and participants' time investments. As for the sunk costs, the website hosting costs ( $€ 300$ per year) per participant drop to a minimum if used widely and are not included in the CEA. Tailored feedback software costs were $€ 7$ per participant per week. In case the participant met his or her challenge in the fifth session, he or she would receive tailored feedback over a period of 3 to 6 weeks. The mean intervention duration was 4 weeks, so the tailored feedback costs were $€ 28$. The five sessions took up 1.5 hours at school (€8.30 per hour) and 1 hour of free time ( $€ 12.50)$. The total of 2.5 hours was valued at $€ 25$ per participant. In sum, the total intervention costs per participant were an estimated $€ 53$.

\section{Health care costs}

Health care costs were calculated by multiplying volumes of health services by related cost prices. Health services measured included contacts with the general practitioner, emergency care, hospital stays, ambulance rides, and mental health services. Cost prices were drawn from the Dutch manual for costing in economic evaluations. ${ }^{37}$

\section{Intersectoral costs}

The ICB-related costs were calculated by multiplying volumes of services and time investments outside the health care sector with related cost prices. The ICBs were classified in sectors according to a classification scheme for ICBs by Drost et al.. ${ }^{30}$ The sectors in this scheme included education, labor and social security, household and leisure, and criminal justice system. The services and time investments measured included school absenteeism and contacts with an attendance officer (education), work absenteeism (labor and social security), failing to perform household and other activities, contacts with youth and family center and family care (household and leisure), and contacts with (youth) police services, court proceedings, and child (health) protection services (criminal justice system). Cost prices were drawn from a Dutch manual for intersectoral costs and benefits of (preventive) interventions. ${ }^{38}$ Cost prices not mentioned in the manual were extracted from the Institute for Medical Technology Assessment (iMTA) questionnaire on intensive youth care. ${ }^{39}$ For ICBs that required valuation of time, such as failing to perform household activities, some additional information was drawn from the Dutch report "The Netherlands in a Day" (free translation). ${ }^{40}$ 


\section{Costs of substance use}

In addition to alcohol use, use of other substances were measured as well. These included packs of cigarettes, use of soft drugs, and use of hard drugs. Cost prices were found on the website of the Jellinek Clinic, which is a renowned Dutch institution specializing in preventing and treating alcohol and substance abuse. ${ }^{41}$

\section{Data preparation}

The basis of the analysis was the dataset used for the Alcoholic Alert effect study. ${ }^{24}$ However, because cost measures were used for conducting the economic evaluation, some additional data cleaning was required to create a dataset that was suitable for conducting the CEA.

First, because the digital questionnaires contained open-ended questions, participants had the opportunity to fill in unrealistic answers. It was a small subsample that systematically filled in these unrealistic answers, but to improve the validity of the results, these respondents were excluded from analysis. To clear the data of these respondents, limits were set for each variable. Participants breaching these limits by providing unrealistic answers were excluded from analysis. For example, because the 4-month recall period between TO and $\mathrm{T} 1$ amounted to 120 days, any respondent claiming to have stayed more than 120 days in a hospital was excluded. In general, to reduce the chance of wrongfully excluding participants, limits were set high, but within the range of credibility. As for all steps during the process of data preparation and analysis, the limits were discussed in author meetings and were agreed on by all authors. A list of these limits can be obtained in Multimedia Appendix 6.1.

Second, the dataset was cleared of respondents who at baseline did not answer a single question related to costs. Based on these two steps, the sample at TO, and accordingly at $\mathrm{T} 1$, was smaller and different in composition in the CEA than the sample used for the effect study. ${ }^{24}$

Finally, to assess the school-based part of the variance in this cluster RCT, intracluster correlation coefficients (ICCs) were calculated for both the weekly alcohol use and binge drinking occasions outcome measures. The ICCs were calculated based on the following formula:

$$
\operatorname{ICC} \text { or } p=\frac{S_{b}{ }^{2}}{\left(S_{b}{ }^{2}+S_{w}{ }^{2}\right)}
$$

, where $s_{b}{ }^{2}=$ the variance between clusters and $s_{w}{ }^{2}=$ the variance within clusters. ${ }^{42}$ Input for both outcome effect sizes was generated using SPSS version 20 by running linear regression mixed models. These analyses and corresponding calculations resulted in $=.06$ for binge drinking occasions and $=.01$ for weekly alcohol use, which shows that the within-cluster variances for both effect sizes were much greater than the between-cluster variances. ${ }^{42}$ Based on these results, no re-estimations of effects were required. 


\section{Analysis}

\section{Descriptive statistics}

Descriptive statistics were used to describe the characteristics of the sample at TO and at T1. Differences between the intervention and control conditions were assessed in SPSS version 20 using independent samples $t$ tests for continuous variables and chi-square tests for discrete variables. The same software was used to conduct stepwise linear regression analyses to assess the dependence of the outcome measures on these variables.

\section{Cost-Effectiveness Analysis}

The base scenario of this study included CEAs from the two perspectives mentioned earlier. We calculated costs of services utilization in three steps: (1) assessment of the services and time consumed in the 4-month period between TO and T1, (2) calculation of the associated costs in $€$, and (3) calculation of the incremental cost-effectiveness ratio (ICER) using the formula $\left(C_{i}-C_{c}\right) /\left(E_{i}-E_{c}\right)$. Here $C$ represents the average total costs per participant during the 4-month period between $\mathrm{TO}$ and $\mathrm{T} 1$ and $E$ represents the mean difference in the number of glasses of alcohol or binge drinking occasions at $\mathrm{T} 1$ in comparison with the number measured at $T O$ in the intervention $\left(C_{i}\right.$ and $\left.E_{i}\right)$ and in the control $\left(C_{c}\right.$ and $\left.E_{c}\right)$ condition.

Stochastic uncertainty in the data was dealt with using nonparametric bootstraps. By using the bootstrapping technique, means and confidence intervals were calculated and 5000 ICERs were simulated, which were plotted in cost-effectiveness planes. These planes provided a visual representation of the probability of the intervention being cost-effective in comparison with the control condition by showing the distribution of ICERs across four quadrants: (1) more effective and more costly in the northeast quadrant (NE), (2) more effective and less costly in the southeast quadrant (SE), (3) less effective and less costly in the southwest quadrant (SW), and (4) less effective and more costly in the northwest quadrant (NW). ${ }^{43}$

An ICER in the SE and NW is negative, indicating that the intervention is dominant over (SE) or inferior to (NW) the control condition. An ICER in the SW or NE is positive, indicating that from a cost-effectiveness viewpoint the intervention is more favorable than the control condition only when the ICER is lower than the willingness to pay (WTP) per unit effect. Because no threshold (ie, maximum WTP) was available for the weekly alcohol use outcome measure, a cost-effectiveness acceptability curve (CEAC) was created for both perspectives. The CEAC showed the likelihood of the intervention being favorable over CAU for several hypothetical thresholds.

\section{Sensitivity and subgroup analyses}

Apart from the analyses to deal with stochastic uncertainty, several other analyses were conducted. First, to assess the impact of cost outliers, ICERs were calculated based on data in which cost outliers were excluded. Based on the output of descriptive statistics, it was decided to exclude participants when total costs were greater than $€ 5000$. Based on this 
approach, in the analyses that were conducted from the health care perspective, one participant was excluded. In the analyses that were conducted from the societal perspective, four participants were excluded. Second, to assess the effect of the uptake, the costs of cigarette use, and of the use of soft and hard drugs in the analyses conducted from the societal perspective, additional analyses were conducted without these costs.

Finally, given the heterogenic composition of the study sample, several subgroup CEAs were conducted based on the background variables measured at TO. These included analyses based on dichotomized background variables, including gender (male, female), age (15-16, 217), educational level (low, high), religion (religious, not religious), and ethnicity (Dutch, non-Dutch). Again, for all these analyses, stochastic uncertainty was dealt with using nonparametric bootstraps.

\section{Results}

\section{Dropout and sample characteristics}

Figure 6.2 shows a flowchart with the number of participating schools and adolescents at TO and T1. In total, 44 schools were randomized into the control condition or intervention condition. Of the schools randomized to the control condition, five withdrew their participation before TO (one secondary lower education, one lower vocational training, two secondary higher education, one secondary education mixed). In addition, three schools in the control condition (all secondary higher education) and two schools in the intervention condition (one lower vocational education, one higher secondary education) did not start the baseline assessment and did not respond to the emails and phone calls. ${ }^{24}$

In total, 2649 adolescents from 34 schools participated in the baseline questionnaire. Of these, and different from the effect study, ${ }^{24}$ an additional 91 participants (3.4\%) were excluded from analysis based on providing unrealistic answers to the cost questions. Another 65 participants were excluded from analysis because they did not answer the cost questions at TO. This resulted in 2493 adolescents who were included in the baseline analysis. Of these, 1538 were in the intervention condition and 955 were in the control condition (Figure 6.2). The $t$ tests and chi-square tests conducted on the baseline sample showed that the adolescents in the two conditions significantly differed on multiple characteristics. Adolescents in the intervention condition were significantly younger, more often female, had a higher educational level, more often indicated being religious, were less likely to be a drinker, were less often a binge drinker, had less binge drinking occasions, and had a lower weekly alcohol use than adolescents in the control condition (Table 6.1). 


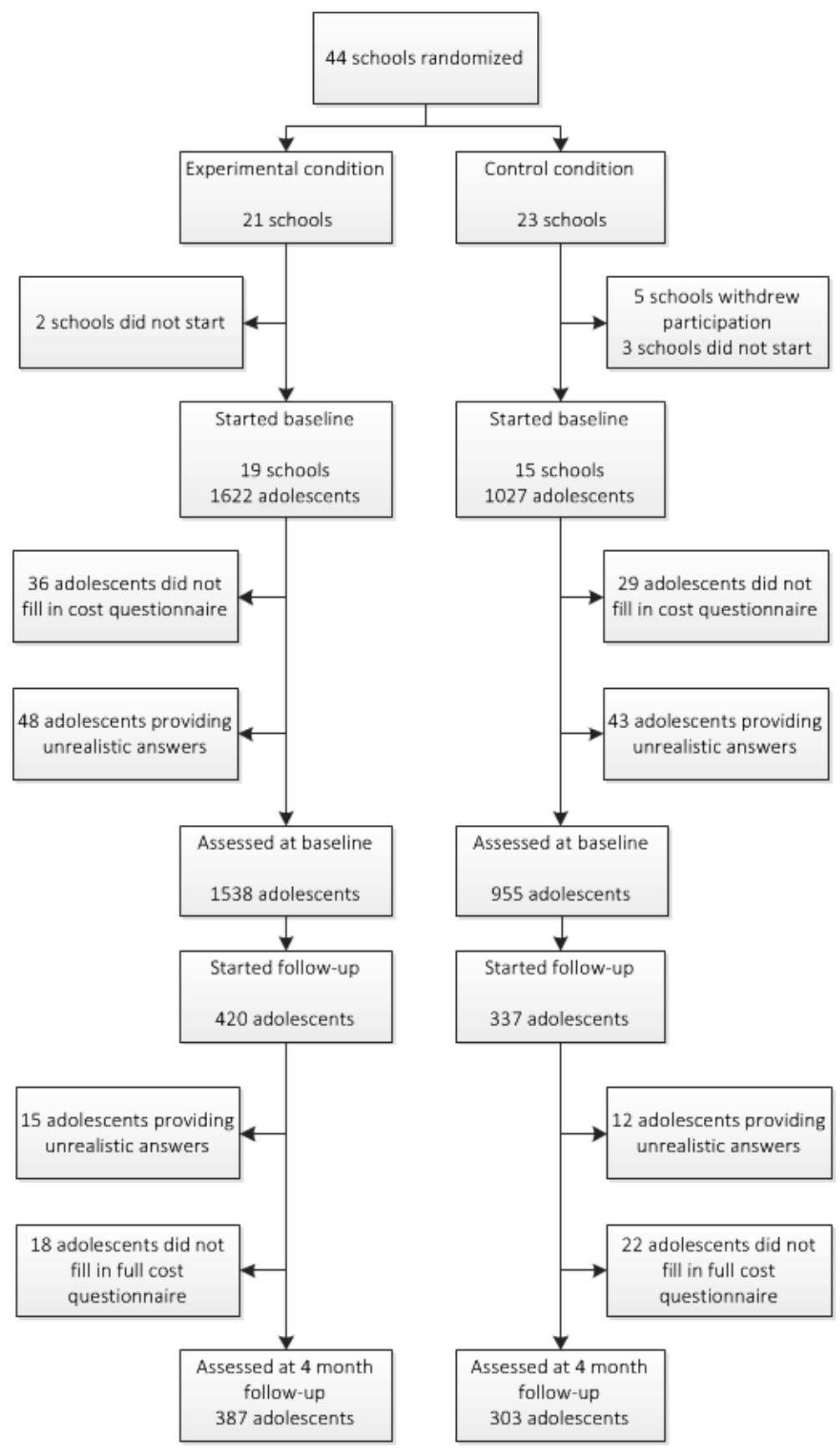

Figure 6.2 Flowchart describing the dropout of participants 
Of the 2493 adolescents, 757 participated in the cost questionnaire at T1 (response rate $30.36 \%$ ). Of these 757 , another 27 participants (3.6\%) were excluded from analysis based on having provided unrealistic answers to the cost questions. An additional 40 were excluded from analysis because they did not answer the cost questions at $\mathrm{T} 1$, resulting in 690 participants to be analyzed at baseline. Of these, 387 were in the intervention condition and 303 were in the control condition. Here, adolescents in the intervention condition were more often female, had a higher educational level, more often indicated being religious, and had a lower weekly alcohol use than participants in the control condition did (Table 6.1).

For the $T 1$ sample, results of the linear regression analyses show that weekly alcohol use was dependent on gender, age and educational level $\left(R^{2}=.146\right)$. For binge drinking occasions, a significant proportion of the variance could be explained by age and educational level $\left(R^{2}=.136\right)$.

Costs

Table 6.2 shows that the total health care costs per adolescent were lower in the intervention group (€85.65) than in the control group (€124.49). This difference can largely be explained by the difference in costs for reported hospital stays. However, costs of ICBs $(€ 162.68)$ and substance use $(€ 36.30)$ were higher in the intervention group than in the control group ( $€ 112.61$ and $€ 24.64$, respectively). The difference in mean costs for court proceedings is noticeable and explains much of the difference in ICB-related costs. Large differences in specific costs were caused by outliers in either the intervention or the CAU arm. As indicated previously, sensitivity analyses were conducted without these outliers. When the intervention costs were included both from the health care and societal perspective, costs were higher in the intervention group. The $z$ score for each cost category was positive and higher than the reference value of $1.96,{ }^{44}$ indicating that costs were skewed and tailed to the right (Table 6.2).

\section{Incremental Costs}

Table 6.3 shows costs per condition. Note that these means slightly differ from the costs presented in Table 6.2, for costs in Table 6.2 are bootstrapped means, whereas costs in Table 6.3 are means drawn from raw data. For both perspectives, costs were higher in the intervention condition. The incremental costs (ie, the difference in mean costs per adolescent between the intervention and control condition) varied per perspective, namely $€ 13.76$ from the health care perspective and $€ 74.03$ from the societal perspective. 


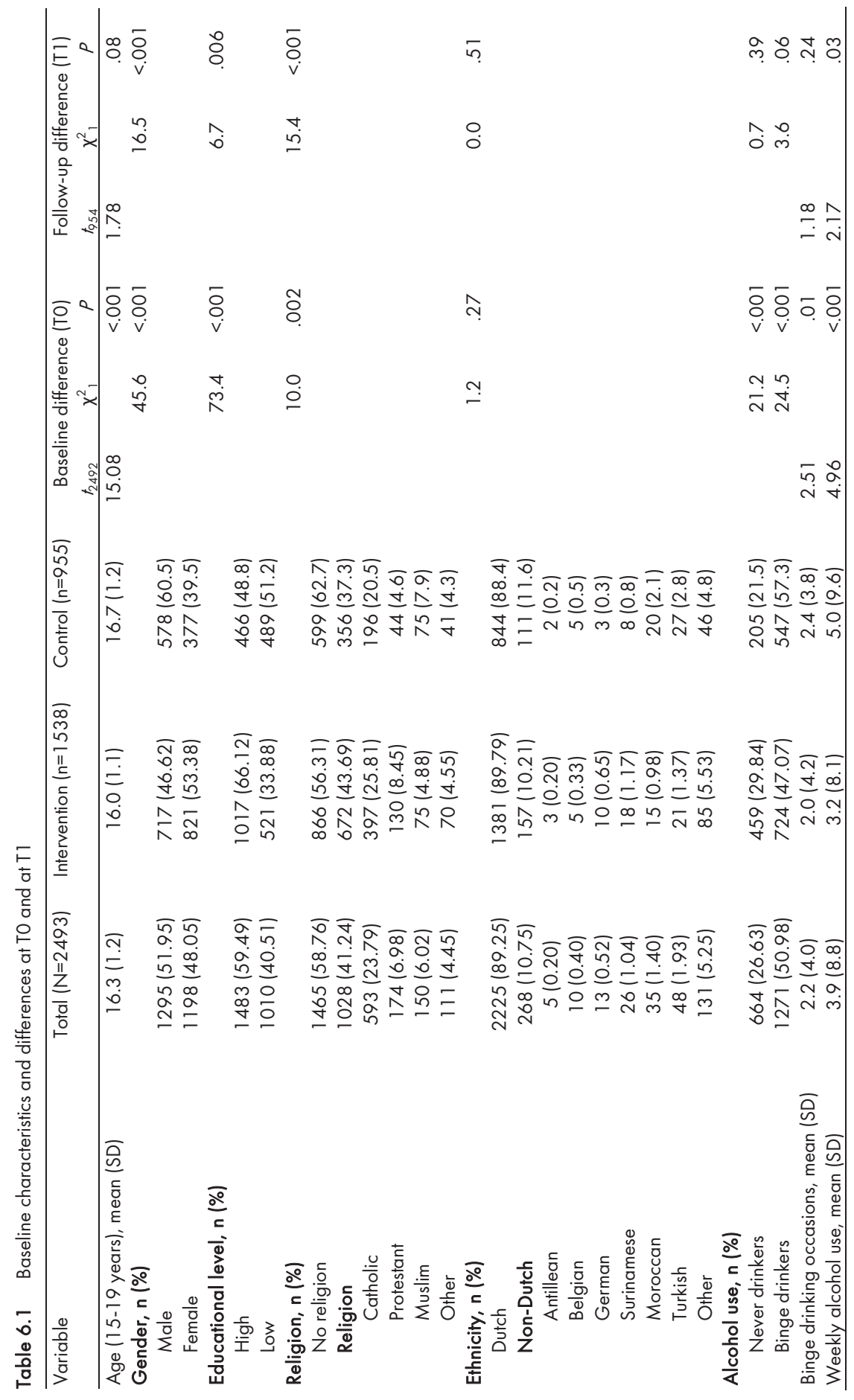




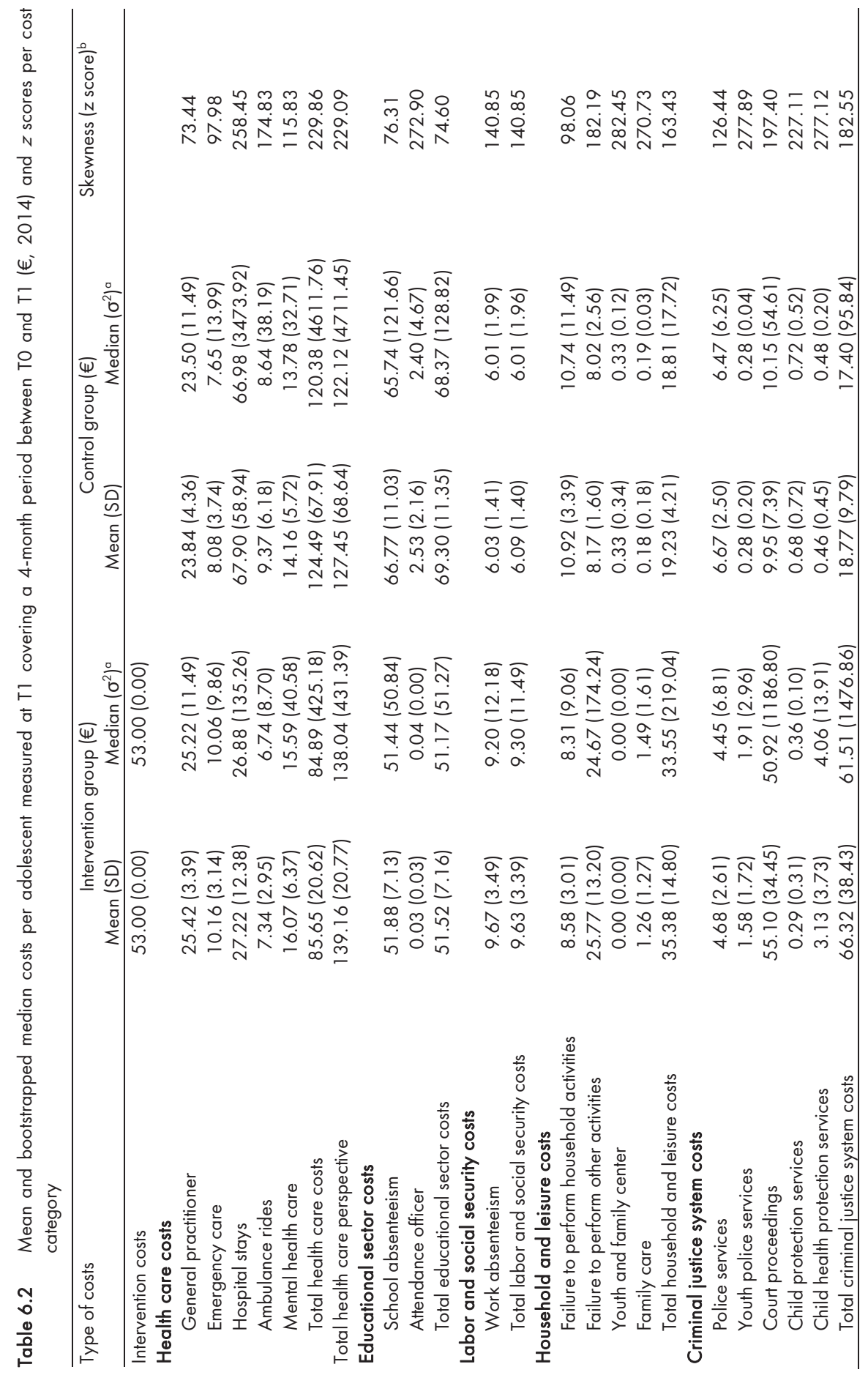




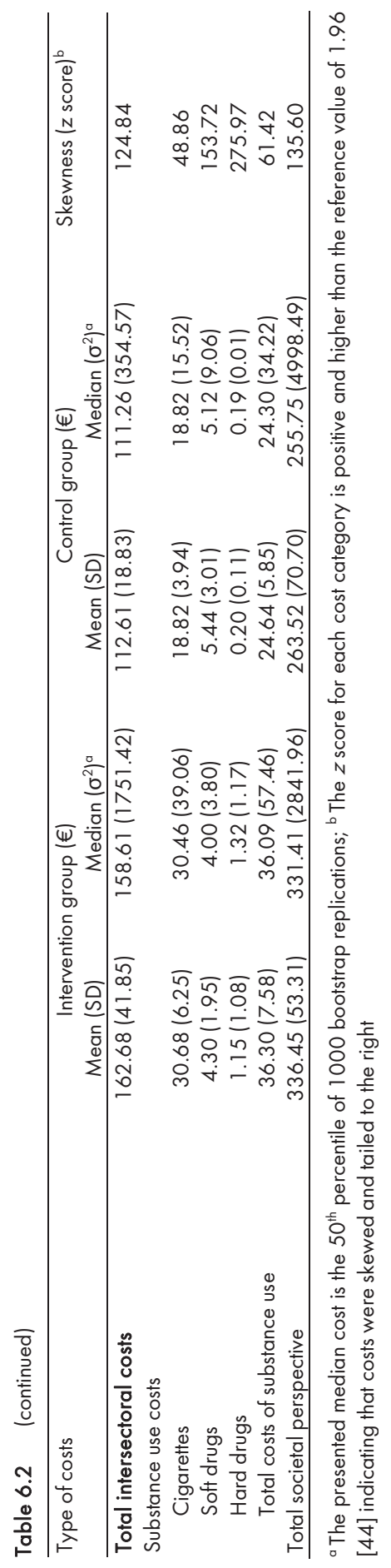




\section{Incremental Effects}

Table 6.3 shows the effects per condition. In comparison with the control condition, the intervention was incrementally effective in reducing the weekly use of alcohol and number of binge drinking occasions. At T1, adolescents in the control condition drank a mean 1.51 glasses of alcohol per week more than at TO. In the intervention condition, there was an increase of 0.78 glasses, resulting in a mean incremental effect of 0.73 glasses per week. Furthermore, in the control condition, there was an increase of 0.33 binge drinking occasions. In the intervention condition, there was a decrease of 0.16 , resulting in a mean incremental effect of 0.49 binge drinking occasions per 30 days. For both outcome measures, this did not change with perspective; a change of perspective within the base case scenario stipulated only a change in costs.

Table 6.3 Summary statistics for the base case sensitivity cost-effectiveness bootstrap analyses

\begin{tabular}{|c|c|c|c|c|c|c|c|}
\hline Perspective ${ }^{a}$ and condition & Costs $(€)^{b}$ & Effect $^{c}$ & ICER $^{d}$ & $\mathrm{NE}$ & $\begin{array}{c}\text { NW } \\
\text { (inferior) }\end{array}$ & SW & $\begin{array}{c}\text { SW } \\
\text { (dominant) }\end{array}$ \\
\hline \multicolumn{8}{|l|}{ Base case analyses } \\
\hline \multicolumn{8}{|l|}{ Weekly alcohol use } \\
\hline \multicolumn{8}{|l|}{ Health care } \\
\hline Control $(n=303)$ & 125.32 & -1.51 & & & & & \\
\hline Intervention ( $n=387)$ & 139.08 & -0.78 & 40 & $55 \%$ & $10 \%$ & $6 \%$ & $30 \%$ \\
\hline \multicolumn{8}{|l|}{ Societal } \\
\hline Control (n=303) & 262.68 & -1.51 & & & & & \\
\hline Intervention ( $n=387)$ & 336.71 & -0.78 & 62 & $60 \%$ & $14 \%$ & $3 \%$ & $23 \%$ \\
\hline \multicolumn{8}{|l|}{ Binge drinking occasions } \\
\hline \multicolumn{8}{|l|}{ Health care } \\
\hline Control (n=303) & 125.32 & -0.33 & & & & & \\
\hline Intervention ( $n=387)$ & 139.08 & 0.16 & 79 & $60 \%$ & $4 \%$ & $2 \%$ & $34 \%$ \\
\hline \multicolumn{8}{|l|}{ Societal } \\
\hline Control $(n=303)$ & 262.68 & -0.33 & & & & & \\
\hline Intervention $(n=387)$ & 336.71 & 0.16 & 144 & $69 \%$ & $5 \%$ & $1 \%$ & $25 \%$ \\
\hline \multicolumn{8}{|l|}{$\begin{array}{l}\text { Sensitivity analyses excluding } \\
\text { outliers }\end{array}$} \\
\hline \multicolumn{8}{|l|}{ Weekly alcohol use } \\
\hline \multicolumn{8}{|l|}{ Health care } \\
\hline Control $(n=302)$ & 59.47 & -1.55 & & & & & \\
\hline Intervention ( $n=387)$ & 139.08 & -0.78 & 72 & $82 \%$ & $17 \%$ & $0 \%$ & $1 \%$ \\
\hline \multicolumn{8}{|l|}{ Societal } \\
\hline Control $(n=302)$ & 193.85 & -1.55 & & & & & \\
\hline Intervention $(n=384)$ & 269.19 & -0.66 & 67 & $80 \%$ & $12 \%$ & $1 \%$ & $7 \%$ \\
\hline \multicolumn{8}{|l|}{ Binge drinking occasions } \\
\hline Control $(n=302)$ & 59.47 & -0.33 & \multicolumn{5}{|c|}{ Health care } \\
\hline Intervention $(n=387)$ & 139.08 & 0.16 & 140 & $93 \%$ & $6 \%$ & $0 \%$ & $1 \%$ \\
\hline \multicolumn{8}{|l|}{ Societal } \\
\hline Control (n=302) & 193.85 & -0.33 & & & & & \\
\hline Intervention $(n=384)$ & 269.19 & 0.21 & 124 & $87 \%$ & $4 \%$ & $0 \%$ & $9 \%$ \\
\hline
\end{tabular}

a Bootstrap analyses were conducted from two perspectives: the health care perspective and the societal perspective; ${ }^{b}$ Mean costs per adolescent at 2014 prices; ${ }^{c}$ Reduction in per week alcohol use or binge drinking occasions between $\mathrm{TO}$ and $\mathrm{T} 1$, with negative values indicating an increase at $\mathrm{T} 1$ compared to $\mathrm{TO} ;{ }^{\mathrm{d}} \mathrm{The}$ presented ICER is the $50^{\text {th }}$ percentile of 5000 bootstrap replications of the ICER 


\section{Incremental cost-effectiveness ratios}

From both perspectives, the mean costs were higher for the intervention condition in comparison with the control condition. Since the intervention was more effective than CAU on both outcome measures, this resulted in positive ICERs (Table 6.3). However, ICERs differed for both perspectives, namely $€ 40$ and $€ 79$ from the health care perspective, and $€ 62$ and $€ 144$ from the societal perspective per incremental reduction of one glass of alcohol per week and binge drinking occasion per 30 days, respectively.

The cost-effectiveness planes (Figures 6.3 and 6.4, left side) show differences in distributions of the 5000 simulated ICERs across the four quadrants between the CEAs carried out from the two perspectives. Corresponding with the median ICERs presented in Table 6.3, the majority of simulated ICERs for all base case analyses are located in the NE quadrant. However, the distribution of the simulated ICERs among the quadrants differs between the perspectives. Notable is the shift of the cloud of ICERs toward the SE quadrant in the analysis carried out from the health care perspective (i.e. $30 \%$ for weekly alcohol use and $34 \%$ for binge drinking occasions) in comparison to the analyses carried out from the societal perspective (i.e. $23 \%$ and $25 \%$, respectively).

The preceding percentages equal the probabilities of the intervention being costeffective at a WTP max of $€ 0$ in the CEACs (Figures 6.3 and 6.4, right side). These results show that for low WTP thresholds the probability of the intervention being cost-effective over the control intervention is higher from a health care perspective than it is from the societal perspective. For all base case analyses, the vast majority of simulated incremental effects were in the NE quadrant; therefore, these probabilities increase to approximately $80 \%$ when the WTP max increases. The probabilities of the intervention being cost-effective do not differ much between the two perspectives for WTP thresholds greater than $€ 500$ (Figures 6.3 and 6.4, right side).

\section{Sensitivity and subgroup analyses}

The results of the sensitivity analyses (i.e. excluding cost outliers) attest to the robustness of the base case analyses (Table 6.3). From the societal perspective, ICERs were close to similar. From the health care perspective, ICERs increased and were higher than those of the societal perspective. However, as for the base case analyses, the probability of the intervention being cost-effective remained dependent on the WTP max. The results of the analyses conducted from a societal perspective minus the costs of drugs and cigarette use were similar to the results of the analyses conducted in which these costs were included (Figures 6.3 and 6.4). 
Health care perspective

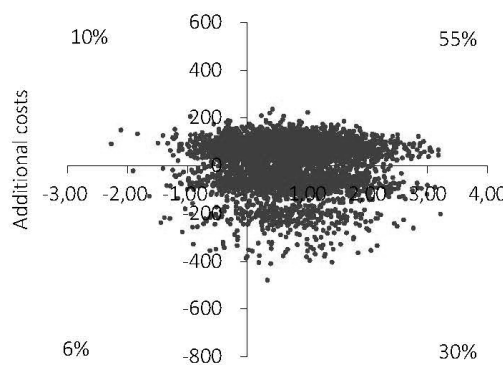

Additional effects

Societal perspective (including drugs and cigarette use)

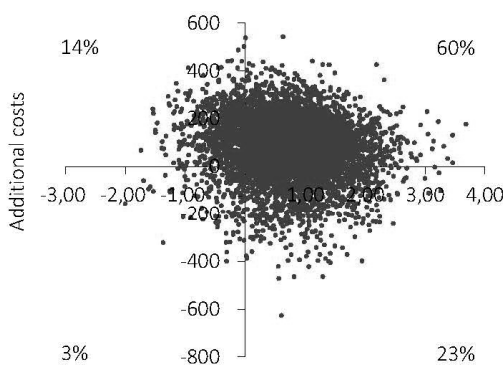

Additional effects

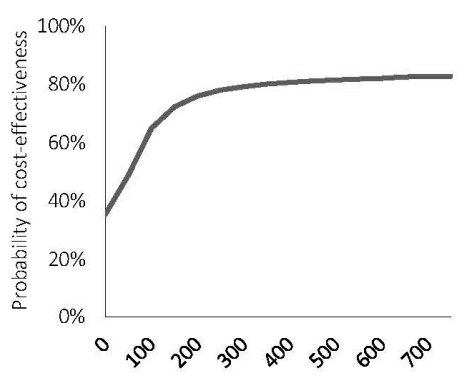

Willingess to pay; $€$ /glass of alcohol

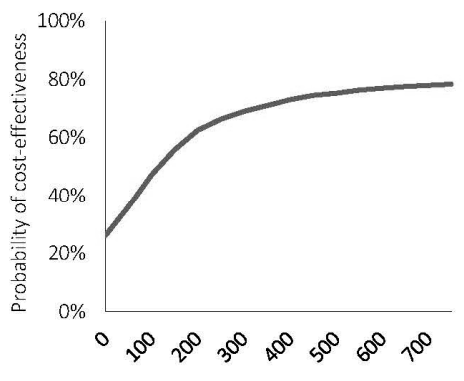

Willingness to pay; $€$ /glass of alcohol

Societal perspective (excluding drugs and cigarette use)
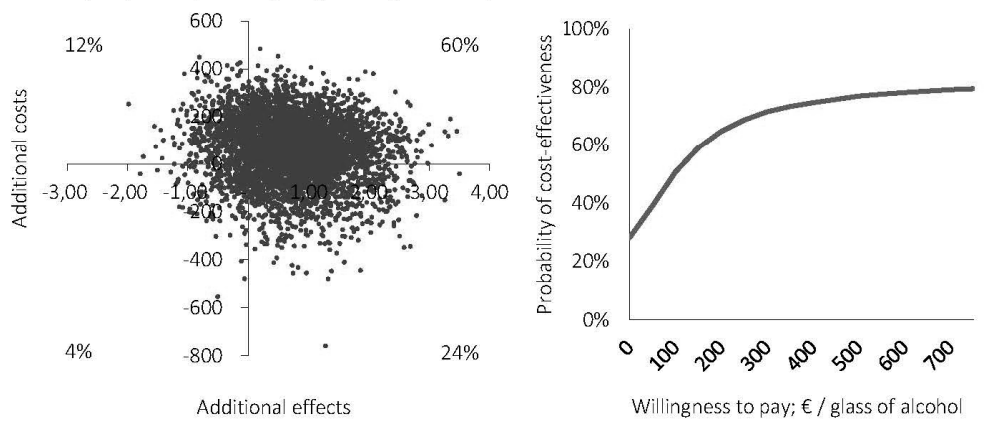

Figure 6.3 Cost-effectiveness planes (left side) and corresponding CEACs (right side) of the economic evaluations based on the weekly alcohol use outcome measure, which were conducted from the health care perspective (upper), societal perspective including drugs and cigarette use (middle) and societal perspective excluding drugs and cigarette use (below) 

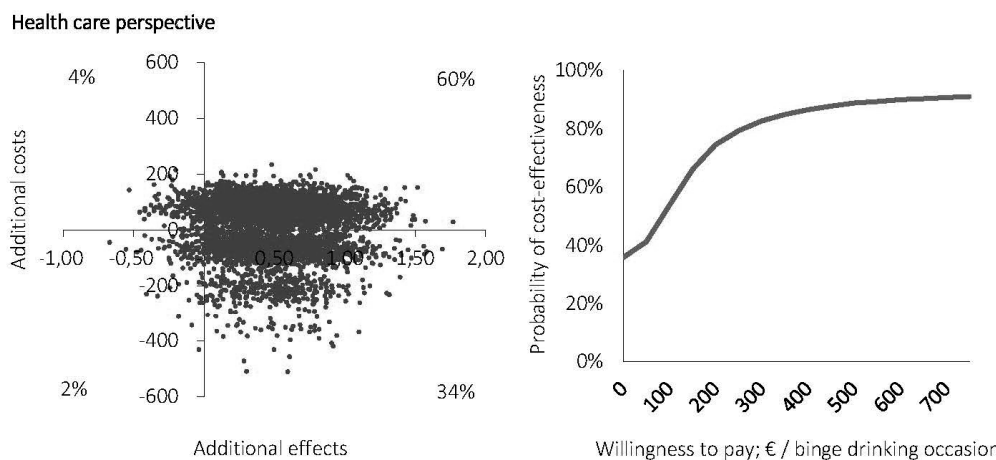

Societal perspective (including drugs and cigarette use)
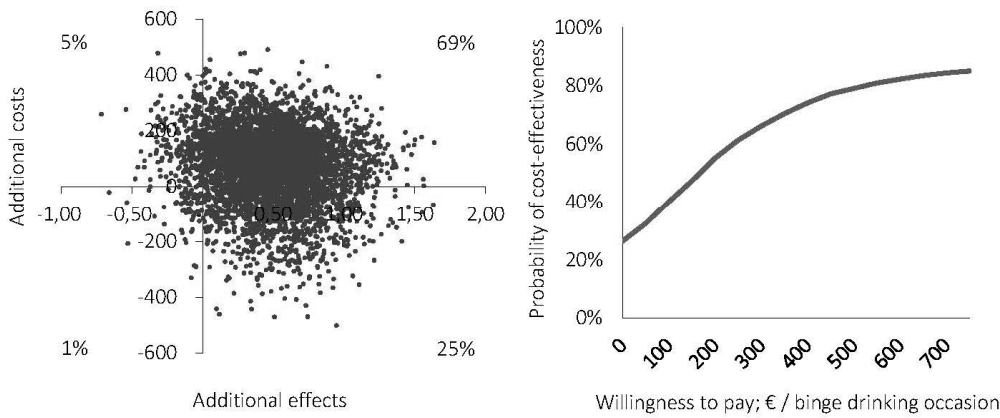

Societal perspective (excluding drugs and cigarette use)
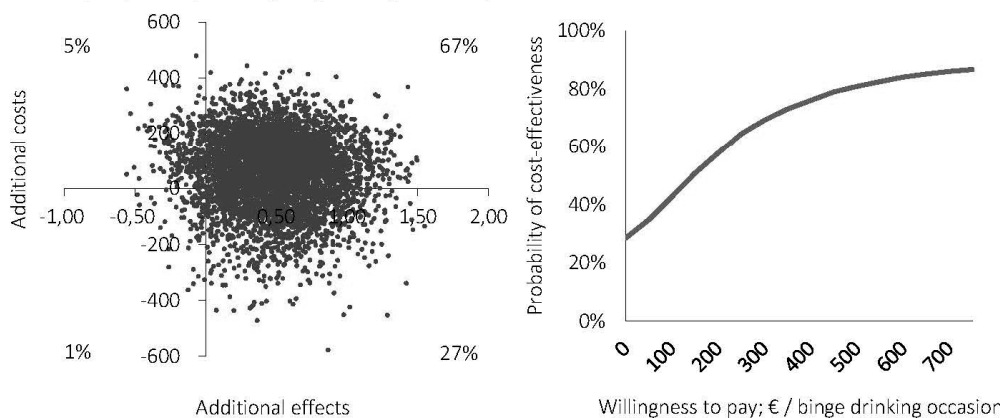

Figure 6.4 Cost-effectiveness planes (left side) and corresponding CEACs (right side) of the economic evaluations based on binge drinking occasions outcome measure, which were conducted from the health care perspective (upper), societal perspective including drugs and cigarette use (middle) and societal perspective excluding drugs and cigarette use (below)

Subgroup analyses showed, from both the health care and the societal perspective, and for both outcome measures, that the intervention was cost-effective for the older adolescents and those at a lower educational level (Tables 6.4 and 6.5). From a health 
care perspective, it was found to be cost-effective for the male and nonreligious adolescent subgroups as well. The intervention was not cost-effective for those with a non-Dutch ethnicity or for female adolescents for the weekly alcohol use outcome measure. For all other subgroups, ICERs were positive, meaning the intervention was cost-effective depending on the WTP max. The corresponding cost-effectiveness planes and CEACs of all subgroup analyses can be obtained in Multimedia Appendices 6.2 and 6.3.

Table 6.4 Summary statistics for the subgroup sensitivity cost-effectiveness bootstrap analyses based on the weekly alcohol use outcome measure

\begin{tabular}{|c|c|c|c|c|c|c|c|}
\hline Perspective ${ }^{a}$ and condition & Costs $(€)^{b}$ & Effect $^{c}$ & ICER $^{d}$ & NE & $\begin{array}{l}\mathrm{NW} \\
\text { (inferior) }\end{array}$ & SW & $\begin{array}{l}\text { SE } \\
\text { (dominant) }\end{array}$ \\
\hline \multicolumn{8}{|l|}{ Gender subgroups } \\
\hline \multicolumn{8}{|l|}{ Male } \\
\hline \multicolumn{8}{|l|}{ Health care } \\
\hline Control (n=162) & 193.96 & -2.19 & & & & & \\
\hline Intervention $(n=147)$ & 164.53 & -0.80 & Dominant & $43 \%$ & $2 \%$ & $3 \%$ & $52 \%$ \\
\hline \multicolumn{8}{|l|}{ Societal } \\
\hline Control $(n=162)$ & 337.21 & -2.19 & & & & & \\
\hline Intervention $(n=147)$ & 352.43 & -0.80 & 21 & $56 \%$ & $3 \%$ & $2 \%$ & $39 \%$ \\
\hline \multicolumn{8}{|l|}{ Female } \\
\hline \multicolumn{8}{|l|}{ Health care } \\
\hline Control $(n=141)$ & 46.46 & -0.73 & & & & & \\
\hline Intervention $(n=240)$ & 123.48 & -0.77 & Inferior & $48 \%$ & $52 \%$ & $0 \%$ & $0 \%$ \\
\hline \multicolumn{8}{|l|}{ Societal } \\
\hline Control $(n=141)$ & 177.04 & -0.73 & & & & & \\
\hline Intervention $(n=240)$ & 327.09 & -0.77 & Inferior & $46 \%$ & $52 \%$ & $1 \%$ & $1 \%$ \\
\hline \multicolumn{8}{|l|}{ Age subgroups } \\
\hline \multicolumn{8}{|c|}{ Younger adolescents ( $15-16$ years) } \\
\hline \multicolumn{8}{|l|}{ Health care } \\
\hline Control $(n=200)$ & 50.05 & -1.24 & & & & & \\
\hline Intervention $(n=281)$ & 145.79 & -0.73 & 108 & $80 \%$ & $20 \%$ & $0 \%$ & $0 \%$ \\
\hline \multicolumn{8}{|l|}{ Societal } \\
\hline Control $(n=200)$ & 177.07 & -1.24 & & & & & \\
\hline Intervention $(n=281)$ & 334.90 & -0.73 & 149 & $77 \%$ & $20 \%$ & $0 \%$ & $3 \%$ \\
\hline \multicolumn{8}{|c|}{ Older adolescents ( $\geq 17$ years) } \\
\hline \multicolumn{8}{|c|}{ Health care } \\
\hline Control $(n=103)$ & 271.48 & -2.03 & & & & & \\
\hline Intervention $(n=106)$ & 121.27 & -0.92 & Dominant & $28 \%$ & $5 \%$ & $11 \%$ & $56 \%$ \\
\hline \multicolumn{8}{|l|}{ Societal } \\
\hline Control $(n=103)$ & 428.90 & -2.03 & & & & & \\
\hline Intervention $(n=106)$ & 341.53 & -0.92 & Dominant & $32 \%$ & $7 \%$ & $10 \%$ & $51 \%$ \\
\hline \multicolumn{8}{|l|}{ Educational level subgroups } \\
\hline \multicolumn{8}{|l|}{ Low } \\
\hline \multicolumn{8}{|l|}{ Health care } \\
\hline Control (n=98) & 263.02 & -2.20 & & & & & \\
\hline Intervention $(n=91)$ & 117.35 & -0.60 & Dominant & $31 \%$ & $4 \%$ & $7 \%$ & $58 \%$ \\
\hline
\end{tabular}


Table 6.4 (continued)

\begin{tabular}{|c|c|c|c|c|c|c|c|}
\hline Perspective ${ }^{a}$ and condition & Costs $(€)^{b}$ & Effect $^{c}$ & ICER $^{d}$ & $\mathrm{NE}$ & $\begin{array}{l}\mathrm{NW} \\
\text { (inferior) }\end{array}$ & SW & $\begin{array}{l}\text { SE } \\
\text { (dominant) }\end{array}$ \\
\hline \multicolumn{8}{|l|}{ Societal } \\
\hline Control ( $n=98)$ & 435.78 & -2.20 & & & & & \\
\hline Intervention $(n=91)$ & 282.38 & -0.60 & Dominant & $26 \%$ & $4 \%$ & $8 \%$ & $63 \%$ \\
\hline \multicolumn{8}{|l|}{ High } \\
\hline \multicolumn{8}{|l|}{ Health care } \\
\hline Control $(n=205)$ & 59.50 & -1.18 & & & & & \\
\hline Intervention $(n=296)$ & 145.76 & -0.83 & 102 & $73 \%$ & $26 \%$ & $0 \%$ & $1 \%$ \\
\hline \multicolumn{8}{|l|}{ Societal } \\
\hline Control $(n=205)$ & 179.93 & -1.18 & & & & & \\
\hline Intervention $(n=296)$ & 353.42 & -0.83 & 172 & $70 \%$ & $28 \%$ & $0 \%$ & $1 \%$ \\
\hline \multicolumn{8}{|l|}{ Religion subgroups } \\
\hline \multicolumn{8}{|l|}{ Religion } \\
\hline \multicolumn{8}{|l|}{ Health care } \\
\hline Control (n=97) & 46.91 & -2.05 & & & & & \\
\hline Intervention $(n=181)$ & 148.11 & -0.71 & 66 & $92 \%$ & $8 \%$ & $0 \%$ & $0 \%$ \\
\hline \multicolumn{8}{|l|}{ Societal } \\
\hline Control (n=97) & 155.80 & -2.05 & & & & & \\
\hline Intervention $(n=181)$ & 336.35 & -0.71 & 110 & $90 \%$ & $9 \%$ & $0 \%$ & $1 \%$ \\
\hline \multicolumn{8}{|l|}{ No religion } \\
\hline \multicolumn{8}{|l|}{ Health care } \\
\hline Control $(n=206)$ & 162.24 & -1.25 & & & & & \\
\hline Intervention $(n=206)$ & 131.13 & -0.84 & Dominant & $37 \%$ & $14 \%$ & $13 \%$ & $37 \%$ \\
\hline \multicolumn{8}{|l|}{ Societal } \\
\hline Control $(n=206)$ & 313.00 & -1.25 & & & & & \\
\hline Intervention $(n=206)$ & 337.04 & -0.84 & 5 & $42 \%$ & $19 \%$ & $8 \%$ & $31 \%$ \\
\hline \multicolumn{8}{|l|}{ Ethnicity subgroups } \\
\hline \multicolumn{8}{|l|}{ Dutch } \\
\hline \multicolumn{8}{|l|}{ Health care } \\
\hline Control $(n=278)$ & 128.83 & -1.65 & & & & & \\
\hline Intervention $(n=356)$ & 136.90 & -0.84 & 36 & $53 \%$ & $8 \%$ & $5 \%$ & $34 \%$ \\
\hline \multicolumn{8}{|l|}{ Societal } \\
\hline Control (n=278) & 262.96 & -1.65 & & & & & \\
\hline Intervention $(n=356)$ & 334.67 & -0.84 & 57 & $60 \%$ & $11 \%$ & $3 \%$ & $26 \%$ \\
\hline \multicolumn{8}{|l|}{ Other } \\
\hline \multicolumn{8}{|l|}{ Health care } \\
\hline Control $(n=25)$ & 86.35 & 0.08 & & & & & \\
\hline Intervention $(n=31)$ & 164.09 & -0.10 & Inferior & $32 \%$ & $51 \%$ & $4 \%$ & $13 \%$ \\
\hline \multicolumn{8}{|l|}{ Societal } \\
\hline Control $(n=25)$ & 259.53 & 0.08 & & & & & \\
\hline Intervention $(n=31)$ & 360.20 & -0.10 & Inferior & $23 \%$ & $49 \%$ & $7 \%$ & $21 \%$ \\
\hline
\end{tabular}

a Bootstrap analyses were conducted from two perspectives: the health care perspective and the societal perspective; ${ }^{b}$ Costs per adolescent at 2014 prices; ${ }^{c}$ Reduction in per week alcohol use between TO and T1, with negative values indicating an increase at $\mathrm{T} 1$ compared to TO; ${ }^{\mathrm{d}}$ The presented ICER is the 50 th percentile of 5000 bootstrap replications of the ICER. When an ICER is negative, then it is labeled as being either "dominant" (suggesting that the intervention is both more effective and less costly than CAU) or "inferior" (suggesting that the intervention is both less effective and more costly than CAU) 
Table 6.5 Summary statistics for the subgroup sensitivity cost-effectiveness bootstrap analyses based on the binge drinking occasions outcome measure

\begin{tabular}{|c|c|c|c|c|c|c|c|}
\hline Perspective $^{a}$ and condition & Costs $(€)^{b}$ & Effect $^{\mathrm{C}}$ & ICER $^{d}$ & NE & $\begin{array}{c}\mathrm{NW} \\
\text { (inferior) }\end{array}$ & SW & $\begin{array}{c}\mathrm{SE} \\
\text { (dominant) }\end{array}$ \\
\hline \multicolumn{8}{|l|}{ Gender subgroups } \\
\hline \multicolumn{8}{|l|}{ Male } \\
\hline \multicolumn{8}{|l|}{ Health care } \\
\hline Control $(n=162)$ & 193.96 & -0.57 & & & & & \\
\hline Intervention $(n=147)$ & 164.53 & 0.08 & Dominant & $44 \%$ & $1 \%$ & $1 \%$ & $54 \%$ \\
\hline \multicolumn{8}{|l|}{ Societal } \\
\hline Control $(n=162)$ & 337.21 & -0.57 & & & & & \\
\hline Intervention $(n=147)$ & 352.43 & 0.08 & 46 & $57 \%$ & $1 \%$ & $1 \%$ & $42 \%$ \\
\hline \multicolumn{8}{|l|}{ Female } \\
\hline \multicolumn{8}{|l|}{ Health care } \\
\hline Control $(n=141)$ & 46.46 & -0.04 & & & & & \\
\hline Intervention $(n=240)$ & 123.48 & 0.21 & 179 & $81 \%$ & $19 \%$ & $0 \%$ & $0 \%$ \\
\hline \multicolumn{8}{|l|}{ Societal } \\
\hline Control $(n=141)$ & 177.04 & -0.04 & & & & & \\
\hline Intervention $(n=240)$ & 327.09 & 0.21 & 291 & $78 \%$ & $19 \%$ & $0 \%$ & $2 \%$ \\
\hline \multicolumn{8}{|l|}{ Age subgroups } \\
\hline \multicolumn{8}{|c|}{ Younger adolescents ( $15-16$ years) } \\
\hline \multicolumn{8}{|l|}{ Health care } \\
\hline Control $(n=200)$ & 50.05 & -0.26 & & & & & \\
\hline Intervention $(n=281)$ & 145.79 & 0.13 & 276 & $71 \%$ & $29 \%$ & $0 \%$ & $0 \%$ \\
\hline \multicolumn{8}{|l|}{ Societal } \\
\hline Control $(n=200)$ & 177.07 & -0.26 & & & & & \\
\hline Intervention $(n=281)$ & 334.90 & 0.13 & 343 & $68 \%$ & $29 \%$ & $1 \%$ & $2 \%$ \\
\hline \multicolumn{8}{|c|}{ Older adolescents ( $\geq 17$ years) } \\
\hline \multicolumn{8}{|l|}{ Health care } \\
\hline Control $(n=103)$ & 271.48 & -0.45 & & & & & \\
\hline Intervention $(n=106)$ & 121.27 & 0.94 & Dominant & $31 \%$ & $0 \%$ & $0 \%$ & $68 \%$ \\
\hline \multicolumn{8}{|l|}{ Societal } \\
\hline Control $(n=103)$ & 428.90 & -0.45 & & & & & \\
\hline Intervention $(n=106)$ & 341.53 & 0.94 & Dominant & $39 \%$ & $0 \%$ & $0 \%$ & $60 \%$ \\
\hline \multicolumn{8}{|l|}{ Educational level subgroups } \\
\hline \multicolumn{8}{|l|}{ Low } \\
\hline \multicolumn{8}{|l|}{ Health care } \\
\hline Control (n=98) & 263.02 & -0.53 & & & & & \\
\hline Intervention $(n=91)$ & 117.35 & 1.04 & Dominant & $35 \%$ & $0 \%$ & $0 \%$ & $64 \%$ \\
\hline \multicolumn{8}{|l|}{ Societal } \\
\hline Control (n=98) & 435.78 & -0.53 & & & & & \\
\hline Intervention $(n=91)$ & 282.38 & 1.04 & Dominant & $30 \%$ & $0 \%$ & $0 \%$ & $70 \%$ \\
\hline \multicolumn{8}{|l|}{ High } \\
\hline \multicolumn{8}{|l|}{ Health care } \\
\hline Control $(n=205)$ & 59.50 & -0.23 & & & & & \\
\hline Intervention $(n=296)$ & 145.76 & -0.10 & 231 & $69 \%$ & $30 \%$ & $0 \%$ & $1 \%$ \\
\hline Societal & & & & & & & \\
\hline Control $(n=205)$ & 179.93 & -0.23 & & & & & \\
\hline Intervention $(n=296)$ & 353.42 & -0.10 & 435 & $69 \%$ & $29 \%$ & $0 \%$ & $1 \%$ \\
\hline Religion subgroups & & & & & & & \\
\hline Religion & & & & & & & \\
\hline Health care & & & & & & & \\
\hline Control (n=97) & 46.91 & -0.34 & & & & & \\
\hline Intervention $(n=181)$ & 148.11 & 0.32 & 148 & $96 \%$ & $4 \%$ & $0 \%$ & $0 \%$ \\
\hline
\end{tabular}


Table 6.5 (continued)

\begin{tabular}{|c|c|c|c|c|c|c|c|}
\hline Perspective $^{a}$ and condition & Costs $(€)^{b}$ & Effect $^{c}$ & ICER $^{d}$ & NE & $\begin{array}{c}\mathrm{NW} \\
\text { (inferior) }\end{array}$ & SW & $\begin{array}{c}\text { SE } \\
\text { (dominant) }\end{array}$ \\
\hline \multicolumn{8}{|l|}{ Societal } \\
\hline Control (n=97) & 155.80 & -0.34 & & & & & \\
\hline Intervention $(n=181)$ & 336.35 & 0.32 & 256 & $95 \%$ & $4 \%$ & $0 \%$ & $1 \%$ \\
\hline \multicolumn{8}{|l|}{ No religion } \\
\hline \multicolumn{8}{|l|}{ Health care } \\
\hline Control $(n=206)$ & 162.24 & -0.32 & & & & & \\
\hline Intervention $(n=206)$ & 131.13 & 0.02 & Dominant & $43 \%$ & $7 \%$ & $6 \%$ & $45 \%$ \\
\hline \multicolumn{8}{|l|}{ Societal } \\
\hline Control $(n=206)$ & 313.00 & -0.32 & & & & & \\
\hline Intervention $(n=206)$ & 337.04 & 0.02 & 47 & $50 \%$ & $8 \%$ & $4 \%$ & $37 \%$ \\
\hline \multicolumn{8}{|l|}{ Ethnicity subgroups } \\
\hline \multicolumn{8}{|l|}{ Dutch } \\
\hline \multicolumn{8}{|l|}{ Health care } \\
\hline Control (n=278) & 128.83 & -0.36 & & & & & \\
\hline Intervention $(n=356)$ & 136.90 & 0.18 & 71 & $59 \%$ & $3 \%$ & $2 \%$ & $37 \%$ \\
\hline \multicolumn{8}{|l|}{ Societal } \\
\hline Control $(n=278)$ & 262.96 & -0.36 & & & & & \\
\hline Intervention $(n=356)$ & 334.67 & 0.18 & 139 & $69 \%$ & $4 \%$ & $1 \%$ & $26 \%$ \\
\hline \multicolumn{8}{|l|}{ Other } \\
\hline \multicolumn{8}{|l|}{ Health care } \\
\hline Control $(n=25)$ & 86.35 & 0.00 & & & & & \\
\hline Intervention $(n=31)$ & 164.09 & 0.03 & Inferior & $36 \%$ & $48 \%$ & $3 \%$ & $13 \%$ \\
\hline \multicolumn{8}{|l|}{ Societal } \\
\hline Control (n=25) & 259.53 & 0.00 & & & & & \\
\hline Intervention $(n=31)$ & 360.20 & 0.03 & Inferior & $24 \%$ & $48 \%$ & $4 \%$ & $24 \%$ \\
\hline
\end{tabular}

a Bootstrap analyses were conducted from two perspectives: the health care perspective and the societal perspective; ${ }^{b}$ Costs per adolescent at 2014 prices; ${ }^{\circ}$ Reduction in per week alcohol use between TO and T1, with negative values indicating an increase at $\mathrm{T} 1$ compared to TO; ${ }^{\mathrm{d}}$ The presented ICER is the $50^{\text {th }}$ percentile of 5000 bootstrap replications of the ICER. When an ICER is negative, then it is labeled as being either "dominant" (suggesting that the intervention is both more effective and less costly than CAU) or "inferior" (suggesting that the intervention is both less effective and more costly than CAU)

\section{Discussion}

\section{Principal results}

To the best of our knowledge, this was the first cost-effectiveness analysis of a Web-based intervention conducted from both the health care and societal perspective that also incorporated the possible impact of ICBs on the cost-effectiveness results. From both a health care and a societal perspective, our study shows the intervention was incrementally more effective and more costly than CAU. This counts for both the analyses in which the weekly alcohol use outcome measure was incorporated and the analyses based on the binge drinking occasions outcome measure.

Although the intervention was incrementally effective in targeting weekly alcohol use, there was an increase in the number of glasses of alcohol between TO and T1 in both arms 
of the trial. This can be explained based on the estimation that approximately one-third of the study sample had his or her birthday during this 4-month period between TO and T1, of which some reached the legal drinking age of 18 years. Furthermore, all adolescents in the sample aged 4 months, which increased the chance of them starting to drink or drink more. This is also true for the younger Dutch adolescents because many start drinking before the legal drinking age. ${ }^{45}$ However, contrary to weekly alcohol use, the number of binge drinking occasions did not increase in the intervention arm; a small decrease of a mean 0.16 binge drinking occasions was noticed compared to an increase of a mean 0.33 in the CAU arm. Therefore, relative to the overall alcohol intake and compared to CAU, it can tentatively be concluded that adolescents in the intervention arm became less irresponsible about drinking.

Our research also shows that the inclusion of ICBs in the economic evaluation impacted the cost-effectiveness results of the analysis, especially for certain subgroups. From a health care perspective, the intervention is cost-effective for the male, lower education, older adolescent, and nonreligious subgroups. However, from a societal perspective (which includes (CBs), the intervention is clearly cost-effective only for the lower education and older adolescent subgroups.

The inferiority of the intervention for certain subgroups could, among other reasons, partly be explained based on the finding that the baseline consumption for these subgroups was relatively low compared to that of their counterparts. For example, the baseline mean weekly alcohol use in the female subgroup was 1.49 glasses (SD 3.57) compared to weekly mean 4.18 glasses (SD 8.42) in the male subgroup. In so far as the following can be concluded based on an analysis of the smallest subgroup $(n=56)$, this also goes for the non-Dutch subgroup (mean 2.16, SD 5.00 glasses and mean 1.21, SD 2.44 binge drinking occasions) versus the Dutch subgroup (mean 2.74, SD 6.48 glasses and mean 1.64, SD 2.77 binge drinking occasions). In these subgroups, there was less effect to be gained. Consequently, this could be related to the possibility of these adolescents not identifying themselves as being part of the target group of, and being affected by, the intervention.

\section{Strengths and limitations}

Some of the strengths of this study are its relatively large sample size and its randomized design. The cluster randomization at the school level minimized the risk of contamination between the study conditions. Furthermore, the large heterogenic study sample was a good representation of the Dutch adolescent school-going population and allowed for subgroup analyses on multiple background variables.

The use of a societal perspective along with a health care perspective was a major strength of this study. The societal perspective is argued to be dominant over other perspectives. ${ }^{46-48}$ This is because of, but not restricted to, health economics' foundations in welfare economics, which means that an economic evaluation should include the impact of an intervention on the whole society. ${ }^{46}$ However, not only the choice of perspective, but 
also the way this was implemented in the study design, can be considered a major strength. Because the study population consisted of school-going adolescents, limiting the societal perspective to including merely labor productivity costs would not have properly reflected this impact. For this study, the results show that labor productivity costs make up just a small part of the total costs of ICBs (Table 6.2). By including costs within the educational sector and criminal justice system, we managed to provide a better reflection of the economic impact of this intervention on society.

Apart from these strengths, the findings of this study need to be placed in the context of the study's limitations. First, both at TO and T1, the composition of adolescents in the intervention condition was significantly different from that of the control condition for various characteristics, including gender, educational level, and religion. This might have been caused by (1) the cluster RCT design instead of randomization at the individual level and/or (2) the large dropout before the baseline assessment within the control condition in comparison with the intervention condition. Although the results of the regression analysis showed a relationship between some of the background variables and the outcome measures, uncertainty around the ICERs that were calculated in the base case analyses was dealt with through various strategies. The sensitivity analyses attest to the robustness of the findings. Furthermore, the heterogeneity of the sample was addressed extensively by calculating ICERs and conducting bootstrap analyses for all subgroups based on all background variables.

Second, the follow-up period of this CEA (ie, 4 months) might be regarded as short. Costs and (health) benefits that fall beyond these 4 months were not assessed. Future studies, including additional follow-up measures and cost-effectiveness modeling, could be interesting. Other studies have shown that the cumulative cost savings in the life span of health promotion interventions for adolescents could be high. ${ }^{49}$

Third, the authors decided not to further modify the original dataset by imputation and restricted the analysis to complete cases. A missing completely at random analysis (MCAR) in SPSS version 20 based on the $\mathrm{N}=2493$ sample that started at baseline showed $71 \%$ to $72 \%$ per cost variable at $\mathrm{T} 1$. Furthermore, the missing values were not at random $(P<.001)$. Although this was expected considering the large dropout between TO and T1, the same goes for the $n=757$ sample that started follow-up ( $R<.001)$. Given the nonnormality of cost variables, the nonrandomness of missing values, and the large dropout as is common in many Web-based interventions, ${ }^{19,50-55}$ it was concluded that additional imputation would have manipulated the original dataset too much. This counts for both the basic imputation methods, such as expectation maximization and last observation carried forward, as well as for the more advanced methods, such as Markov chain Monte Carlo technique with predictive mean matching. ${ }^{56}$ As for imputation strategies, the chosen strategy might have led to biased results. Nevertheless, the alternative of replacing more than $70 \%$ of the values, which would have been needed in this study, would have increased the risk of a type II error. ${ }^{51}$ Imputation would have resulted in an increased chance of underestimating the intervention's effectiveness and an unrealistic representation of costs. 
Fourth, measurements were based on self-reports, which could have led to an underestimation of service use, alcohol use, and use of other goods in comparison with daily diaries. ${ }^{24,57}$ As for any measurement based on recalling services or goods used, this is because of forgetting. ${ }^{17}$ However, in this study, recall periods were kept short. For example, respondents were asked for their alcohol use in the previous week and not in a typical week. Furthermore, the recall period for the cost measurement questions was only 4 months. In addition, because the groups were randomized, this underestimation is likely to be equally distributed among the intervention and control group. Therefore, it is unlikely that the ICERs were affected.

Finally, within the setting of this study, respondents were free to fill in the answers themselves during the measurements. As mentioned earlier, limits needed to be set to exclude respondents who provided unrealistic answers. The choice made by the authors to exclude whole cases might have affected the outcomes of the analysis. However, this choice is justifiable based on the finding that the vast majority of unrealistic answers were not even close to the limits set by the authors and were far higher than the credible range. For example, there were seven respondents who claimed to have spent more than 200 nights in a hospital bed in the previous 4 months, of which three said to have spent more than 200,000. The 27 adolescents at T1 who filled in unrealistic answers (only $3.6 \%$ of the $\mathrm{n}=757$ sample that started follow-up) had a mean 2.9 unrealistic answers. Based on the data, it was clear that the vast majority of these 27 adolescents did this deliberately and systematically. Although the outcome of the analyses might have been affected by the limits that were set by the authors, these limits were carefully considered, discussed, and decided a priori to the analyses. This was done to minimize the chance of biased results. Furthermore, the impact of cost outliers on the outcomes of the base case analyses has been covered in sensitivity analyses in which cost outliers were excluded.

\section{Recommendations}

Computer-tailored feedback can be a cost-effective way to target alcohol use and binge drinking among adolescents. In the Netherlands, despite the Dutch government's change of policy to reduce the minimum legal drinking age, $33.4 \%$ of Dutch adolescents were drinkers in $2014 .^{45}$ This is because in practice drinking rules are set not only by Dutch law, but also by parents or caregivers and alcoholic beverages can easily be obtained via family and friends. Therefore, effective and cost-effective interventions targeting adolescent drinking behavior are still very much needed. The high dissemination capabilities of the Alcoholic Alert intervention, combined with its solid basis in the I-Change model and low intervention costs could make it an interesting investment for reducing alcohol use among adolescents.

Because the cost-effectiveness for the whole sample is dependent on the WTP max per effect, it is difficult to make strong recommendations on whether the intervention should be implemented from an economic point of view. Contrary to the generic outcome measure quality-adjusted life year (QALY), ${ }^{58,59}$ and as is common for the majority of specific 
outcome measures, no guidelines are available that provide a reference cost-effectiveness threshold for reducing the consumption of alcohol. However, the CEACs provide decision supportive information because these provide cost-effectiveness probabilities for a wide range of hypothetical thresholds for all analyses. These also show that, from both the health care and the societal perspective, the intervention is cost-effective for older adolescents and for those at a lower educational level, regardless of which threshold is set. From a health economic viewpoint, it is recommended that these specific groups be targeted. When adopting a health care perspective, the same goes for the male and nonreligious adolescent subgroups.

In general, policy makers should be aware of the impact of the perspective chosen for the analysis on its outcomes. Omitting ICBs could negatively affect the reliability and informative value of analyses that are conducted from a societal perspective. Therefore, it is recommended that researchers should carefully make a priori considerations on the costs to be included because leaving out important costs could lead to biased results. ${ }^{60}$ Finally, as in this study, high attrition rates could affect the outcomes of CEAs. High attrition rates are common in eHealth interventions. ${ }^{61,62}$ It is recommended that more research should be conducted on adherence to eHealth interventions and that these interventions be implemented in practice, thus increasing their effectiveness, cost-effectiveness, and impact on public health. 


\section{References}

1. Rehm J, Taylor B, Room R. Global burden of disease from alcohol, illicit drugs and tobacco. Drug Alcohol Rev. 2006;25:503-13.

2. Ezzati M, Lopez AD, Rodgers A, Murray CJ. Comparative Quantification of Health Risks: Global and Regional Burden of Diseases Attributable to Selected Major Risks. Geneva: World Health Organization, 2004.

3. Smit F, Lokkerbol J, Riper H, Majo MC, Boon B, Blankers M. Modeling the cost-effectiveness of health care systems for alcohol use disorders: how implementation of eHealth interventions improves cost-effectiveness. J Med Internet Res. 2011;13:e56.

4. WHO. Global status report on alcohol and health. Geneva: World Health Organization, 2014.

5. Mohapatra S, Patra J, Popova S, Duhig A, Rehm J. Social cost of heavy drinking and alcohol dependence in high-income countries. Int J Public Health. 2010;55:149-57.

6. Rehm J, Mathers C, Popova S, Thavorncharoensap M, Teerawattananon Y, Patra J. Global burden of disease and injury and economic cost attributable to alcohol use and alcohol-use disorders. Lancet. 2009;373:2223-33.

7. Smit F, Cuijpers P, Oostenbrink J, Batelaan N, de Graaf R, Beekman A. Costs of nine common mental disorders: implications for curative and preventive psychiatry. J Ment Health Policy Econ. 2006;9:193200.

8. WHO. World report on violence and health. Geneva: World Health Organization, 2002.

9. WHO. Youth violence and alcohol. Geneva: World Health Organization, 2006.

10. Chiauzzi E, Green TC, Lord S, Thum C, Goldstein M. My student body: a high-risk drinking prevention web site for college students. J Am Coll Health. 2005;53:263-74.

11. Kypri K, Saunders JB, Williams SM, McGee RO, Langley JD, Cashell-Smith ML, et al. Web-based screening and brief intervention for hazardous drinking: a double-blind randomized controlled trial Addiction. 2004;99:1410-7.

12. Lustria ML, Cortese J, Noar SM, Glueckauf RL. Computer-tailored health interventions delivered over the Web: review and analysis of key components. Patient Educ Couns. 2009;74:156-73.

13. Matano RA, Koopman C, Wanat SF, Winzelberg AJ, Whitsell SD, Westrup D, et al. A pilot study of an interactive web site in the workplace for reducing alcohol consumption. J Subst Abuse Treat. 2007; $32: 71$ 80.

14. Riper H, Kramer J, Smit F, Conijn B, Schippers G, Cuijpers P. Web-based self-help for problem drinkers: a pragmatic randomized trial. Addiction. 2008;103:218-27.

15. van der Wulp NY, Hoving C, Eijmael K, Candel MJJM, van Dalen W, de Vries H. Reducing alcohol use during pregnancy via health counseling by midwives and internet-based computer-tailored feedback: a cluster randomized trial. J Med Internet Res. 2014;16:e274.

16. de Vries H, Brug J. Computer-tailored interventions motivating people to adopt health promoting behaviours: introduction to a new approach. Patient Educ Couns. 1999;36:99-105.

17. Lemmens $P$, Tan ES, Knibbe RA. Measuring quantity and frequency of drinking in a general population survey: a comparison of five indices. J Stud Alcohol. 1992;53:476-86.

18. van Keulen HM, Mesters I, Brug J, Ausems M, Campbell M, Resnicow K, et al. Vitalum study design: RCT evaluating the efficacy of tailored print communication and telephone motivational interviewing on multiple health behaviors. BMC Public Health. 2008;8:216.

19. Smit ES, Evers SM, de Vries H, Hoving C. Cost-effectiveness and cost-utility of Internet-based computer tailoring for smoking cessation. J Med Internet Res. 2013;15:e57.

20. Kreuter MW, Wray RJ. Tailored and targeted health communication: strategies for enhancing information relevance. Am J Health Behav. 2003;27 Suppl 3:S227-32.

21. Schulz DN, Smit ES, Stanczyk NE, Kremers SP, de Vries H, Evers SM. Economic evaluation of a webbased tailored lifestyle intervention for adults: findings regarding cost-effectiveness and cost-utility from a randomized controlled trial. J Med Internet Res. 2014;16:e91

22. Internet Users in the World. Internet World Stats; 2014 [cited 20149 december]; Available from: http://www.internetworldstats.com/stats.htm. Archived at: http://www.webcitation.org/6c7pfXiGN 
23. Eurostat. Internet use statistics-individuals. 2015 [cited 20153 February]; Available from: http://ec.europa.eu/eurostat/statistics-explained/index.php/Internet_use_statistics_-_individuals.

Archived at: http://www.webcitation.org/6c838IG2c

24. Jander A, Crutzen R, Mercken L, Candel MJ, De Vries H. Effects of a Web-based computer-tailored game to reduce binge drinking among Dutch adolescents: a cluster randomized controlled trial. J Med Internet Res. 2016;18:e29.

25. Voogt CV, Kleinjan M, Poelen EA, Lemmers LA, Engels RC. The effectiveness of a web-based brief alcohol intervention in reducing heavy drinking among adolescents aged 15-20 years with a low educational background: a two-arm parallel group cluster randomized controlled trial. BMC Public Health. 2013;13:694.

26. Suijkerbuijk A, Van Gils PF, De Wit GA. De kosteneffectiviteit van interventies gericht op verslaving aan alcohol en middelen. Bilthoven: National Institute for Public Health and the Environment, 2014.

27. Blankers M, Nabitz U, Smit F, Koeter MW, Schippers GM. Economic evaluation of internet-based interventions for harmful alcohol use alongside a pragmatic randomized controlled trial. J Med Internet Res. 2012;14:e134.

28. Ingels JBC, Phaedra S.; Kogan, Steve M.; Brody, Gene H. Cost-effectiveness of the strong African American families-teen program: 1-year follow-up. Drug Alcohol Depend. 2013;133:556-61.

29. Nelson JP. Binge drinking and alcohol prices: a systematic review of age-related results from econometric studies, natural experiments and field studies. Health Econ Rev. 2015;5:6.

30. Drost RMWA, Paulus ATG, Ruwaard D, Evers SMAA. Intersectoral costs and benefits of mental health prevention: towards a new classification scheme. J Ment Health Policy Econ. 2013; 16:179-86.

31. Jander A, Crutzen R, Mercken L, de Vries H. A Web-based computer-tailored game to reduce binge drinking among 16 to 18 year old Dutch adolescents: development and study protocol. BMC Public Health. 2014;14:1054.

32. Wechsler H, Dowdall GW, Davenport A, Rimm EB. A gender-specific measure of binge drinking among college students. Am J Public Health. 1995;85:982-5.

33. de Vries H, Mudde A, Leijs I, Charlton A, Vartiainen E, Buijs G, et al. The European Smoking Prevention Framework Approach (EFSA): an example of integral prevention. Health Educ Res. 2003;18:611-26.

34. Johannesson M. Avoiding double-counting in pharmacoeconomic studies. Pharmacoeconomics. 1997; 11:385-8.

35. Statline. 2014 [cited 20136 May]; Available from: http://statline.cbs.nl/statweb/. Archived at: http://www.webcitation.org/6c7pYgiVK

36. Arkes HR, Blumer C. The Psychology of Sunk Cost. Organ Behav Hum Dec. 1985;35:124-40.

37. Hakkaart-van Roijen L, Tan SS, Bouwmans CA. Handleiding voor kostenonderzoek. Methoden en referentieprijzen voor economische evaluaties in de gezondheidszorg. Geactualiseerde versie 2010.

Diemen: College voor Zorgverzekeringen, 2011 ; Available from:

http://www.zorginstituutnederland.nl/binaries/content/documents/zinl-

www/documenten/publicaties/overige-publicaties/1007-handleiding-voor-kostenonderzoek/1007-

handleiding-voor-kostenonderzoek/Handleiding+voor+kostenonderzoek.pdf. Archived at: http://www.webcitation.org/6c93WU4sJ

38. Drost RMWA, Paulus ATG, Ruwaard D, Evers SMAA. Handleiding intersectorale kosten en baten van (preventieve) interventies: Classificatie, identificatie en kostprijzen. Maastricht: Maastricht University, Department of Health Services Research, 2014. ISBN:9789461593429

39. Bouwmans CAM, Schawo SJ, Jansen DEMC, Vermeulen KM, Reijneveld SA, Hakkaart-van Roijen L. iMTA Questionnaire Intensive Youth Care. 2012 [cited 201320 November]; Available from: https://www.bmg.eur.nl/fileadmin/ASSETS/bmg/Onderzoek/Onderzoeksrapporten__Working_Pape rs/2012.06_-_Handleiding_Vragenlijst_Intensieve_Jeugdzorg.pdf. Archived at: http://www.webcitation.org/6c7qepCdu

40. Cloï M, Kamphuis C, Schols M, Tiessen-Raaphorst A, Verbeek D. Nederland in een dag: Tijdsbesteding in Nederland vergeleken met die in vifftien andere Europese landen. The Hague: Sociaal Cultureel Planbureau, 2011 . ISBN:9789037704051

41. Jellinek. [updated July 2012; cited 201521 April]; Available from: http://www.jellinek.nl/vraagantwoord/hoeveel-kosten-drugs/. Archived at: http://www.webcitation.org/6c7pQEam8

42. Killip S, Mahfoud Z, Pearce K. What is an intracluster correlation coefficient? Crucial concepts for primary care researchers. Ann Fam Med. 2004;2:204-8. 
43. Drummond M, O'Brien BJ, Stoddart G, Torrance GW. Methods for the Economic Evaluation of Health Care Programmes. New York: Oxford University Press; 2005. ISBN:0198529457

44. Cramer D, Howitt $D$. The Sage dictionary of statistics: a practical resource for students in the social sciences. Thousand Oaks: Sage; 2004. ISBN: 978-0761941385

45. CBS. Leefstijl en (preventief) gezondheidsonderzoek; persoonskenmerken. 2015 [cited 201520 August]; Available from: http://statline.cbs.nl/Statweb/publication/? DM=SLNL\&PA=8302 1 NED\&D $1=11$ 16\&D2=a\&D3=0\&D4=|\&VW=T. Archived at: http://www.webcitation.org/6c7pHUss6

46. Byford S, Raftery J. Perspectives in economic evaluation. BMJ. 1998;316:1529-30.

47. Jonsson B. Ten arguments for a societal perspective in the economic evaluation of medical innovations. Eur J Health Econ. 2009; 10:357-9.

48. Knies S, Severens JL, Ament AJ, Evers SM. The transferability of valuing lost productivity across jurisdictions. differences between national pharmacoeconomic guidelines. Value Health. 2010;13: 519-27.

49. Ahmad S. Closing the youth access gap: the projected health benefits and cost savings of a national policy to raise the legal smoking age to 21 in the United States. Health Policy. 2005;75:74-84.

50. Blankers M, Koeter MW, Schippers GM. Missing data approaches in eHealth research: simulation study and a tutorial for nonmathematically inclined researchers. J Med Internet Res. 2010;12:e54.

51. Eysenbach $G$. The law of attrition. J Med Internet Res. 2005;7:e 11 .

52. McKay HG, Danaher BG, Seeley JR, Lichtenstein E, Gau JM. Comparing two web-based smoking cessation programs: randomized controlled trial. J Med Internet Res. 2008; 10:e40.

53. Shahab L, McEwen A. Online support for smoking cessation: a systematic review of the literature. Addiction. 2009; 104:1792-804.

54. Webb TL. Commentary on Shahab \& McEwen (2009): Understanding and preventing attrition in online smoking cessation interventions: a self-regulatory perspective. Addiction. 2009; 104:1805-6.

55. West R, Hajek P, Stead L, Stapleton J. Outcome criteria in smoking cessation trials: proposal for a common standard. Addiction. 2005; 100:299-303. PMID: 15733243.

56. Acock AC. Working with missing values. J Marriage Fam. 2005;67:1012-28.

57. Sobell LC, Cellucci T, Nirenberg TD, Sobell MB. Do quantity-frequency data underestimate drinkingrelated health risks? Am J Public Health. 1982;72:823-8.

58. Devlin N, Parkin D. Does NICE have a cost-effectiveness threshold and what other factors influence its decisions? A binary choice analysis. Health Econ. 2004; 13:437-52.

59. Neumann PJ, Cohen JT, Weinstein MC. Updating cost-effectiveness--the curious resilience of the $\$ 50,000$ per-QALY threshold. N Engl J Med. 2014;371:796-7.

60. Evers SM, Hiligsmann M, Adarkwah CC. Risk of bias in trial-based economic evaluations: identification of sources and bias-reducing strategies. Psychol Health. 2015;30:52-71.

61. de Vries H, Logister M, Krekels G, Klaasse F, Servranckx V, van Osch L. Internet based computer tailored feedback on sunscreen use. J Med Internet Res. 2012;14:e48.

62. Kohl LF, Crutzen R, de Vries NK. Online prevention aimed at lifestyle behaviors: a systematic review of reviews. J Med Internet Res. 2013;15:e146. 


\section{Additional file 6.1}

List of limits of realistic answers to the questions in the cost questionnaires at TO and T1.

\begin{tabular}{lcc}
\hline Cost category & Unit & Maximum amount \\
\hline Health care sector & & \\
General practitioner & Contacts & 60 \\
Emergency care & Contacts & 40 \\
Hospital stays & Days & 120 \\
Ambulance rides & Rides & 20 \\
$\quad$ Mental health care & Contacts & 60 \\
Educational sector & & \\
School absenteeism & Days & 120 \\
Attendance officer & Contacts & 40 \\
Labor \& social security & & \\
Work absenteeism & Days & 120 \\
Household \& leisure & & \\
Failure to perform household activities & Days & 120 \\
Failure to perform other activities & Days & 120 \\
Youth and family center & Contacts & 40 \\
Family care & Contacts & 40 \\
Criminal justice system & & \\
Police services & Contacts & 40 \\
Youth police services & Contacts & 40 \\
Court proceedings & Amount & 40 \\
Child protection services & Contacts & 40 \\
Child health protection services & Contacts & 40 \\
Substance use & & \\
Cigarettes & Packs & 360 \\
Soft drugs & Joints etc. & 360 \\
Hard drugs & Pills etc. & 360 \\
\hline & & \\
\hline
\end{tabular}




\section{Additional file 6.2}

Cost-effectiveness planes (left side) and corresponding CEACs (right side) of the economic evaluations based on the weekly alcohol use outcome measure, which were conducted from the health care perspective (upper), societal perspective including drugs and cigarette use (middle) and societal perspective excluding drugs and cigarette use (below) for the subgroups: male/female, younger/older, lower education/higher education, religious/non-religious, and Dutch/non-Dutch. 
Male subgroup

Health care perspective
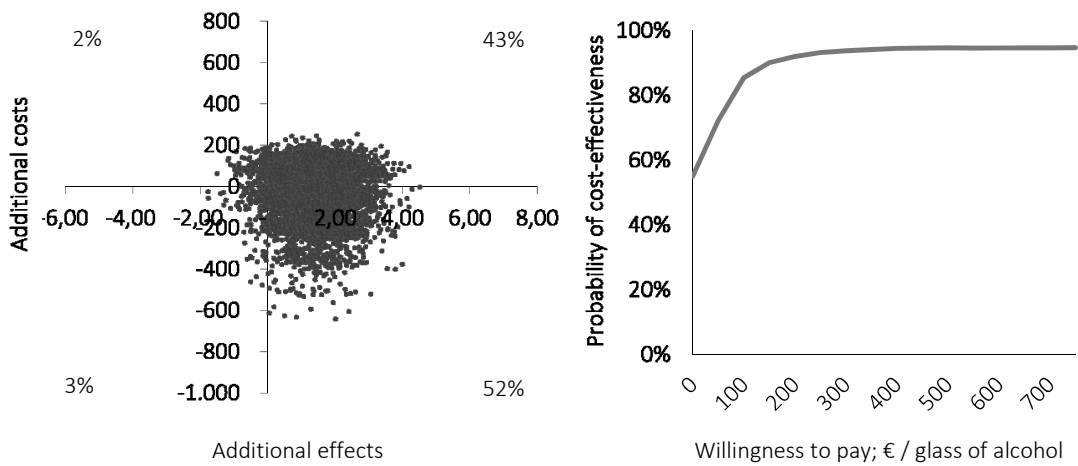

Societal perspective (including drugs and cigarette use)
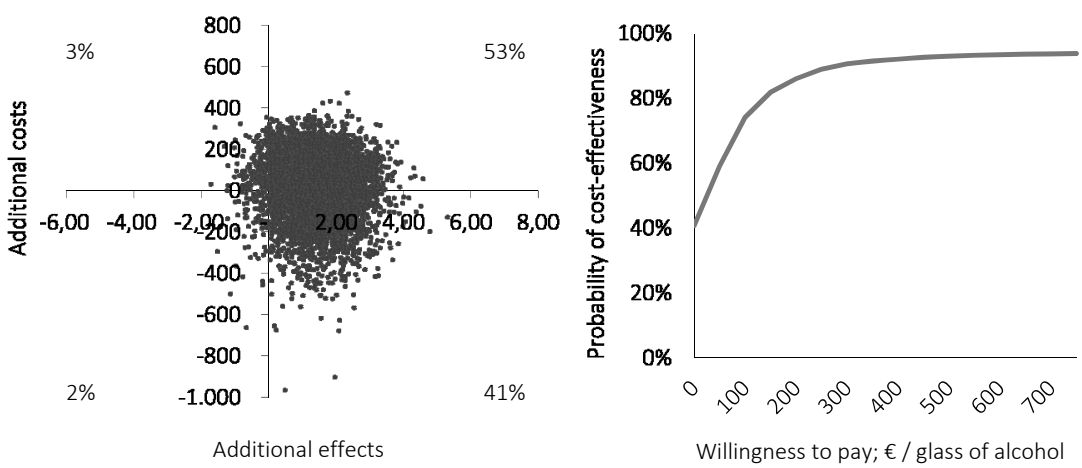

Societal perspective (excluding drugs and cigarette use)
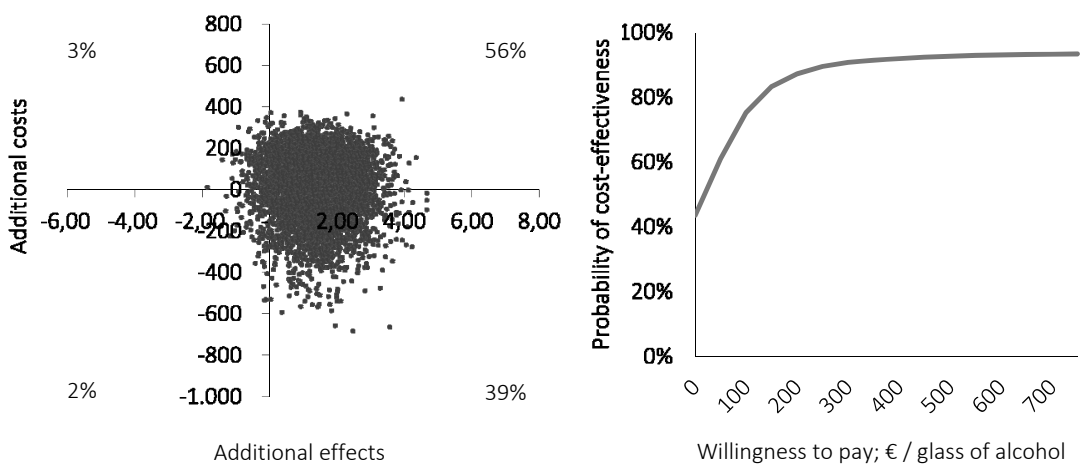
Female subgroup

Health care perspective
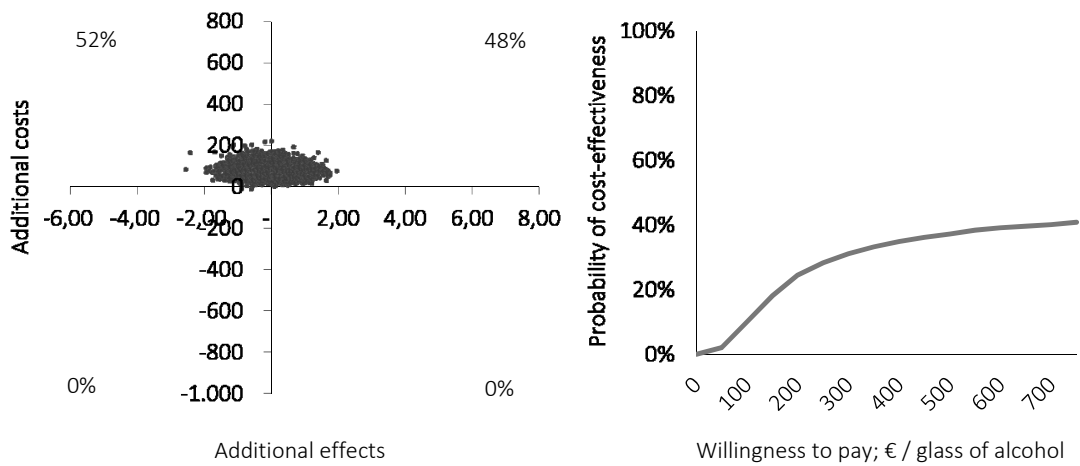

Societal perspective (including drugs and cigarette use)
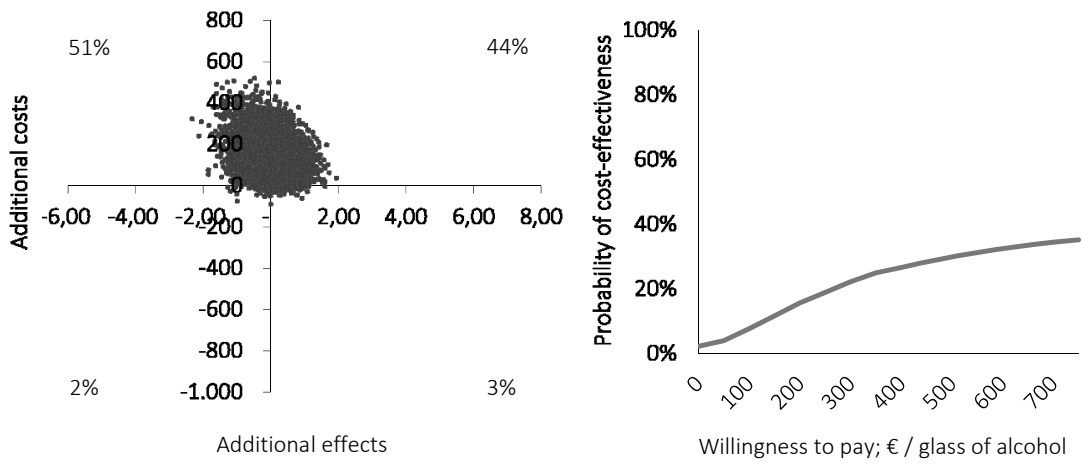

Societal perspective (excluding drugs and cigarette use)
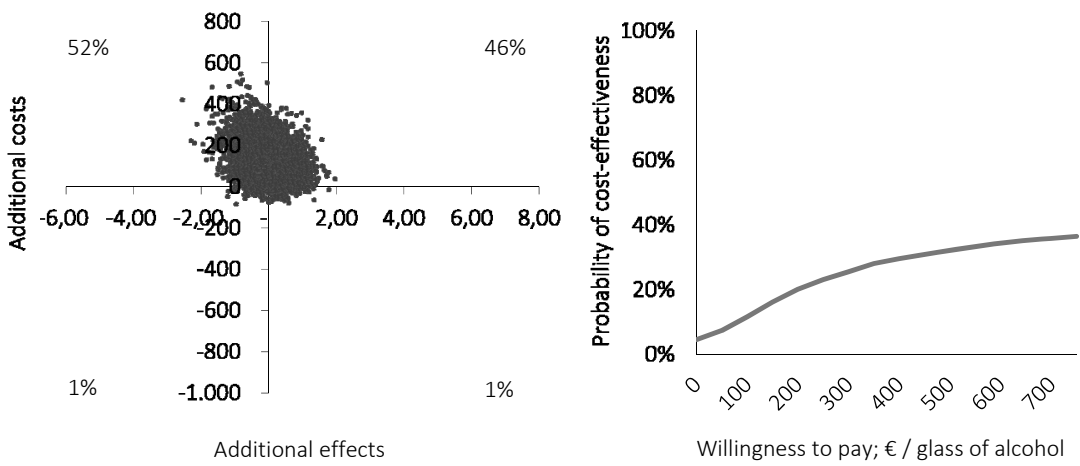
Younger adolescents subgroup

Health care perspective
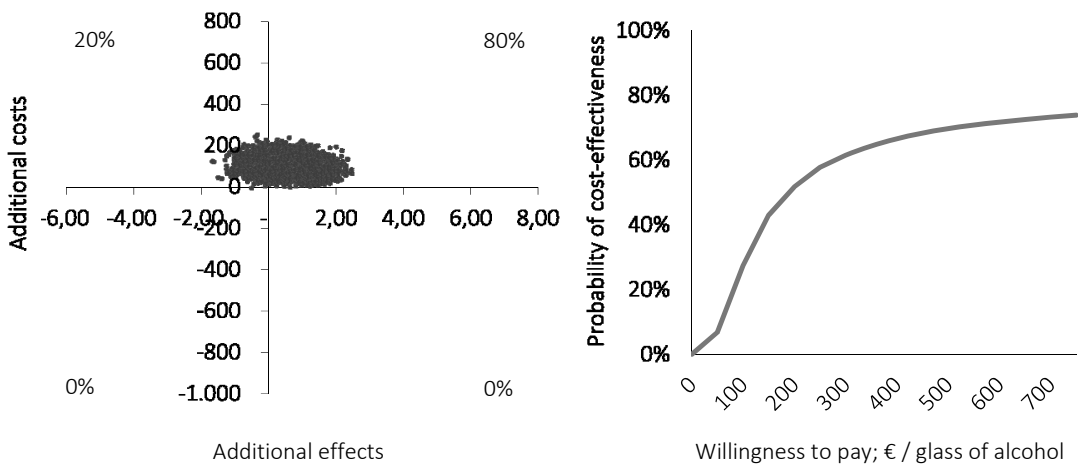

Societal perspective (including drugs and cigarette use)
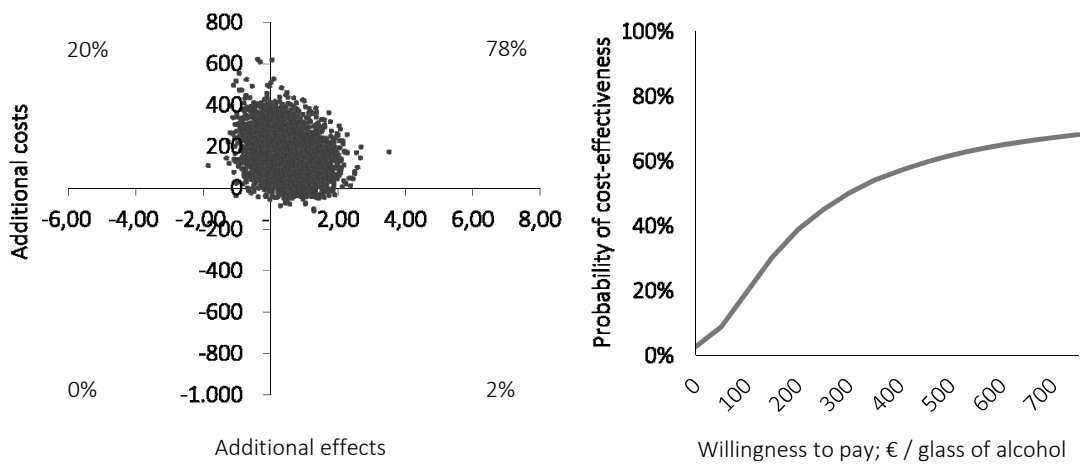

Societal perspective (excluding drugs and cigarette use)
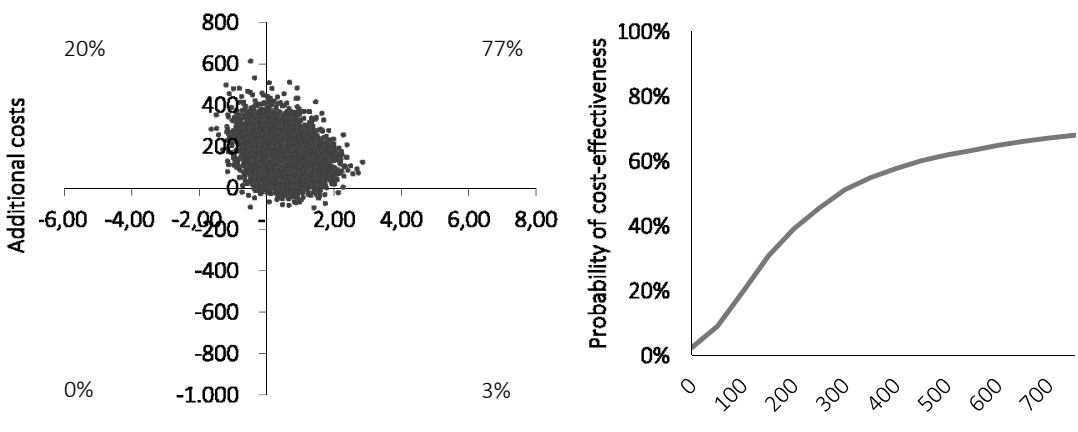

Additional effects

Willingness to pay; $€$ / glass of alcohol 
Older adolescents subgroup

Health care perspective
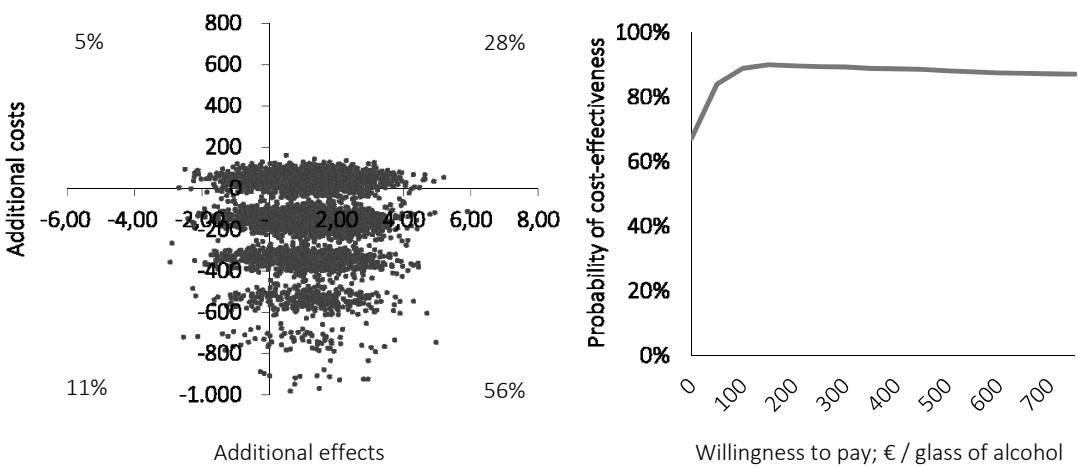

Societal perspective (including drugs and cigarette use)
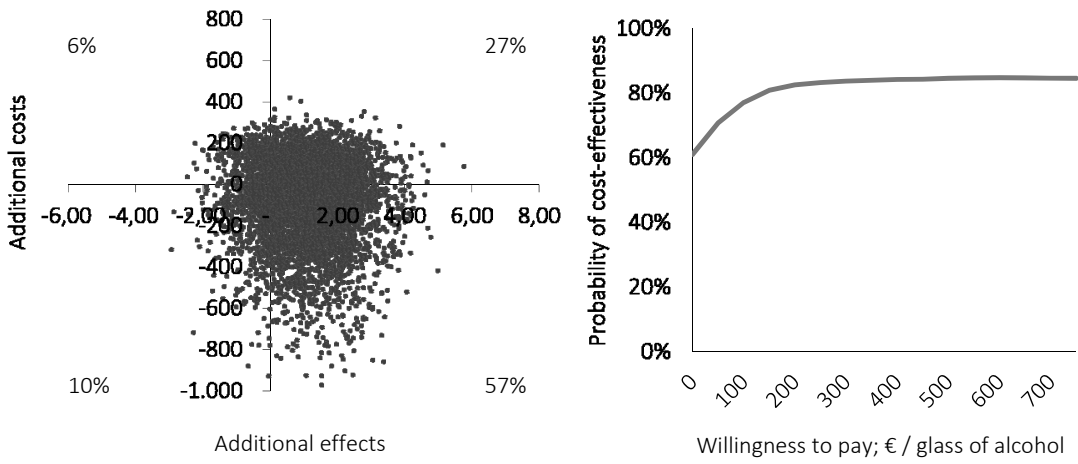

Societal perspective (excluding drugs and cigarette use)
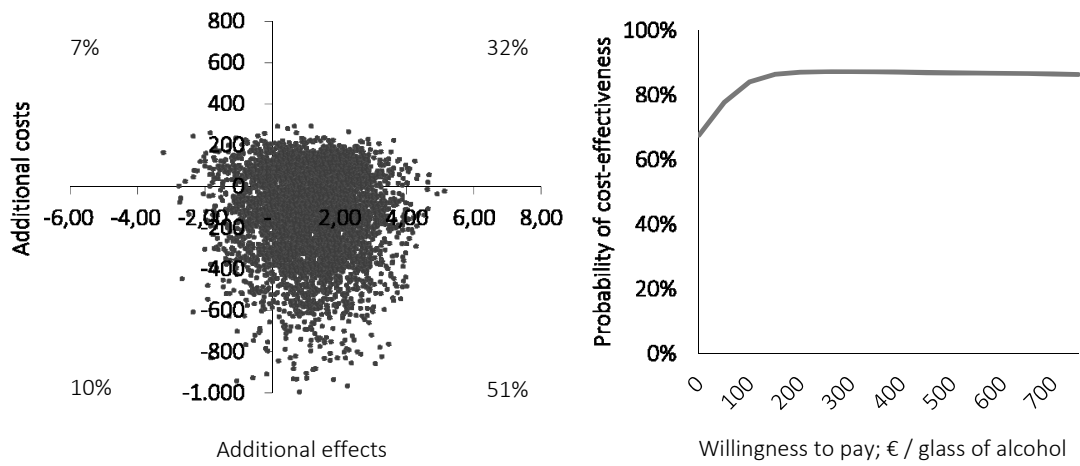


\section{Lower educational level subgroup}

Health care perspective
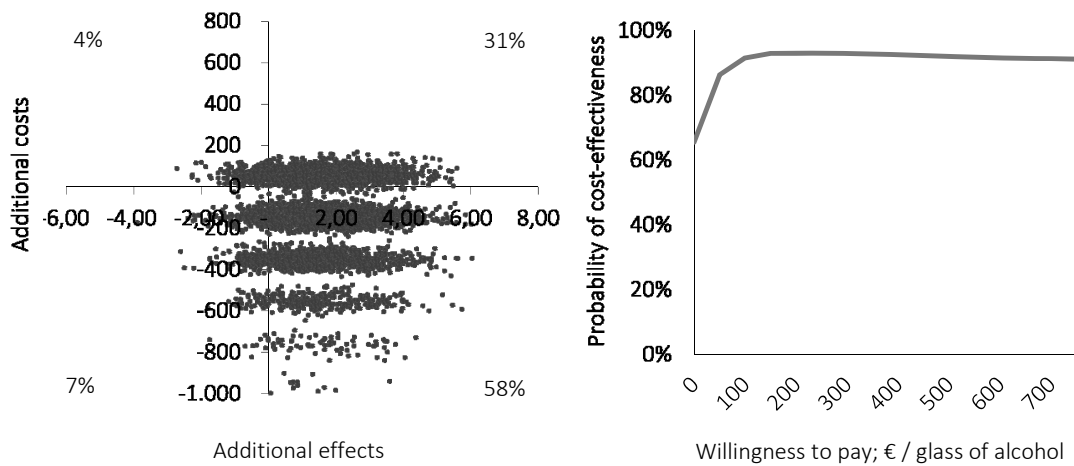

Societal perspective (including drugs and cigarette use)
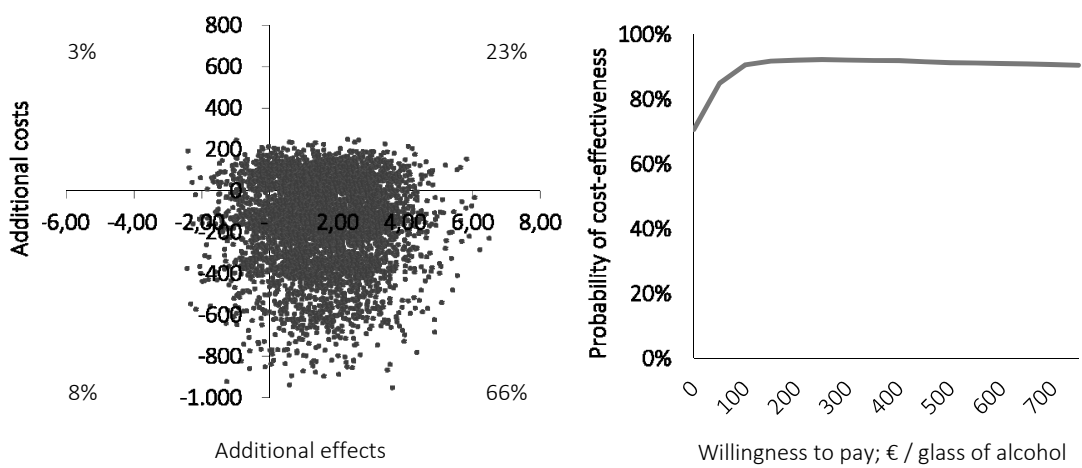

Societal perspective (excluding drugs and cigarette use)
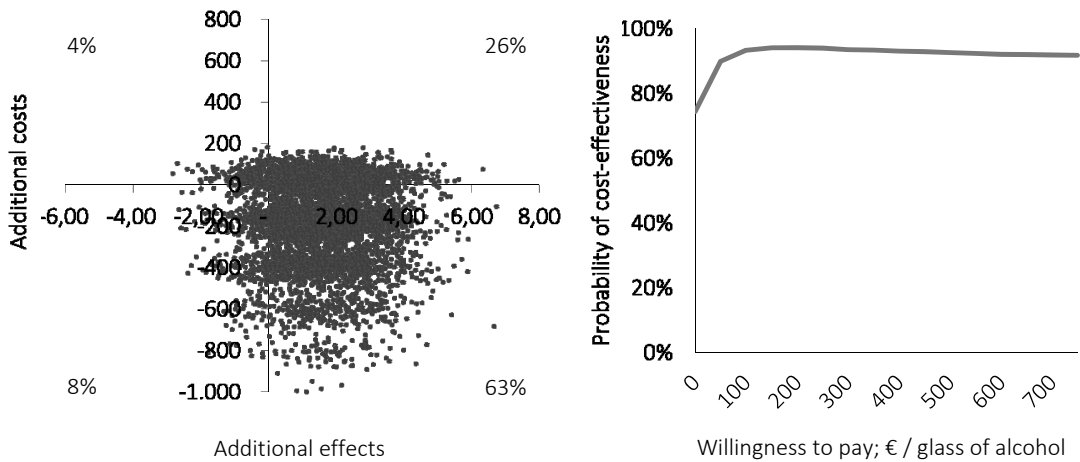

Willingness to pay; $€$ / glass of alcohol 
Higher educational level subgroup

Health care perspective

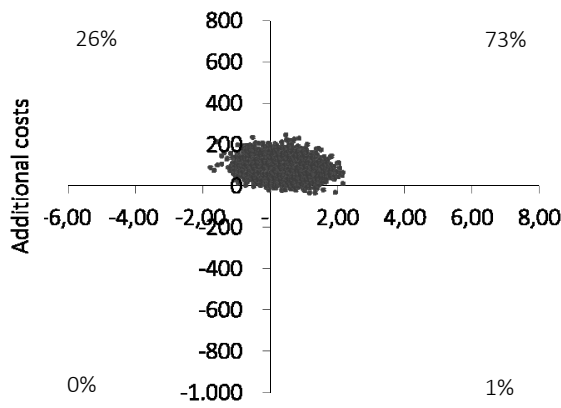

Additional effects

Societal perspective (including drugs and cigarette use)

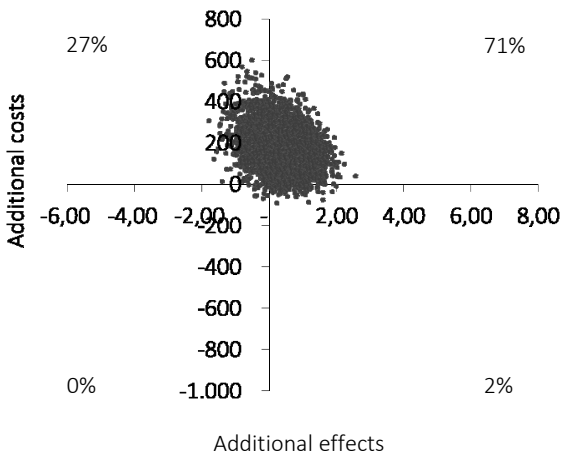

Societal perspective (excluding drugs and cigarette use)

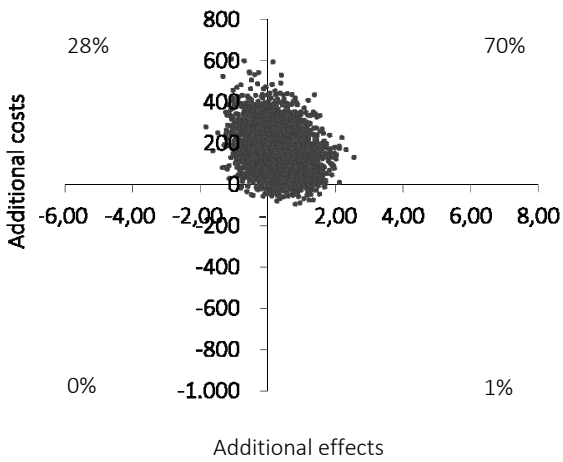

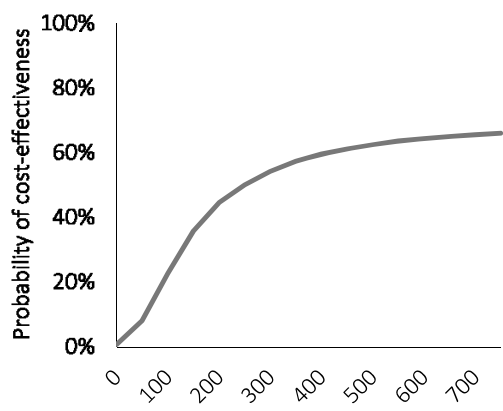

Willingness to pay; $€$ / glass of alcohol
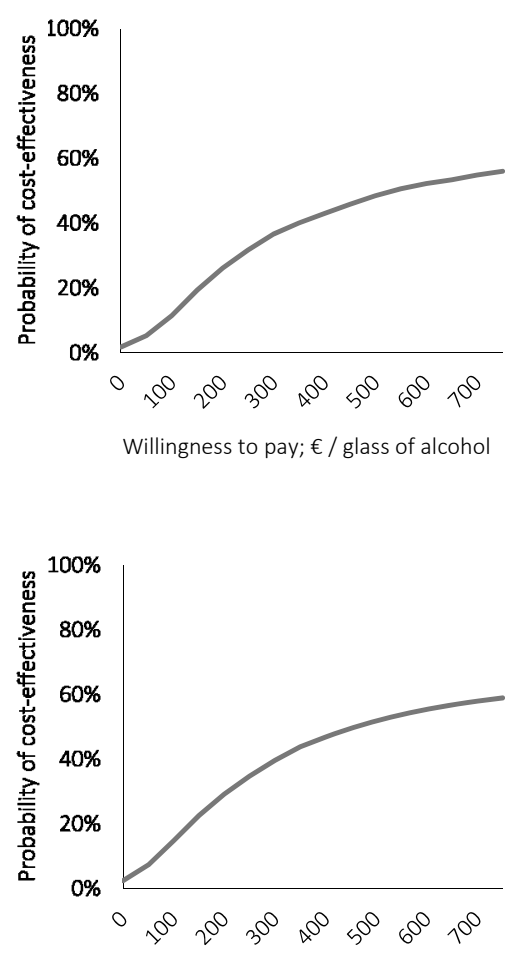

Willingness to pay; $€$ / glass of alcohol 
Religious subgroup

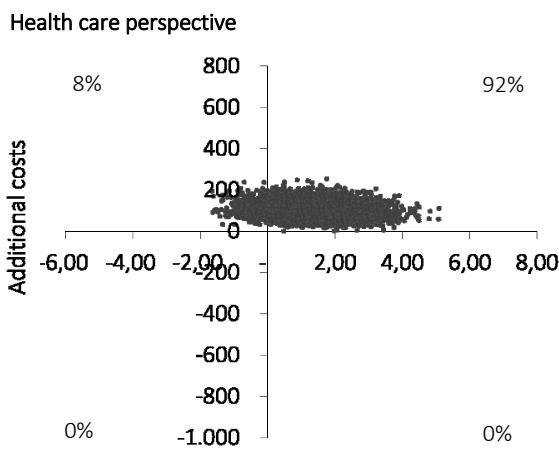

Additional effects

Societal perspective (including drugs and cigarette use)

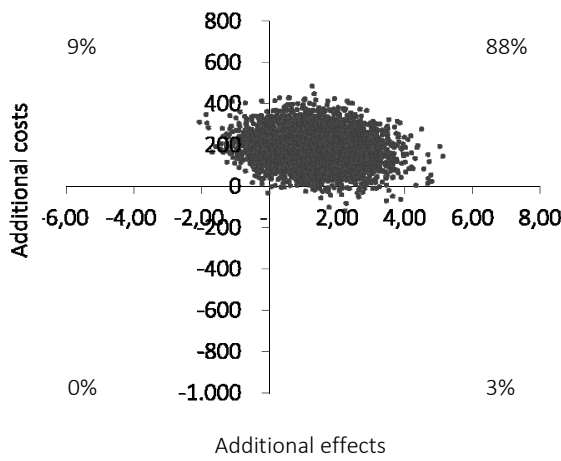

Societal perspective (excluding drugs and cigarette use)

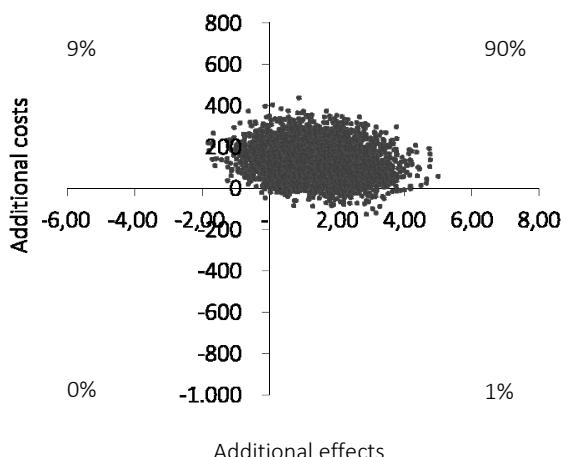

Additional effects

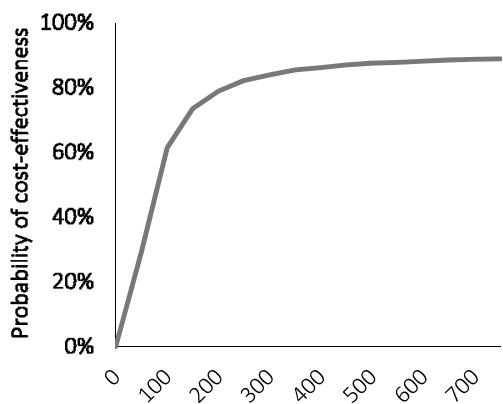

Willingness to pay; $€$ / glass of alcohol

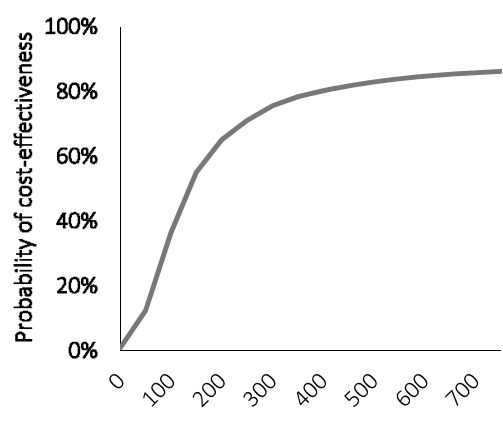

Willingness to pay; $€$ / glass of alcohol

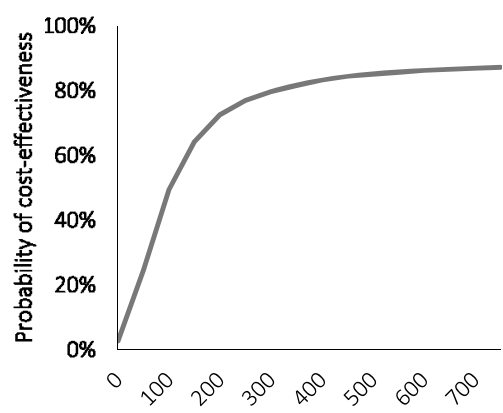

Willingness to pay; $€$ / glass of alcohol 
Non-religious subgroup

Health care perspective

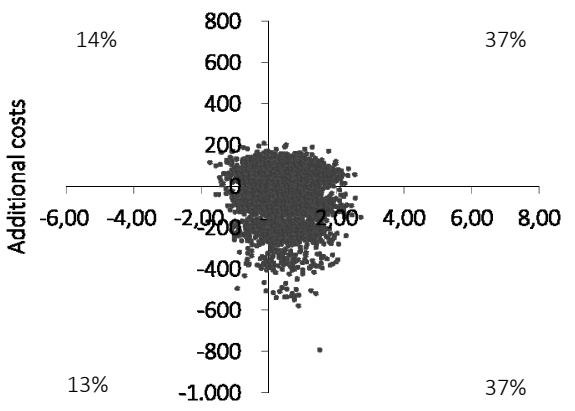

Additional effects

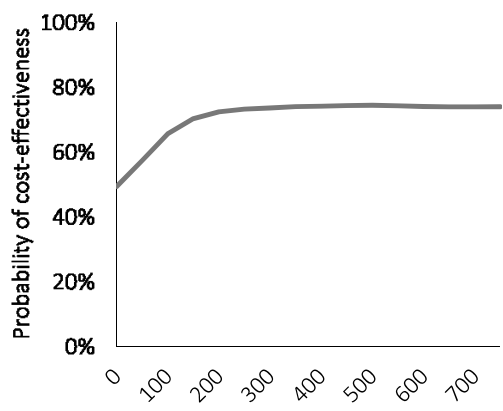

Willingness to pay; $€$ / glass of alcohol

Societal perspective (including drugs and cigarette use)
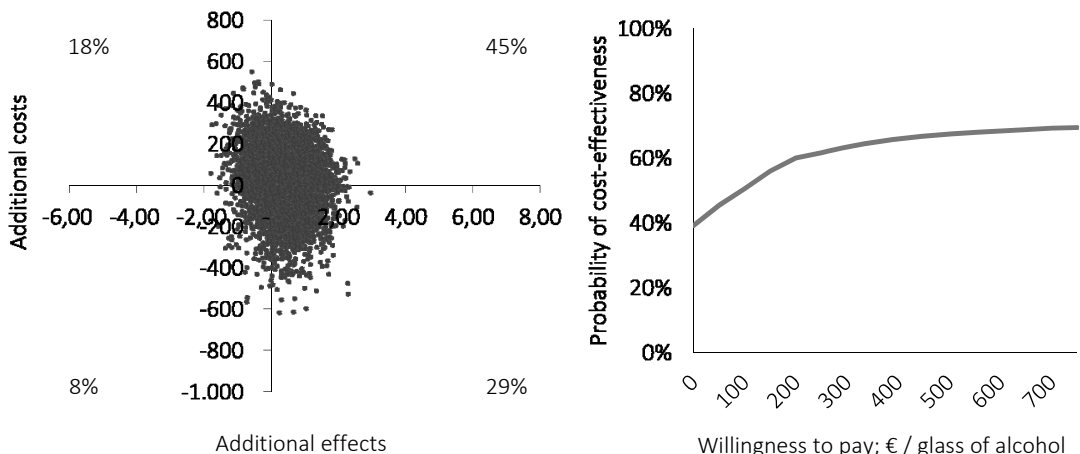

Willingness to pay; $€$ / glass of alcohol

Societal perspective (excluding drugs and cigarette use)
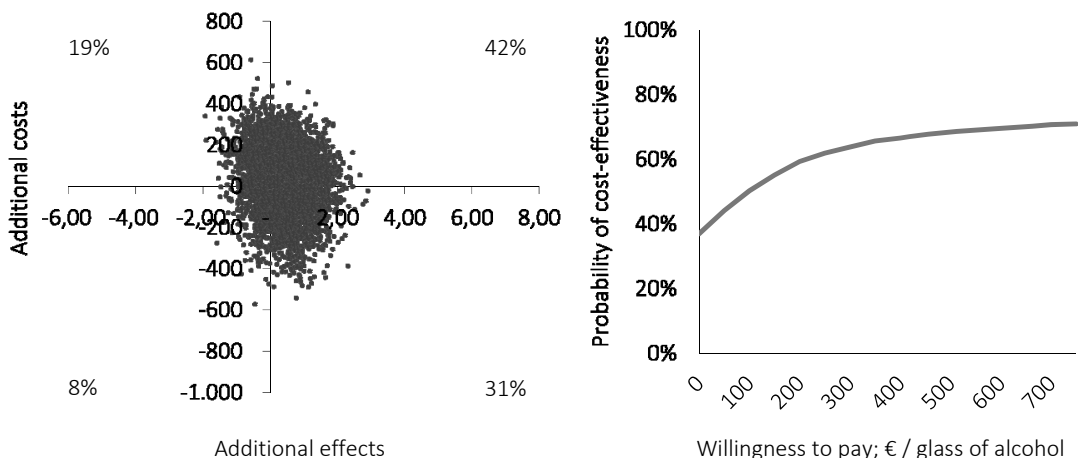

Willingness to pay; $€$ / glass of alcohol 
Dutch ethnicity subgroup

Health care perspective

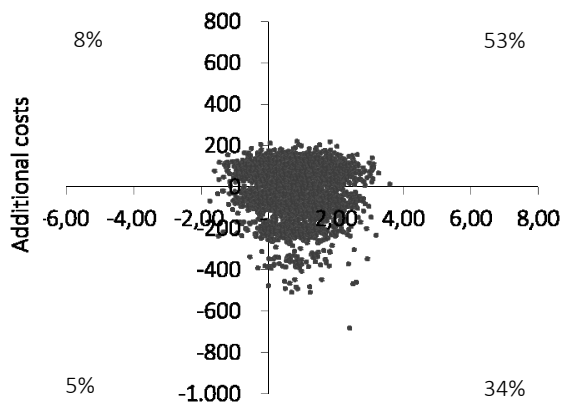

Additional effects

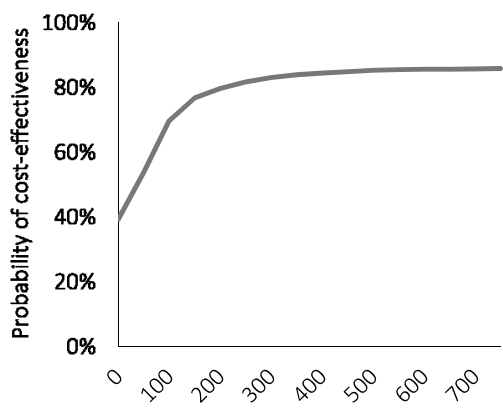

Willingness to pay; $€$ / glass of alcohol

Societal perspective (including drugs and cigarette use)
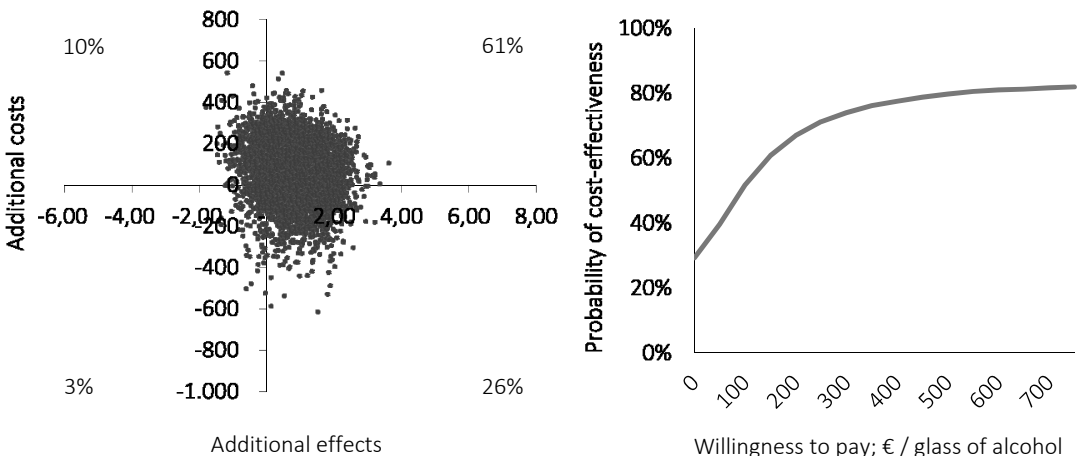

Societal perspective (excluding drugs and cigarette use)
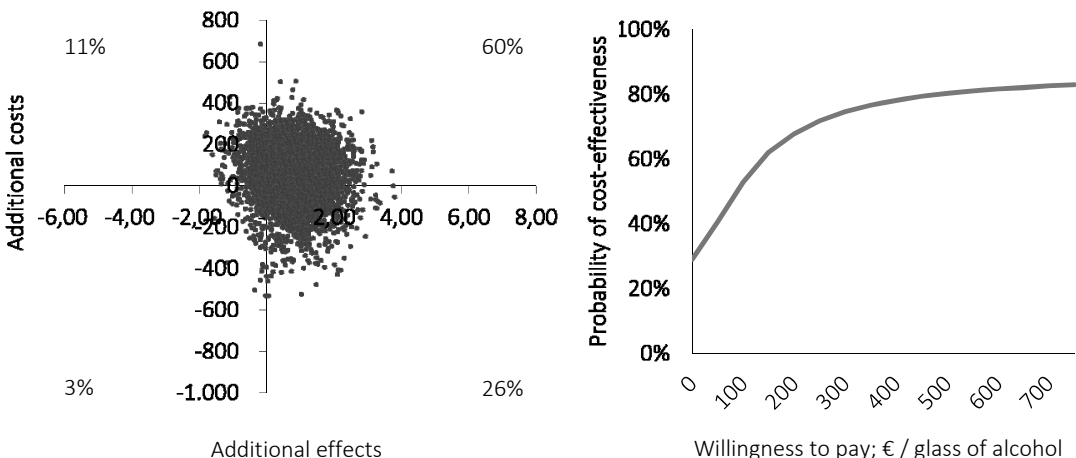

Willingness to pay; $€$ / glass of alcohol 
Other ethnicity subgroup

Health care perspective

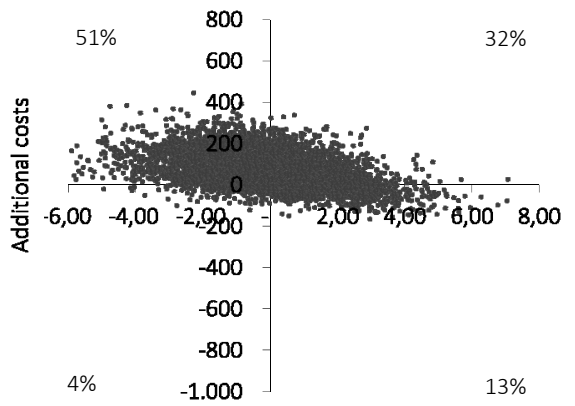

Additional effects

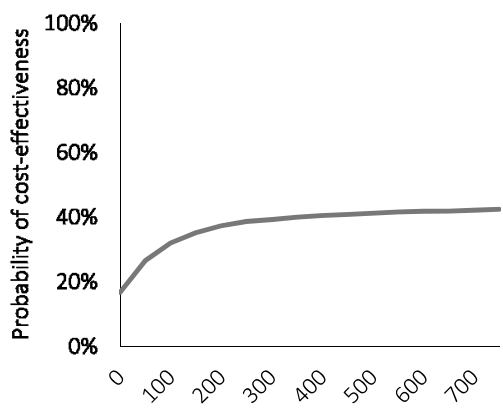

Willingness to pay; $€$ / glass of alcohol

Societal perspective (including drugs and cigarette use)
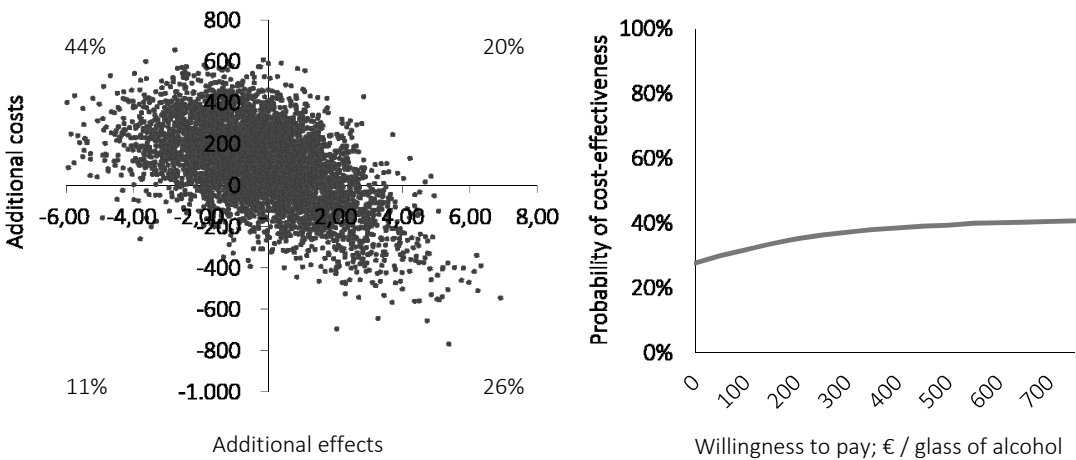

Societal perspective (excluding drugs and cigarette use)
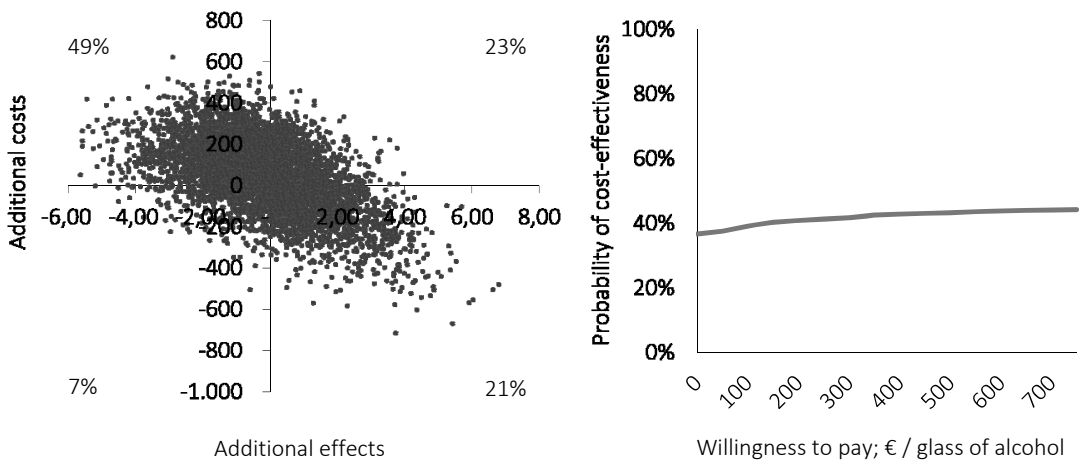


\section{Additional file 6.3}

Cost-effectiveness planes (left side) and corresponding CEACs (right side) of the economic evaluations based on binge drinking occasions outcome measure, which were conducted from the health care perspective (upper), societal perspective including drugs and cigarette use (middle) and societal perspective excluding drugs and cigarette use (below) for the subgroups: male/female, younger/older, lower education/higher education, religious/non-religious, and Dutch/non-Dutch. 
Male subgroup
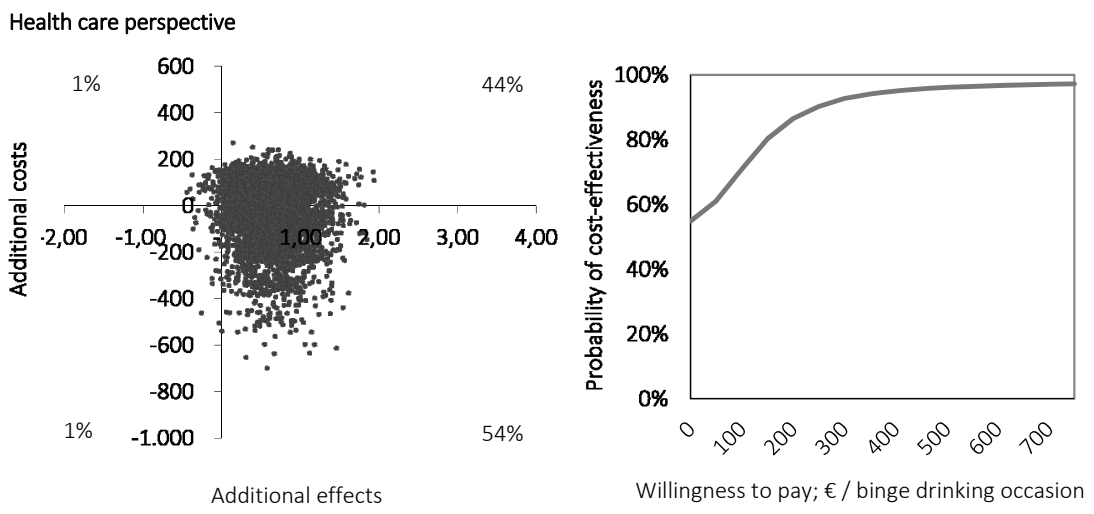

Societal perspective (including drugs and cigarette use)
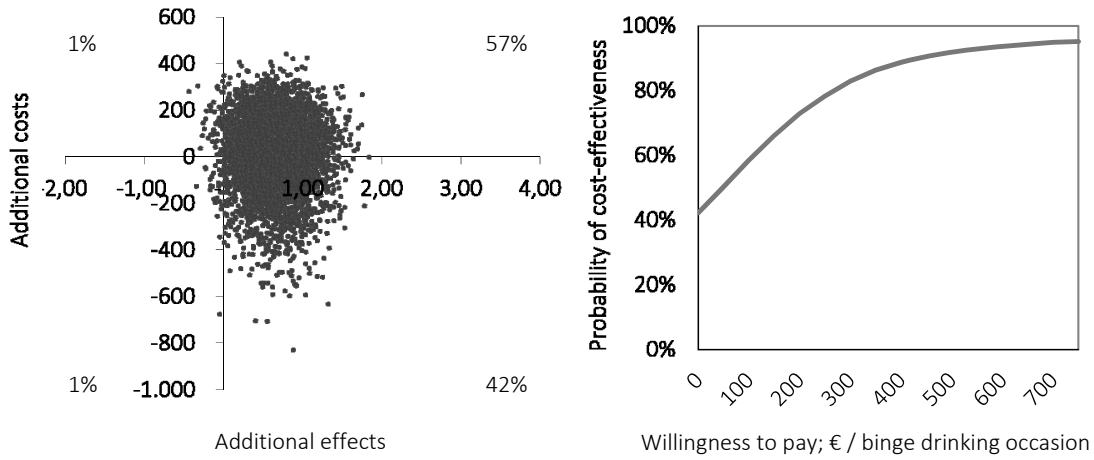

Societal perspective (excluding drugs and cigarette use)
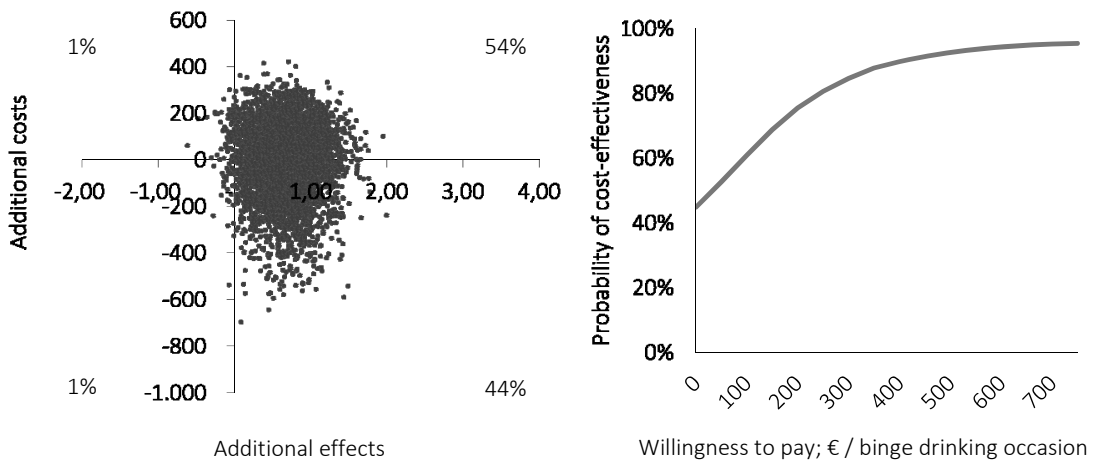

Willingness to pay; $€ /$ binge drinking occasion 
Female subgroup

Health care perspective
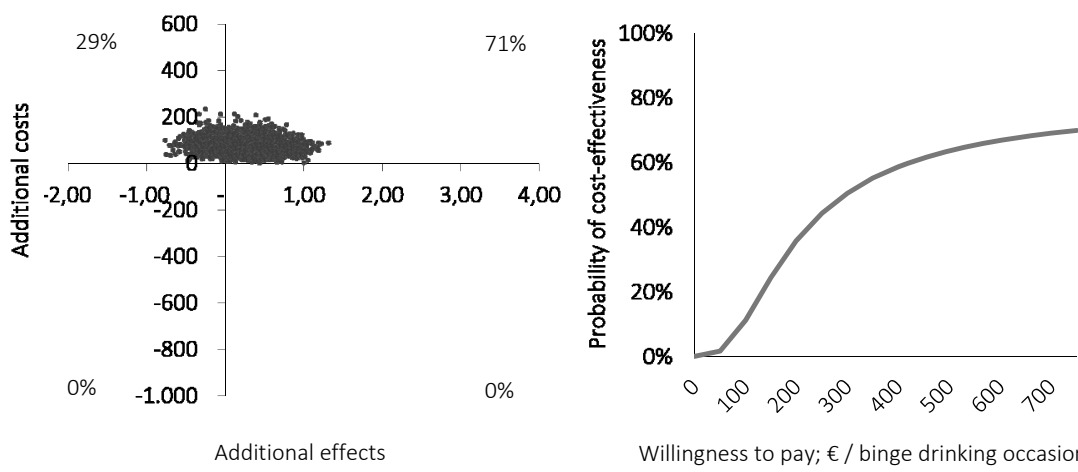

Willingness to pay; $€$ / binge drinking occasion

Societal perspective (including drugs and cigarette use)
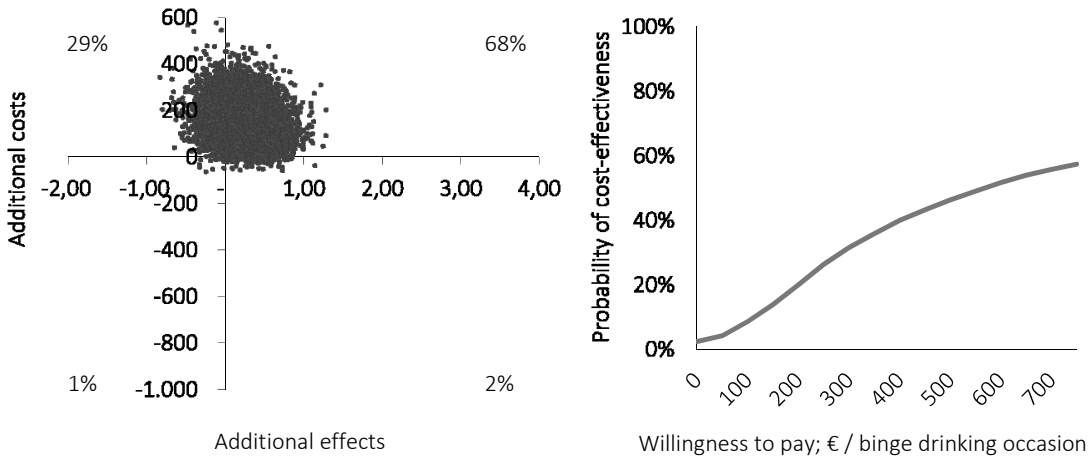

Societal perspective (excluding drugs and cigarette use)
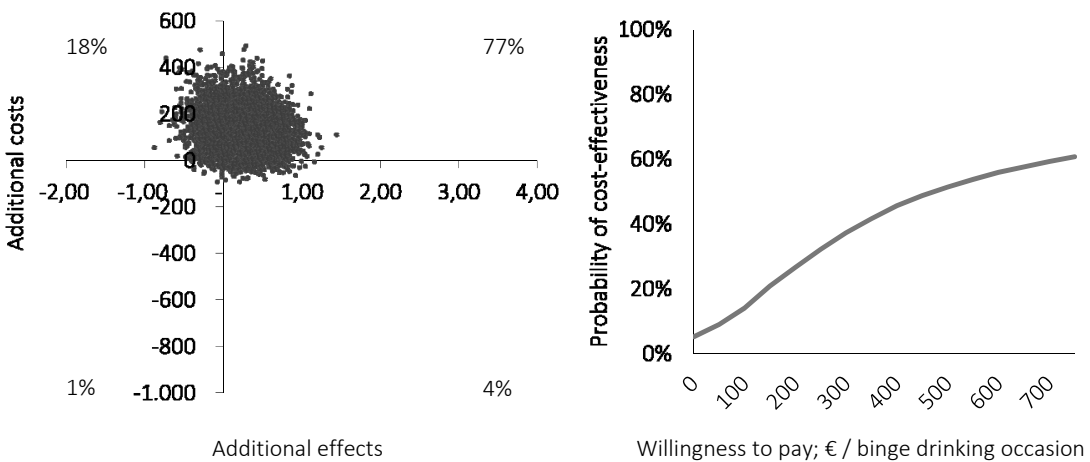
Younger adolescents subgroup

Health care perspective
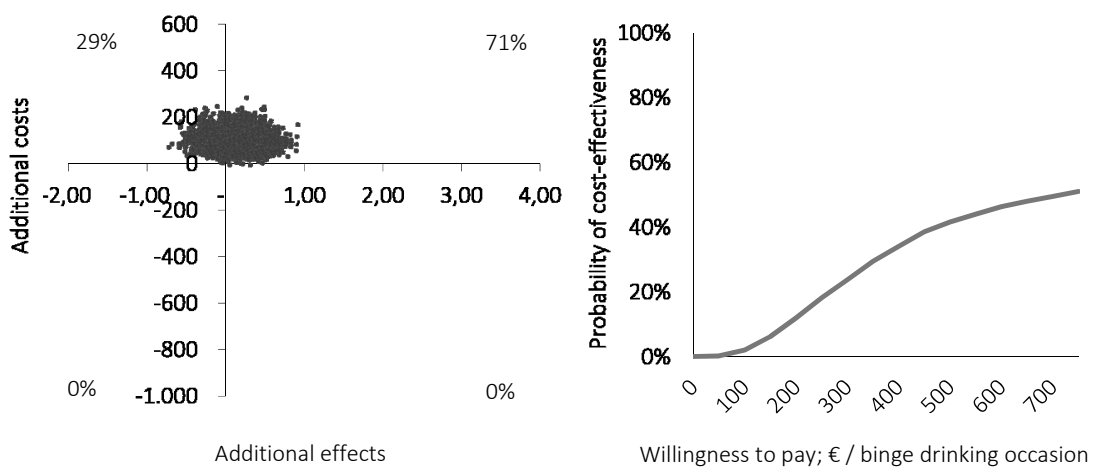

Societal perspective (including drugs and cigarette use)
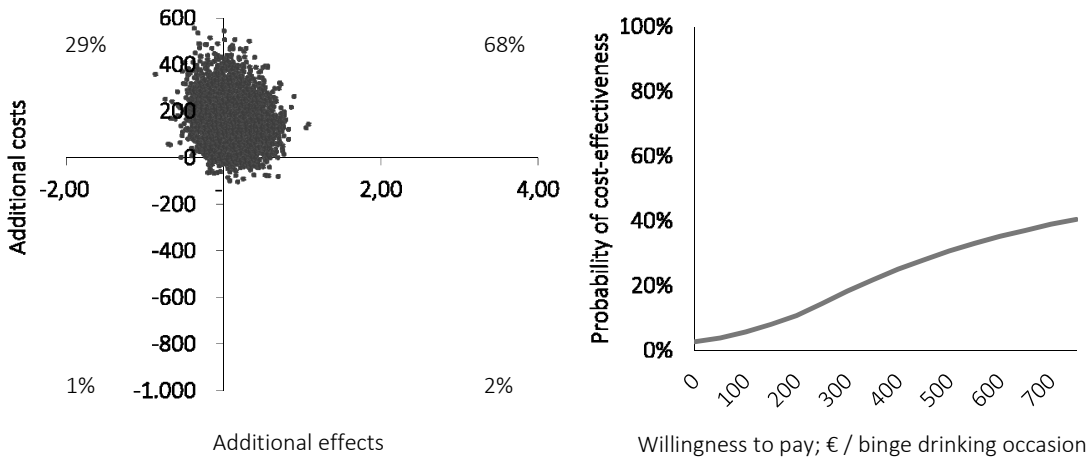

Societal perspective (excluding drugs and cigarette use)
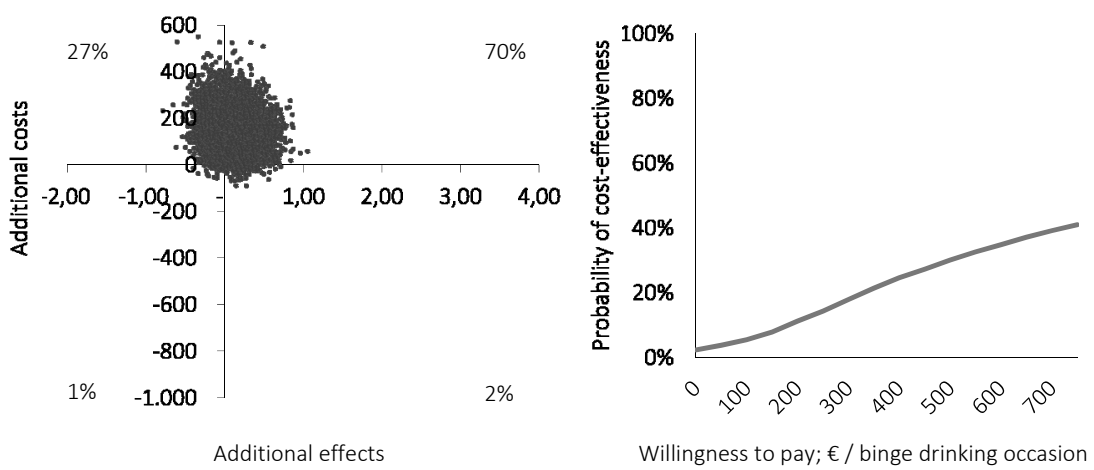

Willingness to pay; €/ binge drinking occasion 
Older adolescents subgroup
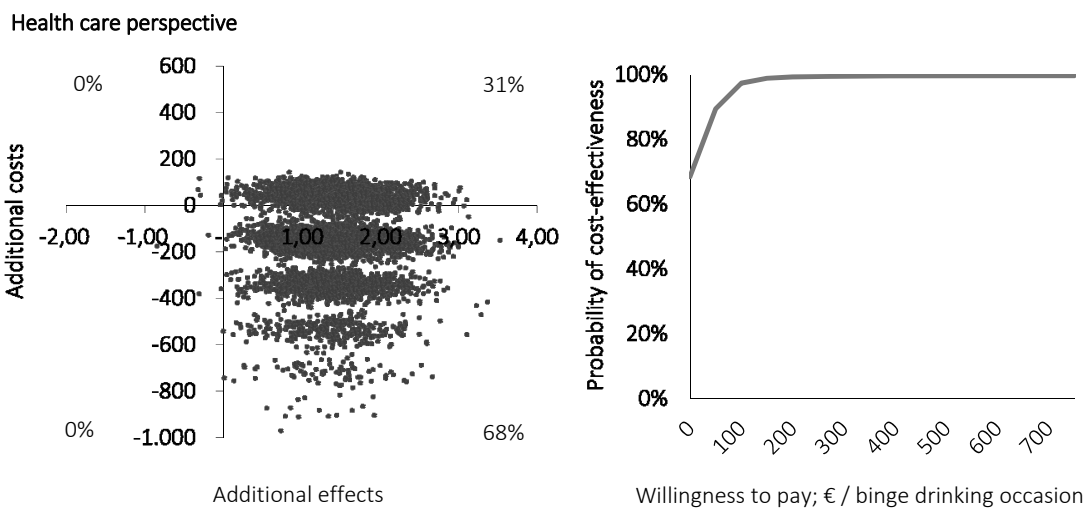

Societal perspective (including drugs and cigarette use)
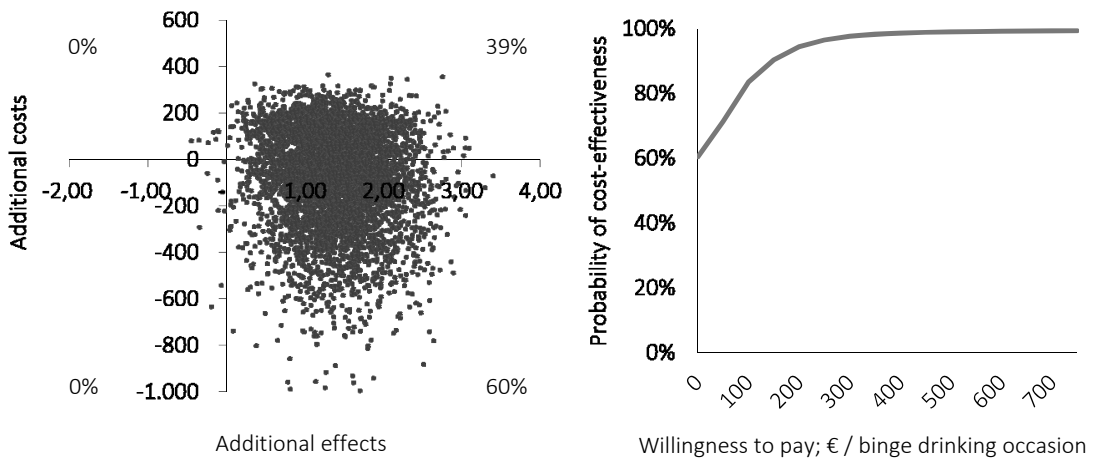

Societal perspective (excluding drugs and cigarette use)
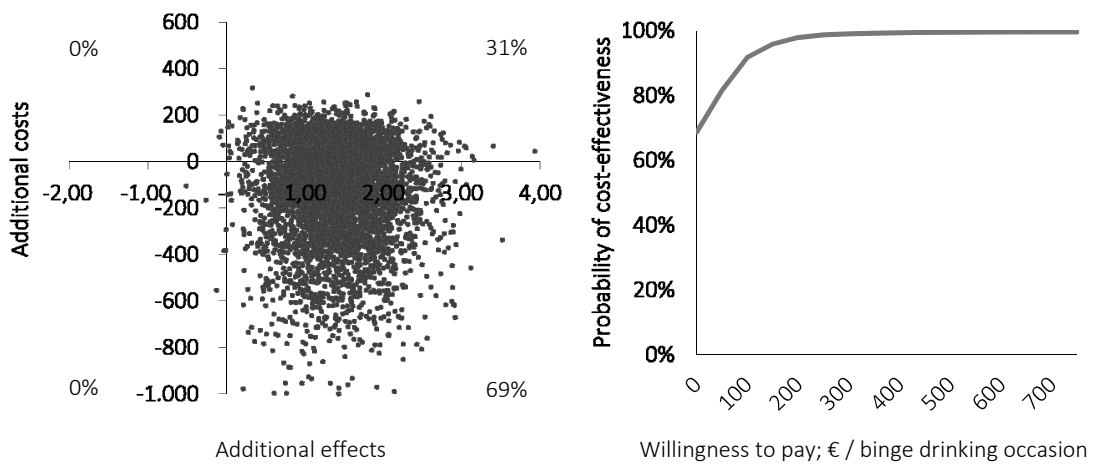


\section{Lower educational level subgroup}

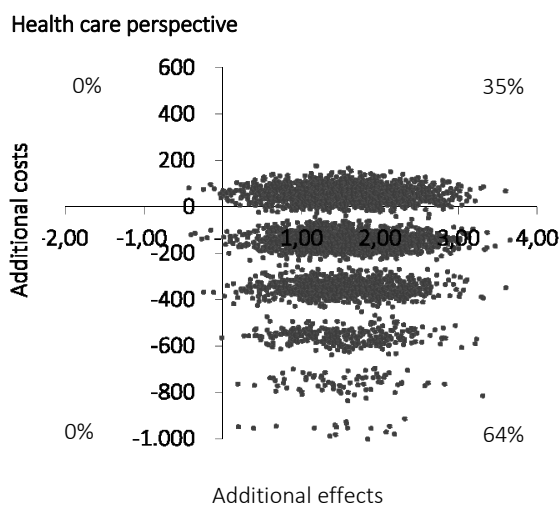

Societal perspective (including drugs and cigarette use)

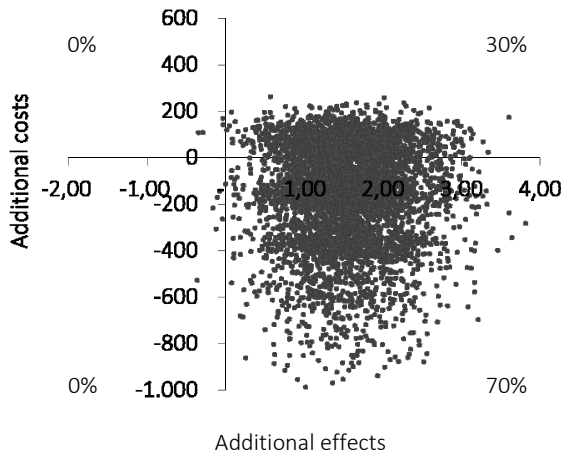

Societal perspective (excluding drugs and cigarette use)

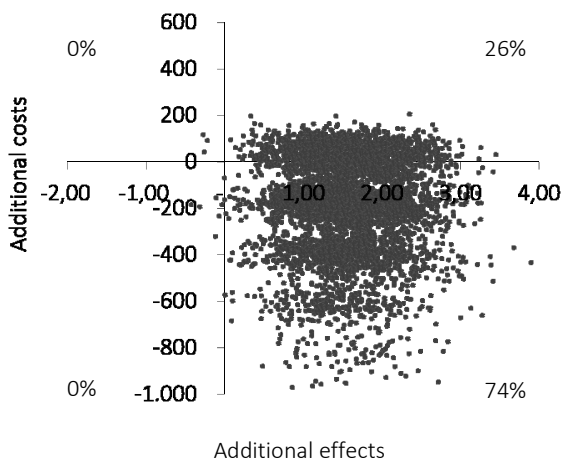

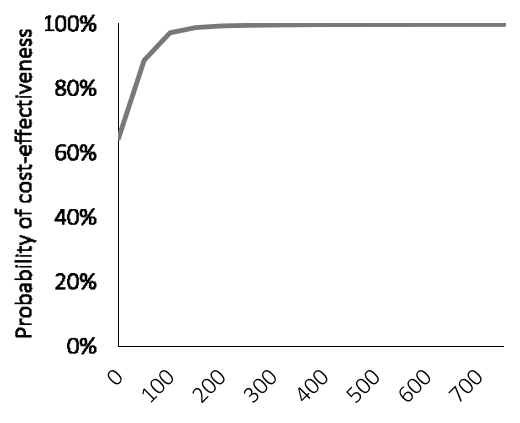

Willingness to pay; $€$ / binge drinking occasion

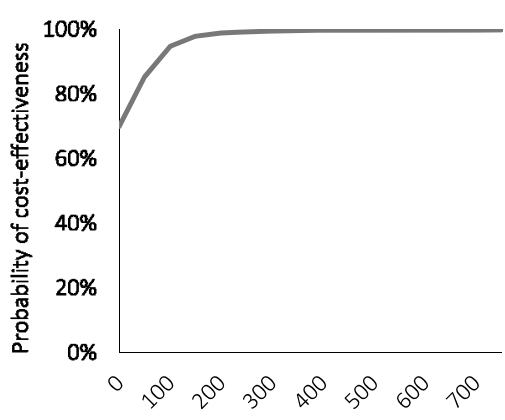

Willingness to pay; $€$ / binge drinking occasion

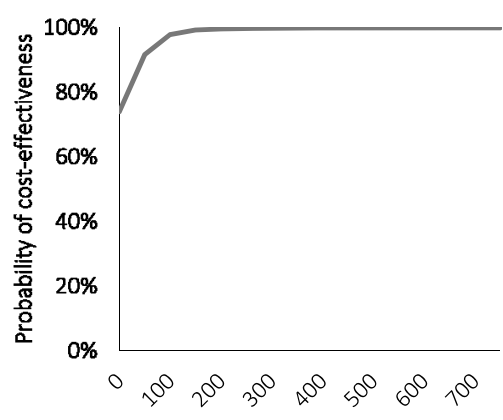

Willingness to pay; € / binge drinking occasion 
Higher educational level subgroup

Health care perspective
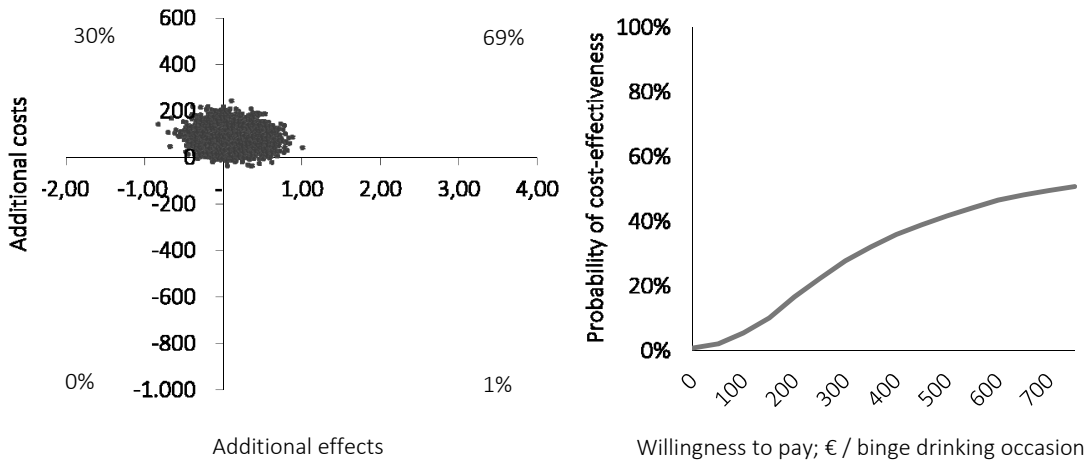

Societal perspective (including drugs and cigarette use)
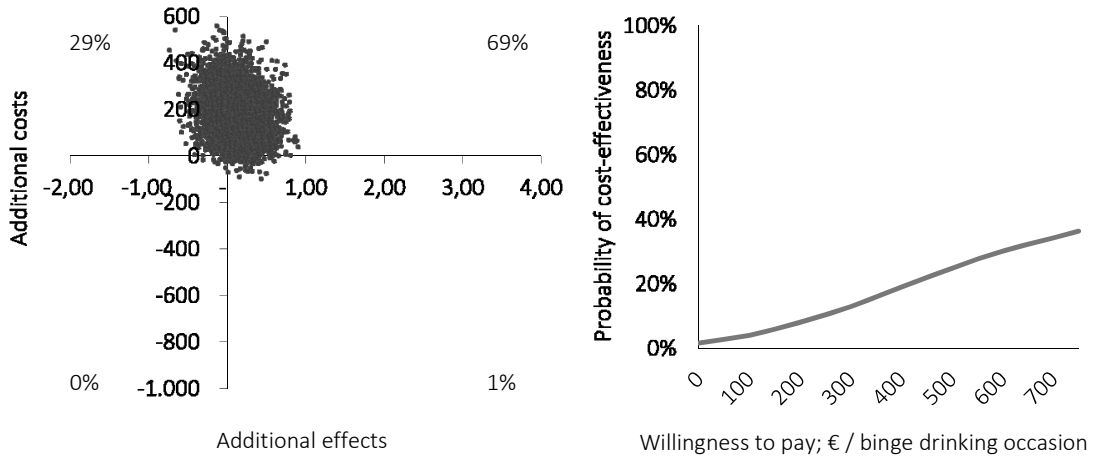

Societal perspective (excluding drugs and cigarette use)
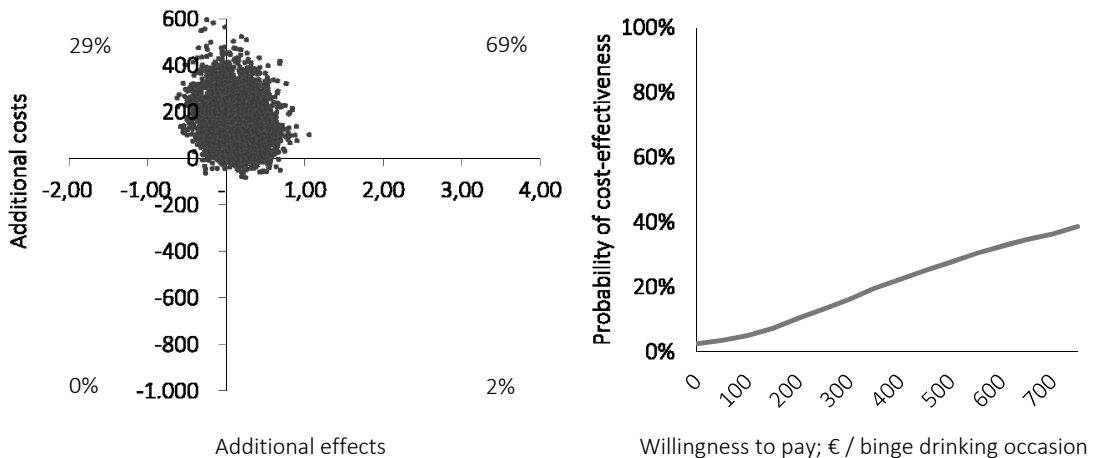
Religious subgroup

Health care perspective
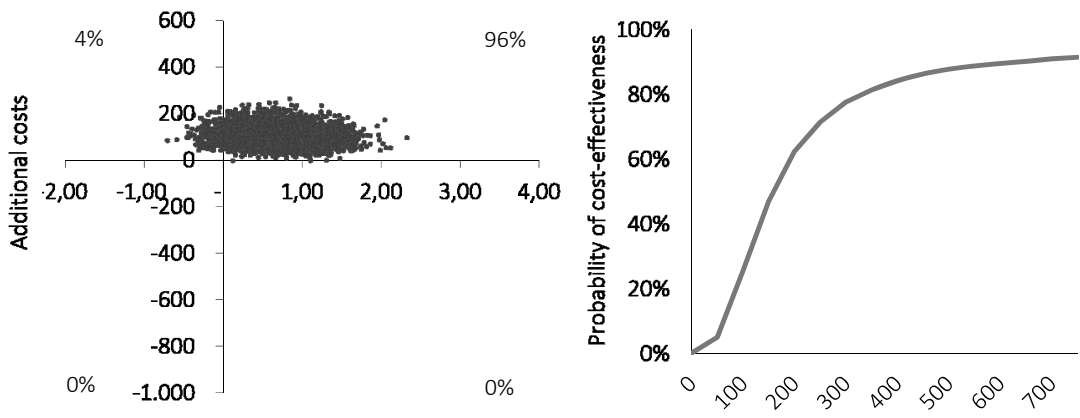

Additional effects

Willingness to pay; $€$ / binge drinking occasion

Societal perspective (including drugs and cigarette use)
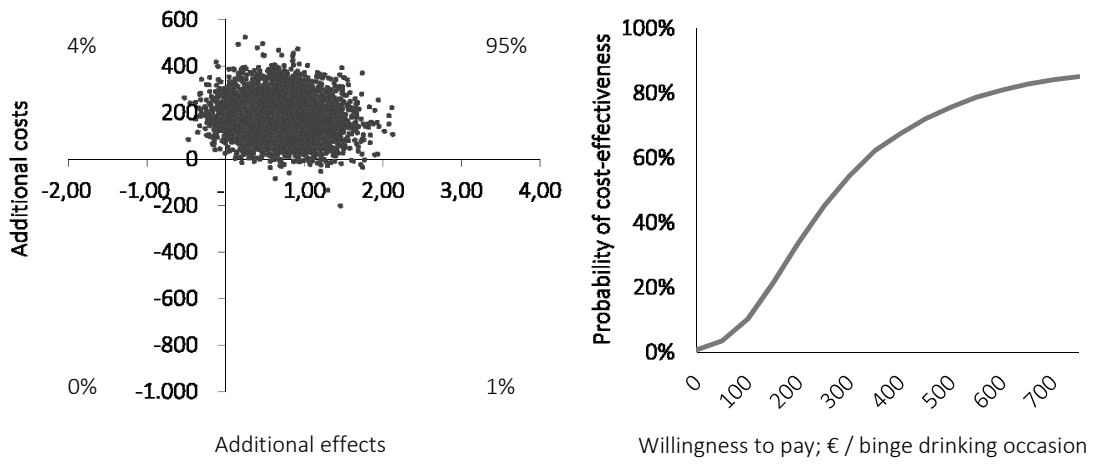

Societal perspective (excluding drugs and cigarette use)
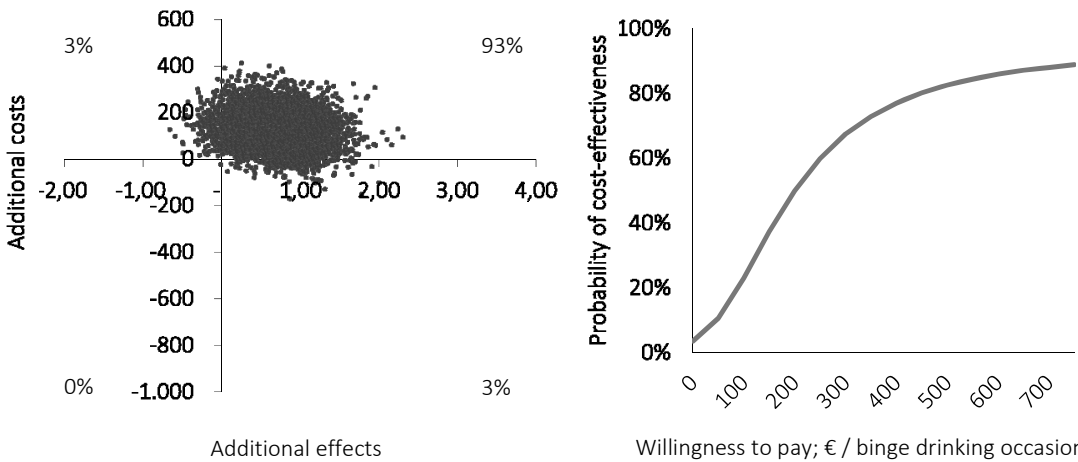

Willingness to pay; $€ /$ binge drinking occasion 
Non-religious subgroup
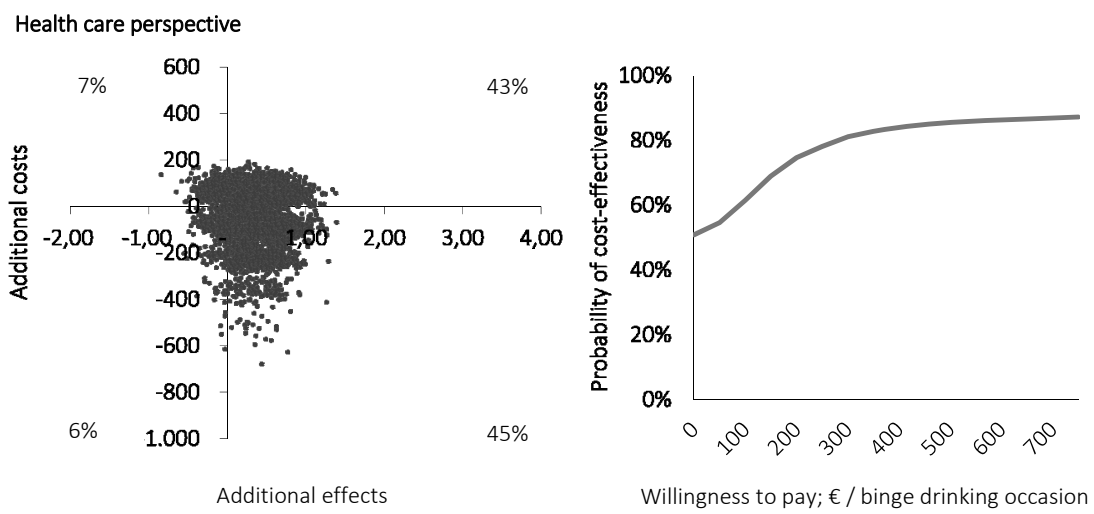

Societal perspective (including drugs and cigarette use)
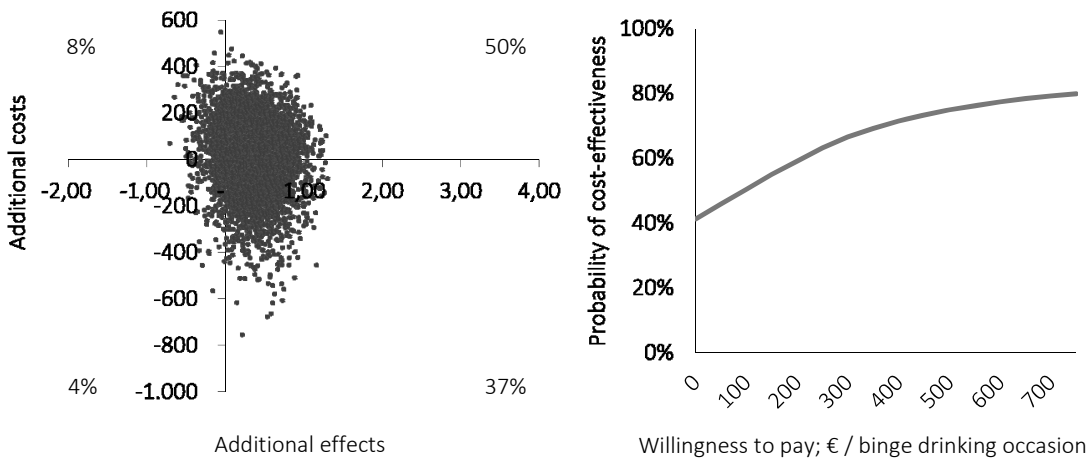

Societal perspective (excluding drugs and cigarette use)
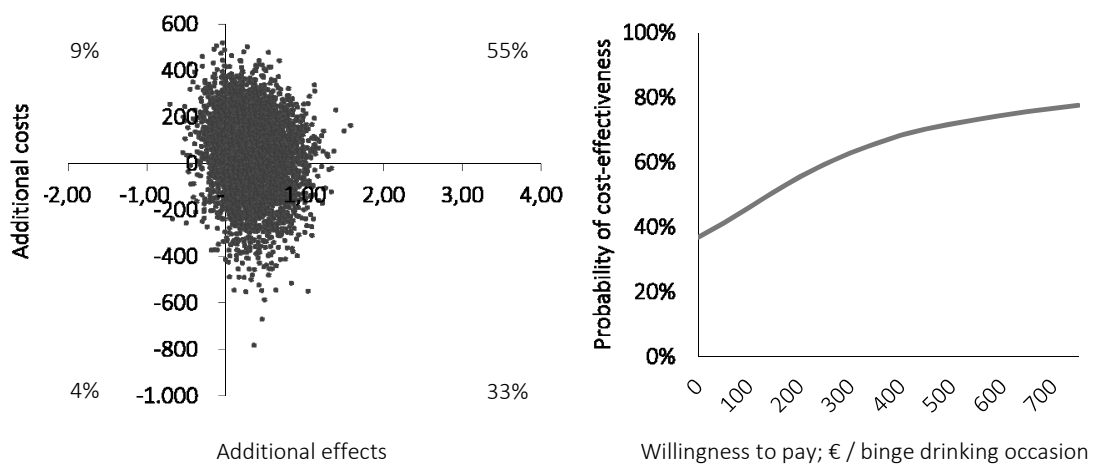
Dutch ethnicity subgroup

Health care perspective
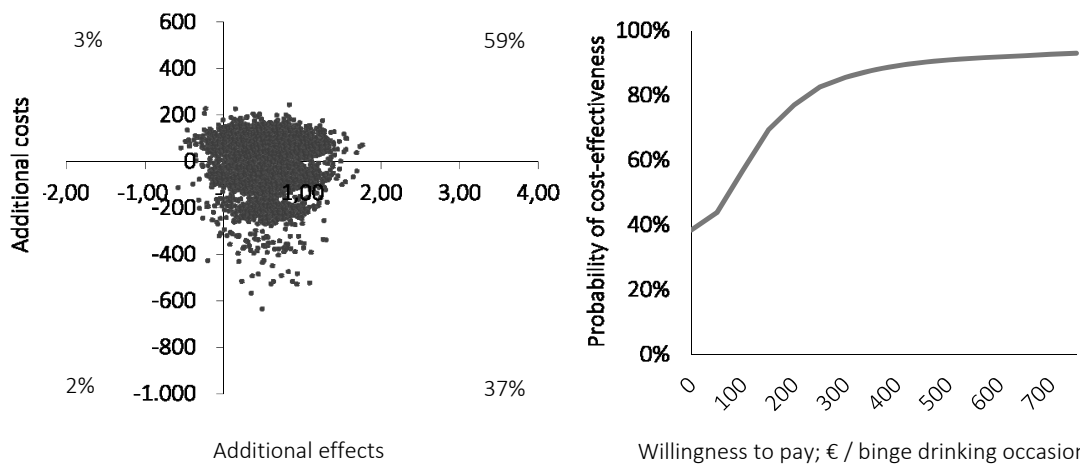

Willingness to pay; €/ binge drinking occasion

Societal perspective (including drugs and cigarette use)
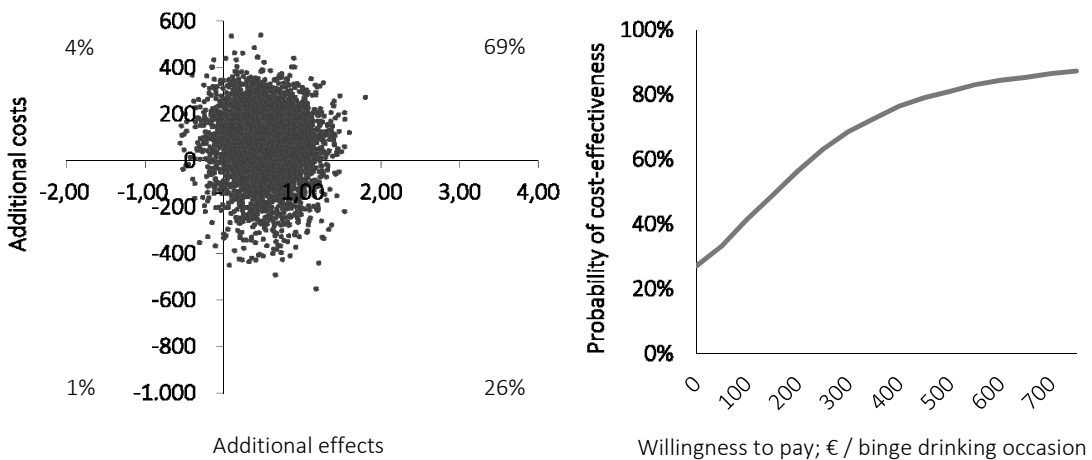

Societal perspective (excluding drugs and cigarette use)
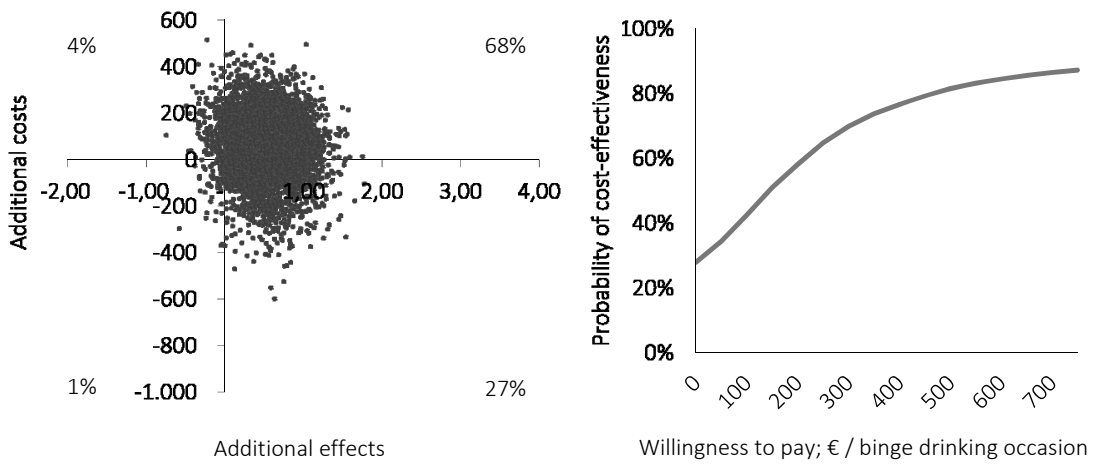
Other ethnicity subgroup

Health care perspective
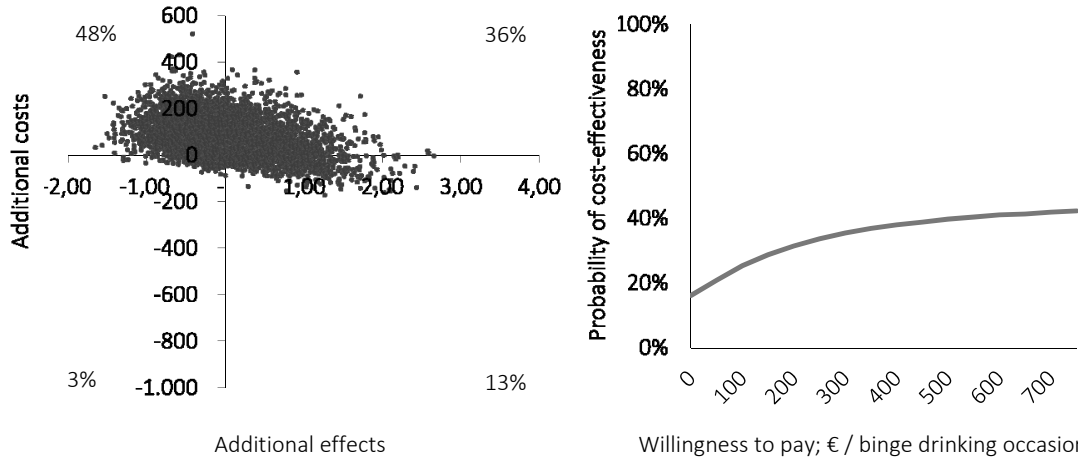

Willingness to pay; $€$ / binge drinking occasion

Societal perspective (including drugs and cigarette use)
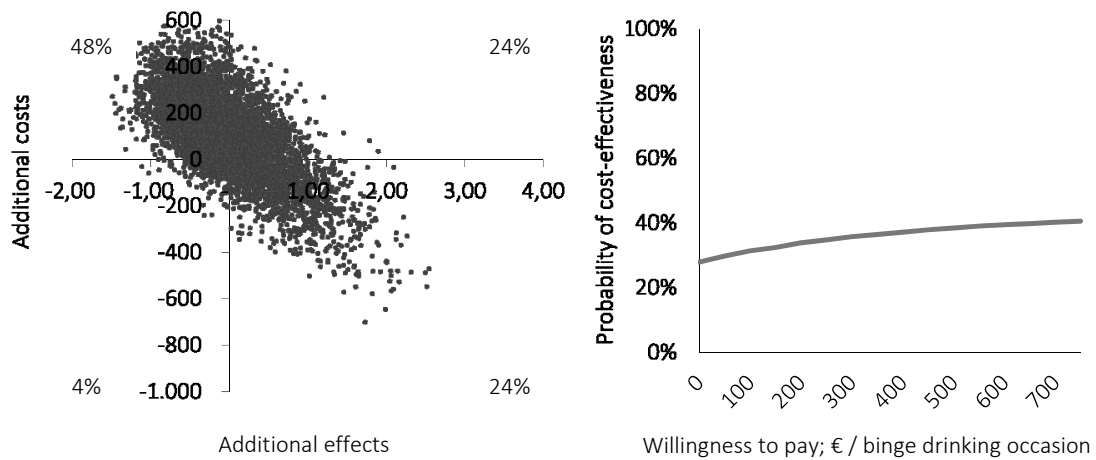

Societal perspective (excluding drugs and cigarette use)
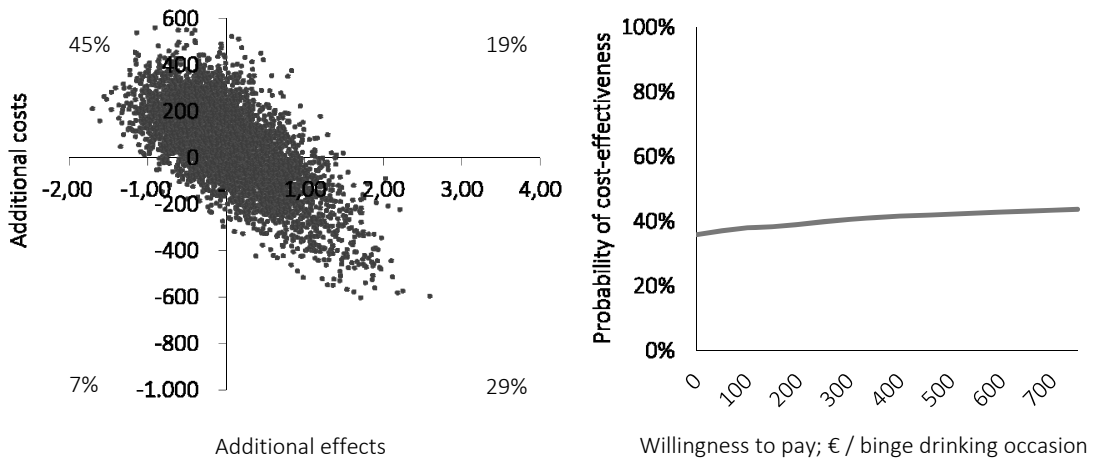


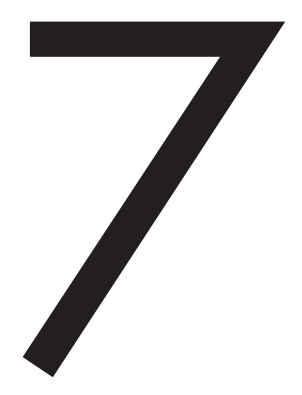

General discussion 
Chapter 7 


\section{General discussion}

Economic evaluation supports making choices between competing alternatives. ${ }^{1,2}$ From a welfarist (i.e. broadly considered to be dominant) point of view, the quality of an economic evaluation is higher when all relevant costs and benefits are considered. For health(care) interventions which are conducted from the societal perspective, this implies that one should measure and value not only costs and benefits within the healthcare sector, but also those which accrue in other sectors. These costs and benefits which accrue in sectors outside the healthcare sector are also known as 'intersectoral costs and benefits' (ICBs). To achieve an efficient allocation of scarce resources within the healthcare sector, insights into these ICBs are indispensable. This thesis focuses on these ICBs.

The objective of this thesis, as introduced in Chapter 1, is threefold: 1) to investigate how the societal perspective is conceptualized and interpreted within health economic evaluations, and to assess how ICBs determine the results of these evaluations (Chapter 2), 2) to develop methods for identifying, classifying and valuing ICBs (Chapters 3 and 4), and 3) to apply these methods within health economic evaluations (Chapters 5 and 6). This final chapter summarizes the main findings and discusses study considerations, both theoretical and methodological. Furthermore, implications for policy makers and researchers are presented. Finally, the chapter ends with concluding remarks.

\section{Summary of main findings}

Concerning the first objective of this thesis, the inclusion of ICBs in economic evaluations which are conducted from the societal perspective is not new. However, a true societal perspective would imply that all relevant ICBs have to be included. Results of the first literature review of this thesis (Chapter 2) show that there is great variety in the way the societal perspective is conceptualized and interpreted within health economic evaluations. ${ }^{3}$ Furthermore, the term societal perspective is often used in combination with including merely labor productivity as an ICB along with healthcare costs (HCCs), omitting other ICBs. However, several of the studies assessed showed that other ICBs could be relevant as well. For example, some of these studies showed that the incremental costs between the intervention and care as usual were affected by costs in the criminal justice sector. This affirmed the need for tools for the identification, classification and valuation of all kinds of ICBs (objective 2).

The second objective was met by developing tools which support the identification, classification and valuation of ICBs. The tool which supports the identification and classification of ICBs is provided in the form of a sector-specific classification scheme (Chapter 3), which was constructed based on a literature search for ICBs of mental disorders and related (psycho)social effects. ${ }^{4}$ It consists of over 70 ICBs drawn from 52 studies; these ICBs are classified in one of four sectors: "Education", "Labor \& Social Security", "Household \& Leisure" or "Criminal Justice System". Psycho(social) effects are 
placed in a separate section under "Individual \& Family". Given the generic use and representation of ICBs, use of the scheme goes well beyond the mental health domain. The scheme functioned as the basis for the development of methods for (obtaining unit prices for) the valuation of ICBs (Chapter 4). ${ }^{5}$ These include the opportunity cost method (method $A$ ), and valuation using available unit prices (method $B$ ), self-constructed unit prices (method $C$ ) or hourly labor costs (method D). A feasibility study resulted in two lists of unit prices for ICBs in the Dutch educational and criminal justice sectors.

Results of the third objective, i.e. applying these methods within two health economic evaluations (Chapters 5 and 6), show that ICBs in these and other sectors, to lesser or greater extent, determine economic evaluation results. ${ }^{6,7}$ Both studies show that costeffectiveness results differ between the healthcare perspective (including $\mathrm{HCCs}$, excluding ICBs) and the societal perspective (including HCCs, including ICBs). The studies show that omitting ICBs from analysis would have led to biased results, and that the tools which are presented in this thesis showed their worth in providing a more complete overview of the societal value of interventions. This, in turn, lowers the chance of misguided decision making.

\section{Strengths and limitations of this thesis}

\section{Contribution to health economics}

The products which are presented in this thesis and the tools which were developed as part of the research into ICBs are of major importance and of added value to the already existing health economic literature. To begin with, the literature study which was aimed at identifying conceptualizations of the societal perspective (Chapter 2) affirmed one of the major shortcomings when it comes to conducting health economic evaluations. The societal perspective, which is broadly acknowledged to be the dominant (i.e. most important) perspective within health economics from a theoretical standpoint, ${ }^{8,9}$ is in practice found to be conceptualized in various ways and often found to be applied in a scaled down or even 'emaciated' form. Whether several studies deliberately omitted ICBs or not, and whether non-included ICBs would have made a difference would require disease- and intervention-specific expertise or an in-depth analysis of the considerations and capabilities of the researchers. Yet, whatever the reasons for in- or excluding ICBs, omitting relevant ICBs must be considered a form of bias. ${ }^{10}$ This finding is, therefore, important for both research and policy, for semi-broad perspectives are often presented as the societal perspective. Consequently, policy makers might base their decisions on evaluations in which ICBs are neglected, forgotten or left out because of the inability to identify and valuate them, hence risking misguided decisions. The main added value of this literature study is that it affirms that tools are needed for the identification and valuation of ICBs, so that researchers are not limited to merely valuing productivity and informal care, but will have the means provide a more complete picture of the ICBs of an intervention. The first 
phase in providing these tools was developing a classification scheme which supports the identification of ICBs (Chapter 3).

As mentioned in the general introduction (Chapter 1), the classification scheme for ICBs is not the first to provide a classification of costs and benefits in health economics. Yet it has some serious advantages over older taxonomies, ${ }^{1,11-13}$ namely a sector-specific classification of ICBs and a more in-depth description of the relevant costs and benefits outside the healthcare sector. This type of classification, which was built from a policy perspective, shows on a generic policy level which groups of stakeholders can be affected by particular ICBs. Older overviews lack such a specific classification. For example, although taxonomies described in the commonplace evaluation texts of Gold et al. and Drummond et al. do focus on productivity at work as an important category outside the healthcare sector, they do not provide readers with a detailed representation of ICBs possibly engendered as a consequence of a (preventive) intervention. ${ }^{1,11}$ Although the taxonomy of Drummond et al., as opposed to the one defined by Gold et al., does mention "other sectors" as a separate category for costs and savings (C2/S2) alongside the health sector $(\mathrm{Cl} / \mathrm{S} 1)$, patient and family (C3/S3) and productivity (C4/S4), neither taxonomy provides extensive information on which of the sectors outside the healthcare sector can be affected by a health intervention, nor do they provide a detailed overview of ICBs within these other sectors. Other taxonomies, such as those described by Luce \& Elixhauser and French et al. do provide some items which have the characteristics of ICBs. ${ }^{12,13}$ However, mention of ICBs is fairly limited in comparison with their more extended focus on items falling within the healthcare sector. Furthermore, like the taxonomies of Gold et al. and Drummond et al., and contrary to the classification scheme which was introduced in this thesis, these taxonomies do not provide a sector-specific classification for ICBs. Other valuable characteristics of the scheme developed for this thesis include a good level of detail, a second classification into population subgroups (i.e. "students", "the labor force" and "all groups") and the neutral representation of ICBs. These make the scheme detailed enough to provide guidance for researchers and policy makers, yet generic enough to be used internationally, as has been acknowledged by international experts. More specific implications for researchers are discussed later on.

Genericity was also the key word during the development of methods for the valuation of ICBs (Chapter 4). ${ }^{5}$ Monetary valuation requires unit prices, which are country-specific. Therefore, it was a challenge to contribute to the health economic literature by providing a methodological framework which can be used internationally. This challenge was overcome by primarily focusing on generic methods rather than only on country-specific methods for obtaining these unit prices. The result is an overview of several methods which can be used for a broad range of ICBs, such as those in the educational and criminal justice sectors. The value these methods add to the literature already available is twofold. First, not only are the underlying theoretical considerations for valuation methods provided, but also the practicalities and feasibility of the various methods are tested and discussed. By explaining how unit prices can be obtained and assessing their feasibility by applying them in practice, including providing examples of data sources, international researchers 
now have an important supportive tool for valuing ICBs. Second, while the available methods in current health economic literature are introduced specifically for subsets of ICBs, such as productivity costs and informal care, ${ }^{14-16}$ the methods which are provided in this thesis are more generic, and can be applied more generally. Although the theoretical foundations of the methods which are provided in this thesis, such as the opportunity cost method and proxy good method, are not new and have already been introduced as methods for valuing informal care, ${ }^{14}$ this thesis explains that these can be used for valuing ICBs in other sectors as well, such as the educational sector and criminal justice sector. Given that ICBs in these sectors could be important, internationally usable generic methods for valuing these are indispensable.

The results of the two economic evaluations (Chapters 5 and 6), in which ICBs were valued using the aforementioned valuation methods, confirm the value of these methods by showing that the inclusion of relevant ICBs can determine economic evaluation results. A major strength of these evaluations is that they are more complete than many others, as they consider more potentially relevant ICBs. Although the role of productivity costs in health economic evaluations has already been studied, ${ }^{17}$ the importance of other ICBs, particularly those in the educational sector and criminal justice sector, was not clear. As for the studies which were thoroughly assessed in the literature review on the societal perspective within health economic evaluations (Chapter 2), the two applications of the valuation methods in this thesis show that these ICBs matter as well, and that not valuing these would have led to different and biased results.

\section{Methodological considerations}

This thesis opens up a new area of research within health technology assessment (HTA). At the start of the research which is the core of this thesis, little was known about ICBs; the concept was not clearly defined in the available literature and little information was available about identifying, classifying and valuing ICBs. As mentioned in the introduction of this thesis (Chapter 1), during the development of the concept of ICBs, questions arose such as 'How can a sector be defined?' and 'What is intersectoral?'. Although these gaps in knowledge offered an opportunity to contribute to an underdeveloped field within HTA, there was also the need to proceed with caution. Like solving a mathematical equation, the input for every subsequent step is the product of previous choices; alternative choices would have led to different results along the way. A major strength in this process was the frequent consultation with various experts in the fields of health promotion, disease prevention, HTA, health economics, education, justice, and healthcare policy by means of semi-structured interviews, expert meetings and conference discussions. Their contributions, in addition to the information provided by literature, were invaluable. The mix of several methods, including the review of literature, frequent consultation with experts, and the application of new tools, can be considered a major methodological strength of the research which is the foundation of this thesis. 
At the start, this mixed methods approach proved its worth during the development of the classification scheme for ICBs. The initial scheme was based on a literature review, in which mental health-related literature was searched for mention of ICBs. The choice to assess only mental health-related literature can be considered a strength as well as a limitation. The strength of this strategy was its feasibility and expected efficiency, for mental disorders are known to lead to various costs outside the healthcare sector. For example, contrary to many somatic diseases, such as cardiovascular diseases, the likelihood of several mental disorders (e.g. behavioral disorders, addiction to alcohol or drugs) leading to costs in the criminal justice system is higher. ${ }^{18}$ The limitation of this strategy was that this remains an assumption, for a conclusive answer could only have been found if other literature had been assessed as well. On the other hand, this does not mean that the effect of the lack of different literature was automatically discounted. To compensate for possible missing items, to validate the findings of the review and to bring more structure to the scheme, the interviews with international experts in the aforementioned fields proved their worth, for the final scheme is saturated and generic enough to be used internationally as a checklist for identifying ICBs.

The same goes for the development of methods for the valuation of ICBs. The consultation of experts operating in sectors outside the healthcare sector was particularly valuable; ICBs, namely, may appear in various sectors, and knowledge of the policy structures and stakeholders was needed to gain an overview of data sources for obtaining relevant information. However, since there is a broad range of ICBs, it soon became clear that extensively addressing all possible ICBs was not feasible, and that choices of focus had to be made. Using the classification scheme as the foundation for subsequent steps in research, our choice of focus was on the educational sector and criminal justice sector, which can be considered a limitation. This choice, however, was justified considering the lack of literature and tools for the valuation of ICBs in these sectors in comparison with literature and tools for other ICBs. For example, methods for the valuation of productivity costs resulting from changes in absenteeism, presenteeism and loss of work had already been discussed elsewhere. ${ }^{15,16}$ The same goes for the provision of informal care, ${ }^{14,19}$ which can also be considered an ICB when health care is narrowly defined. Furthermore, although the updated version of the Dutch guidelines for costing research, which was published in 2010, paid extensive attention to these two types of ICBs, the attention to ICBs in the educational sector and criminal justice sector was limited only to mentioning that these ICBs could be important as well, without any further description of how these should be valued. ${ }^{20}$

A second choice of focus during this process, which can also be considered a limitation, was the focus on developing methods which support the inclusion of ICBs in the input side of the health economic equation; this thesis primarily considered ICBs which can be valued in monetary terms using unit prices. For example, the focus was on ICBs such as special education, and not on ICBs such as teacher-student conflicts. Although such intangible ICBs can be valued based on willingness to pay (WTP) research, obtaining these WTP estimates would require extensive additional research. Furthermore, it was 
assumed that various intangible costs are already reflected in utility and frequently used outcome measures which capture utilities such as quality adjusted life years (QALYs). To elaborate further on this, a separate valuation of such ICBs could lead to an increased risk of double counting if utility outcome measures were to be included. ${ }^{21}$ And this is often the case; the first literature review in this thesis (Chapter 2) showed that the QALY was the most frequently used outcome measure in analyses which were conducted from the societal perspective between 2013 and 2015. Furthermore, the 2016 Dutch pharmacoeconomic guidelines state that the QALY should be the standard outcome measure for health economic evaluations, ${ }^{22}$ which would make a double valuation in both costs and utility a recurrent threat. Because of this, and although broader outcomes beyond health and the QALY can be important, ${ }^{23}$ this prioritization seems justifiable.

As a last limitation, given that the application of the methods resulted into lists of unit prices which can be used for the valuation of ICBs in the educational and criminal justice sectors in the Netherlands, the methods for obtaining unit prices which were presented in this thesis seem to be tailor-made for use on a national level. Since one of the project objectives was to develop a manual which can be used for the valuation of ICBs in the Netherlands, it was a challenge to produce not only a worthy contribution to the national, but also to international health economic literature. The possibility to reflect on findings with the aforementioned experts was valuable in this regard. This resulted in adding the opportunity cost method alongside the methods applied for obtaining unit prices. This opportunity cost method was already available and proposed as one of the methods for the valuation of informal care. ${ }^{14}$ Supportive of the approach chosen, however, was the consensus among the experts that the opportunity cost method - although theoretically superior - would not have been feasible, and that in practice the methods which were applied to obtain unit prices would have been used anyway. These methods proved themselves in the Netherlands, although it should be acknowledged that the transferability and international feasibility can only be fully understood when applied in other countries as well.

\section{Implications for policy and research}

\section{Implications for policy makers}

From a welfarist point of view, one of the major problems in decision making is that policy is rarely based on the societal perspective. ${ }^{2}$ Even within the larger national and international policy bodies, policy makers are often primarily concerned with meeting short-term targets within their own policy domain. ${ }^{24}$ Operating predominantly within these so-called 'policy silos' is a threat to the welfare of society, as it may lead to sub-optimal decision making from a societal point of view ${ }^{24}$ However, since the success of policy makers is primarily determined based on meeting targets within their own domain, it is understandable that this threat will remain an issue. Given that returns on intersectoral 
investments are often indirect and unknown, operationalising such more holistic policy structures is far from commonplace. Policy makers need, among other things, financial incentives for making investments. One of the major contributions of this thesis is that it lays the foundation for research which supports gaining insight on intersectoral returns. Hence, it supports policy making from a societal perspective.

The contribution of this thesis with regards to intersectoral policy is twofold. First, this thesis offers decision makers supporting information on how to optimally allocate scarce resources within health care. If this allocation is done on the basis of a more complete societal perspective (in which relevant ICBs are considered), then this leads to a higher probability that the policy enacted will be beneficial for both the healthcare sector and other sectors. Second, this thesis is supportive of 'Health in All Policies' (HiAP). ${ }^{25}$ Intersectoral policy, including initiatives such as $\mathrm{HiAP}$, is considered to be a major key to gains to public health. ${ }^{26}$ Other sectors of society outside the healthcare sector also need to assume responsibility for public health and related measures. ${ }^{27}$ As different sectors contribute the skills, knowledge and measures available to them, intersectoral collaboration is an important part of many health promotion (and other) programmes, and has a huge potential to affect public health. Intersectoral action, however, requires financing from several sectors of society, and this is an acknowledged barrier. Although such programmes exist, such as the Dutch 'Alles is Gezondheid' (Everything is Health) programme, contributions of stakeholders are often based on external incentives which are translated into pledges without knowing the returns on investments. ${ }^{28}$ Additional economic incentives could function as catalysts for investing in health. There are insufficient tools to quantify the economic benefits to non-health sectors of investing in health interventions. ${ }^{29}$ Comprehensive data on the benefits to the collaborators are needed if incentives are to be truthfully reflected in analyses. By providing relevant tools, this thesis supports obtaining such data.

\section{Implications for researchers}

This thesis offers researchers tools for conducting research into ICBs, and its theoretical and methodological framework can be considered a supportive example of how ICBs should be dealt with. It has several research implications, which should be considered consecutively. First, researchers should carefully consider which ICBs could be relevant for economic evaluation and measure those which are expected to be important. As follows from Chapter 2, no two 'societal' economic evaluations are alike. One can speak of a true societal perspective only when all relevant ICBs for a particular study are considered. The classification scheme which is presented in Chapter 3 can function as a checklist for possible relevant ICBs. Consultation and explicit reporting of the way the societal perspective has been conceptualized and relating this to the choices made when selecting ICBs will improve the quality of the evaluation. Subsequently, the methods which are provided in Chapter 4 will help researchers in valuing the ICBs selected. The methods can be used internationally to create lists of unit prices. Depending on the availability of data 
sources, these methods make it possible to include ICBs in economic evaluations. Two examples of how this is done are presented in Chapters 5 and 6. Generic elements of the methodology in these evaluations, such as the economic evaluation design which was also introduced in Chapter 1, as well as the technical details will be helpful for researchers in conducting their own research on ICBs.

Next to the direct application possibilities of this thesis, there are challenges for the future in research on ICBs. Within health economics, there is constant need to build better methodological tools. ${ }^{30}$ It is important to be able to reflect the societal value of health gains, and there is considerable room for growth and improvement. ${ }^{30}$ This is particularly the case for methods for evaluating public health interventions, as these methods are less well established than those for medical interventions. ${ }^{31,32}$ Several important challenges for future research are described below.

First, it is important to know in which situations which ICBs are considered to be 'big tickets'. The importance of measuring ICBs depends, among other factors, on the type of intervention and target group. This thesis highlights this variety among studies. Although the classification scheme provides some guidance in this respect, more insights into which ICBs are relevant for which disease, intervention or target group are needed. Since the efficiency and quality of measurement are greatly determined by its relevance, more insights into the relevancies of specific ICBs in specific situations are necessary. Such disease- and intervention-specific information could be obtained from literature, experts and patients. This, in turn, could result in disease-specific checklists.

Second, and related to the aforementioned implication, is the development of generic and specific tools for measuring ICBs. A scoping review of the Database of Instruments for Resource Use Measurement (and several other sources), 33,34 which was conducted during the construction of a Dutch manual on intersectoral costs and benefits, ${ }^{35}$ showed that there are only a limited number of measurement tools which cover ICBs. Furthermore, the coverage of ICBs provided by these tools is itself quite limited. Since choices need to be made when measuring ICBs, the availability of generic or specific measurement tools - for example custom-built tools based on validated decision trees - could save researchers a lot of time. The development of such tools could be beneficial not only for trial-based economic evaluations, but also for models; many ICBs of an intervention may accrue in the distant future. ${ }^{2,30}$ Therefore, thought needs to be given to lifetime costs and benefits, about which there is considerable uncertainty. ${ }^{32}$ Accordingly, insights regarding these ICBs are indispensable.

Third, uncertainty surrounding results leads to decision uncertainty. When ICBs are included within health economic evaluations, costs of both the intervention group(s) and control group increase, which - in the case of a cost-effectiveness analysis or cost-utility analysis - leads to a larger spread around the incremental cost-effectiveness ratio (ICER). This higher spread around the mean might lead to an increased chance of a wrong reimbursement decision. It is, therefore, valuable to quantify the consequences of such a wrong decision beforehand, given the probabilities provided in an analysis. One technique for dealing with such uncertainty is the value of information analysis (VOI). ${ }^{36-38}$ 
Although this requires a calculation of net monetary benefits, and such an analysis is restricted to evaluations in which outcome measures can be translated into monetary terms (such as the QALY), a VOI alongside the calculation of the ICER is an important step in bridging the gap between research and decision-making. It could be worthwhile to assess the impact of including ICBs on this VOI outcome, and, in turn, on policy making in general.

Last, this thesis presents studies which were aimed at gaining insight into the ICBs of health(care) interventions. In practice, however, the interaction and consequences can also come from the other direction; interventions outside the healthcare sector might lead to costs and benefits inside the healthcare sector. These, of course, can also be considered ICBs from another point of view, e.g. an educational/criminal justice perspective. Research into these ICBs bridges policy gaps and is crucial in reflecting the true societal value of decisions outside the healthcare sector. One such overarching tool for which ICBs could be relevant is the societal cost-benefit analysis (SCBA). The SCBA is an ex ante type of analysis in which the expected impact of a policy measure is projected. In the Netherlands, this type of analysis has been used for infrastructural projects for years, and has come to be an important tool for supporting healthcare decision making as well. ${ }^{39,40}$ Costing data, such as unit prices related to ICBs, could be supportive in conducting such SCBAs.

\section{Concluding remarks}

The overall aim of this thesis was to contribute to a new area in the field of health economics by placing the concepts 'health' and 'disease' in a broader economic context and providing insight into ICBs. Health should not be considered to be an isolated goal; the impact of health on the welfare of society should also be considered in decisionmaking processes. This thesis on ICBs is a step towards improving such practices. Moreover, good knowledge of the ICBs of health and health interventions could shift the discussion from 'health (care) as a cost' to 'health (care) as an investment'. 


\section{References}

1. Drummond M, Sculpher MJ, Claxton K, Stoddart G, Torrance GW. Methods for the Economic Evaluation of Health Care Programmes. New York: Oxford University Press; 2015.

2. Hale J. What contribution can health economics make to health promotion? Health Promot Int 2000;1 2(4):341-8.

3. Drost RMWA, van der Putten IM, Paulus ATG, Ruwaard D, Evers SMAA. Conceptualizations of the societal perspective within economic evaluations: systematic review [under review].

4. Drost RMWA, Paulus ATG, Ruwaard D, Evers SMAA. Inter-sectoral costs and benefits of mental health prevention: towards a new classification scheme. J Ment Health Policy Econ. 2013; 16:179-86.

5. Drost RMWA, Paulus ATG, Ruwaard D, Evers SMAA. Valuing inter-sectoral costs and benefits of interventions in the healthcare sector: methods for obtaining unit prices. Expert Rev Pharmacoecon Outcomes Res. 2016 Feb 12:1-8.

6. Drost RMWA, Paulus ATG, Jander AF, Mercken L, de Vries H, Ruwaard D, et al. A Web-Based ComputerTailored Alcohol Prevention Program for Adolescents: Cost-Effectiveness and Intersectoral Costs and Benefits. Journal of medical Internet Research. 2016;18(4):e93.

7. Drost RMWA, Wansink HJ, Paulus ATG, Ruwaard D, Hosman CMA, Janssens JMAM, et al. Costeffectiveness of preventive case management for parents with a mental illness: a randomized controlled trial from three economic perspectives. BMC Health Serv Res [accepted for publication]. 2016.

8. Byford S, Raftery J. Perspectives in economic evaluation. BMJ. 1998;316(7143):1529-30.

9. Jonsson B. Ten arguments for a societal perspective in the economic evaluation of medical innovations. Eur J Health Econ. 2009; 10(4):357-9.

10. Evers SM, Hiligsmann M, Adarkwah CC. Risk of bias in trial-based economic evaluations: identification of sources and bias-reducing strategies. Psychology \& Health. 2015;30(1):52-71.

11. Gold MR, Siegel JE, Russel LB, Weinstein MC. Cost-Effectiveness in Health and Medicine. New York: Oxford University Press; 1996.

12. Luce BR, Elixhauser A. Estimating costs in the economic evaluation of medical technologies. Int J Technol Assess Health Care. 1990;6(1):57-75.

13. French MT, Rachal JV, Hubbard RL. Conceptual framework for estimating the social cost of drug abuse. J Health Soc Policy. 1991;2(3):1-22.

14. Koopmanschap MA, van Exel JN, van den Berg B, Brouwer WB. An overview of methods and applications to value informal care in economic evaluations of healthcare. Pharmacoeconomics. 2008;26(4):269-80.

15. Koopmanschap MA, Rutten FF, van Ineveld BM, van Roijen L. The friction cost method for measuring indirect costs of disease. J Health Econ. 1995; 14(2):171-89.

16. Weisbrod BA. Economics of Public Health: Measuring the Economic Impact of Diseases: University of Pennsylvania Press; 1961.

17. Krol M, Papenburg J, Koopmanschap M, Brouwer W. Do productivity costs matter?: the impact of including productivity costs on the incremental costs of interventions targeted at depressive disorders. Pharmacoeconomics. 2011;29(7):601-19.

18. Toevoegen artikel TvP.

19. van den Berg B, Brouwer WB, Koopmanschap MA. Economic valuation of informal care. An overview of methods and applications. Eur J Health Econ. 2004;5(1):36-45.

20. Hakkaart-van Roijen L, Tan SS, Bouwmans CA. Handleiding voor kostenonderzoek. Methoden en referentieprijzen voor economische evaluaties in de gezondheidszorg. Geactualiseerde versie 2010 Diemen: College voor Zorgverzekeringen, 2010.

21. Johannesson M. Avoiding double-counting in pharmacoeconomic studies. Pharmacoeconomics. $1997 ; 11(5): 385-8$.

22. ZiNL. Richtlijn voor het vitvoeren van economische evaluaties in de gezondheidszorg. 2016.

23. Benning TM, Alayli-Goebbels AF, Aarts MJ, Stolk E, de Wit GA, Prenger R, et al. Exploring Outcomes to Consider in Economic Evaluations of Health Promotion Programs: What Broader Non-Health Outcomes Matter Most? BMC Health Serv Res. 2015; 15:266.

24. OECD. Breaking out of silos: Joining up policy locally. [cited 20167 June]; Available from: http://www.oecd.org/regional/leed/43056251.pdf. 
25. Ståhl T, Wismar M, Ollila E, Lahtinen E, Leppo K. Health in all policies. Prospects and potentials. Finland: 2006.

26. RVZ. Intersectoraal gezondheidsbeleid.

27. Johansson PT, P. Financing intersectoral health promotion programmes: some reasons why collaborators are collaborating as indicated by cost-effectiveness analyses. Scand J Public Health. 2011;39/6 Suppl):26-32.

28. Available from: http://www.allesisgezondheid.nl/pledges.

29. OECD. Promoting Health, Preventing Disease: The economic case.

30. Chalkidou K, Culyer A, Naidoo B, Littlejohns P. Cost-effective public health guidance: asking questions from the decision-maker's viewpoint. Health Econ. 2008; 17(3):441-8.

31. Lorgelly PK, Lawson KD, Fenwick EA, Briggs AH. Outcome measurement in economic evaluations of public health interventions: a role for the capability approach? Int J Environ Res Public Health. 2010;7(5): 2274-89.

32. Weatherly H, Drummond M, Claxton K, Cookson R, Ferguson B, Godfrey C, et al. Methods for assessing the cost-effectiveness of public health interventions: key challenges and recommendations. Health Policy. 2009;93(2-3):85-92.

33. Ridyard $\mathrm{CH}$, Hughes DA, Team D. Development of a database of instruments for resource-use measurement: purpose, feasibility, and design. Value Health. 2012;15(5):650-5.

34. DIRUM. 2014 [cited 201318 November]; Available from: http://www.dirum.org/.

35. Drost RMWA, Paulus ATG, Ruwaard D, Evers SMAA. Handleiding intersectorale kosten en baten van (preventieve) interventies: Classificatie, identificatie en kostprijzen. Maastricht: Maastricht University, Department of Health Services Research, 2014.

36. Claxton K, Neumann PJ, Araki S, Weinstein MC. Bayesian value-of-information analysis. An application to a policy model of Alzheimer's disease. Int J Technol Assess Health Care. 2001 Winter; 17(1):38-55.

37. Claxton K, Sculpher M, Drummond M. A rational framework for decision making by the National Institute For Clinical Excellence (NICE). Lancet. 2002;360(9334):711-5.

38. Thorn J, Coast J, Andronis L. Interpretation of the Expected Value of Perfect Information and Research Recommendations: A Systematic Review and Empirical Investigation. Med Decis Making. 2016;36(3):285-95..

39. Romijn G, Renes G. Algemene leidraad voor maatschappelijke kosten-batenanalyse. Den Haag: Centraal Planbureau/Planbureau voor de Leefomgeving, 2013.

40. Pomp M, Schoemaker CG, Polder JJ. Themarapport Volksgezondheid Toekomst Verkenning (VTV). Op weg naar maatschappelijke kosten-baten analyses voor preventie en zorg. Bilthoven: Rijksinstituut voor Volksgezondheid en Milieu, 2014. 
Summary 


\section{Summary}

For health(care) interventions which are conducted from the societal perspective, one should identify, measure and value costs and benefits not only within the healthcare sector, but also those which accrue in other sectors. Many interventions within the healthcare sector have costs and benefits in other sectors; these are known as 'intersectoral costs and benefits' (ICBs). To achieve an efficient allocation of scarce resources, insights on ICBs are indispensable (Chapter 1). However, little is known about these ICBs. Therefore, the main objectives of this thesis were to 1) investigate how the societal perspective is conceptualized and interpreted within health economic evaluations, and to assess how ICBs determine the results of these evaluations (Chapter 2), 2) develop methods for identifying, classifying and valuing ICBs (Chapters 3 and 4), and 3) apply these methods within health economic analyses (Chapters 5 and 6).

Chapter 1 provides background information on economic analysis methods, the societal perspective within economic analysis, its relation with and the conceptualization of ICBs, and the role of ICBs within economic evaluations. It introduces the concept of ICBs by explaining their vital role within analyses from the societal perspective. This perspective, in turn, is dominant over other perspectives; the societal perspective is necessary for making optimal decisions regarding resource allocations, and a proper societal perspective should reflect all relevant ICBs. However, there is uncertainty on which ICBs can be identified, in which sectors outside the healthcare sector they accrue, how these can be valued, and how these can be included within health economic evaluations. This chapter lays the theoretical and methodological foundations for research in this yet underexplored, but important field within health economics. Furthermore, this chapter provides the research objectives and ends with an overview of this thesis.

Chapter 2 describes a systematic literature review, which is designed to investigate how the societal perspective is conceptualized in economic evaluations and to assess the way ICBs determine the outcomes of these evaluations. Results show that there is great variety in the way the societal perspective is conceptualized and interpreted. The use of the term societal perspective often means simply that productivity costs are included, while other ICBs could be relevant as well. An in-depth analysis of trial-based evaluations of interventions in the fields of 'musculoskeletal disorders/dysfunction' and 'mental and behavioral disorders' (MH) shows that ICBs partly determine the results of economic evaluation. In roughly half of the studies which explicitly report productivity costs, these costs make up more than $50 \%$ of total costs. However, in several $\mathrm{MH}$ studies, criminal justice and informal care costs also appear to be important.

Chapter 3 presents a sector-specific classification scheme for ICBs. The scheme is constructed based on a literature search for ICBs of mental disorders and related (psycho)social effects, and is validated based on semi-structured interviews with (inter)national experts in the broad fields of health promotion and disease prevention. The scheme consists of over 70 identified ICBs drawn from 52 studies, which are classified in one of four sectors: "Education", "Labor \& Social Security", "Household \& Leisure" or 
"Criminal Justice System". (Psycho)social effects are placed in a separate section under "Individual \& Family". This classification scheme is an aggregate of different sector classifications used by several Dutch public institutions, which makes it recognizable to and serve not only researchers, but also policy makers and others who decide how to invest in the healthcare sector. The scheme, furthermore, has a population-based dimension. The main conclusion is that this first ever sector-specific classification scheme for ICBs is saturated enough to be used by stakeholders to check whether all relevant ICBs of a specific intervention are assessed. The scheme is generic enough to be used internationally. Because of the generic use and representation of ICBs, this goes beyond the mental health domain.

Chapter 4 builds on these findings and develops methods for obtaining unit prices for the valuation of ICBs. By conducting an exploratory literature study and expert interviews, several generic methods are presented, including the opportunity cost method (method $A$ ), and valuation using available unit prices (method B), self-constructed unit prices (method $C$ or hourly labor costs (method D). These methods were discussed during an expert meeting, which was attended by policy makers and leading experts in the fields of public health, health economics and health technology assessment. A feasibility study resulted in two lists of unit prices for ICBs in the Dutch educational and criminal justice sectors. Although these unit prices are country-specific, the methods themselves can be used internationally and are valuable for the broad international field of health technology assessment. The classification scheme, valuation methods and lists with unit prices, along with detailed descriptions of the specific processes for producing unit prices and the implications for researchers and policy makers, are laid out in a manual for conducting and assessing research on ICBs in the Netherlands.

Based on this manual, in the final two studies (Chapters 5 and 6), these methods are applied within two separate health economic analyses. In both studies, the impact of including ICBs is assessed by conducting trial-based cost-effectiveness analyses from two perspectives: the healthcare perspective (including healthcare costs, excluding ICBs) and the societal perspective (including both healthcare costs and ICBs), and comparing both outcomes. In these studies, for which secondary data is used, the focus is on ICBs within the educational sector and criminal justice sector in particular.

Chapter 5 focuses on the cost-effectiveness of preventive basic care management ( $P B C M)$ for improving parenting quality in families with children of parents with a mental illness (COPMI). PBCM is an intervention which is aimed at reducing risk factors and satisfying the needs of COPMI-families in different domains. Data comes from the SOOPP study (in Dutch 'Studie naar Ondersteuning voor Ouders met Psychische Problemen'). Results at 18-month follow-up show that parenting quality improved in the PBCM group and declined in the care as usual (CAU) group. PBCM is more costly than CAU; costs are $€ 1,793$ from the healthcare perspective and $€ 596$ from the societal perspective. This results in positive incremental cost-effectiveness ratios (ICERs), which differ from $€ 461$ (healthcare perspective) to $€ 175$ (societal perspective). The difference in costs of $€ 1,197$ is caused by ICBs. Between both conditions, there is an $€ 88$ difference related to use of 
services in the educational sector and criminal justice sector. This means that ICBs matter, but that the impact of costs within the educational sector and criminal justice sector on economic evaluation results was limited.

Chapter 6 deals with the same data analytic approach, but for a completely different intervention. This chapter assesses the cost-effectiveness of a web-based computer-tailored intervention for reducing alcohol use and binge drinking by adolescents. Data comes from the Alcohol Alert study; a cluster randomized controlled trial with randomization at the level of schools into tailored feedback on alcohol awareness (intervention condition) or a waiting list control condition (CAU). Results at four-month follow-up show that from both the healthcare perspective and the societal perspective, and for both outcome measures (i.e. weekly alcohol use and number of binge drinking occasions per 30 days) the intervention is more effective, but also more costly in comparison with CAU. Costs are $€ 13.76$ from the healthcare perspective and $€ 74.03$ from the societal perspective. The difference of $€ 60.27$ is caused by ICBs, of which $48.0 \%$ (€28.93) is attributable to differences in use of services in the educational sector and criminal justice sector. ICERs differ for both perspectives, namely $€ 40$ and $€ 79$ from the healthcare perspective to $€ 62$ and $€ 144$ for the societal perspective per reduction of one glass of alcohol per week and one binge drinking occasion per 30 days, respectively. This means that ICBs matter, including those within the educational sector and the criminal justice sector.

Chapter 7 summarizes the main findings and discusses theoretical and methodological strengths and limitations. Furthermore, this chapter presents implications for policy makers and other decision makers, as well as researchers. The chapter ends with concluding remarks. The main contribution of this thesis is that it shows that there are many ICBs, that there are opportunities to value these, and that ICBs, when taken into account, partly determine the results of economic evaluations. This, in turn, might influence healthcare decision making. Furthermore, ICBs within the educational sector and criminal justice sector can be the cause of a considerable proportion of cost differences between perspectives. Depending on the intervention, excluding these or other ICBs from analysis might, from a societal perspective, lead to biased results. 
Samenvatting 


\section{Samenvatting}

Voor economische evaluaties van gezondheidsinterventies die vanuit het maatschappelijk perspectief worden uitgevoerd is het van belang dat men niet alleen oog heeft voor het identificeren, meten en waarderen van kosten en baten binnen de gezondheidszorg, maar ook voor kosten en baten die in andere sectoren terecht komen. Vele interventies binnen de gezondheidszorg leiden tot deze kosten en baten in andere sectoren, ook wel 'intersectorale kosten en baten' (IKB'en) genoemd. Voor een optimale verdeling van schaarse goederen binnen de gezondheidszorg is inzicht in deze IKB'en van groot belang (Hoofdstuk 1). Er is echter weinig bekend over deze IKB'en. De belangrijkste doelen van dit proefschrift waren daarom om 1) te onderzoeken hoe het maatschappelijk perspectief wordt geconceptualiseerd en geïnterpreteerd in economische evaluaties, alsmede te onderzoeken hoe IKB'en de resultaten van deze economische evaluaties bepalen (Hoofdstuk 2), 2) methoden te ontwikkelen voor het identificeren, classificeren en waarderen van IKB'en (Hoofdstukken 3 en 4) en 3) deze methoden toe te passen binnen economische analyses van gezondheidsinterventies (Hoofdstukken 5 en 6).

Hoofdstuk 1 levert informatie over de methodiek achter economische analyses, de rol van het maatschappelijk perspectief binnen economische analyses, diens relatie met de conceptualisatie van IKB'en en de rol van IKB'en binnen economische evaluaties. Het hoofdstuk introduceert het concept van IKB'en door de belangrijke rol van deze kosten en baten binnen analyses die worden vitgevoerd vanuit het maatschappelijk perspectief te benadrukken. Dit perspectief is dominant boven andere perspectieven; het maatschappelijk perspectief is belangrijk voor het maken van optimale beslissingen betreffende de allocatie van schaarse goederen binnen de gezondheidszorg. In een analyse die is uitgevoerd vanuit een maatschappelijk perspectief zouden alle relevante $I B^{\prime}$ en moeten worden meegenomen. $\mathrm{Er}$ is echter een hoge mate van onzekerheid over welke IKB'en geïdentificeerd zouden kunnen worden, in welke sectoren deze IKB'en kunnen opkomen, hoe deze kunnen worden gewaardeerd en hoe deze kunnen worden meegenomen in economische evaluaties. Dit hoofdstuk levert de theoretische en methodologische basis voor onderzoek in dit relatief onontgonnen, maar belangrijke veld binnen de gezondheidseconomie. Daarnaast staan in dit hoofdstuk de doelen van dit proefschrift beschreven en bevat dit hoofdstuk een overzicht van de inhoud van dit proefschrift.

Hoofdstuk 2 beschrijft een systematisch literatuuronderzoek, dat is ontwikkeld om te onderzoeken hoe het maatschappelijk perspectief is geconceptualiseerd en geïnterpreteerd binnen economische evaluaties. Daarnaast is onderzoek gedaan naar de invloed van IKB'en op de resultaten van deze evaluaties. Resultaten laten zien dat er een grote verscheidenheid is in de manier waarop het maatschappelijk perspectief is geconceptualiseerd en geïnterpreteerd. Het gebruik van de term 'maatschappelijk perspectief' wordt vaak gehanteerd wanneer productiviteitskosten worden meegenomen in het onderzoek. Dit, terwiil andere IKB'en ook relevant kunnen zijn. Een analyse van trialbased evaluaties van interventies voor aandoeningen betreffende het bewegingsapparaat 
en psychische aandoeningen laat zien dat IKB'en van invloed zijn op de resultaten van economische evaluaties. In ongeveer de helft van de studies die expliciet aangeven dat productiviteitskosten worden meegenomen, nemen productiviteitskosten meer dan $50 \%$ van de totale kosten voor hun rekening. In verscheidene studies van interventies gericht op psychische aandoeningen blijken juridische kosten en kosten van informele zorg van belang.

Hoofdstuk 3 introduceert een sectorspecifiek classificatieschema voor IKB'en. Dit classificatieschema is ontwikkeld op basis van de resultaten van een literatuuronderzoek naar de IKB'en van psychische aandoeningen en daaraan gerelateerde (psycho)sociale effecten. Het schema is gevalideerd op basis van semi-gestructureerde interviews met (inter)nationale experts in de brede aandachtsgebieden gezondheidsbevordering en ziektepreventie. Het bevat meer dan 70 IKB'en uit 52 studies, die zijn geclassificeerd in een van de vier volgende sectoren: "onderwijs", "arbeid en sociale zekerheid", "huishouden en vrije tijd" en "justitieel systeem". (Psycho)sociale effecten zijn onder de noemer "individueel en familie" in een aparte sectie geplaatst. Deze nieuwe classificatie is een aggregaat van verschillende classificaties van sectoren die door Nederlandse publieke instellingen worden gehanteerd. Dit maakt dat het nieuwe schema niet alleen de wetenschap dient, maar ook herkenbaar is voor beleidsmakers en anderen die besluiten om in de gezondheidszorg te investeren. Het schema bevat tevens een populatie-dimensie, wat de selectie van IKB'en voor onderzoek naar verschillende subpopulaties vergemakkelijkt. De belangrijkste conclusie is dat dit eerste sectorspecifieke classificatieschema compleet genoeg is om als checklist gebruikt te worden om na te gaan of alle relevante IKB'en van een interventie zijn onderzocht. Het schema is generiek genoeg voor internationaal gebruik. Vanwege de generieke aard van het schema zijn toepassingsmogelijkheden breder dan alleen voor het domein psychische gezondheid.

Hoofdstuk 4 borduurt voort op deze bevindingen en presenteert methoden voor het verkrijgen van kostprijzen voor de waardering van IKB'en. Op basis van bevindingen uit een literatuuronderzoek en expert interviews worden er een aantal generieke methoden gepresenteerd, te weten waardering op basis van opportuniteitskosten (methode $A$ ), reeds beschikbare kostprijzen (methode B), zelf berekende kostpriizen (methode $C$ ) of arbeidskosten per uur (methode D). Deze methoden zijn gepresenteerd en bediscussieerd tijdens een expertmeeting, die werd bijgewoond door vooraanstaande experts in de gebieden publieke gezondheid, gezondheidseconomie en health technology assessment (HTA). Een toepassing in een haalbaarheidsonderzoek resulteerde in twee lijsten met kostprijzen voor IKB'en in de Nederlandse onderwijssector en justitiële sector. Hoewel deze kostpriizen specifiek zijn voor Nederland, kunnen de methoden waarmee ze verkregen zijn ook in andere landen worden toegepast en zijn hiermee van waarde voor het brede internationale onderzoeksveld van HTA. Het classificatieschema, de methoden en lijsten met kostprijzen, alsmede gedetailleerde beschrijvingen van de specifieke processen die zijn doorlopen om de kostprijzen te bemachtigen dan wel te berekenen, staan beschreven in een handleiding voor onderzoek naar IKB'en binnen Nederland. 
Deze bevat tevens een beschrijving van de implicaties voor onderzoekers en beleidsimplicaties.

Met behulp van deze handleiding worden in de laatste twee studies van dit proefschrift (Hoofdstukken 5 en 6) deze methoden toegepast in twee aparte gezondheidseconomische analyses. In beide studies is de invloed van IKB'en onderzocht door trial-based kosteneffectiviteitsanalyses uit te voeren vanuit twee perspectieven: het gezondheidszorg perspectief (inclusief zorgkosten, exclusief $\mathrm{IKB}^{\prime} \mathrm{en}$ ) en het maatschappelijk perspectief (inclusief zorgkosten, inclusief IKB'en) en het vergelijken van beide uitkomsten. In deze studies, die zijn uitgevoerd op basis van secundaire data, is er met name onderzocht wat de invloed is van IKB'en binnen de onderwijssector en het justitiële systeem.

Hoofdstuk 5 richt zich op de kosteneffectiviteit van basiszorgcoördinatie (PBCM) voor het verbeteren van de kwaliteit van opvoeden in gezinnen met kinderen van ouders met psychische problemen (KOPP). PBCM is een interventie die zich richt op de risicofactoren hiervan en het tegemoetkomen aan de basisbehoeften van KOPP-families in verschillende domeinen. Data is afkomstig van de SOOPP studie (Studie naar Ondersteuning voor Ouders met Psychische Problemen). Resultaten na 18 maanden laten zien dat de kwaliteit van opvoeden verbetert in de PBCM groep en verslechtert in de care as usual (CAU) groep. PBCM blijkt daarentegen ook duurder dan CAU; kosten zijn $€ 1.793$ vanuit het gezondheidszorg perspectief en $€ 596$ vanuit het maatschappelijk perspectief. Het verschil in kosten van $€ 1.197$ wordt veroorzaakt door IKB'en. Dit resulteert in positieve incrementele kosteneffectiviteitsratios (IKERs), die viteenlopen van $€ 461$ (gezondheidszorg perspectief) tot $€ 175$ (maatschappelijk perspectief). Van de $€ 1.197$ wordt slechts $€ 88$ veroorzaakt door een verschil in een beroep op diensten in de onderwijssector en justitiële sector. Dit betekent dat IKB'en er toe doen, maar dat de invloed van kosten in de onderwijssector en justitiële sector op de resultaten van de economische evaluatie beperkt was.

Hoofdstuk 6 beschrijft een studie met een zelfde analytische benadering, maar ten behoeve van een geheel andere interventie. Dit hoofdstuk beschrifft de kosteneffectiviteit van een op maat gemaakte online interventie voor het verminderen van alcoholgebruik en binge drinken, d.w.z. tenminste vier glazen alcohol voor meiden of viff glazen alcohol voor jongens bij een gelegenheid, onder adolescenten. Data is afkomstig uit de Alcohol Alert studie; een cluster gerandomiseerde gecontroleerde trial met randomisatie op schoolniveau in een op maat gemaakt advies over alcohol gebruik (interventiegroep) of een wachtlijst controle conditie (CAU). Resultaten na vier maanden laten zien dat vanuit zowel het gezondheidszorg perspectief als vanuit het maatschappelijk perspectief en voor beide vitkomstmaten (wekelijks alcoholgebruik en binge drink momenten in de afgelopen dertig dagen) de interventie effectiever, maar ook duurder is dan CAU. Kosten zijn $€ 13,76$ vanuit het gezondheidszorg perspectief en $€ 74,03$ vanuit het maatschappelijk perspectief. Het verschil van $€ 60,27$ wordt veroorzaakt door IKB'en, waarvan $48 \%$ $(€ 28,93)$ is toe te schrijven aan verschillen in het beroep op diensten in de onderwijssector en justitiële sector. IKERs verschillen tussen beide perspectieven, namelijk $€ 40$ en $€ 79$ vanuit het gezondheidszorg perspectief tot $€ 62$ en $€ 144$ vanuit het maatschappelijk 
perspectief voor respectievelijk één glas alcohol per week minder en één binge drink per dertig dagen minder. Dit betekent dat IKB'en er toe doen, inclusief IKB'en in de onderwijssector en justitiële sector.

Hoofdstuk 7 vat de belangrijkste bevindingen van dit proefschrift samen en bediscussieert de theoretische en methodologische sterke punten en limitaties. Daarnaast presenteert dit hoofdstuk de implicaties voor beleidsmakers en onderzoekers. Het hoofdstuk sluit af met een algemene conclusie. De grootste bijdrage van dit proefschrift aan het gezondheidseconomisch veld is dat het laat zien dat er veel IKB'en zijn, dat er mogelijkheden zijn om deze te waarderen en dat IKB'en, wanneer ze in een analyse worden meegenomen, de resultaten van economische evaluaties mede bepalen. Dit, op zijn beurt, zou beslissingen binnen de gezondheidszorg kunnen beïnvloeden. Daarnaast kunnen IKB'en binnen de onderwijssector en justitiële sector een belangrijke rol spelen. Afhankelijk van de aard van de interventie en de doelgroep kan het negeren van deze en andere IKB'en tijdens het uitvoeren van analyses vanuit het maatschappelijk perspectief leiden tot vertekende resultaten en verkeerde conclusies. 
Valorisation 


\section{Valorisation}

In this chapter, the relevance of this thesis for researchers, policymakers and the general public will be discussed. Scientific work should benefit not only the scientific community; it is more important than ever to translate the value of scientific work into ideas and solutions for problems which societies face, and to evolve beyond these to create a more sustainable, healthy and wealthy society. In this context, this chapter provides some ideas and activities, and concludes with a description of the dissemination of the findings of this thesis.

\section{Relevance for researchers}

The main relevance of this thesis for researchers lies in the new tools which support the identification, classification, and valuation of the intersectoral costs and benefits (ICBs) of health interventions. These tools are generic enough to be applied in various fields of health research, including preventive, cure, and care interventions. By using the classification scheme for ICBs and methods for valuing ICBs, a more complete economic evaluation can be conducted from the societal perspective. Furthermore, the classification scheme also creates more awareness of the diversity of costs and benefits which may result from a health change. These tools can therefore be seen as guidelines for improving the quality of costing research, and economic evaluations. The applications of these tools in the economic evaluations which are presented in this thesis are but the first; these studies can be used as examples for other researchers who are interested in conducting economic evaluations which include ICBs, both inside and outside the Netherlands. Furthermore, this thesis may function as a basis for future research into ICBs, such as investigating the specificity of ICBs for certain diseases, but also research into tools which support the measurement of ICBs.

Research into these ICBs may bridge policy gaps between sectors, especially at the national level, and is also crucial in reflecting the true societal value of decisions outside the healthcare sector. One such overarching tool for which ICBs could be relevant is the societal cost-benefit analysis (SCBA). The SCBA is an ex ante type of analysis in which the expected impact of a policy measure is projected. In the Netherlands, this type of analysis has been used for infrastructural projects for years, and has come to be an important tool for supporting healthcare decision making as well. In a letter to the Dutch House of Representatives in December 2013 (IRF/2013/993), the Minister of Finance, Jeroen Dijsselbloem, presented a new generic guideline on SBCA, which was written by the Netherlands Bureau for Economic Policy Analysis (CPB, or 'Centraal Planbureau') and the Netherlands Environmental Assessment Agency (PBL, or 'Planbureau voor de Leefomgeving '). The year after, the National Institute for Public Health and the Environment (RIVM, or 'Rijksinstituut voor Volksgezondheid en Milieu'), published a thematic report on the role of SCBAs for the healthcare sector and public health. Costing data, such as unit prices related to ICBs, could be supportive in conducting such SCBAs. 
It is important to use an intersectoral approach when it comes to health-related research, as health is intertwined with all aspects of everyday life. This thesis presents studies which were aimed at gaining insight into the ICBs of health(care) interventions. In practice, however, the interaction and consequences can also come from the other direction, so to speak; interventions outside the healthcare sector might lead to costs and benefits inside the healthcare sector. This means that it is important to investigate the effect of a health change not only in the case of a health(care) intervention, but also the effect on health when an intervention is primarily aimed at other sectors. An example of a tool which can be used to calculate this effect is the health effect screening, or GES ('gezondheidseffectscreening'). In the GES, the impact of a non-health policy measure or decision by the national or a local government, company or other decision-maker on population health is investigated. One such application of this tool is the assessment of the impact on health of various types of transportation, such as air traffic. Important stakeholders in the GES are the Ministry of Health, Welfare and Sport, the Ministry of Infrastructure and the Environment, and local governments. When it comes to ICBs, even more stakeholders could play a vital role, such as the Ministry of Education, Culture and Science, and the Ministry of Security and Justice, as many ICBs of health interventions might end up in their policy domain.

\section{Relevance for policymakers and society}

Several policymakers who were consulted as experts during this research project acknowledged the important role of ICBs in decision-supportive information. Improved decision-supporting information leads to improved decision-making. Health insurers, pharmaceutical companies, and public policy makers could consult this thesis, for it may be helpful for decision-making processes. For example, research into ICBs may lead to improved reimbursement decisions, but it may also benefit decisions when setting out research. Insights into ICBs disclose the payers and beneficiaries of such decisions and show the proportional distributions of costs and benefits among these. Furthermore, this thesis could be supportive for Health in All Policies (HiAP) initiatives. Decision-makers who are operating outside the health domain need reasons for investing in health. If the returns on investments for their own domain, e.g. education or the justice system, can be quantified, this might give a boost to HiAP.

In the end, developments in the scientific world and policy changes affect society's health. Prevention, cure and care are derived demands. These are but pathways to create or maintain health, and health is life. If ICBs change the outcome of an economic evaluation and if this economic evaluation weighs heavily in the decision-making process on whether or not an intervention is worth paying for, the relevance of paying attention to ICBs becomes very clear. 


\section{Dissemination of knowledge}

Reflecting on the efforts which have been made to disseminate the results of this dissertation, these have been quite extensive already. The lead author and co-authors of the studies which are presented in this thesis have put much effort into disseminating the results of their work alongside the writing of this thesis, instead of waiting for the thesis to be finished. Between 2013 and 2016, four out of five chapters were published in international peer-reviewed impact journals. Of these, three were published 'open access', which means that these are publically and freely available to whomever is interested in these studies. Open access publishing has been made one of the top priorities of the Dutch Secretary of State, Sander Dekker. In a letter to the Dutch House of Representatives in November 2013 (31288-354), he defends the open access initiative by stating that publically funded research should be publically available.

Apart from these publications, a Dutch guideline on ICBs was published in 2014, which supports Dutch researchers and policymakers in conducting and assessing costing research and economic evaluations from the societal perspective. This work has now been cited in the new 2015 guideline on costing research of the Netherlands Healthcare Institute. Dutch studies and debates on this work have been published or are accepted for publication in 'Tijdschrift voor Psychiatrie' and 'Tijdschrift voor Gezondheidswetenschappen'. Furthermore, results of the various studies have been presented at fifteen conferences and symposia, within and outside the Netherlands. One of these was a symposium on ICBs and SCBA at the Dutch Ministry of Health, Welfare and Sport in October 2014. During these conferences and symposia, the audience had the opportunity to provide feedback. The same goes for the guideline, which is freely available and can still be commented on via an online questionnaire on the website of the Department of Health Services Research of Maastricht University. Feedback can be used for this type of research to evolve and to improve guidelines for the future of health economics.

Opportunities for spreading the results are specified in a dissemination plan. This plan, which was presented to the Netherlands Organisation for Health Research and Development, provides an overview of strategies for the dissemination and implementation of the products resulting from this research project, including activities related to publishing, presenting and spreading knowledge on ICBs through education. Finally, this work can be used to educate not only students, but also policymakers on both the national and local levels. This is necessary, for health economics is becoming more and more important in healthcare decision-making, and well-informed decision-making will lead to better population health. 
List of publications 


\section{List of publications}

\section{Scientific articles in international journals}

Drost, RMWA, Wansink, HJ, Paulus, ATG, Ruwaard, D, Hosman, CMH, Janssens, JMAM \& Evers, SMAA. Cost-effectiveness of preventive case management for parents with a mental illness: a randomized controlled trial from three economic perspectives. BMC Health Services Research, 2016; 16:228. doi: 10.1186/s12913-016-1498-z

Drost, RMWA, Paulus, ATG, Jander, AF, Mercken, L, de Vries, H, Ruwaard, D \& Evers, SMAA. A web-based computer-tailored alcohol prevention program for adolescents: costeffectiveness and intersectoral costs and benefits. Journal of Medical Internet Research, 2016; 18(4):e93. doi: 10.2196/jmir.5223

Drost, RMWA., Paulus, ATG, Ruwaard, D \& Evers, SMAA. Valuing inter-sectoral costs and benefits of interventions in the healthcare sector: methods for obtaining unit prices. Expert Review of Pharmacoeconomics and Outcomes Research, 2016; Feb 12:1-8. doi: 10.1586/14737167.2016.1141679

Drost, RMWA, Paulus, ATG, Ruwaard, D \& Evers, SMAA. Inter-sectoral costs and benefits of mental health prevention: towards a new classification scheme. Journal of Mental Health Policy and Economics, 2013; 16(4), 179-186.

Jacobs, N, Drost, RMWA, Ament, A, Evers, SMAA \& Claes, N. Willingness to pay for a cardiovascular prevention program in highly educated adults: a randomized controlled trial. International Journal of Technology Assessment in Health Care, 2011 ; 17(4), pp 283-289. doi: 10.1017/S0266462311000341

\section{Scientific articles in national journals}

Paulus, ATG, Drost, RMWA, Ruwaard, D \& Evers, SMAA. Intersectorale kosten en baten van geestelijke (on)gezondheid. Tijdschrift voor Psychiatrie (accepted for publication).

Drost, RMWA. Gezondheid in een breder perspectief: intersectorale kosten en baten. Tijdschrift voor Gezondheidswetenschappen, 2015; 93(5): 162-3. doi: 10.1007/s12508-015-0064-0

\section{Submitted articles}

Drost, RMWA, van der Putten, IM, Paulus, ATG, Ruwaard, D \& Evers, SMAA. Conceptualizations of the societal perspective within economic evaluations: a systematic review (under review) 


\section{Reports}

Drost, RMWA, Paulus, ATG, Ruwaard, D \& Evers, SMAA (2014). Handleiding intersectorale kosten en baten van (preventieve) interventies: classificatie, identificatie en kostprijzen. Maastricht: Maastricht University, Department of Health Services research. ISBN 9789461593429

\section{Other publications}

Drost, RMWA, Paulus, ATG, Ruwaard, D \& Evers, SMAA. Samenvatting handleiding intersectorale kosten en baten van (preventieve) interventies: classificatie, identificatie en kostpriizen. VGE Bulletin, 2014; 30(2).

\section{Conference contributions - oral presentations}

Drost RMWA, Paulus ATG, Jander AF, Mercken L, de Vries H, Ruwaard D, Evers SMAA (2016). Valuing eHealth: cost-effectiveness of a web-based computer-tailored alcohol prevention program for adolescents. 30th Conference of the European Health Psychology Society, Aberdeen, Scotland.

Drost RMWA, van der Putten IM, Ruwaard D, Evers SMAA \& Paulus ATG (2016). conceptualizations of the societal perspective within economic evaluations: a systematic review. Lowland Health Economists' Study Group (LolaHESG) conference, Ghent, Belgium.

Drost, RMWA, Wansink, HJ, Paulus, ATG, Ruwaard, D, Hosman, CMH, Janssens, JMAM \& Evers, SMAA (2015). Cost-effectiveness and inter-sectoral costs and benefits of case management for parents with a mental illness. Vol. 17. Bulletin of the European Health Psychology Society, 29th Conference of the European Health Psychology Society, Limassol, Cyprus.

Drost, RMWA, Paulus, ATG, Ruwaard, D \& Evers, SMAA (2015). Intersectorale kosten en baten van (preventieve) interventies. Vol. 93. Tijdschrift voor Gezondheidswetenschappen, Nederlands Congres Volksgezondheid, Rotterdam, the Netherlands.

Drost, RMWA \& Evers, SMAA (2014). Intersectorale kosten en baten van (preventieve) interventies. Symposium Maatschappelijke Kosten-Baten Analyse en Intersectorale Kosten en Baten: een Stap Voorwaarts!?, The Hague, the Netherlands.

Drost, RMWA, Paulus, ATG, Ruwaard, D \& Evers, SMAA (2014). Identification, classification and valuation of inter-sectoral costs and benefits of prevention. 10th World Congress of the International Health Economics Association (IHEA), Dublin, Ireland. 
Drost, RMWA, Paulus, ATG, Ruwaard, D \& Evers, SMAA (2014). A manual for identifying and valuing intersectoral costs and benefits of prevention. Lowland Health Economists' Study Group (LolaHESG) conference, Oostvoorne, the Netherlands.

Drost, RMWA, Paulus, ATG, Ruwaard, D \& Evers, SMAA (2014). Intersectorale kosten en baten van (preventieve) interventies. Vol. 92. Tijdschrift voor Gezondheidswetenschappen, Nederlands Congres Volksgezondheid, Rotterdam, the Netherlands.

Drost, RMWA, Paulus, ATG, Ruwaard, D \& Evers, SMAA (2013). Inter-sectoral costs and benefits of prevention. Lowland Health Economists' Study Group (LolaHESG) conference, Nunspeet, the Netherlands.

Drost, RMWA, Paulus, ATG, Ruwaard, D \& Evers, SMAA (2013). Inter-sectoral costs and benefits of prevention of mental disorders. Vol. 16, Supp. 1. The Journal of Mental Health Policy and Economics, Mental Health Policy, Economics and Health Care Reforms, $17^{\text {th }}$ workshop on Costs and Assessment in Psychiatry, Venice, Italy.

\section{Conference contributions - poster presentations}

Drost, RMWA, Paulus, ATG, Jander, AF, Mercken, L, Vries, H de, Ruwaard, D \& Evers, SMAA (2015). A cost-effectiveness computer-tailored alcohol prevention program for adolescents. CAPHRI Day 2015, Maastricht, the Netherlands.

Drost, RMWA, Paulus, ATG, Ruwaard, D \& Evers, SMAA (2014). Monetary Valuation of Inter-Sectoral Costs and Benefits. CAPHRI Day 2014, Maastricht, the Netherlands. 
Dankwoord 
D 


\section{Dankwoord}

Dit proefschrift is het eindproduct van een zeer interessant en viterst belangrijk project. Uiteindelijk kan de beslissing tot het wel of niet meenemen van intersectorale kosten en baten in een economische evaluatie de uitkomst van de evaluatie veranderen. Als de vitkomst van deze economische evaluatie meeweegt in een besluit om een medicijn of een andere zorginterventie te vergoeden, dan ervaart de burger de consequenties van dit besluit. Het wel of niet meenemen van kosten en baten buiten de zorg bepaalt dus mede onze gezondheid en (onze kwaliteit van) leven. Dit belang van het onderzoek was vier jaar geleden al meteen duidelijk. Ik was gelijk geïnteresseerd en heb destijds ook niet lang overwogen om op dit project te solliciteren.

Een buitenmens binnenhalen en een Global Health student aan een 'desk job' krijgen en houden kost echter wel wat energie. Mijn passie voor het vak ontwikkelde ik pas gaandeweg. Ik genoot dan ook het meest en leerde het meest van de momenten dat ik les gaf of erop uit kon: naar het Ministerie voor interviews, op congres in Dublin, Venetië of op Cyprus. Voor overige momenten is passie niet genoeg. De wetenschap is traag; het duurt lang voordat je een succes boekt. Je hebt dus mensen nodig die je af en toe motiveren, die je herinneren aan het belang van je onderzoek, zeker als je voor je gevoel zo ver weg staat van de echte wereld. Gelukkig had ik die mensen om me heen, zowel op werk als thuis. Mijn promotieteam was hierin geweldig. Mijn promotors en co-promotor gaven me veel vertrouwen en lieten me gaandeweg steeds vrijer om zelf mijn onderzoek in te kleden. Die vrijheid, in combinatie met de juiste inhoudelijke, doelgerichte en praktische begeleiding, was de sleutel tot dit succes. Aggie, Silvia, Dirk, mijn dank gaat daarom in de eerste plaats uit naar jullie.

Aggie, iij eerst. Al vóór mijn sollicitatiegesprek in 2012 had ik met jou al een gesprek over het onderzoek. Wat was je al meteen vriendelijk en open, en dat ben je de afgelopen 4 jaar ook altijd gebleven. "Als er iets is, je kan altijd langskomen hè" is jouw standaard slotzin. En dat waren geen loze woorden. Ik kon altijd even aankloppen. En dan ook écht voor van alles: Onderzoek, onderwijs of even een babbel over je kat Mimi of de nieuwste films. Je bent geduldig - heel handig, aangezien ik nogal koppig kan zijn - je bent duidelijk en je houdt het overzicht. Met al die kwaliteiten heb je mooie onderwijsprijzen gewonnen. En dik verdiend: tijdens de trainingen micro-economie die we samen hebben verzorgd liepen studenten helemaal met je weg. Je hebt je rol als directe begeleider, ondanks je vele onderwijsverplichtingen, perfect vervult en ik ben blij dat je ook betrokken blijft bij mijn postdoc project.

Silvia, als jii een kans ziet om onderzoek vit te zetten, een symposium te organiseren, een nieuwe samenwerking aan te gaan, noem maar op, je duikt er altijd bovenop. Door jou en met jou heb ik Europa doorkruist. Italië, lerland, Cyprus, België, Schotland en vele locaties in Nederland: Op vele congressen en symposia, een stuk of 15 denk ik, gaven we, vaak na elkaar, presentaties over ons onderzoek. En zonder vitzondering werden al 
mijn ingediende abstracts geaccepteerd voor een 'oral presentation'. Niet zo gek, met Silvia als co-auteur moesten reviewers wel kwaliteit in huis halen. Dan te bedenken dat je natuurlijk ook zonder mij naar vele andere congressen gaat, waar je na elke congresdag wel in bent voor een drankje of dansje. En altijd met een lach: je schaterlach is door heel het Duboisdomein te horen. Je bent een globetrotter, je gaat als een trein, je bent een katalysator, en in combinatie met je enorme HTA-kennis en grote netwerk was je van onschatbare waarde voor dit project. Heel veel dank.

Dirk. Ik raad iedereen Dirk aan als promotor. Waar je een Professor Dirk kan kopen of huren weet ik niet, maar het is ontzettend nuttig om er een in je team te hebben. Probleem of lastige situatie? Bespreek het met Dirk, weg probleem. En volgens mij ben ik niet de enige die jou als een zeer praktisch ingesteld persoon ervaart. $l k$ ben al een paar jaar je overbuurman en ik zie regelmatig collega's bij je aankloppen, die dan een minuut later met een smile je kamer verlaten. Je las al mijn stukken en becommentarieerde deze tot in detail. De aard van jouw commentaar was een perfecte graadmeter voor mijn voortgang. Het belangrijkste woord hierin was "peanuts". Als je dit woord tijdens ons DAS (Dirk Aggie Silvia) overleg gebruikte om een deel van mijn tekst te beschrijven, dan wist ik dat het artikel bijna klaar was om ingediend te worden: "Ruben, ik zie nog een foutje, het is misschien peanuts hoor, maar in regel 271 zeg je...". We blijven nog even overburen. Als er in de toekomst nog een belangrijke knoop moet worden doorgehakt klop ik graag nog even op je deur. Ook iij hartelijk dank!

Voor twee studies binnen dit project heb ik gebruik gemaakt van data uit andere onderzoeksprojecten. Ik ben daarom ook heel blij dat jullie, Henny en Astrid, jullie datasets met mij hebben willen delen. Dit heeft geresulteerd in publicaties in de vooraanstaande impacttijdschriften Journal of Medical Internet Research en BMC Health Services Research. Henny, iij was al iemand met vele jaren ervaring in het veld en ik iemand die net klaar was met mijn masteropleiding. We hebben er daarom een tijdje over gedaan om op één lijn te komen, maar de analyse was dan ook complex. We hebben veel van elkaar geleerd en ik ben blij dat er een mooi artikel is uit komen rollen; een artikel dat bovendien veel waardering geniet van experts in jouw vakgebied. Je promoveert een week na mij. Het is mooi om te zien dat we allebei ons traject op hetzelfde moment afsluiten. Astrid, je had dit artikel niet meer nodig voor jouw proefschrift, maar je hebt er toch alles aan gedaan om het mij makkelijker te maken jouw data te analyseren. Heel veel dank en veel succes in de States!

Veel dank aan de overige co-auteurs. Bij het ter perse gaan van dit proefschrift zijn vier van de vijf artikelen voor mijn proefschrift in mooie tijdschriften gepubliceerd en is de vijfde hard op weg. Dit is mede mogelijk dankzij jullie: Jan Janssens, Clemens Hosman, Hein de Vries, Liesbeth Mercken en Inge van der Putten. Inge, wij hebben aan het eind van mijn traject nog monnikenwerk verricht door meer dan 100 artikelen compleet binnenstebuiten te keren. Je ging daarbij heel gestructureerd te werk en hebt daarbij een belangrijke 
bijdrage geleverd aan wat ik persoonlijk beschouw als het belangrijkste artikel van dit proefschrift. Heel veel succes nog tijdens je eigen traject!

Mijn dank gaat uit naar de leescommissie, bestaande uit Prof. dr. Carmen Dirksen, Dr. Ghislaine van Mastrigt, Prof. dr. Hans Maarse, Prof. dr. Johan Polder, Prof. dr. Filip Smit. Dank dat $u$ allen tijd heeft genomen om mijn proefschrift te lezen en te beoordelen. Ook dank aan alle experts die de afgelopen vier jaar zijn geraadpleegd in de verschillende stadia van mijn project. De feedback die ik tijdens de interviews, expert meetings, congressen en symposia heb ontvangen was zeer waardevol voor mijn studies.

Tanja en Theresa, jullie waren/zijn hele fijne kamergenootjes! Inmiddels zijn jullie allebei getrouwd en allebei aan de kids. Dat in combinatie met promoveren, ga d'r maar aan staan! Dr. Tanja, ik kreeg bij jou een warm en groen welkom. Onze kamer had dan wel geen ramen, maar verse zuurstof was er genoeg. Je had de kamer omgetoverd in een jungle met al je planten. Dit was wel een gemis toen je weg ging; alle planten vertrokken ook, maar gelukkig kreeg ik er een leuke nieuwe kamergenoot voor terug! Theresa, ik ben heel blij dat je paranimf wilt zijn. Je bent een hele fijne roomie. Ik ben heel blij dat je, nu je net moeder bent geworden en nog maar net weer bent begonnen met werken, hier tijd voor vrij maakt. Heel veel dank!

Uiteraard zijn er nog veel meer collega's bij HSR die ik moet bedanken: het secretariaat, congres- en lunchbuddies Kei Long en Ben, alle treinbuddies, waaronder Hanneke en Mariska, en nog vele anderen. HSR is een grote vakgroep met een prettige werksfeer. Als PhD student word je vrijgelaten om zelf iets van je project te maken. Je leert ook verantwoordelijkheid te nemen: als ik productief was dan ging ik een avondje of in het weekend door, was ik moe dan ging ik wat eerder naar huis. Dat was wel zo prettig met al dat forensen heen en weer vanuit Eindhoven. Als je deze ruimte krijgt, dan hou je plezier in je werk en kunnen er mooie dingen ontstaan.

Vóór mijn PhD heb ik ook mijn Bachelor en Masteropleidingen in Maastricht gevolgd. Ik kijk terug op een geweldige tijd en moet daarvoor zeker mijn jaarclub bedanken, die to op de dag van vandaag nog steeds een hechte vriendengroep is. Dirk, van iedereen die ik tijdens mijn studie in Maastricht heb ontmoet ken ik jou het langst: al sinds het Intro weekend van Koko! Sindsdien hebben we heel veel ondernomen: vakanties, skiën, festivals, toertochten, carnavals, weekendjes, noem maar op. Ook al hebben we allebei hierna onze eigen sportvereniging gevonden en ook al zijn we al lang student-af, we knallen hier onverminderd hard mee door. De wekelijkse biertjes bij Koko hebben wel plaatsgemaakt voor de wekelijkse koffie op de UNS en we hebben het ook wat vaker over serieuze zaken. Ik ben blij dat ik ook die serieuze zaken met je kan delen. Je bent een hele goede vriend en ik ben heel blij dat je volgend jaar mijn getuige wilt zijn bij mijn huwelijk. En over goede vrienden gesproken, Luc, ook jii heel veel dank voor een fijne tijd in Maastricht, maar ook daarbuiten. Een die hard Roda supporter, wandelende encyclopedie, haast obsessieve fan van de States, Clint en The Boss, maar je bent nog 
heel veel meer dan dat. Met jou erbij is het nooit saai. Je zocht na je studie wat je wilde doen en via de advocatuur en een extra master in Brussel heb je je plek gevonden in de Hofstad, waar je als Hagenaar hard op weg bent om carrière te maken. Het is mooi om te zien dat dat je goed doet. En dan Nicolaas, onze Verre Oosten expert. Nu heb ook jij je mooie papiertje binnen en ben je een stap dichter bij het vinden van je droombaan. De mooie, soms hilarische momenten met jou zijn er veel te veel om op te noemen. Ik ben blij dat we ook na jouw tijd in Maastricht vrienden zijn gebleven, dat ik nog veel met jou heb ondernomen en dat er nog veel mooie momenten zullen volgen!

Pap en mam. Jullie hebben mij altijd gesteund. Mijn school, mijn studie, mijn interesses: ik kreeg de vrijheid om steeds zelfstandiger te worden en dat vond ik en vind ik nog steeds heel fijn. Liefde, aandacht, ondersteuning, oneindig veel energie; alles om mij te brengen waar ik nu ben. De echte basis voor dit proefschrift ligt bij jullie en ik ben jullie daarvoor heel erg dankbaar.

Arthur, Valérie. Je hoort wel eens van broers en zussen die het echt niet met elkaar kunnen vinden. Bij ons was dit nooit het geval. We delen veel met elkaar, de leuke momenten, maar ook als het even tegenzit. We maken tijd voor elkaar vrij en zijn er voor elkaar. Het is mooi dat we ieder onze eigen weg kiezen, maar toch dicht bij elkaar blijven. Jullie zitten in mijn harde kern. Ik ben dan ook heel blij dat iij Arthur volgend jaar op mijn huwelijk mijn getuige wilt zijn en Valérie, dat iij als paranimf wilt optreden bij mijn promotie.

Veel dank aan mijn familie en schoonfamilie. Jos, Sjan, Irene, Thomas, Nina, Frederik, dank voor tien fijne jaren in de familie Muskens en nog alle jaren die gaan komen. Ik bof met jullie.

Dan nog, in geheel willekeurige volgorde, dank aan de Draaiscene, mijn Uros bestuur, Moreno, Erwin, Pinguin Radio, Eindhoven Atletiek, de Uros mannen, de Eindhoven partycrew, strandpavilioen Scheldezicht, Dave Grohl, excellente patisserie deluxe a.k.a. broodjes afbakker Leon, Pinkpop, Gaia, Lowlands, mijn Nomad Desert Storm II (R.I.P.), Brain Boost, Foals, alle piloten voor hun veilige landingen en mijn Global Health buddies: Guys, our time on and outside the Thammasat campus in Pathum Thani was unique and truly amazing. I learned so much in the three months we spent in Thailand. The whole experience partly made me who I am today. Thank you.

En dan tot slot iii, Laura. Mijn energiebom. Je brengt me veel geluk en plezier. Al bijna 10 jaar hebben we heel veel lol en steunen we elkaar door dik en dun. Je hebt het ongelofelijk druk nu met je opleiding, maar je vindt altijd wel tijd om er ook voor mij te zijn. Je bent open, je bent lief en je laat me altijd vrij. Toen je 'ja' antwoordde op mijn huwelijksaanzoek kon ik wel salto's maken. Ik kijk erg uit naar de vele vele jaren met jou die nog gaan komen. Een betere vrouw, maar bovenal een betere vriendin kan ik niet wensen. Ik hou van je. 
About the author 


\section{About the author}

Ruben Drost was born in Tilburg, the Netherlands, in 1986. After graduating from Gymnasium Beekvliet in Sint-Michielsgestel, he studied Health Sciences at Maastricht University, obtaining his bachelor's degree in 2009, his master's degree in Health Policy, Economics \& Management in 2010, and a second master's degree in Global Health in 2011 , for which he followed elective courses in human rights and disaster management at Thammasat University (Thailand). Extracurricular activities during these years included the music committee at Student Association Koko and a board membership at Maastricht Student Athletics Association Uros.

Between 2012 and 2016, Ruben was a PhD candidate at the Department of Health Services Research at Maastricht University. His PhD study focused primarily on the development of tools for identifying, classifying, and valuing costs and benefits outside the healthcare sector, also known as 'intersectoral costs and benefits' (ICBs). In the second phase of the project, he applied these tools within health economic evaluations and assessed the importance of ICBs for evaluating the economic impact of health interventions. Educational activities during these years included the thesis supervision of master's students, tutoring in health economics and health policy, and teaching in several other courses. He is currently employed as a postdoctoral researcher at the same department, where he focuses primarily on the economic evaluation of re-employment interventions for chronically ill patients.

Ruben has presented his research at over fifteen (inter)national conferences and symposia. $\mathrm{He}$ was organiser of and speaker at a symposium on ICBs and societal cost-benefit analysis at the Dutch Ministry of Health, Welfare and Sport in 2014. Furthermore, he was the lead author of a Dutch manual on ICBs. At the time of printing this thesis, four out of the five core chapters have been published in international peer-reviewed impact journals. His work is now cited in the updated Dutch guideline for conducting economic evaluations in health care of the National Health

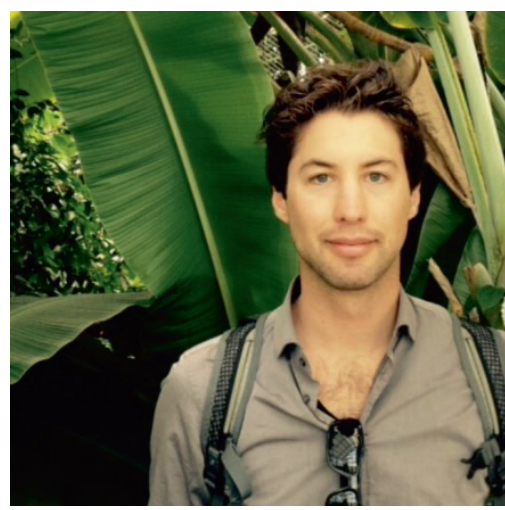
Care Institute. 



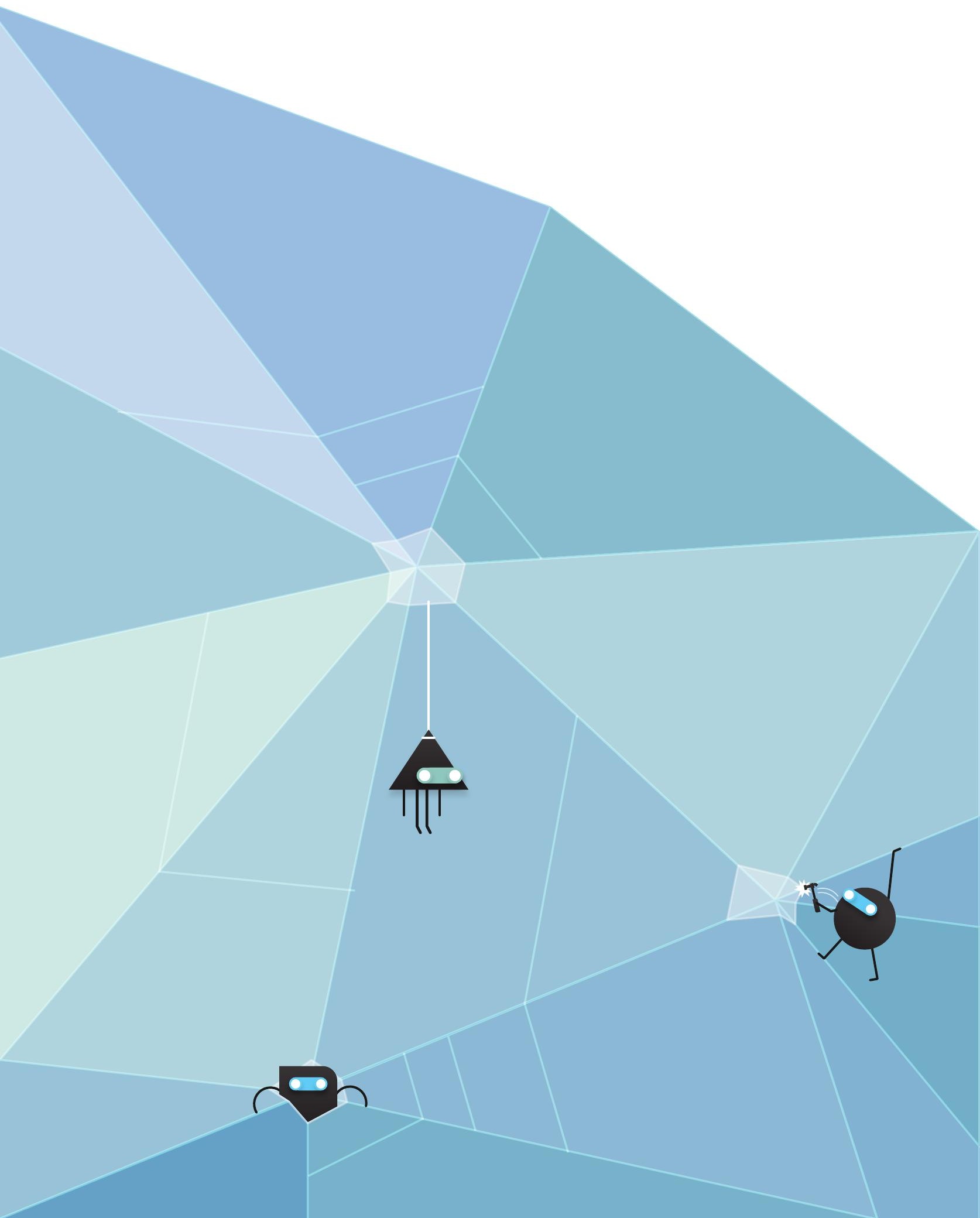


